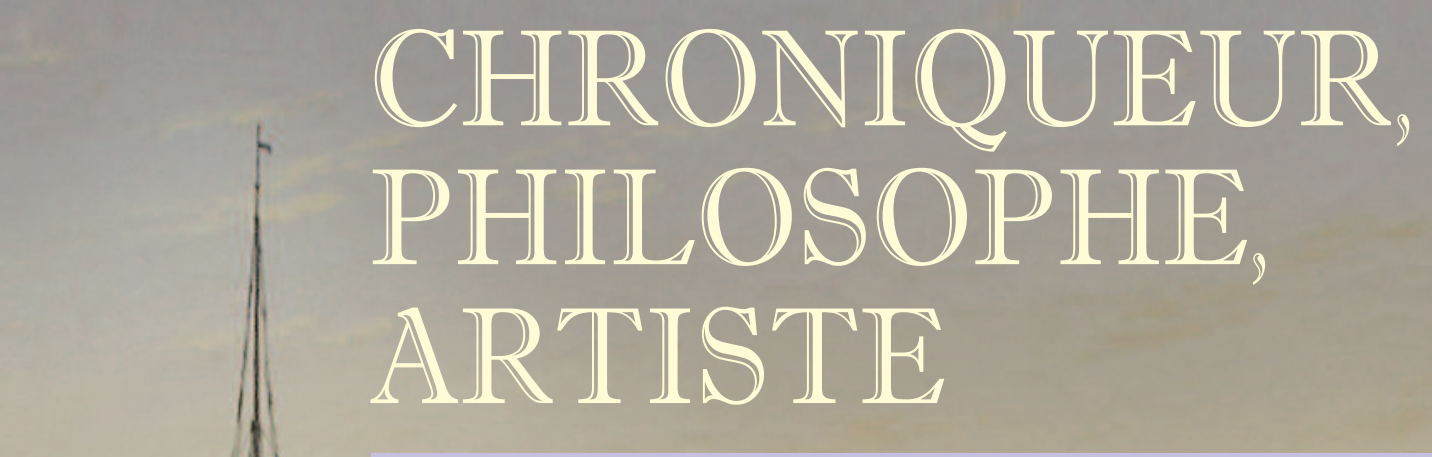

Figures du voyageur dans la littérature française aux XVIII ${ }^{\mathrm{e}}=\mathrm{XIX}^{\mathrm{e}}$ siècles 


\section{CHRONIQUEUR, PHILOSOPHE, ARTISTE}




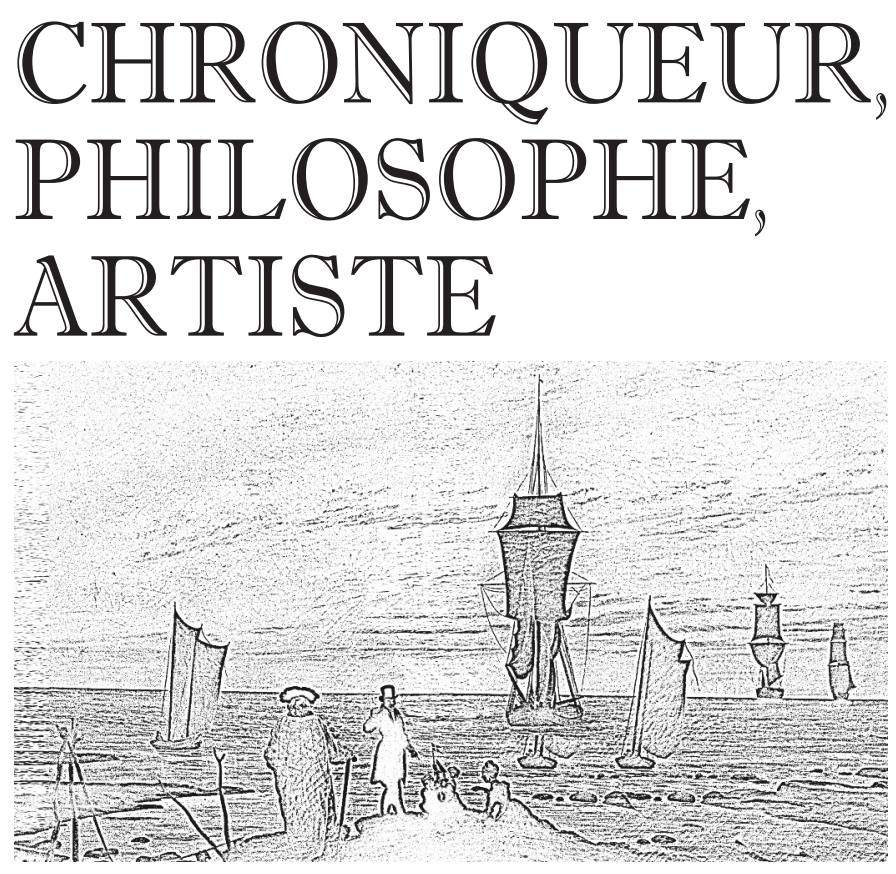

Figures du voyageur dans la littérature française aux $\mathrm{XVIII}^{\mathrm{e}}=\mathrm{XIX}^{\mathrm{e}}$ siècles

sous la direction de

Małgorzata Sokolowicz et Izabella Zatorska

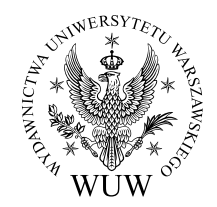


Rapporteur : Sarga Moussa

Responsable éditoriale : Ewa Wyszyńska

Rédaction : Pascale Peeters

Projet de la couverture et des pages de titre : Zbigniew Karaszewski

En couverture : Caspar Friedrich, Die Lebensstufen, 1834,

Leipzig, Museum der bildenden Künste,

https://commons.wikimedia.org/wiki/File:Leipzig,_Museum_der_

bildenden_K\%C3\%BCnste,_Caspar_David_Friedrich,_die_Lebensstufen.JPG

(CC BY 4.0), photo : Dguendel

Composition : Piotr Molski

Ouvrage publié avec le concours de l'Université de Varsovie

(C) Copyright by Wydawnictwa Uniwersytetu Warszawskiego, Warszawa 2021

Małgorzata Sokołowicz, University of Warsaw, ORCID 0000-0003-0554-8852 Izabella Zatorska, University of Warsaw, ORCID 0000-0003-2048-4033

ISBN 978-83-235-5114-0 (e-pub)

ISBN 978-83-235-5106-5 (pdf online)

ISBN 978-83-235-5122-5 (mobi)

Wydawnictwa Uniwersytetu Warszawskiego

Presses de l'Université de Varsovie

00-838 Warszawa, ul. Prosta 69

e-mail : wuw@uw.edu.pl

librairie en ligne : www.wuw.pl

Première édition, Varsovie 2021 


\section{Chroniqueur, philosophe, artiste. Figures du voyageur dans la littérature française aux XVIII ${ }^{\mathrm{e}}$-XIX ${ }^{\mathrm{e}}$ siècles. Introduction}

"Le désir de voir et de connaître est naturel à tous les hommes ${ }^{1}$, lit-on dans la Préface au Recueil de cent estampes représentant les diverses nations du Levant, tirées d'après nature en 1707 et 1708 par les ordres de M. de Ferriol, ambassadeur $d u$ Roy à la Porte. C'est la raison pour laquelle les gens se mettent à voyager. «Et ceux qui ne peuvent en cela se satisfaire par eux-mêmes, marquent au moins l'envie qu'ils en auraient, par l'avidité avec laquelle ils lisent les Relations des Voyageurs. $»^{2}$ L'obligation de rédiger une relation de son voyage, preuve tangible de ses découvertes, observations, exploits et des dangers encourus hante le voyageur depuis longtemps. Change uniquement, selon l'époque, ce que le viator souhaite accentuer le plus : la volonté de divertir, d'instruire, de plaire, d'impressionner, d'influencer ou tout simplement de partager avec autrui ce qu'on a vu et/ou ce qu'on a senti.

"Si je disais que cet Itinéraire n'était point destiné à voir le jour, que je le donne au public à regret et comme malgré moi, je dirais la vérité, et vraisemblablement on ne me croirait pas ", déclare Chateaubriand dans sa fameuse préface à l'Itinéraire de Paris à Jérusalem qui marque un grand changement dans la littérature viatique ${ }^{3}$. L'écrivain est pourtant lui-même

\footnotetext{
1 "Préface ", dans : Recueil de cent estampes représentant les diverses nations du Levant, tirées d’après nature en 1707 et 1708 par les ordres de M. de Ferriol, ambassadeur du Roy à la Porte, Paris, le Hay et Duchange, 1715, p. I.

2 Ibid., p. I-II.

3 Fr. de Chateaubriand, "Préface de la première édition ", dans : Itinéraire de Paris à Jérusalem, éd. J.-C. Berchet. Paris, Gallimard, 2005, p. 55. Jean-Claude Berchet l'appelle « créateur du voyage littéraire », « voyage entrepris par un écrivain pour lécrire ». Cf. J.-C. Berchet,
} 
conscient du fait que le public ne le croirait pas. D'ailleurs, pourrait-il le croire ? Aurait-il vraiment publié des centaines de pages contre son gré ? Et n'ajoute$\mathrm{t}$-il pas, quelques lignes plus bas : «Toutefois je sais respecter le public, et l'on aurait tort de penser que je livre au jour un ouvrage qui ne m'a coûté ni soins, ni recherches, ni travail : on verra que j'ai scrupuleusement rempli mes devoirs d'écrivain $»^{4}$ ?

Depuis longtemps, les lecteurs savaient qu'il était malsain de croire les voyageurs. "Il y a bien peu de relations auxquelles on ne puisse appliquer ce que Strabon disait de celles de Ménélas : je vois bien que tout homme qui décrit ses voyages est un menteur $»^{5}$, avertissaient les encyclopédistes. "Multum mentitur qui multum vidit ", "À beau mentir qui vient de loin », disait le proverbe ${ }^{6}$. Les voyageurs se défendaient contre ces accusations : «[J]'ai pensé, dit, par exemple, Volney à la fin du XVIII e siècle, que le genre des voyages appartenait à l'Histoire et non aux Romans ${ }^{7}$. Pourtant, une excellente étude du $\mathrm{XX}^{\mathrm{e}}$ siècle qui parle justement de cette époque a été intitulée : "Les récits de voyages aux lisières du roman $»^{8}$.

Homme chargé d'une mission, éducateur, menteur, imposteur, romancier? Le voyageur semble montrer au public de multiples visages, revêtir différents costumes et identités. "Le voyageur est un être si divers, si mobile, si impressionnable ", s'exclame en 1839 Louis Reybaud, et il recommande aux lecteurs d'" étudier [le voyageur], deviner ce qu'il est comme tempérament, comme capacité, comme nationalité, comme humeur, savoir d'où il vient et où il va $»^{9}$. Tel est aussi le but de ce volume qui vise à montrer plusieurs figures du voyageur émergeant de la littérature française des XVIII ${ }^{\mathrm{e}}$-XIX ${ }^{\mathrm{e}}$ siècles, là où le genre viatique se développe le plus.

Le sujet n'est pas nouveau. Les dernières années prouvent que la littérature viatique passionne les chercheurs, même si les publications concentrées

"Un voyage vers soi », Poétique, n 53, 1983, p. 95. Sur le tournant autobiographique dans le genre viatique au début du XIX ${ }^{\mathrm{e}}$ siècle voir, entre autres, J.-C. Berchet, «Introduction », dans : Le Voyage en Orient, Paris, Robert Laffont, 1985, p. 3-20.

4 Fr. de Chateaubriand, op. cit., p. 55-56. À ce sujet voir aussi : Ph. Antoine, Les récits de voyage de Chateaubriand. Contribution à l'étude d’un genre, Paris, Honoré Champion, 1997.

5 "Voyageur", dans : Encyclopédie ou dictionnaire raisonné des sciences, des arts et des métiers par une société de gens de lettres. Mis en ordre \& publié par M. Diderot et M. d'Alembert, Genève, Pellet, 1778, t. XXXV, p. 842.

${ }^{6}$ Voir à ce sujet, entre autres, A.-G. Weber, À beau mentir qui vient de loin : savants, romanciers et voyageurs au XIX ${ }^{e}$ siècle, Paris, Honoré Champion, 2004.

7 C.-F. Volney, " Préface », dans: Voyage en Syrie et en Egypte pendant les années 1783, 1784, \& 1785, Paris, Volland, 1787, t. I, p. viij.

8 J. Chupeau, "Les récits de voyages aux lisières du roman ", Revue d'histoire littéraire de la France, no $3 / 4$ (77), 1977, p. 536-553.

9 L. Reybaud, "Voyageurs et géographes modernes ", dans : Revue des Deux Mondes, t. XVII, janv.-mars 1839, p. 155. 
uniquement sur la figure du voyageur semblent être un peu moins fréquentes ${ }^{10}$. Cela permet d'espérer que ce volume - se posant des questions sur la fiabilité du voyageur, son caractère, sa sensibilité, son attitude envers le monde qu'il décrit, et faisant émerger trois figures de voyageur qui deviennent, peut-être, les plus représentatives pour cette période : chroniqueur, philosophe et artiste contribuera au développement de ces recherches et rétablira l'équilibre dans l'intérêt qu'on doit y porter.

Dans le volume, l'accent semble être mis surtout sur le siècle des Lumières, une époque qui fait pivoter l'approche de l'expérience viatique, à travers des remises en question et des renouvellements méthodologiques. Pourtant, le XIX ${ }^{\mathrm{e}}$ siècle est présent, d'abord dans la perspective du tournant, ensuite à travers la transcription artistique. Nous espérons avoir ainsi montré que le moi viatique bien affirmé ne naît pas ex nihilo du génie d'un Chateaubriand mais à l'issue d'un long processus de maturation et de tâtonnements qui s'étend sur des décennies antérieures au romantisme. Le XVIII siècle est le temps d'une mise en ordre de la production viatique en croissance libre ; mais ordonner ne veut pas dire faire taire ni brimer le tempérament, non plus que limiter l'innovation ; même si le statut de l'imagination, mise au service de la recherche et de l'exploration, change. Sur ce fond, il est plus facile de percevoir ainsi le renouveau - moins novateur qu'on ne le croie ? - apporté par le XIX ${ }^{\mathrm{e}}$ siècle.

Le volume ne dépasse pas le XIX ${ }^{\mathrm{e}}$ siècle, se voulant modeste dans son projet. Il est pourtant tout à fait désirable qu'il inspire d'autres chercheurs à y donner une suite et à faire découvrir au public la figure du voyageur qui émerge des écrits des $\mathrm{XX}^{\mathrm{e}}$ et $\mathrm{XXI}^{\mathrm{e}}$ siècles ${ }^{11}$.

10 Pour ne donner que quelques références : le voyageur est souvent analysé dans des textes consacrés au genre viatique, par exemple A. Pasquali, le Tour des horizons. Critique et récits de voyage, Paris, Klincksieck, 1994, S. Venayre, Panorama du voyage (1780-1920). Mots, figures, pratiques, Paris, Les Belles Lettres, 2012, Ph. Antoine, Quand le voyage devient promenade: écriture du voyage au temps du romantisme, Paris, PUPS, 2011 ou R. le Huenen, le Récit de voyage au prisme de la littérature, Paris, PUPS, 2015.Parfois sa figure émerge des relations entre le récit de voyage et un domaine précis, par exemple N. Hafid-Martin, Voyage et connaissance au tournant des Lumières (1780-1820), Oxford, Voltaire Foundation, 1995, Miroirs de textes. Récits de voyage et intertextualité, sous la dir. de S. Linon-Chipon, V. Magri-Mourgues et S. Moussa, Nice, Publications de la Faculté des Lettres, Arts et Sciences Humaines de Nice, 1998. Pour la figure du voyageur mise au centre des réflexions, voir par exemple Fr. Wolfzettel, Le discours du voyageur. Pour une histoire littéraire du récit de voyage en France, Paris, PUF, 1996 ; L'oil aux aguets ou lartiste en voyage, sous la dir. de Fr. Moureau, Paris, Klincksieck, 1995, le numéro 13 de la revue Astrolabe (mai/juin 2007) : https://astrolabe.msh.uca.fr/mai-juin-2007, consulté le 8/02/2021, ou Voyageuses européennes au XIX siècle. Identités, genres, codes, sous la dir. de Fr. Estelmann, S. Moussa et Fr. Wolfzettel, Paris, PUPS, 2012.

11 Voir un ouvrage très inspirant : La littérature de voyage aujourd'hui. Héritages et reconfigurations, sous la dir. de Ph. Antoine, Ch. Chaudet, G. Louÿs et S. Moussa, Paris, Lettres modernes Minard, 2021. 
L'ouvrage se compose de quatre parties. La première, « Voyageur, chroniqueur fidèle ou imposteur?", se concentre sur le statut du voyageur, sa disposition, déjà mentionnée, à mentir ou, au moins, à coloriser son attitude envers le voyage raconté. C'est ainsi que la partie s'ouvre sur l'étude de Jean-Michel Racault qui, en se référant aux contributions de Denis Diderot pour l'Histoire des deux Indes, montre comment la conception ancienne du voyageur, plutôt valorisante, se mue au XVIII siècle en une image plus critique, " cette fois centrée sur "la figure du voyageur" entendue comme une abstraction conceptuelle largement indépendante de la diversité des expériences concrètes, mais relevant plutôt d'un jugement éthique et politique a priori ». C'est sur cette nouvelle figure du voyageur que se concentre aussi Sylviane Albertan-Coppola. "Peut-on se fier au voyageur? ", demande-t-elle dans le titre même de sa contribution, et elle apporte des réponses à cette question, en analysant le portrait du voyageur qui émerge des introductions qui parsèment L'Histoire générale des voyages de l'abbé Prévost. S. Albertan-Coppola montre, entre autres, que « [1]a figure du voyageur [qui en émerge] est tributaire de ce triple objectif : plaire et instruire certes, mais aussi glorifier l'expansion de la France au-delà des mers ». La dernière contribution de cette partie, celle d'Izabella Zatorska, se focalise sur la figure du narrateur-voyageur dans Le Monde vrai de Marivaux. «La réflexion de Marivaux pourrait bien avoir un sens universaliste, voire anticipateur par rapport aux relations socio- et ethnographiques des siècles à venir, et à leur critique ", déclare I. Zatorska, qui met en valeur le triple statut du voyageur marivaudien : esthétique, ontologique et épistémologique.

Ce voyageur qui émerge d'une fiction constitue aussi une sorte de transition vers la deuxième partie de ce volume, "Voyageur qui se (re)met en valeur ", laquelle sera consacrée à la figure du voyageur qui ne voyage autrement que dans le texte écrit. Pour faire les plus beaux voyages, il n'est pas nécessaire de se déplacer réellement. C'est dans l'esprit et non dans l'espace que sont nés les voyages imaginaires. Dans la contribution qui ouvre cette partie, François Rosset examine justement les relations entre voyages réels et voyages imaginaires, et cherche à répondre à la question de savoir quelle figure du voyageur émerge de ces derniers. « [C]e dont il est question ici, ce n'est pas de la qualité intellectuelle et morale des voyageurs, mais de tout ce qui fait que le plus sincère et le plus honnête d'entre eux pourra toujours être suspecté de mentir parce qu'une distance plus ou moins grande se mesure inévitablement entre ce qu'il dit et ce que ses lecteurs présument ou croient savoir de la réalité décrite», constate avec justesse Fr. Rosset. Stanisław Świtlik, en revanche, se concentre uniquement sur le voyageur imaginaire. "Les commentaires sur les voyages de Nicolas Klimius, Pierre Wilkins et Édouard Alfrède dans les terrains bien éloignés de l'Europe, permettent de mettre en relief les points communs, ainsi que les nuances et différences nettes entre les trois voyageurs devenus maîtres de l'Ailleurs ", déclare S. Świtlik, en définissant ainsi la voie interprétative choisie. 
Linda Gil, la seule dans ce volume, nous présente une figure de la voyageuse, et encore d'une voyageuse bien particulière, Cunégonde, la belle demi-cousine du Candide voltairien. "Le voyage, apprentissage de la vie et découverte de sa force intérieure, a forgé le caractère de Cunégonde, sa capacité de résistance et de résilience, la conscience de ses droits, sa détermination ", affirme L. Gil, en montrant dans sa contribution cette trajectoire rarement analysée par les spécialistes en œuvre voltairienne.

La troisième partie, "Voyageur qui se (re)met en cause ", se concentre sur la figure bien particulière du voyageur-philosophe. La première contribution, celle d'Odile Richard-Pauchet, met en scène Denis Diderot lui-même voyageant. Encouragé par Grimm à rédiger un court récit de son déplacement à Langres et Bourbonne, le philosophe, déçu par le voyage réel et son résultat littéraire, ne publie pas la relation de son vivant. «Ce texte présente donc une énigme que nous tâcherons d'élucider ", annonce O. Richard-Pauchet, en se penchant sur la figure du voyageur qui en émerge : un philosophe mélancolique et désenchanté. Un tout autre voyageur fait son apparition dans la contribution d'Alain Guyot, qui présente le Voyage à l'île de France de Bernardin de Saint-Pierre et le projet de sa réédition par l'auteur. Les changements que l'auteur de Paul et Virginie apporte à son texte montrent clairement qu'" [u]ne ère nouvelle s'ouvre bien au voyageur qui, à travers la mise en avant de sa personnalité, l'opacité de son écriture et les variations de son point de vue, prétendra désormais donner à son lecteur moins une information qu'une perspective sur le monde et sur lui-même ». La dernière contribution de cette partie, celle de Nicolas Brucker, se concentre sur une figure kantienne du voyageur qui émerge des Lettres westphaliennes de Charles de Villers. Poussé à l'émigration après la déroute de l'Armée des Princes, cet officier d'artillerie, enthousiasmé à l'égard de la philosophie de Kant, présente dans ses lettres la leçon du solitaire de Königsberg plutôt que la Westphalie. "Située au centre du recueil, elle constitue une clé de lecture de l'ensemble des lettres : elle définit en effet la figure même du voyageur et rédacteur des lettres".

La quatrième et dernière partie du volume, "Voyageur, artiste créatif ou récréatif ? ", est inaugurée par la contribution de Katalin Bartha-Kovács qui met en scène la figure de Jean-Baptiste Le Prince - peintre qui voyage en Russie et reflète ses impressions de voyage sur ses tableaux - et cela à travers la critique que Denis Diderot fait de ses toiles. On a affaire là à deux figures du voyageur : celle qui émerge des toiles et celle qui est représentée par Diderot lui-même. "Le Prince n'est certainement pas un peintre-voyageur "documentariste" au sens strict du terme, mais il n'est pas non plus le créateur d'un monde purement fantaisiste, comme le suggère Diderot », conclut K. Bartha-Kovács. Après le peintre-voyageur vient le tour du musicien. "Quelles sont les spécificités de l'écriture du voyage quand un musicien s'y engouffre? ", demande Aleksandra Wojda dans sa contribution "Vers une écriture de l'humeur inquiète : le Voyage musical en Allemagne et en Italie de Berlioz ». L'écriture berlozienne, tout à fait 
romantique, nous fait découvrir un tout autre type de voyageur et une tout autre forme de sensibilité. De même que la dernière contribution du volume où Małgorzata Sokołowicz décrit l'œuvre du peintre-écrivain qui voyage, Gustave Guillaumet. "L'intermédialité nous aidera à relire l'œuvre picturale et littéraire de Gustave Guillaumet, d'examiner son expérience viatique et de voir quelle figure du voyageur en émerge ", annonce $M$. Sokołowicz et en effet, en analysant différents types de relations intermédiales, elle esquisse une figure du voyageur qui, indépendamment du médium choisi, tient à éterniser son expérience viatique.

Plusieurs contributions, plusieurs figures du voyageur qui, nous l'espérons bien, donneront envie de se (re)pencher sur la littérature viatique et sa richesse. Les différents portraits de voyageurs qui émergent des textes analysés racontent des périples réels ou imaginaires, font réfléchir au monde qui nous entoure, aux valeurs qui le forment, et nous rendent conscients des changements qui ont lieu non pas uniquement dans la façon de voyager et de percevoir le voyage, mais aussi dans celle de penser et de sentir. Le chroniqueur, le philosophe et l'artiste vous invitent au voyage qui se déroulera au fil des pages. 
Première partie

Voyageur, chroniqueur fidèle ou imposteur? 
Jean-Michel Racault

Université de La Réunion

\title{
« Il n'y a point d'état plus immoral que celui de voyageur » : autour des contributions de Diderot à I'Histoire des deux Indes
}

À la mémoire de Laurent Versini

\begin{abstract}
"Of all trades, being a traveller is the most immoral ": about Diderot's Contributions to the Histoire des deux Indes
\end{abstract}

Borrowed from one of Diderot's anonymous contributions to Raynal's famed anticolonialist encyclopedia of travels (1770-1780), the quotation opposes strongly to a long-standing humanist tradition of travelling as a precious medium of education, especially for young men, established at the sixteenth century from classical sources. New eighteenth-century representations of travel as useless or even morally dangerous (Muralt, Rousseau) result in Diderot's moral condemnation of the European traveller, mainly on political grounds. However, his so-called "anticolonialism", highly rhetorical and ambiguous, may be seen both as an expression of his own dialogic turn of mind and as a kind of mock echo to Raynal's personal ambiguities.

Keywords: Diderot, Raynal, travel, traveller, anti-colonialism, rhetoric, irony

Mots-clés : Diderot, Raynal, voyage, voyageur, anticolonialisme, rhétorique, ironie

«Qu'il soit permis de le dire, il n'y a point d'état plus immoral que celui de voyageur ", écrit l'abbé Raynal - ou plutôt, sous la signature de ce dernier, le principal de ses collaborateurs occultes, Denis Diderot, auteur réel d'une partie considérable de la version dite " définitive" de l'Histoire des deux Indes ${ }^{1}$.

1 G.-Th. Raynal, Histoire philosophique et politique des établissements et du commerce des Européens dans les deux Indes, Genève, Jean-Léonard Pellet, 1781 [texte de 1780], tome IV, 
Il s'agit en effet d'une addition au livre IX dans l'édition de 1780 de la célèbre encyclopédie militante des voyages, qui fut l'un des ouvrages les plus largement diffusés au tournant des Lumières et l'un de ceux qui contribuèrent le plus à la chute de l'Ancien Régime ${ }^{2}$. La précaution oratoire ("Qu'il soit permis de le dire...») qui accompagne cette formule frappante, mais quelque peu énigmatique hors contexte, montre bien que son auteur a conscience d'énoncer une proposition à contre-courant, voire de risquer un paradoxe choquant. Paradoxe en effet, car l'«immoralité » assez bizarrement imputée au voyageur au singulier - s'oppose au jugement globalement très favorable que porte sur les voyages - au pluriel - une longue tradition humaniste antérieure. Celle-ci, née au XVI $\mathrm{X}^{\mathrm{e}}$ siècle à partir de sources antiques, encore dominante jusqu'aux années 1770 , reconnaît à cette activité une valeur formatrice irremplaçable dans l'éducation des jeunes gens, à quoi s'ajoutent bien sûr l'apport scientifique des grandes expéditions, l'ouverture à autrui et les rencontres de cultures, les bienfaits supposés du " doux commerce » et la diffusion pacifique des idéaux des Lumières.

Nous souhaiterions montrer comment et pourquoi émerge, à partir d'une conception ancienne et globalement valorisante des voyages et des voyageurs, une autre image plus critique, cette fois centrée sur " la figure du voyageur " entendue comme une abstraction conceptuelle largement indépendante de la diversité des expériences concrètes, mais relevant plutôt d'un jugement éthique et politique a priori. Nous esquisserons ensuite l'étude de ce nouveau topos, sans doute plus ambivalent qu'on ne serait tenté de le croire, dans les contributions

livre IX, ch. V, p. 16. Nos références renvoient par commodité à l'édition moderne des Euvres de Diderot par Laurent Versini, tome III, Politique, "Contributions à l'Histoire des deux Indes ", Paris, Laffont, 1995, p. 685 (ci-après H2I). Nous indiquons entre parenthèses l'édition de l'Histoire des deux Indes concernée par l'ajout de Diderot (1770, 1774 ou 1780), le livre dans lequel il prend place (en chiffres romains) et le chapitre (en chiffres arabes), enfin la pagination de la citation dans lédition Versini. L’orthographe des citations a été partout modernisée.

2 Quoique non signées, les contributions de Diderot à l'Histoire des deux Indes sont identifiées avec certitude par les copies, notes et documents provenant du fonds Vandeul reproduits dans l'édition Versini. Elles concernent les trois versions : l'édition originale de 1770, le texte remanié de 1774, mais surtout les ajouts très importants de la version de 1780 (on recense quelque 48 éditions des différentes moutures jusquà la mort de Raynal en 1796, ce qui donne une idée de l'influence de l'ouvrage). Parmi les collaborateurs cachés de cette vaste entreprise collective (Suard, Saint-Lambert, Thomas, Guibert, d'Holbach, Naigeon, Pechméja, Deleyre notamment), auxquels il faudrait joindre beaucoup de correspondants ou d'informateurs dans la haute administration, dans les colonies, à l'étranger, Diderot semble avoir été l'un des plus constants, ayant participé à toutes les versions, et il est probablement celui qui a pris la part la plus importante - près d'un tiers - à la version finale. Sur les contributions de Diderot, voir parmi une très importante bibliographie les ouvrages classiques de Michèle Duchet, Diderot et l'Histoire des deux Indes, ou l'écriture fragmentaire, Paris, Nizet, 1978, et de Gianluigi Gozzi : D. Diderot, Mélanges et morceaux divers. Contributions à l'Histoire des deux Indes, éd. G. Gozzi, Sienne, [s.n.], 1977. 
écrites par Diderot pour l'Histoire des deux Indes, en concluant sur la mise en scène narrative et les relais rhétoriques que ce lieu commun mobilise.

\section{Dangers des voyages : vers d'autres représentations}

Il y a pour un voyageur bien des manières d'être « immoral». Son rapport à la vérité du réel, à son pays, à sa religion, à lui-même peut-être, paraît problématique. " A beau mentir qui vient de loin ", affirme un ancien dicton faisant de tout récit de voyage un témoignage suspect et de tout voyageur un imposteur en puissance. Abondamment étudié ${ }^{3}$, le topos du "voyageur menteur » ne sera évoqué ici qu’en passant. Peu digne de confiance, le voyageur est-il loyal aux siens? Voyager, ce n'est pas seulement - selon la formule de Montaigne - « frotter et limer sa cervelle contre celle d'autrui $»^{4}$, c'est se séparer de sa communauté d’appartenance et d'une certaine façon la trahir. Plus gravement, c'est mettre en péril sa propre identité morale, philosophique, religieuse, au profit par exemple du relativisme sceptique des libertins et autres " esprits forts » : pour La Bruyère, "quelquesuns achèvent de se corrompre par de longs voyages, et perdent le peu de religion qui leur restait $»^{5}$. Parmi les divers voyageurs immoraux que comptent les romans sadiens, le plus inquiétant est le Portugais Sarmiento, devenu le ministre des plaisirs du souverain Ben Mâacoro ainsi que le porte-parole et l'idéologue de la terrifiante utopie africaine de Butua insérée dans l'Histoire de Sainville et de Léonore (1788-1795), dont il justifie philosophiquement les crimes au nom de la Nature, se flattant ainsi de participer à l'accomplissement de la finalité destructrice qu'il prête à cette dernière.

Voyager a certes toujours passé pour une activité non seulement physiquement dangereuse pour celui qui s'y risque, mais moralement ambiguë, voire théologiquement punissable, car suspecte de démesure et d'orgueil. La poésie latine y voit une sorte de transgression qui appelle logiquement le châtiment, surtout lorsque le voyage est maritime ${ }^{6}$. Assimilant le voyageur à Prométhée ou à Dédale, héros emblématiques de l'aspiration sacrilège de l'homme à égaler

3 Voir P. G. Adams, Travelers and travel liars, 1660-1800, Berkeley/Los Angeles, University of California Press, 1962, et plus récemment A.-G. Weber, A beau mentir qui vient de loin. Savants, voyageurs et romanciers au XIX ${ }^{e}$ siècle, Paris, Champion, 2003.

${ }_{4}$ Montaigne, Les Essais, éd. P. Coste, Londres, Tonson et Watts, 1724, tome I, livre I, chap. 25, p. 144.

5 J. de La Bruyère, « Des esprits forts », dans : Les Caractères, II, 16, Amsterdam, Changuion, 1741, p. 268.

6 Nous nous permettons de renvoyer à notre étude "Fortune d'un lieu commun : la condamnation de la navigation, des poètes latins à Bernardin de Saint-Pierre ", dans : L'aventure maritime, sous la dir. de J.-M. Racault, Paris, Université de La Réunion/LHarmattan, 2001, p. 131-180, dont nous reprenons ci-après quelques éléments. 
les dieux en s'appropriant un élément qui leur appartient, les Odes d'Horace associent condamnation économique de la navigation et du commerce maritime liés au luxe corrupteur et à l'abandon de la frugalité primitive, dénonciation psychologique de l'insatisfaction et de l'instabilité inhérentes à l'errance du voyageur au nom de l'enracinement terrien, horreur scandalisée de l'impiété face à l'audace de celui qui n'hésite pas à risquer sa propre vie en tentant le destin sur les mers, milieu hostile qui s'oppose à la sécurité terrienne :

Vainement un dieu, dans sa prévoyance, mit entre les terres, pour les désunir, les barrières de l'océan, puisque, malgré tout, des esquifs impies franchissent de leurs bonds l'étendue inviolable des eaux. Dans son audace à tout endurer, la race humaine s'élance sur la voie interdite du sacrilège ; dans son audace, le fils de Japet apporta, par une ruse malheureuse, le feu aux nations : à la suite du feu ravi à la demeure éthérée, la consomption, le cortège nouveau des fièvres s'abattirent sur la terre, et le trépas, reculé jusqu’alors et lent dans sa loi nécessaire, hâta sa marche. Dédale s'est risqué dans le vide de l'air sur des ailes refusées à l'homme; forcer l'Achéron fut l'un des travaux d'Hercule. Il n'est rien de trop haut pour les mortels. Le ciel même, notre déraison veut y atteindre, et notre scélératesse ne permet pas à Jupiter de déposer ses foudres irrités. ${ }^{7}$

Le thème de la double condamnation de la navigation et du voyage, comme forme d'hubris suicidaire et comme défi sacrilège adressé aux dieux, comporte aussi une dimension sociale et politique. Comme dans le récit biblique de la Chute, la transgression accomplie par le voyageur trouble l'ordre sacré des choses, introduit dans le monde la maladie et la mort, fait basculer dans l'instabilité de l'Histoire le temps immobile de l'Âge d'Or. Une élégie de Properce fait du voyageur insatiable, qui abandonne son pays natal pour courir les mers, le responsable de son propre malheur : «C'était trop peu de la terre et de ses hasards; nous y avons ajouté l'onde : nous nous ingénions à ouvrir au mauvais sort des routes nouvelles. Une ancre pourrait-elle donc te retenir quand tes pénates n'ont pu le faire? dis-moi, que mérite l'homme à qui son pays ne suffit pas? $»^{8}$

Porté par des sources anciennes, gréco-latines pour une part, bibliques pour une autre part, le topos de la condamnation des voyages et des voyageurs s'est longtemps effacé devant le topos inverse de leur utilité mais a continué d'irriguer souterrainement la culture occidentale. Dans les littératures de tradition réformée ou puritaine, le livre de Jonas ou la parabole du retour de l'enfant prodigue ont pu servir de support à une réflexion théologique sur le voyage. Ainsi dans

7 Horace, «Ode XXIV », dans : Odes, trad. F. Villeneuve, Paris, Les Belles-Lettres, 1997, Livre III, v. 21-40.

8 Properce, Élégies, trad. D. Paganelli, Paris, Les Belles-Lettres, 1970, III, 7, v. 31-34. 
Robinson Crusoé (1719) de Daniel Defoe, allégorie puritaine, le héros voyageur, en transgressant la volonté paternelle pour aller courir l'aventure sur les mers, attire sur lui le châtiment du naufrage puis l'expiation de la solitude, avant que la grâce divine ne lui accorde enfin la rédemption et le retour au pays natal. Ce n'est probablement pas un hasard si ce sont deux auteurs d'origine protestante et suisse qui ont contribué à ramener sur le devant de la scène dans la littérature française le topos un peu oublié faisant du voyageur un personnage négatif, transgressif, obscurément coupable.

En concluant ses Lettres sur les Français et les Anglais (1725) par une « Lettre sur les voyages » contestant leurs bienfaits supposés, le Bernois Muralt fait implicitement écho à la situation de ses compatriotes que la misère contraint à s'engager comme mercenaires à l'étranger. Plus généralement il inverse une idée reçue, s'efforçant non seulement de démontrer l'inutilité des voyages, notamment pour l'éducation des jeunes gens, mais aussi leurs effets corrupteurs sur les voyageurs et sur la nation tout entière, car « ils introduisent parmi nous des mœurs qui nous perdent $»^{9}$, comme le goût du luxe, la dissipation, la liberté excessive des mœurs. Vantant « la vie retirée dont on jouit à la campagne », il se défend contre tout reproche de sécession sociale ; au contraire, explique-t-il, « comme je m'étais approché de ma patrie, en quittant les pays étrangers, pour me rendre auprès d'elle, je m'en rapproche à présent, en quittant tout ce qui m'est étranger, et qui m'empêche d'être homme $»^{10}$. Cette dissertation qui n'épargne pas banalités et platitudes contient aussi des remarques fines annonciatrices de Rousseau («Les voyages prouvent parfaitement l'humanité méconnue et perdue, que nous allons chercher dans le monde, sans savoir ce que nous y cherchons, et que nous nous flattons d'avoir trouvée, à mesure que ce que nous trouvons est apparent, et qu'il nous flatte $\left.\aleph^{11}\right)$, lequel en fut le lecteur attentif, voire du Voyage à l'île de France de Bernardin de Saint-Pierre (1773) : " Je croirai avoir rendu service à ma patrie, si j'empêche un seul honnête homme d'en sortir, et si je peux le déterminer à y cultiver un arpent de plus dans quelque lande abandonnée ", écrit Bernardin en conclusion de son Avant-propos ${ }^{12}$, en écho à une formule de Muralt : «Je croirais n'avoir pas voyagé tout à fait inutilement, si, en faisant voir l'abus sur les voyages, je pouvais empêcher quelqu'un de perdre son temps à voyager $»^{13}$.

C'est chez Rousseau, dans le chapitre "Des voyages » de l'Émile, que se mesure le mieux comment s'opère le basculement de l'ancien au nouveau topos,

9 B.-L. de Muralt, « Lettre sur les voyages ", dans : Lettres sur les Anglais et les Français et sur les voyages, Cologne, s. n., 1725, p. 302.

10 Ibid., p. 266-267.

11 Ibid. p. 275.

12 J.H. Bernardin de Saint-Pierre, Voyage à l'île de France, dans : CEuvres Complètes - t. 2 : Voyages, Paris, Classiques Garnier, 2019, vol. I ${ }^{\text {er }}$, p. 444.

13 B.-L. de Muralt, « Lettre sur les voyages », op. cit., p. 268-269. 
ainsi que la quasi-impossibilité de séparer réellement ces représentations en principe antagonistes. Dans un développement assez touffu, dont l'essentiel porte sur la philosophie politique en marge du Contrat Social, puis sur des conseils de bonheur conjugal liés au futur mariage d'Émile et Sophie, la place du voyage est apparemment secondaire. Mais le débat sur son utilité ou inutilité permet de résoudre la tension entre la vérité de la nature, qui commande à chacun de rester dans sa patrie, et la réalité de la vie sociale, qui fait du voyage une étape obligatoire du cursus éducatif pour les rejetons de familles aisées. Partant du débat traditionnel sur l'utilité ou l'inutilité des voyages, Rousseau suggère qu'on pose autrement la question en se demandant non pas s'il est souhaitable de faire voyager les jeunes gens, mais « s'il est bon que les hommes aient voyagé $»^{14}$. Or, il se trouve qu'ils l'ont fait, pour leur malheur peut-être, à la différence du sauvage « qui n'a besoin de personne et ne convoite rien au monde, [qui] ne connaît et ne cherche à connaître d'autres pays que le sien $»^{15}$. Ce qui explique que Rousseau, citoyen de Genève, pourtant patriote et hostile à tout cosmopolitisme, choisit paradoxalement de faire voyager son élève, même s'il est réservé sur l'intérêt intrinsèque de cette pratique ${ }^{16}$. Cette contradiction apparente a trois motifs. D’abord, Émile est voué à vivre au sein de la société, non pas dans un état de nature qui n'existe plus, s'il a jamais existé. Ensuite, le voyage permet la connaissance de l'homme et - comme chez Fénelon, dont l'auteur recommande la lecture - le choix, éclairé par l'expérience, du meilleur modèle politique, qui lui permettra de devenir non pas roi, mais citoyen. Enfin, la véritable finalité du voyage étant, comme chez Muralt, d'apprendre à s'en passer, il prépare l'intéressé à une réappropriation heureuse de soi-même au sein de la patrie retrouvée. La dialectique inhérente à la pensée de Rousseau parvient ainsi à réconcilier les deux topiques de la positivité et de la négativité du voyage, ou plutôt à dépasser leur antagonisme en faisant du voyage la condition politique de son propre dépassement et le moyen de rétablir artificiellement par la vertu civique une sorte d'équivalent de la nature perdue.

\section{Immoralité du voyageur : ambigüités d'un discours anticolonial}

La rupture paraît au contraire pleinement accomplie chez Diderot dans ses contributions à l'Histoire des deux Indes et dans le Supplément au Voyage de Bougainville, textes élaborés sur la même période, en gros celle des années

14 J.-J. Rousseau, Émile ou de léducation, éd. Ch. Wirz et P. Burgelin, dans : CEuvres Complètes, éd. B. Gagnebin et M. Raymond, Paris, Gallimard, t. IV, p. 826 (Livre V, « Des voyages »).

15 Ibid., p. 831.

${ }_{16}$ Voir J. Morice, "Voyage et anthropologie dans l'Émile de Rousseau ", Revue de métaphysique et de morale, $\mathrm{n}^{\circ}$ 1, 2013, p. 127-142. 
$1770-1780^{17}$. Tous les deux relèvent d'un statut "supplémentaire », à la fois fictionnel et réflexif, au regard d'un ensemble viatique déjà constitué les matériaux primitifs de l'ouvrage de Raynal, le récit de l'expédition de Bougainville. De plus, ils sont unis par d'évidentes relations d'intertextualité : des développements ont été repris, les motifs de la dénonciation du colonialisme et de la contradiction des trois codes, naturel, civil et religieux, y sont pareillement présents. Mais c'est moins du voyage que de « la figure du voyageur » qu'il est question dans ces textes, autrement dit d'une construction idéologique à finalité polémique. Le voyageur dénoncé comme "immoral " est forcément européen. Certes la critique dont il est l'objet est susceptible de s'appuyer sur des cas concrets empruntés aux conquêtes coloniales, notamment à la « légende noire » de l'Amérique espagnole. Elle est néanmoins fortement tributaire d'un répertoire de clichés et de stéréotypes auxquels l'auteur, conscient de l'artifice rhétorique de son discours, n'adhère qu'à moitié, en tout cas avec une certaine distance.

On peut partir de l'imputation d'immoralité adressée non pas au voyageur en général, mais au "voyageur par état », qui fait du voyage un métier, sans innocenter pour autant les prétendus naturalistes ou cosmographes dont les articles de L'Encyclopédie dénoncent souvent la crédulité, les fables et les impostures ${ }^{18}$. Marin, conquérant, colonisateur ou marchand, le "voyageur par état " s'introduit chez les peuples sauvages et, profitant de leur hospitalité, " indice de l'instinct et de la destination de l'homme pour la sociabilité ${ }^{19}$, s'approprie ce qui leur appartient, les terres, l'or et surtout les femmes, ce qui est l'origine de ces établissements fondés par « des hommes industrieux, rapaces et vils ». Toutefois, cette longue addition pour l'édition de 1780, greffée sur un développement de Raynal relatif aux mœurs des tribus du Brésil, est plus complexe que ne le laisserait supposer cette dénonciation de la colonisation européenne : Diderot souligne que le devoir d'hospitalité, sacré pour les Amérindiens et considéré comme tel pour les étrangers qui en bénéficient, implique pour ces derniers l'acceptation d'une hospitalité érotique. Celle-ci paraît choquante aux Européens, du moins en apparence, puisqu'ils ne font que se plier à une règle sociale un peu particulière, qui pour leurs hôtes n'est nullement «immorale», car la coutume fait de l'étranger « quelquefois l'époux,

${ }_{17}$ La première rédaction du Supplément (octobre 1772), sur la base d'un compte rendu non publié du Voyage autour du monde de Bougainville, rédigé l'année précédente par Diderot, fut reprise et augmentée plusieurs fois. Les derniers remaniements, intervenus en 1778-1779, seraient contemporains de la préparation de l'édition de 1780 de l'Histoire des deux Indes.

18 Sur ce point, notamment sur la prétendue plante-animal nommée Agnus Scythicus, objet d'une entrée fameuse, voir E. Kovacs, « De la méfiance à la critique raisonnée : considérations sur les voyageurs et les voyages chez Diderot ", Recherches sur Diderot et L'Encyclopédie, $\mathrm{n}^{\circ} 45$, 2010 , p. 26-43.

19 H2I (1780), livre IX, chap. 5, p. 685. 
le ravisseur ou le séducteur de la fille de la maison $»^{20}$. Cette explication anthropologique, à laquelle est référée aussi l'origine des demi-dieux du paganisme, "fruits du libertinage et de l'hospitalité ", innocente quelque peu les voyageurs de leurs débordements, «immoraux» seulement selon nos mœurs. Ce qui est aussi le cas de l'aumônier de Bougainville, lequel - après s'être écrié "Mais ma religion! mais mon état! $»^{21}$ - finit par céder à l'insistance de son hôte Orou en rendant aux trois filles et à l'épouse de ce dernier ce qu'il est convenu d'appeler « la politesse de Tahiti». Toutefois, les motivations initiales du voyageur font l'objet d'un jugement moins favorable :

Le voyageur par état ressemble au possesseur d'une habitation immense qui, au lieu de s'asseoir à côté de sa femme, au milieu de ses enfants, emploierait toute sa vie à visiter ses appartements. La tyrannie, le crime, l'ambition, la misère, la curiosité, je ne sais quelle inquiétude d'esprit, le désir de connaître et de voir, l'ennui, le dégoût d'un bonheur usé, ont expatrié et expatrieront les hommes dans tous les temps. ${ }^{22}$

À l'origine du voyage, il y a donc les diverses formes objectivement constatables du mal physique, instinct de prédation, pulsions meurtrières, désir d'appropriation. Mais le désir d'ailleurs est aussi la manifestation moins évidente d'une maladie de l'âme, une sorte de vide ontologique qui incite à chercher là où l'on n'est pas le " divertissement » quasi pascalien capable de remédier à l'insatisfaction vague de l'ici. Ce dernier aspect est pour une part le prolongement du motif antique de la condamnation de la navigation, artifice qui soustrait celui qui s'y livre à l'ordre naturel des choses, défi suicidaire lancé à la Fortune, activité sacrilège qui empiète sur le domaine réservé des dieux, bien que Diderot en donne une version laïcisée qui met l'accent surtout sur la dimension économique et politique de la transgression :

Notre véritable bonheur exige-t-il la jouissance des choses que nous allons chercher si loin? Sommes-nous destinés à conserver éternellement des goûts aussi factices ? L'homme est-il né pour errer continuellement entre le ciel et les eaux ? Est-il un oiseau de passage, ou ressemble-t-il aux autres animaux, dont la plus grande excursion est très limitée ? Ce qu'on retire de denrées peut-il compenser

20 Ibid.

21 D. Diderot, "Supplément au Voyage de Bougainville», dans : Euvres philosophiques, éd. P. Vernière, Paris, Classiques Garnier, 1972, p. 503.

${ }_{22}$ H2I (1780), livre IX, chap. 5, p. 685. Cette addition prend pour point de départ une remarque du Salon de 1767 où la même comparaison est appliquée au voyageur, homme «sans morale », ou bien " tourmenté d'une espèce d'inquiétude naturelle qui le promène malgré lui » : D. Diderot, «Salon de 1767 », dans : Euvres de Diderot, t. IV, Paris, Belin, 1818, p. 347. 
avec avantage la perte des citoyens qui s'éloignent de leur patrie pour être détruits, ou par les maladies qui les attaquent dans la traversée, ou par le climat à leur arrivée ?23

Comme souvent chez l'auteur, la pensée joue sur les contradictions. Si le voyage est en somme contre nature, si l'« inquiétude vague " ${ }^{24}$, qui est son premier motif (plutôt qu'un projet d'exploration raisonné : Diderot rappelle le rôle du hasard dans les découvertes), est le symptôme psychologique du vide et de l'ennui, il a, pourtant, un rôle positif dans la dynamique de l'Histoire. C'est à l'insatisfaction des Européens voyageurs que l'on doit l'expansion des nouvelles colonies américaines, promesse peut-être d'une nouvelle civilisation naissant du monde sauvage fécondé par la violence des envahisseurs, car " pourquoi Athènes et Lacédémone ne renaîtraient-elles pas un jour dans l'Amérique septentrionale? ${ }^{25}$ Et Diderot d'imaginer une Nouvelle-Angleterre future s'illustrant par ses Homères, ses Théocrites, ses Sophocles, un Nouveau-Monde devenu centre, désormais capable d'éclairer et de régénérer l'Ancien. Ce qui revient à légitimer à l'échelle du temps historique le choix initialement donné pour négatif du voyageur européen que l'« inquiétude " pousse à l'expatriation coloniale.

La même ambivalence - condamnation morale cinglante, puis justification historique inversant le négatif en positif - marque les motivations extérieurement visibles du voyage. Tous les lecteurs de Raynal au XVIII ${ }^{\mathrm{e}}$ siècle connaissent les tirades célèbres dirigées contre la violence coloniale, l'avidité des Européens et singulièrement les horreurs sanguinaires de la conquête espagnole du Nouveau Monde $^{26}$, comme si le changement d'hémisphère ramenait le civilisé à sa férocité primitive :

Passé l'Équateur, l'homme n'est ni anglais, ni hollandais, ni français, ni espagnol, ni portugais. Il ne conserve de sa patrie que les principes et les préjugés qui autorisent ou excusent sa conduite. Rampant quand il est faible, violent quand il est fort, pressé d'acquérir, pressé de jouir, et capable de tous les forfaits qui le conduiront le plus rapidement à ses fins. C'est un tigre domestique qui rentre dans la forêt. La soif du sang le reprend. Tels se sont montrés tous les Européens, tous indistinctement, dans les contrées du Nouveau Monde, où ils ont porté une fureur commune, la soif de l'or. ${ }^{27}$

${ }^{23}$ H2I (1780), livre XIII, chap. 1, p. 695.

${ }^{24} H 2 I(1770,1780)$.

${ }^{25}$ H2I (1780), livre XVIII, chap. 23, p. 754.

${ }_{26}$ H2I (1774), livre VIII, chap. 32, p. 596-597.

27 H2I (1780), livre IX, chap. 1, p. 692-693. 
Cependant si l'expatriation décivilise l'Européen, que le voyage en terre lointaine a dépouillé de ses caractères nationaux en le réduisant à la nécessité de la "guerre de tous contre tous » de l'état de nature selon Hobbes, elle libère aussi en lui une énergie brutale, étouffée ailleurs par la contrainte des lois, la civilité des mœurs, les préceptes de la religion, énergie dans laquelle l'esthétique intensiviste de Diderot voit malgré tout quelque chose de positif. D'où la fascination qu'exerce sur lui le mythe libertaire des républiques pirates (sans doute fait-il allusion aux boucaniers des Caraïbes et à la prétendue tentative d'établissement utopique de Libertalia à Madagascar ${ }^{28}$ ) et la figure ambivalente des flibustiers, "des hommes sortis des climats les plus tempérés de l'Europe [qui] allaient puiser sous l'Equateur des forces inconnues à la nature ». Toutefois « cette fermentation passagère que le ciel, la mer, la terre, la nature et la fortune avaient excitée dans des hommes couverts d'or et de haillons, plongés dans le sang et la volupté, fit des flibustiers un peuple isolé dans l'histoire, mais un peuple éphémère qui ne brilla qu'un moment $»^{29}$, faute d'habitude du travail et de persévérance.

Aux aventuriers européens, Diderot propose en réalité une alternative : ou bien rentrer chez eux et faire prospérer par leur travail les terres de leur pays ; ou bien - à défaut - "si l'autre hémisphère vous offre plus de puissance, de force, de sûreté, de bonheur, allez vous y établir. Portez-y votre autorité : vos armes, vos mœurs et vos lois y prospéreront $»^{30}$. Invitation qui nuance sérieusement la véhémence " anticolonialiste " (terme passablement anachronique) des tirades sur l'Amérique espagnole. Critiquant les conquêtes coloniales établies par la force des armes, mais justifiant la colonisation de peuplement appuyée sur l'émigration de jeunes colons laborieux, sur le développement de l'agriculture et du commerce, sur une administration sage et même sur la diversité des religions pourvu qu'elles soient tolérantes ${ }^{31}$, l'addition intitulée « Principes que doivent suivre les Français dans l'Inde, s'ils parviennent à y rétablir leur considération et leur puissance » dresse un programme très général d'implantation coloniale aux lisières de l'utopie, un peu à la manière de Bernardin de Saint-Pierre dans ses fragments sur l'île Bourbon ${ }^{32}$. Sans paraître conscient des résistances que la mise en œuvre de ce plan pourrait susciter, l'auteur se borne à recommander à cet égard de « ménager les indigènes » ${ }^{33}$.

${ }_{28}$ Sur cette affaire à lorigine d'une abondante littérature, mais dont la réalité historique est pour le moins incertaine, nous nous permettons de renvoyer à notre ouvrage Mémoires du Grand Océan. Des relations de voyages aux littératures francophones de l'océan Indien, Paris, Presses de l'Université de Paris-Sorbonne, 2007, p. 81-102.

${ }^{29}$ H2I (1770 et 1780$)$, livre X, chap. 10, p. 703.

${ }^{30}$ H2I (1780), livre XIII, chap. 1, p. 696

31 H2I (1780), livre IV, chap. 33, p. 698-701.

32 Voir les textes réunis sous le titre «Sur l'esprit de colonie», dans : J.-H. Bernardin de Saint-Pierre, Euvres Complètes - tome 2 : Voyages, Paris, Classiques Garnier, 2019, vol. II, p. $1003-1334$.

${ }^{33}$ H2I (1780), livre IV, chap. 33, p. 699. 
La perspective d'avenir implicitement ouverte par ce discours est l'installation durable, dans les colonies ainsi créées, des anciens voyageurs devenus eux-mêmes à leur façon des « indigènes » sédentaires, non plus des Européens conquérants en terre étrangère, mais des Créoles enracinés qui, un jour, seront peut-être à l'origine d'une nouvelle civilisation, s'ils ont le courage de s'émanciper politiquement de l'Europe et de leur propre dépendance à l'économie de la servitude. Les différentes moutures de l'Histoire des deux Indes ont été chronologiquement encadrées par les grandes étapes de l'Indépendance américaine ${ }^{34}$, dont il faut rappeler qu'elle est politiquement puis bientôt militairement soutenue par la France. C'est évidemment à la collectivité en devenir que fait référence Diderot lorsqu'il prévoit que "après avoir été dévasté, ce monde nouveau doit fleurir à son tour, et peut-être commander à l'ancien ", si toutefois les Américains " cessaient un jour d'avoir des nègres pour esclaves et des rois éloignés pour maîtres $»^{35}$.

\section{Rhétorique de l'interpellation et mise en scène de la parole}

La cruauté, la complicité ou l'indifférence des Européens face à la question de « l'esclavage des nègres » font précisément l'objet d'un long développement, abondamment remanié et redécoupé, dans les diverses éditions de l'Histoire des deux Indes ${ }^{36}$, remarquable par le glissement progressif de l'analyse historicophilosophique au discours militant personnellement engagé et à la controverse fictivement mise en scène. Celle-ci prend la forme d'un dialogue imaginaire opposant le porte-parole des Lumières à un partisan de l'esclavage, dont il réfute les arguments. Ailleurs, ce sont les conquérants espagnols du Mexique qui sont en quelque sorte appelés à comparaître comme s'ils étaient présents par le « vous » de la rhétorique interpellative ${ }^{37}$, ou encore l'intensité hallucinatoire d'une scène d'autodafé de l'inquisition hispano-américaine qui suscite l'entrée du narrateur dans son propre tableau (" Il me semble que j'assiste à cette horrible expiation. Je la vois, je m'écrie : "Monstres exécrables, arrêtez [...]" $\left.{ }^{38}\right)$. Les accents anti-esclavagistes et quelquefois " républicains» du propos, ou même l'appel à l'indépendance des colonies (mais le contexte montre souvent qu'il s'agit des colonies anglaises d'Amérique du Nord, et c'est la monarchie

${ }^{34}$ Massacre de Boston, 1770 ; «Boston tea party », 1773 ; congrès de Philadelphie, 1774 ; proclamation de l'Indépendance, 1776 ; déclaration de guerre de la France à l'Angleterre et expédition de Rochambeau, 1780.

${ }_{35}$ H2I (1770, 1774,1780), livre XI, chap. 31, p. 708-709.

${ }^{36}$ H2I. Cet insert a été utilisé par fragments répartis différemment selon les éditions, en particulier pour celle de 1780, dans les livres XI, chap. 22 et 24, et VII, ch. 35, p. 737-744.

37 H2I (1780), livre VI, chap. 12, p. 723-724.

38 H2I (1780), livre VI, chap. 13, p. 726. 
anglaise qui est visée dans le passage du livre XI cité plus haut), n'ont rien de bien subversif à l'époque où la France s'engage aux côtés des Insurgents. Ils méritent moins d'être retenus que le contraste entre le jugement, finalement positif sur le long terme, concernant les conséquences lointainement prévisibles de l'exode des Européens vers le Nouveau-Monde, d'où naîtra peut-être une civilisation nouvelle, et la virulence dénonciatrice des harangues dirigées contre les conquérants et les colonisateurs débarquant sur des rivages inconnus pour massacrer ou asservir les peuples sauvages.

La plus remarquable est la célèbre adresse aux Hottentots du Cap, saisis juste avant l'arrivée des Européens dans la rusticité d'un mode de vie que le civilisé jugera primitif voire répugnant, mais aussi dans ce qui est subjectivement vécu par eux comme «le bonheur, l'innocence et le repos de la vie patriarcale $»^{39}$. Engagé, à propos du bonheur paradoxal dont jouissent les Hottentots malgré leur misère et l'étrangeté de leurs coutumes, dans un dialogue imaginaire avec son lecteur, c'est d'abord ce dernier que prend à partie le narrateur, personnage ou plutôt entité semi-fictionnelle qu'on ne peut ici confondre avec l'auteur : « Je sais bien que vous vous éloignerez avec dégoût d'un homme emmailloté, pour ainsi dire, dans les entrailles des animaux. Croyez-vous donc que la corruption dans laquelle vous êtes plongés, vos haines, vos perfidies, votre duplicité, ne révoltent pas plus ma raison que la malpropreté de l'Hottentot (sic) ne révolte mes sens? " 40

Suit une confrontation polémique des deux mondes, le sauvage et le civilisé, visant à faire accepter à l'interlocuteur imaginaire la supériorité du premier sur le second : vous vous moquez des superstitions des Hottentots, mais vos préjugés sont pires, vous êtes fier de vos lumières, mais elles sont inutiles au sauvage, etc. ; et d'ailleurs "vous êtes descendus dans son pays pour l'en dépouiller. Vous ne vous êtes approchés de sa cabane que pour l'en chasser, que pour le substituer, si vous le pouviez, à l'animal qui laboure sous le fouet de l'agriculteur, que pour achever de l'abrutir, que pour satisfaire votre cupidité $»^{41}$. Insidieusement, l'orateur a changé d'interlocuteur. Il ne s'adresse plus au lecteur réel ou virtuel de l'Histoire des deux Indes en 1780, qu'on peut supposer anti-esclavagiste, progressiste, sympathisant de l'idéal des Lumières, mais aux lecteurs fictifs hautement improbables qu'étaient les compagnons de Van Riebeck, fondateur de la colonie du Cap aux alentours de 1650. Il le fait, en jouant sur la confusion de destinataire pour identifier le premier aux seconds et leur imputer conjointement dans la suite de sa tirade les forfaits et les crimes dont se souille le "voyageur immoral » évoqué au livre IX : hypocrisie, mensonge, traîtrise, cruauté, spoliation, vol, corruption des femmes, séduction

\footnotetext{
39 H2I $(1774,1780)$. Pour lédition de 1780, livre II, chap. 18, p. 679.

40 H2I (1774, 1780), livre II, chap. 18, p. 679.

${ }^{41}$ Ibid., p. 680.
} 
des filles. La théâtralisation de la prosopopée transforme l'adresse en une scène à multiples personnages. Destinataires encore plus improbables, les Hottentots y sont eux aussi harangués - vainement, on s'en doute, et du reste trop tard, car hélas « Riebeck approche» :

Fuyez, malheureux Hottentots, fuyez ! enfoncez-vous dans vos forêts. Les bêtes féroces qui les habitent sont moins redoutables que les monstres sous l'empire desquels vous allez tomber. Le tigre vous déchirera peut-être, mais il ne vous ôtera que la vie. L'autre vous ravira l'innocence et la liberté. Ou si vous vous en sentez le courage, prenez vos haches, tendez vos arcs, faites pleuvoir sur ces étrangers vos flèches empoisonnées. Puisse-t-il n'en rester aucun pour porter à leurs citoyens la nouvelle de leur désastre ! ${ }^{42}$

Cette harangue semble proche du discours du vieillard tahitien adressée à Bougainville dans le second chapitre du Supplément, mais moins voilée de réticences, car ici l'appel au meurtre des envahisseurs étrangers est explicitement formulé. L'exhortation ainsi lancée aux indigènes du Cap peut se comprendre de plusieurs manières. Pour qui la replace dans la version publiée en 1780 de l'Histoire des deux Indes, elle apparaît comme un signal métadiégétique annonçant le refermement de l'insert digressif dont Diderot est l'auteur et l'ouverture d'un nouveau développement dû à une autre plume, celle de Raynal désormais, reprenant au paragraphe suivant l'historique de la colonisation hollandaise au Cap demeuré en suspens. Riebeck " approche» en effet et, "se conformant aux idées malheureusement reçues chez les Européens, commença par s'emparer du territoire qui était à sa bienséance, et il songea ensuite à s'y affermir. Cette conduite déplut aux naturels du pays ", avec lesquels un accord fut toutefois négocié, si bien que les Hollandais « continuèrent depuis assez paisiblement leurs usurpations ${ }^{43}$. Sans exonérer entièrement les colonisateurs européens, cet accommodement intervenu dans l'histoire réelle prend l'exact contrepied de l'appel imaginaire à la vengeance préventive, si l'on ose dire, lancé sur le mode de l'irréel du passé par l'auteur de la harangue ("Hâtez-vous donc, embusquez-vous; et lorsqu'ils se courberont d'une manière suppliante et perfide, percez-leur la poitrine. Ce ne sont pas les représentations de la justice qu'ils n'écoutent pas, ce sont vos flèches qu'il faut leur adresser $\left.{ }^{44}\right)$. On peut aussi s'interroger sur la motivation personnelle de l'orateur dans cette exhortation à la violence, certes purement verbale, mais d'une véhémence impressionnante, et retournée bizarrement en conclusion contre d'autres destinataires nettement moins irréels que les Hottentots du Cap : «Et vous, cruels Européens, ne vous

\footnotetext{
42 Ibid.

${ }_{43}$ G.-Th. Raynal, op. cit., tome I, livre II, chap. 18, p. 249.

${ }^{44} H 2 I(1774,1780)$, livre II, chap. 18, p. 679.
} 
irritez pas de ma harangue. Ni l'Hottentot (sic), ni l'habitant des contrées qui vous restent à dévaster ne l'entendront. Si mon discours vous offense, c'est que vous n'êtes pas plus humains que vos prédécesseurs ; c'est que vous voyez dans la haine que je leur ai vouée celle que j'ai pour vous. $»^{45}$

Cette fois c'est bien au lecteur réel de l'Histoire des deux Indes que ce discours (dont la seconde phrase souligne avec une certaine distance humoristique le caractère fictif) est réellement adressé. Reste cette " haine » avouée et même proclamée, dont on ne sait trop contre qui elle est dirigée : contre les voyageurs conquérants du siècle précédent, "voyageurs immoraux " fondateurs de la colonie hollandaise du Cap ? ou bien contre les Européens d'aujourd'hui, lecteurs de l'encyclopédie militante de Raynal, donc selon toute vraisemblance hommes des Lumières que rien n'autorise à englober avec leurs prédécesseurs dans la même réprobation ? À moins que, rejoignant ces derniers dans l'opprobre par le mauvais accueil qu'ils pourraient réserver à ces propos, si l'on en croit le trait final d'une ambigüité singulièrement retorse, ils ne méritent pleinement cette exécration dont leur propre «immoralité » serait alors la seule responsable.

Bien des choses interrogent dans cette tirade éloquente, peut-être un peu trop : la rhétorique de la haine complaisamment affichée, l'exhibition d'une indignation qui fait implicitement de l'énonciateur le porte-parole autodésigné de la moralité, la colère qui tire de sa véhémence sa propre justification, et même l'appel au meurtre des « voyageurs immoraux » européens, futurs colonisateurs des sauvages hottentots, au nom d'une étrange conception de la vengeance préventive châtiant par avance les crimes qu'ils n'ont pas encore commis, mais qu'ils commettront nécessairement. Incarnation d'une Justice supérieure et pour ainsi dire supra-humaine, le narrateur embrasse en effet simultanément le passé, le présent et l'avenir, surplombant aussi tous les espaces, du Mexique à l'époque de la conquête espagnole au début du XVI siècle au Cap de BonneEspérance au milieu du XVII siècle. Sans origine, détachée de toute solidarité communautaire, en particulier européenne, cette voix qui interpelle les nations excède manifestement les limites de la condition humaine. On ne peut évidemment la confondre avec la voix propre de Diderot, et même si les idées formulées ici sont en gros les siennes, on a un peu de mal à croire qu'il puisse adhérer sans ironie à la violence et à l'emphase du discours. La prosopopée, en déplaçant l'instance d'énonciation vers une figure allégorique chargée de figurer la Justice ou la Vengeance à la manière d'une sculpture à l'antique, permet à l'auteur réel de grossir le trait tout en prenant ses distances, d'exprimer comme par la voix de la postérité mais avec un soupçon d'exagération humoristique ses opinions et ses jugements. De même, en écrivant pour Raynal et sous son nom, Diderot utilise le masque d'un personnage célèbre et controversé, icône de l'anti-

45 Ibid. 
esclavagisme, à ce titre promis déjà à la gloire posthume du buste de marbre blanc représenté sur un tableau de Girodet souvent reproduit ${ }^{46}$.

Où chercher le véritable Diderot ? Dans l'éloquence dénonciatrice des tirades contre les exactions des voyageurs européens devenus colonisateurs? Ou bien dans l'analyse nuancée de la colonisation du Nouveau-Monde envisagée comme un processus historique plutôt positif sur le long terme? Mais la question a-t-elle vraiment un sens ? Est-ce bien la personnalité de Diderot qui s'exprime dans ces fragments sur deux modes souvent divergents? Les contributions rédigées pour l'Histoire des deux Indes sont anonymes, ou plutôt, pour la version de $1780 \mathrm{du}$ moins, signées d'un autre nom, celui de Raynal, dont l'extraordinaire notoriété oscille alors entre deux images, celle glorifiante d'un martyr de la vérité prêt à encourir tous les risques (le livre fut condamné et Raynal exilé), l'autre moins flatteuse d'un entrepreneur des Lettres souvent indélicat avec ses collaborateurs, aux convictions fluctuantes malgré les hardiesses affichées ${ }^{47}$. Mimant pour ainsi dire avec un soupçon de distance ironique la tension entre les deux faces du personnage public qu'était Raynal, les textes sur la figure du voyageur européen, individu immoral ou promesse d'un renouvellement de l'ancienne civilisation, correspondent aussi à l'écriture spontanément dialogique de Diderot, leur véritable auteur.

46 Il s’agit du portrait du député noir de la Convention Jean-Baptiste Belley par Anne-Louis Girodet-Trioson (1798), postérieur de deux ans à la mort de Raynal.

47 Voir F. Moureau, «L'abbé Raynal et la fabrication d'un best-seller : de l'agent d'influence à l'apôtre », Dix-Huitième Siècle, no 43, 2011, p. 541-555. 
Sylviane Albertan-Coppola

Université d'Amiens (CERCLL)

\section{Peut-on se fier au voyageur? Réponses de l'abbé Prévost dans les introductions de l'Histoire générale des voyages (1746-1759)}

\section{Can We Trust the Traveller? Prévost's Answers in his Introductions to the Histoire générale des voyages (1746-1759)}

The publication of the Histoire générale des voyages, with its subtitle the Nouvelle collection de toutes les relations de voyages par mer et par terre, qui ont été publiées jusqu'à présent dans les différentes langues de toutes les nations connues, caused to Prévost a number of problems. The introductions, which open different parts (and books) of the Histoire, show how the author copes with sources. Through his meticulous work of analysis a traveller figure takes shape. Prévost presents merits and weaknesses of travellers and brings about the question of the reliability of travel narratives he presents in his Histoire.

Keywords: travel narratives, definition of the traveller, credibility of the traveller, criticism of sources, $18^{\text {th }}$ century

Mots-clés : récits de voyage, définition du voyageur, crédibilité du voyageur, critique des sources, XVIII ${ }^{\mathrm{e}}$ siècle

L'Histoire générale des voyages de l'abbé Prévost, qui se veut la " Nouvelle collection de toutes les relations de voyages par mer et par terre, qui ont été publiées jusqu'à présent dans les différentes langues de toutes les nations connues $»^{1}$, semble a priori le lieu idéal pour observer la figure du voyageur au

1 Sous-titre de l'Histoire générale des voyages (Paris, Didot, 1746-1759, 15 vol. in-4º plus un volume de tables). Les références des citations qui suivent renverront à cette édition. Une 
milieu du XVIII ${ }^{e}$ siècle. Portraits, descriptions en action ou simples mentions pullulent, donnant de lui une image vivante et variée. Une telle multiplicité, liée aux différences de contrées, d'auteurs et de dates, rend cependant la tâche du chercheur difficile, vouant à l'échec toute tentative d'exhaustivité et de synthèse. C'est pourquoi, afin de faciliter et en même temps unifier la recherche, je me cantonnerai dans cet article aux introductions qui jalonnent la volumineuse collection Prévost. Elles sont présentes un peu partout dans les quinze volumes in-quarto de l'Histoire générale des voyages, mais de manière inégale. Parfois remplacées par un avertissement, une préface, un avant-propos, parfois coexistant avec l'un d'entre eux, les introductions remplissent un rôle bien spécifique, quel que soit leur emplacement au sein du volume ${ }^{2}$. Prévost y énonce les sources du livre ${ }^{3}$ ou du chapitre ${ }^{4}$ qui suit, en se livrant le cas échéant à leur confrontation, dans un évident souci scientifique et encyclopédique ${ }^{5}$. Il dit souvent quelques mots - en général élogieux - des auteurs des relations de voyage, qui sont pour la plupart les voyageurs eux-mêmes. Il retrace parfois avec admiration l'historique d'une conquête ou d'une découverte, non sans quelque arrière-pensée nationaliste ou visée colonialiste. L'Histoire générale des voyages est en effet une commande officielle du ministre de la marine Maurepas et bénéficie de la protection du chancelier d'Aguesseau, et son contenu s'en ressent ${ }^{6}$. Autant d'objectifs, plus ou moins affirmés, qui influent sur la présentation des voyageurs, encensés ou critiqués au gré des intentions du collecteur. La figure

Continuation en quatre volumes sera publiée par d’autres auteurs (t. XVII, 1761 ; t. XVIII, 1768 ; t. XIX, 1770 ; t. XX, an X).

2 Je ne retiendrai comme introductions que les textes liminaires auxquels Prévost donne spécifiquement ce nom en titre ou en marge.

${ }^{3}$ Quatre des quatorze livres qui forment la première partie, consacrée aux voyages aux Indes orientales par le sud-est (du tome I jusqu'au début du tome V), sont précédés d'une introduction.

4 Dix des quinze chapitres qui composent le livre I des "Voyages en Asie ", à la fin du tome $\mathrm{V}$, en sont pourvus. Il y en a une au début de chacun des huit chapitres du livre II (tomes VI et VII) et six pour les huit chapitres du livre III (fin du tome VII). Il y en aura beaucoup moins dans les huit volumes qui suivent.

${ }^{5}$ Sur le traitement critique des sources dans la collection, voir S. Albertan-Coppola, « Les introductions sur l'Afrique dans l'Histoire générale des voyages de Prévost : un "discours de la méthode" du traitement des sources", Les Cahiers du GRREA 17/18, $\mathrm{n}^{\circ} \mathrm{I}$ : Continuités et ruptures des sources du savoir sur l'Afrique aux $17^{e}$ et $18^{e}$ siècles, sous la dir. de D. Diop, 2017, p. 23-39 ; et "Un canal d'information de troisième main sur l'Afrique : la collection Prévost ", Colloque "L’Afrique des savants européens $\left(17^{\mathrm{e}}-20^{\mathrm{e}}\right.$ siècles) », Université de Dakar, 5-7 février 2018 (actes à paraître).

6 Voir l'introduction de Jean-Paul Mas à l'Histoire générale des voyages, dans : CEuvres de Prévost, éd. J. Sgard, t. VII, Grenoble, PU de Grenoble, 1985, p. 398 ; J. Sgard, Vie de Prévost, Paris, PUF, p. 202-204. Prévost évoque le chancelier d'Aguesseau dans l'« Avertissement » du tome XI de l'Histoire générale des voyages. 
du voyageur est tributaire de ce triple objectif : plaire et instruire certes, mais aussi glorifier l'expansion de la France au-delà des mers.

\section{Définitions du voyageur}

Trois grandes figures se dégagent de notre corpus : celle de Magellan au tome I, celle de Marco Polo au tome VII, celle de Christophe Colomb au tome XII. Dans les trois cas, leur aventure est exaltée et leurs mérites vantés. Magellan trouva en 1519 une route aux Indes orientales en passant par le Détroit qui porte son nom : "Il eut le malheur de périr dans ce voyage ; mais son vaisseau fit le tour du monde, pour la première fois, et l'expérience apprit que la Terre est un globe " (I, x). Polo, qui s'embarqua en $1252^{7}$ pour la Tartarie avec ses frères Nicolas et Mathieu, « se rendit capable de parler et d'écrire en quatre différentes langues tartares » et se fit tellement apprécier que «malgré sa jeunesse, le Khan l'employa aux affaires les plus importantes ", dont il s'acquitta tout en notant les observations les plus curieuses (VII, 307-308). Colomb est « le premier qui trouva dans sa grandeur d'âme et dans ses réflexions assez de force et de lumière pour s'élever au-dessus des obstacles", avec seulement "l'opinion des Anciens, soutenue par quelques expériences récentes, avec sa hardiesse naturelle et ses raisonnements pour guides, dans une entreprise pleine de difficultés et de dangers, dont le succès a rendu sa mémoire immortelle » (I, 3-4). Telles sont quelques-unes des louanges prodiguées aux grands navigateurs au fil des introductions.

L'Histoire générale des voyages construit ainsi, peu à peu, pour le plus grand plaisir des lecteurs, une image du voyageur zélé et courageux, prêt à affronter tous les obstacles pour servir une noble cause, et pourvu des qualités morales et intellectuelles nécessaires pour mener son entreprise à bien. Ce stéréotype ne concerne pas que les grands découvreurs; présent de manière latente dans toute la collection de voyages, il s'applique aussi çà et là à de plus modestes voyageurs. Par exemple, à un Français nommé le Vacher de la Case, embarqué en 1656 pour le maréchal de la Meillerie, "sans autre motif que de voir le monde », mais « dont les aventures méritent d'être publiées, en faveur de son courage extraordinaire et du service qu'il rendit dans cette occasion à l'établissement de Madagascar » (VIII, 557). Ou encore à ces obscurs « voyageurs errants » qui, « ne s'attachant point à suivre les routes communes, et se laissant conduire, tantôt par la seule curiosité, tantôt par le hasard des événements ", se rendent utiles à l'Histoire et à la Géographie en « visit[ant] des pays ignorés, et les parties des pays connus qui n’avaient jamais été visitées par d’autres voyageurs » (XI, 263).

7 Prévost se fie pour la date au manuscrit de Berlin (VII, 308, note 33). 
La collection intègre même en son sein une typologie du bon voyageur, due à Careri qui dans son Voyage $d u$ tour $d u$ monde édicte, en s'appuyant sur sa propre expérience, six règles à suivre par les voyageurs :

I. Un Voyageur doit être à l'épreuve des plus horribles dangers. [...]

II. On doit être bien pourvu d'argent, parce que les dépenses vont quelquefois beaucoup plus loin qu'on ne s'y est attendu. [...]

III. Un Voyageur doit avoir quelque teinture de médecine et surtout de chirurgie, autant pour sa propre utilité que pour elle d'autrui. [...]

IV. On doit savoir parfaitement la Géographie, la Sphère, l'usage de l'astrolabe et celui de la boussole, pour mesurer la hauteur polaire, et pour remarquer les erreurs des cartes. [...]

V. Heureux le Voyageur qui sait un peu de dessin! [...]

VI. Il est indispensable de parler plusieurs langues, particulièrement celles qui servent au commerce, telles que la française, l'italienne, l'espagnole, la portugaise et l'esclavone, à la faveur desquelles on trouve partout des interprètes. [...] (XI, 557-559)

Cette liste recoupe en partie les critères sous-jacents à l'éloge des grands voyageurs omniprésent dans les introductions (courage, connaissances, dont celle des langues), mais c'est à un autre type de lecteur que s'adressent ces conseils pratiques, non plus le lectorat qu'il s'agit d'éblouir pour assurer le succès commercial de l'ouvrage, mais celui qui cherche dans la lecture des récits de voyages des informations utiles à son propre voyage. À travers cette série de règles, Careri élabore un portrait de ce qu'il appelle " un véritable Voyageur ", se distinguant du Politique, du Naturaliste, du Géographe, de l'Historien, de l'Antiquaire, du Marchand et de l'Artiste, qui tous ne s'intéressent qu'à leur propre spécialité : «Ce n'est pas le but d'un véritable Voyageur, qui doit travailler pour la postérité autant que pour soi-même, et rendre ses écrits utiles à tout le monde. Il doit être exercé à faire une relation, non seulement où la vérité ne manque pas, mais qui renferme, sans distinction, tous les objets de la curiosité et du savoir. » (XI, 560)

La question de la définition du voyageur, concentrée ici dans une grille définitoire, court en fait dans toute l'Histoire générale des voyages. À plusieurs reprises, Prévost prend soin de préciser, dans la présentation qu'il fait des voyageurs en introduction, les caractéristiques de ces derniers, afin de donner du crédit à leurs remarques ou au contraire inviter le lecteur à la défiance. Ainsi, au début du chapitre portant au tome III sur les côtes de Guinée, prend-il ses distances par rapport aux premiers voyages figurant dans le tome I, qu'il

8 G. F. Gemelli Careri, Giro del mondo, Napoli, Roseri, 1699-1700, 6 vol. in- $8^{\circ}$; trad. fr. 1717, Voyage du tour du monde, Paris, Ganeau, 1719 ; rééd. augm. 1727. 
juge superficiels : "Ils regardent les mêmes pays, dans un temps où l'avidité de s'enrichir commençait à s'accorder avec le goût du savoir et le désir de l'instruction. » Une évolution se serait donc produite, allant dans le sens d'une intellectualisation du regard du voyageur. Villault, Atkins, Snelgrave, Smith, Loyer, des Marchais et plusieurs voyageurs présentés dans le livre qui suit «paraissent - selon Prévost - avoir été plus jaloux de la qualité d'Observateurs que de celle de Marchands ", ce qui lui permettra de "réduire [...] toutes leurs observations dans un corps avec celles d'Arthus, de Bosman, et de quelques autres, qui ont écrit fort au long sur la Guinée, mais plutôt en Géographes qu'en Voyageurs » (III, 333-334). C'est ce qu'il nomme, à la suite de ses prédécesseurs anglais, la méthode de la "réduction ", qui consiste à détacher le journal du voyageur proprement dit des informations qu'il contient, en vue de constituer une description savante des pays visités et des mœurs de leurs habitants ${ }^{9}$. Néanmoins, au livre XI, Prévost tiendra à distinguer de l'historien allemand Arthus l'humaniste néerlandais Dapper et l'érudit français Jean Barbot, qui "méritent moins le nom de Voyageurs, que celui d'Historiens Géographes », du fait que leurs ouvrages " ne sont qu'une revue des observations d'autrui » (IV, $400-401)^{10}$. Dans la perspective de l'auteur de l'Histoire générale des voyages, mieux vaut donc, pour sa contribution à la science, le voyageur observateur que le voyageur marchand, mais il faut se méfier de celui qui est plus savant que voyageur à cause de son information de seconde main ${ }^{11}$.

La grille d'évaluation de Prévost s'écarte ainsi de celle de Careri, certes soucieux d'inciter le voyageur à multiplier les observations (c'est à cette fin que vise la règle II car le manque d'argent, précise Careri, empêche de pousser plus loin les investigations ${ }^{12}$ ), mais ne disposant pas du recul critique offert à Prévost par sa position de collecteur, qui permet la confrontation de sources diverses sur

${ }^{9}$ Il ne se sentira vraiment libre d'appliquer cette méthode qu'après l'abandon des Anglais (voir l'" Avertissement » du tome IX). Sa démarche, qui privilégie l'exactitude de l'information sur le pays visité, est à l'opposé de celle d'un Bernardin de Saint-Pierre, qui s'attachera en fin de siècle à remanier le récit de son voyage à l'île de France en insistant sur ses impressions personnelles par déplacement de l'intérêt vers l'ego vians. Voir l'article d'Alain Guyot dans le présent volume.

${ }_{10}$ Gothard Arthus est l'auteur d'une Historia Indiae Orientalis (1608). On doit à Jean Barbot, employé par la Compagnie du Sénégal, le Journal d’un voyage de traite en Guinée, à Cayenne et aux Antilles (1678-1679) et à Olfert Dapper, qui n’a jamais quitté les Pays-Bas, une Description de l'Afrique (1686).

11 Sur la définition de l'historien, on consultera avec profit les ouvrages de François Hartog, Régimes d'historicité. Présentisme et expériences du temps, Paris, Seuil, 2003, et Évidence de l'histoire. Ce que voient les historiens, Paris, Éditions EHESS, coll. « Cas de figure 5 », 2005.

12 «Un Voyageur, qui n’a pas au-delà du nécessaire, ne peut faire un grand nombre d’observations, qui l'obligent souvent de s'arrêter, ou de prendre par des chemins détournés qui allongent sa route ; sans compter qu'il est quelquefois utile de faire de petits présents, pour s'attirer du respect, et pour faire ouvrir des lieux dont l'accès n'est pas libre à tout le monde. » (XI, 559) 
les mêmes lieux. De fait, si l'on en juge par les introductions de l'Histoire générale des voyages, la fiabilité des sources semble être le critère principal du jugement porté par Prévost sur les voyageurs. Si élogieux que soit le portrait des grands navigateurs, il s'accompagne toujours de remarques critiques sur leurs récits de voyages. En dépit des obligations qu’on lui doit pour ses découvertes, « on est forcé de reconnaître que les relations de Marco Polo sont remplies de défauts ", estime par exemple Prévost, qui lui reproche le manque d'exactitude des noms et des mesures, ses erreurs ou fictions historiques, et même le fait d'avoir décrit des régions qu'il n'a jamais visitées. C'est qu'il n'a pas dû, contrairement à ce qu'il affirme, tenir un journal de son voyage; il composa sa relation de mémoire à son retour à Venise et "sans avoir vérifié ses informations, il jeta par écrit, comme ses propres remarques, des récits fabuleux auxquels il avait légèrement ${ }^{13}$ ajouté foi »(VII, 311-313). La question de la fiabilité du voyageur est ainsi centrale dans l'Histoire générale des voyages : c'est elle, au fond, qui sous-tend toutes les remarques portant sur la définition du voyageur. Définir le voyageur, c'est d'une certaine manière le jauger et par voie de conséquence mettre en examen sa crédibilité.

\section{Crédibilité du voyageur}

Le voyageur apparaît clairement dans les introductions de l'Histoire générale des voyages comme un individu dont il convient de se méfier, quels que soient ses qualités morales et son degré d'instruction ${ }^{14}$. Prévost en effet met aussi bien en cause l'extrait douteux d'un voyageur inconnu sur les habitants de la petite Bukkarie (VII, 223) que les affirmations partisanes de savants jésuites sur les quatre religions de la Chine (VI, 320 sq). On ne compte plus dans sa collection les mises en garde préliminaires adressées au lecteur pour l'inciter à la défiance. Ici, l'auteur l'invite à juger lui-même par comparaison du crédit à accorder aux témoignages de voyageurs hollandais sur la Corée : "Mais c'est au lecteur à juger de la confiance qu'il doit prendre à leur témoignage, après l'avoir comparé avec les observations dont leur récit sera précédé [issues des Pères Régis et Du Halde] " (VI, 500). Là, il l'incite à ne "se servir qu'avec précaution " d'une Description du Royaume de Butan, "cet ouvrage étant anonyme, sans aucune explication qui puisse donner de l'autorité aux Mémoires sur lesquels il

13 Entendre : avec légèreté.

14 Il y aurait à cet égard un rapprochement à faire entre le Prévost romancier et le Prévost éditeur de voyages. La mauvaise foi du narrateur à la première personne dans les romansmémoires tels que Manon Lescaut et Histoire d’une Grecque moderne a été magistralement étudiée par Jean Sgard, notamment dans sa thèse sur Prévost romancier (Paris, Corti, 1968) et dans L'Abbé Prévost, labyrinthes de la mémoire (Paris, PUF, 1986). 
est écrit» (VII, 104). Et évidemment il lui signale en les rejetant avec véhémence les "fictions" diffusées par les voyageurs ayant suivi Marco Polo, tels que Odoric d'Udin et Jean de Mandeville qui, « suivant les idées romanesques de leur siècle, $[. .$.$] ont pris les fables qu'on leur racontait comme autant de vérités »$ (VII, 374-376) ${ }^{15}$.

Prévost se livre en fait, avant que d'aborder le moindre voyage, à un examen critique des récits en sa possession. D’abord, il écarte systématiquement les témoins de peu de foi, au premier rang desquels ceux qui ne se sont pas rendus sur les lieux, quoi qu'ils en disent, comme ces auteurs de relations confuses sur le Tibet (VII, 103), ou qui utilisent des matériaux de seconde main tels que les extraits des historiens orientaux sur les princes de la grande Bukkarie (VII, 218 sq), ou tout simplement ceux qui sont à ses yeux sans aucun intérêt, à l'instar de cette multitude d'auteurs de "voyages errants", rejetés dans l'index parce qu'ils " ne méritent guère d'être mieux connus » $(\mathrm{X}, 1)$. Il se montre toujours très soucieux en effet de remonter à la source première afin d'accréditer les dires d'un écrivain-voyageur ou d'asseoir la valeur d'un témoignage. Tel est le cas pour l'ouvrage de Pigafetta, dont il précise bien qu'il a été rédigé à partir des Mémoires d'Edoardo Lopez sur le Congo (IV, 47), ou pour celui d'Arthus à qui un Hollandais a fourni ses observations sur la Côte d'Or (IV, 399).

Dans un second temps, Prévost passe méthodiquement au crible les récits des voyageurs. Celui d'un secrétaire de vaisseau, nommé Hamel, portant sur la Corée a beau être confirmé par huit témoins, le collecteur ne se prive pas pour autant de faire une "Objection contre la fidélité de cette Relation ${ }^{16}$ ", due au fait qu'elle ne s'accorde point avec la carte de Corée pour les noms de ville, dans la route que les Hollandais suivirent depuis la mer jusqu'à la Capitale du Royaume » (VI, 517). Ceux des différents voyageurs passés par le Tibet pour se rendre en Chine sont examinés un par un dans le but d'évaluer leur niveau de vérité. Selon Prévost, par exemple, le journal du jésuite portugais Andrada est " extrêmement superficiel », alors que les voyages de Chesaud, jésuite français, " ont plus d'apparence de vérité " (VII, 423-424). On peut même dire que Prévost s'adonne, en tant que directeur de l'ouvrage, à une réflexion théorique assez poussée sur la validité d'un témoignage ou l'autorité d'un écrivain. Son introduction sur la «Description du Tibet » est un modèle du genre en ce qui

15 Voir encore l'appel de Prévost au lecteur, qu'il pousse à suivre l'Histoire du Karazm d'Abulghazi, qui est " ce qu'il y a de plus clair sur les Khans Usbeks de la grande Bukkarie » (VII, 218), en le guidant dans sa tâche : "Quoi qu'il en soit, Abulghazi s'accorde peu avec les Historiens persans; et nos lecteurs décideront sans peine à laquelle de ces deux autorités ils doivent accorder la préférence » (VII, 221).

${ }^{16}$ Il sagit de la Relation du naufrage d'un vaisseau holandois sur la coste de l'isle de Quelpaerts, avec la description du royaume de Corée, écrite par Hendrick Hamel et traduite du flamand par Minutoli, Paris, T. Jolly, 1670. 
concerne la certification des données. Elle commence par un état des recherches sur les cartes géographiques mettant en avant les lacunes des fameuses cartes de Guillaume Delisle ${ }^{17}$, faute de sources précises :

Quoique le Tibet soit une région fort étendue, à peine se faisait-elle remarquer, dans nos Cartes, avant celles qui ont été publiées par Delisle. Elle y était représentée comme une espèce de désert étroit, situé entre l'Inde et la Chine, sans villes, sans rivières, et sans montagnes, quoiqu'il n'y ait aucune partie de l'Asie où les montagnes et les rivières soient en plus grand nombre. Nous en avions à la vérité quelques Relations confuses, qui nous venaient des Missionnaires; mais il n’y en avait aucune assez détaillée pour donner une juste idée des dimensions et des propriétés du Pays. (VII, 103)

Prévost souligne ensuite le rôle de deux missionnaires jésuites dans l'apport des matériaux sur le Tibet, tout en regrettant le peu de lumières qu'ils ont procurées sur la géographie :

Grueber et Dorville, deux Jésuites, furent les premiers qui après en avoir parcouru une grande partie en 1661, pour revenir de la Chine en Europe, nous firent une peinture supportable de son étendue et des usages de ses habitants. Les Lettres qui contiennent le récit de leurs usages, ont été publiées dans la Collection française de Thevenot ${ }^{18}$.

Kirker nous a donné aussi, dans sa Chine illustrée $e^{19}$, une Relation de leur voyage au travers du Tibet, avec les figures des choses les plus remarquables qu'ils y observèrent, telles qu'il les avait reçues d'eux-mêmes (14). Mais comme ils avaient toujours suivi la même route, ils n'ont pu nous fournir beaucoup de lumières sur la géographie d'une région si peu fréquentée. En un mot, les Compositeurs des Cartes n'avaient presque pas d'autres matériaux, pour travailler sur le Tibet, que ceux de ces deux Voyageurs, (car Desideri (15) ne dit presque rien du Pays et de la route qu'il fut obligé de suivre) avant que les derniers Missionnaires de la Chine nous en eussent donné une Carte, qui sans être complète et bien exacte dans les détails, ne laisse pas de satisfaire assez la curiosité d'un Géographe. (VII, 103)

17 Guillaume Delisle (1675-1726), cartographe du roi, élève de l'astronome Jean-Dominique Cassini, s'est rendu célèbre par ses cartes appuyées sur des observations astronomiques, complétées par les relations de voyages.

18 Melchisédech Thévenot, Relations de divers voyages curieux, qui nont point été publiées ou qui ont été traduites..., Paris, 1663-1696, 4 vol. in-fol. Les Voyages à la Chine des PP. I. Grueber et d'Orville figurent au tome IV.

19 Athanasius Kircher, China monumentis illustrata, Amsterdam, J. Jeansson, 1667, in-fol ; trad. F. S. Dalquié, La Chine d'Athanase Kircher illustrée, Amsterdam, J. Jeansson, 1670, in-fol. 
Il fallut donc attendre longtemps pour passer d'une « peinture supportable » du Tibet à une connaissance suffisante pour permettre aux cartographes de dresser, d'après les voyageurs, une carte relativement satisfaisante pour un géographe.

Après cet historique de la cartographie du Tibet, Prévost passe à un examen critique des sources sur la population et les ressources du pays, en pesant leurs mérites respectifs :

On n'a peut-être pas tardé tant à se louer de leurs soins pour tout ce qui regarde les habitants, les animaux et les autres productions du Pays. Comme ils n'avaient pas fait eux-mêmes ce voyage, ils n'ont guère eu d'autres matériaux pour l'Histoire que ceux des premiers Missionnaires, auxquels ils ont joint quelques Remarques dispersées qu'ils ont reçues des Mathématiciens-Lamas, d'après lesquels ils ont travaillé (16). Telles sont celles du Père d'Avril, et les Observations historiques sur la Tartarie que le Père Gerbillon tenait d'un Envoyé Chinois. D’autres écrivains, comme Tavernier et Thevenot, ont parlé du Butan, ou du Tibet, par occasion, suivant les récits qu'ils avaient entendus. Enfin, ce que nous avons de plus complet et de plus particulier sur ce sujet, paraît être la Description du Royaume du Butan. Mais cet Ouvrage étant anonyme (17), sans aucune explication qui puisse donner de l'autorité aux Mémoires sur lesquels il est écrit, on ne doit s'en servir qu'avec beaucoup de précaution ${ }^{20}$. (VII, 103-104)

Ces quelques lignes font apparaître clairement les critères suivis par Prévost pour démêler le vrai du faux. L'absence de témoignage direct est manifestement le défaut le plus grave à ses yeux : ne pas avoir fait soi-même le voyage, recevoir ou tenir les renseignements d'un autre, d'après lequel on travaille, se fier à ce qu'on a entendu, tels sont les principaux reproches implicites adressés aux écrivains dans cette introduction. Mais le témoignage direct ne saurait pour autant suffire, il faut encore au récit du voyageur l'auctoritas : sans auteur déclaré, point d'autorité des sources.

Un autre exemple particulièrement significatif nous est fourni par le jugement critique que porte Prévost sur les écrits du jésuite Navarette en mission en Chine, dont il critique l'excès d'hybridité, de prolixité et de digressivité :

L'ouvrage de Navarette est rempli de choses curieuses, et respire dans toutes ses parties la bonne foi et la vérité. Mais, outre qu'il est mêlé d'une infinité de matières qui ont rapport aux disputes des missionnaires et au progrès des conversions, il est

${ }^{20}$ Notes de bas de page : « (14) Il s'en trouve une Traduction dans la Chine d'Ogilby. Thevenot a supprimé les figures. ", " (15) le Père Desideri, Jésuite, fit en 1714 un voyage depuis Kashmir dans l'Inde jusqu’à Lapas ; mais il sétend peu sur sa route ou sur ce Pays. », " (16) Elles ont été publiées par le Père Du Halde, dans le quatrième tome de sa Description de la Chine, sous le titre d'Observations géographiques et historiques sur la Carte du Tibet, etc. tirées des Mémoires du Père Regis. », «(17) On en trouve l'Extrait dans le Mercure de Paris pour le mois de juillet 1718. » 
mal digéré dans sa forme, et le style en est extrêmement prolixe. L'auteur se permet des digressions sur toutes sortes de matières : il introduit continuellement des citations et des autorités, pour appuyer ses propres sentiments et les tire surtout des auteurs religieux. $(\mathrm{V}, 395)$

La bonne foi et la vérité ne suffisent donc pas non plus à faire un bon témoignage. L'auteur doit en outre répondre à certains critères de forme et il semble qu'il perde de son autorité en appuyant ses dires sur ceux d'autrui (d'autant plus si l'autorité de la religion prend le pas sur celle de l'auteur-voyageur).

On est étonné néanmoins de voir Prévost adopter ici un critère subjectif quand il affirme sans démonstration que l'ouvrage " respire " la bonne foi et la vérité, et accorder autant d'importance au style. Il fait de même ailleurs à propos de Gautier Schouten, voyageur errant dont les courses furent livrées au hasard :

Cette apparence de légèreté serait une forte raison de se défier de son jugement et de sa bonne foi, si ces deux qualités n'éclataient au contraire dans ses récits et dans ses descriptions. Non seulement les peintures y sont vives et les détails intéressants, mais il y règne un air de candeur et de sagesse, qui plaît autant que la variété de ses aventures. (XI, 264)

Là aussi, les qualités morales apparaissent comme une donnée d'évidence (jugement et bonne foi éclatent, "il règne un air de candeur et de sagesse ") et les qualités stylistiques (vivacité, intérêt, variété) tiennent une grande place dans l'appréciation portée sur le voyageur ${ }^{21}$.

En fait, Prévost se montre parfois étonnamment confiant envers ses sources. Au moment d'introduire les voyages des Anglais dans les Indes, par exemple, il constate que ces derniers n'ont pas publié d'histoire de leurs conquêtes comme l'ont fait les Portugais et les Espagnols, mais cela ne l'empêche pas de se montrer sûr de son information :

Cependant les mémoires de la Compagnie des Indes, les Lettres de ses agents, et les Comptes de ses Facteurs, qu'on ne peut soupçonner d'infidélité, les Relations particulières qui ont paru par intervalles, enfin les remarques que divers Capitaines de Vaisseaux et d'habiles Pilotes ont publiés sur leurs navigations, me mettront en état de rendre un compte assez exact des principaux Voyages et de l'établissement des Anglais au Sud et à l'Est. (I, 217)

${ }^{21}$ M. Duchet avait déjà noté cette tendance de Prévost à privilégier la forme, au point de récrire certains passages afin d'en " réparer le style » (à propos du P. Charlevoix, " Avantpropos ", t. XII, p. XIII), Anthropologie et histoire au siècle des Lumières, Paris, Maspero, 1971, p. 85. J. Sgard rappelle les qualités d'écrivain que manifeste Prévost traducteur dans l'Histoire générale des voyages, Vie de Prévost, op. cit., p. 208. 
Que penser, de la part d'un critique exigeant comme l'auteur de l'Histoire générale des voyages, de ce postulat sur la fidélité insoupçonnable de ses sources?

Bien plus, Prévost n'hésite pas à embellir, voire à fausser la vérité quand il s'agit de mettre à l'honneur l'action des Français au-delà des mers. Le livre VII consacré dans le dernier tome aux "Voyages et établissements aux Antilles ", notamment, regorge de remarques partisanes, qui coexistent paradoxalement avec quantité de notes correctrices concernant les chiffres, les faits, les usages rapportés par les voyageurs. Force est de constater l'ambiguïté du propos de l'auteur qui tient à la fois du savant et du propagandiste. On le sent pressé, dans sa tâche de traducteur de la collection anglaise, de se détacher du plan des Anglais, qu'il accuse d'avoir privilégié les voyages de leurs compatriotes ${ }^{22}$, pour mettre au plus vite les Français en avant. On le voit s'exalter au rappel des conquêtes françaises. À propos de l'île de St Domingue, par exemple, il s'écrie : "pour ne dissimuler aucun de nos motifs, serions-nous insensibles à l'honneur du nom français, qui a reçu tant d'éclat de la belle Colonie que nos Aventuriers y ont formée depuis près d'un siècle ? " $\mathrm{XV}, 374)$. On remarque même la présence au tome XIV (1757) d'un écrit de circonstance, visant à faire valoir les droits des Français en Nouvelle France, en pleine guerre de sept ans ${ }^{23}$. Le voyageur apparaît dès lors dans la collection Prévost comme un instrument au service de la science de son temps en même temps quacteur de la course au pouvoir maritime. Michèle Duchet, tout en rendant hommage dans sa thèse à la " véritable critique des sources » à laquelle il se livre, voit même en Prévost un " écrivain à gages » et dans l'Histoire générale des voyages une «chronique de la colonisation $»^{24}$.

Revenons, à l'issue de ce parcours des introductions, à la question formulée dans le titre de cette contribution. Peut-on se fier au voyageur? La réponse dans l'Histoire générale des voyages est négative, car toutes sortes de considérations peuvent faire entrave à la vérité dans le récit du narrateur. C'est pourquoi Prévost interroge patiemment chaque témoignage. Le voyageur s'est-il rendu sur place? Les observations qu'il transcrit sont-elles les siennes? Les a-t-il faites sans parti pris? Et si oui, ont-elles été transcrites, puis transmises sans subir d'altération? Pour finir, recoupent-elles les informations données par d'autres

${ }^{22}$ Avertissements des tomes I (p. XIV) et VIII ( $2^{\mathrm{e}}$ et $3^{\mathrm{e}}$ p., non paginé). Prévost réitère ce reproche dans l'introduction des « Voyages des Hollandais aux Indes orientales » (t. VIII, p. 67).

23 Voir S. Albertan-Coppola, "Eclaircissement sur les différends des Français et des Anglais dans l'Amérique septentrionale”, par l'abbé Prévost : Messieurs les Anglais ont tiré les premiers... ", dans : L’Angleterre et nous : concurrence, influence, rivalité... (Rencontre académique du Grand Ouest), Académie des sciences, lettres et arts d’Amiens, 17 juin 2017.

${ }_{24}$ M. Duchet, Anthropologie et histoire au siècle des Lumières, op. cit., p. 91, 85 et 93. 
voyageurs? Telles sont les principales questions que se pose à chaque fois Prévost afin de valider ou invalider les dires des voyageurs qu'il publie. Elles construisent au fil des introductions, parallèlement à la figure d'un voyageur peu fiable, l'image d'un directeur de collection rigoureux et digne de foi. En dépit de quelques pétitions de principes et jugements à l'emporte-pièce, on peut en effet saluer l'effort critique de Prévost, qui en ce siècle des Lumières n'épargne aucun penchant à l'affabulation, ne se range derrière aucune figure d'autorité, ne recule devant aucune vérification des données. Sa recherche de la vérité ressemble assurément à celle préconisée dans l'article PHILOsophe de l'Encyclopédie, qui recommande de remonter aux sources des principes, c'està-dire aux observations qui les ont produits, et de distinguer le vrai du faux, sans le confondre avec le douteux ni le vraisemblable ${ }^{25}$. Il est permis néanmoins de se demander si Prévost a toujours fait les bons choix, si sa méthode de "réduction " en particulier ne contribue pas à dénaturer les informations fournies par les voyageurs en les détachant de leur contexte, si surtout les contraintes éditoriales qu'il subit ne le conduisent pas à enfreindre les principes d'accréditation que luimême établit avec une grande exigence. De telle sorte qu'on est tenté de dire, en définitive, pour revenir cette fois au titre de ce volume, que dans l'Histoire générale des voyages la figure du voyageur est confisquée au nom de la science, quand ce n'est pas au service du commerce ${ }^{26}$.

25 «Le philosophe forme ses principes sur une infinité d’observations particulieres. Le peuple adopte le principe sans penser aux observations qui l'ont produit : il croit que la maxime existe pour ainsi dire par elle-même ; mais le philosophe prend la maxime dès sa source; il en examine l'origine ; il en connoît la propre valeur, \& n'en fait que l'usage qui lui convient. / La vérité n'est pas pour le philosophe une maitresse qui corrompe son imagination, \& qu'il croie trouver partout ; il se contente de la pouvoir démêler où il peut l'appercevoir, Il ne la confond point avec la vraissemblance; il prend pour vrai ce qui est vrai, pour faux ce qui est faux, pour douteux ce qui est douteux, \& pour vraissemblable ce qui n'est que vraissemblable. Il fait plus, \& c'est ici une grande perfection du philosophe, c'est que lorsqu'il n'a point de motif propre pour juger, il sait demeurer indéterminé. » (éd. de Paris, t. XII, 1765, p. 509, col. b), disponible sur le site http:// enccre.academie-sciences.fr, consulté le 2/02/2021.

${ }^{26}$ J. F. de La Harpe ne sera d'ailleurs pas tendre à l'égard de Prévost dans la préface de son Abrégé de l'Histoire générale des voyages, auquel il reproche l’absence de choix et de sobriété dans l'usage des matériaux, son manque d’ordre et de méthode, et même les défauts de son style (éd. Paris, Hôtel de Thou [Laporte], t. I, 1780, p.v-vii). 
Izabella Zatorska

Université de Varsovie

ORCID 0000-0003-2048-4033

\section{Le statut esthétique, ontologique et épistémologique du narrateur dans Le Monde vrai de Marivaux}

\section{The Aesthetic, Ontological and Epistemological Status of the Narrator in Marivaux's Le Monde vrai (The True World)}

Brought about by the reflections of the author-narrator of Le Cabinet $d u$ philosophe (In The Philosopher's Study), Marivaux's last jornalistic endeavour (1734-1738), the narrative fiction that occupies the last six issues, could make one puzzled, even disturbed. From the second episode, the title metamorphoses from Le Voyageur dans le Nouveau Monde into Monde vrai [Suite du] (The True World [Continuation of]), as if the narrator, with his own way of being and seeing, wanted to disappear behind the result of the changes in his vision of humanity. However, it is his triple status that determines what follows. Our analysis will therefore look at the status of the narrator-traveler, at his own perception of that status, at his evolution and at the commentary on it. Marivaux's reflections could well have a universalist implication, even one that points towards the socio- and ethnological relations and their critiques of later centuries.

Keywords: Marivaux, Cabinet $d u$ philosophe, traveler, meta-discourse, reality and appearance

Mots-clés : Marivaux, Cabinet du Philosophe, voyageur, métadiscours, être/paraître 
Le « Monde vrai », par conséquent, adviendra non pas nécessairement quand, dans le monde profane, chacun fera - à l'instar des bienfaiteurs

de Marianne ou de Tervire - un usage du mot

" charité » conforme à la religion chrétienne bien entendue, mais quand, au lieu de cloisonner comme Climal le monde et la religion, les

hommes avanceront sans masque, dans une parfaite coïncidence entre l'être et le paraître. ${ }^{1}$

Amenée par les réflexions de l'auteur-narrateur du Cabinet du Philosophe, la dernière (1734-1738) initiative journalistique de Marivaux (1688-1763), la fiction narrative qui occupe les six dernières feuilles de cette édition a de quoi rendre rêveur, sinon inquiet. Son titre se métamorphose dès le second épisode : Le Voyageur dans le Nouveau Monde devient Monde vrai [Suite du]. Comme si le narrateur voulait s'effacer lui-même, avec sa façon d'exister et de voir, derrière les résultats du changement opéré dans sa vision des hommes. Cependant, c'est son triple statut - esthétique, ontologique et épistémologique - qui détermine le reste. Notre interrogation portera donc sur le statut du narrateur-voyageur, sa perception de ce statut et de son évolution. La réflexion de Marivaux pourrait bien avoir un sens universaliste, voire anticipateur par rapport aux relations socio- et ethnographiques des siècles à venir, et à leur critique. Nous étudierons également l'incidence de cette figure de voyageur sur l'écriture adoptée et l'écart par rapport au schème générique de récit de voyage, que la poétique marivaudienne du dévoilement entraîne.

Trois dates ponctuent la parution du Cabinet du Philosophe : le 17 septembre 1733, l'écrivain obtient une approbation pour le publier, fin janvier 1734 paraît la première feuille (en parallèle à la seconde partie de La Vie de Marianne) et trois mois après, en avril, la onzième et dernière feuille; une "nouvelle édition augmentée » du Cabinet voit le jour en $1738^{2}$. La fiction du Voyageur dans le Nouveau Monde surgit vers la fin de la $6^{\mathrm{e}}$ feuille ; œuvre implicite du philosophe éponyme, créateur présumé de la dernière feuille marivaudienne ${ }^{3}$.

1 S. Albertan-Coppola, «À la recherche du Monde vrai : vrais et faux dévots dans La Vie de Marianne ", Malice, $n^{\circ} 5$ : Marivaux entre les genres : le corps, la parole, l'intrigue, sous la dir. de S. Lojkine, 2015 : https://cielam.univ-amu.fr/node/1443, consulté le 4/02/2021.

2 D'après la "Chronologie " de la vie de Marivaux, dans ses Journaux et Euvres diverses, éd. F. Deloffre et M. Gilot, Paris, Classiques Garnier, 2001 [1988], p. X-XI. Dorénavant la référence dans le texte : le sigle $J O D$ suivi du chiffre romain pour le $\mathrm{n}^{\circ}$ de la feuille et du chiffre arabe pour la page.

3 Mais c'est un ami de l'éditeur présumé qui, lui-même ami du philosophe éponyme, aurait remis les manuscrits de celui-ci au premier, après la mort de leur auteur. Voilà l'explication qui nous est donnée en ouverture (JOD, I, 335), Marivaux se plaisant, à son habitude, à exaspérer 
Dans le triple statut du voyageur, le rôle fondamental échoit à la reconnaissance esthétique. Elle décide du mode sur lequel son propos est transcrit. Nous pouvons y détecter une allure borgésienne avant la lettre, puisque la fiction et la réalité n'ont plus de frontières étanches. Cette fluidité semble informer le statut ontologique du narrateur-voyageur, jusqu'à nous faire chercher sur quoi son existence est garantie, pour justifier, enfin, son statut épistémologique qui nous fait examiner les horizons de sa découverte (réalité à fonds intersubjectif), si ce n'est de sa trouvaille (invention unique en son genre mais récupérable dans l'application).

Avec le premier intitulé de la fiction, le lecteur de la $6^{\mathrm{e}}$ feuille du Cabinet $d u$ philosophe est plongé dans l'ambiance d'un genre bien connu, devenu depuis un siècle un bestseller : la relation de voyage. Celle-ci est bien précédée, dans la même feuille, par de petits essais qui traitent $D u$ style et De la critique (excursions voilées contre les critiques de l'expression marivaudienne) ${ }^{4}$. Mais l'analogie avec les classiques du genre tourne court dès le premier paragraphe du Voyageur, à cause d'un très long préambule, reporté encore sur les deux premières pages de la $7^{\mathrm{e}}$ feuille : le narrateur-voyageur y négocie avec son lecteur virtuel les conditions de s'embarquer avec lui dans une aventure symbolique : la lecture. Ce qui aurait pu décourager le lecteur virtuel, c'est la vision du monde à découvrir au bout du périple : le toponyme évocateur mais banalisé (Le Nouveau Monde) est vite remplacé par un autre, plus intrigant (Le Monde $v r a i)$ - plus inquiétant aussi par son ambiguïté sur laquelle le narrateur expérimenté ne cesse de renchérir tout en ménageant le suspens, en doublant ainsi la démarche de son ami anonyme et maître d'initiation :

Par ce Monde vrai, je n'entends pas un monde plus réel que le nôtre, plus véritablement existant : car de ce côté-là, ce me semble, il n'y a rien à redire au nôtre, et le pyrrhonien [sceptique - IZ] le plus déterminé ne doutera jamais de sa réalité que par raison de système, et jamais par sentiment.

Ainsi par ce mot de Monde vrai, c'est des hommes vrais que j'entends, des hommes qui disent la vérité, qui disent tout ce qu'ils pensent, et tout ce qu'ils sentent : qui ne valent pas pourtant mieux que nous, qui ne sont ni moins méchants, ni moins intéressés, ni moins fous que les hommes de notre monde [...]. (JOD, VI, 389)

La tradition littéraire voulait que le narrateur-voyageur garantisse l'existence objective d'un monde inexploré, présenté par lui comme intersubjectif ;

la convention de service, celle de "manuscrit trouvé ». Voir là-dessus J. Hermann, Le récit génétique au XVIII siècle, Oxford, Voltaire Foundation, 2009, p. 6-7, 95-97 (exemple puisé dans La Vie de Marianne).

${ }^{4}$ En termes voilés, Marivaux se plaint de Crébillon fils, qui a pastiché son style, au lieu de s’en prendre aux idées, s'il le fallait, dans L'Écumoire. Histoire japonaise (1734) : JOD, VI, 388-389. 
mais, chez Marivaux, embarqué pour un périple rempli de lecture suivie de discussions, le narrateur se voit débarquer dans une contrée similaire à la France (" exactement pareille à la nôtre »), comme l'avertit son compagnon (JOD, IX, 414). Aucun dépaysement au bout sinon celui, paradoxal, de voir «non pas [...] la France que vous connaissez », comme l'assure son guide ami, « mais [...] celle de ce nouveau monde où je vous mène, et qui est exactement le double du nôtre " (JOD, VII, 397). Le dédoublement concerne non seulement le décor paysage, architecture, transports - mais aussi (surtout!) les humains : les amis du narrateur, dont Folville, un officier de Paris, rencontré - son double, alors? dans la ville portuaire. Qu'en est-il du héros-narrateur? Lorsqu'ils arrivent à Paris « bis ", dans la maison de ce dernier, abandonnée par lui aux soins des serviteurs, son mentor lui laisse entendre qu'ils auraient aussi leurs sosies dans cette ville :

Ne vous ferez-vous jamais à cette idée-là, que tout se passe dans ce monde-ci comme dans l'autre?

Quoi ! lui dis-je, j'ai un chez moi dans cette ville-ci et des gens qui m'y attendent ? Sur ce pied-là, ajoutai-je, allons y descendre tout droit, et en arrive ce qui pourra. Je n'aurais jamais deviné que j’avais deux ménages, ni que je vivais ailleurs, pendant que je vivais à Paris [nous soulignons - IZ]. Ce qu'il y a d'heureux à tout cela, c'est que je n’ai point senti que je faisais double dépense ; ainsi, je ne regrette point l'argent qu'il m'en a coûté sans le savoir. (JOD, IX, 415)

Il va rabattre de son optimisme en voyant la dépense que ses serviteurs, aussi débauchés qu'hypocrites, font sous prétexte de divers malheurs dont ils lui avaient parlé dans leurs lettres pour obtenir plus de libéralités de sa part. Mais ce qui ne manque pas de troubler le lecteur - à moins qu'il ne s'en amuse, en devinant la clé du mystère - c'est la bonne foi avec laquelle, au début, le narrateur accueille l'idée, soufflée par son guide, d'avoir vécu dans un monde parallèle sans le savoir (voir nos italiques dans la citation) : pouvait-il avoir mené une vie double sans en avoir eu la conscience ? Alors, il faudrait supposer un dédoublement de celle-ci, il aurait donc eu un vrai sosie? Mais le narrateur ne semble guère le croire. Comme si le principe d'analogie - voire de copie, mais en plus net et en plus parlant - appliqué à " l'autre monde ", Le Monde vrai $^{5}$, s'arrêtait au seuil de la conscience du héros-narrateur, resté unique, lui. Bientôt nous apprendrons que le dédoublement en question résulte de l'évolution qui s'est opérée dans le voyageur durant la navigation, stratagème de l'ami généreux pour le préparer à de nouvelles découvertes et à la révision des vues anciennes :

5 Pareil en cela à l'utopie moderne, un monde souvent à rebours du nôtre, mais pour choisir une « troisième voie ». Cf. L. Marin, Utopiques. Jeux d'espaces, Paris, Éditions de Minuit, 1973. 
Un peu de navigation donnait à notre voyage un air d'importance et de difficulté qui en imposait à mon imagination, et me persuadait mieux que je verrais quelque chose de rare et de nouveau. (JOD, VII, 396)

C'est notre navigation qui vous a fait illusion, [...] vous avez cru que nous allions loin, et que je vous menais dans un pays inconnu. Je vous avais promis un monde que j'appelais le double du nôtre. Il y a longtemps que nous voyageons ; nous nous sommes arrêtés sur les côtes de France ; vous vous êtes imaginé à la descente du vaisseau que nous étions enfin arrivés à ce nouveau monde; et préoccupé comme vous l'étiez de cette idée dans laquelle j'avais soin de vous entretenir, vous avez pris la France et Paris où nous sommes, pour cette France, et ce Paris imaginaire, dont je vous disais avoir fait la découverte. Mais que toute illusion cesse : le Folville que vous avez rencontré est le vrai Folville, celui que vous connaissez; ce sont là vos domestiques, et c'est là votre maison. Il est pourtant vrai que je ne vous ai point trompé dans l'essentiel, et que je vous ai tenu parole à l'égard des personnes, si ce n'est à l'égard du pays. Vous n'aviez jamais vu d'hommes vrais ; je vous avais promis de vous en faire voir, et vous les avez vus. Ce ne sont pas d'autres gens que ceux de notre monde, j'en conviens ; mais ils n'en sont pas moins nouveaux pour vous, puisque vous les avez pris pour des hommes d'une espèce différente, et que vous n'en avez reconnu que la physionomie, et non pas le caractère. Les voilà tels qu'ils sont, au reste ; et à présent que la lecture des livres que je vous ai donnés, et que les réflexions que vous avez faites en conséquence, vous ont appris à connaître ces hommes, et à percer au travers du masque dont ils se couvrent, vous les verrez toujours de même, et vous serez le reste de votre vie dans ce Monde vrai, dont je vous parlais comme d'un monde étranger au nôtre... (JOD, X, 418-419)

Comme chaque voyageur avant l'arrivée dans une contrée insolite, le narrateur a mobilisé toutes les ressources de sa perception. Ce qui bouleverse ses attentes, c'est qu'au lieu de l'Autre, il y rencontre (apparemment) le Même : seul le langage et les autres moyens d'expression corporelle produisent de l'écart.

J'avertis ici que, dans tous les discours que je vais faire tenir aux gens avec qui j'aurai affaire, je ne rapporterai jamais leurs expressions, mais leurs pensées que j'entendais clairement. C'est un avertissement que j'ai donné une ou deux fois ${ }^{6}$,

${ }^{6}$ « Nous ne nous arrêtâmes pendant la journée que pour boire un coup sans descendre de notre chaise, et le soir nous arrivâmes à une petite ville dont le nom ne métait pas inconnu. / Il y a une ville de ce nom-là dans la France de là-bas, lui dis-je. Eh ! vraiment, ce sera toujours de même ; vous n'ignorerez le nom d'aucune des villes que nous allons trouver sur la route, puisque cette France où nous sommes est exactement pareille à la nôtre. / J'éclatai de rire à ce discours, sans bien savoir de quoi je riais, sinon que je ne pouvais m'accoutumer à des réponses aussi extraordinaires que les siennes. » $(J O D$, IX, 414) 
et que je réitère, parce que, si on l'oubliait, on prendrait les récits que je ferai pour des extravagances auxquelles on ne comprendrait rien. (JOD, XI, 430)

Personne n'entre deux fois dans le même fleuve, aurait noté Héraclite d'Éphèse. La révolution lockienne ${ }^{7}$, dont le voyageur marivaudien transmet les résultats, suggère que ce n'est pas le fleuve qui change mais celui qui le passe. Encore, faut-il le préciser, seule sa perception du fleuve ayant changé, cela suffit pour constituer le voyageur différent, à travers sa conscience reconstruite. Ayant changé à ce niveau-là, il pourra bien croire, à son tour, avoir devant lui un fleuve métamorphosé. Observations banales, dira-t-on. Oui, mais, au début du XVIII ${ }^{\mathrm{e}}$ siècle, cela vaut un tournant : le "Je pense, donc je suis " cartésien devient " Je suis ce que je pense ${ }^{8}$. En l'occurrence, « ce que je pense des autres». Rien d'étonnant que le héros refuse de reconnaître son interlocuteur, en entendant ce que débite Folville, pourtant une vieille connaissance de Paris :

Tu ne ressembles que de visage à ce jeune officier que je connais, dis-je en moimême ; mais tu ne penses pas comme lui, il n'est pas si vain que toi.

Il est certain que celui que j’avais vu à Paris, et qui portait la même physionomie, ne m'avait jamais paru si fat que cet homme-ci ; j'avais bien entrevu, quelquefois, qu'il croyait en valoir un autre. Mais de cette bonne opinion de lui-même, si ridicule et si grossièrement déclarée, je ne l'en avais jamais soupçonné.

Cependant je n'avais encore rien répondu ; je regardais cet homme-ci comme un étranger, et j'avais de la peine à me conformer à la méprise où je croyais qu'il tombait à mon égard. (JOD, VIII, 399)

À défaut d'avoir «navigué » - avoir fait de la lecture et en avoir discuté avec un ami expérimenté, à quoi le narrateur avait employé quelques mois avant la rencontre rapportée - Folville, sans avoir lui-même changé, prend le narrateur pour ce qu'il semble être, une vieille connaissance. Mais il suffit que Folville ait parlé : son discours dénudé détruit l'apparence d'identité que le narrateur voulait lui reconnaître. Si la parole détermine et révèle la pensée, le voyageur, lui, a eu le temps d'apprendre le code secret qui permet de lire ce que les « hommes vrais » (malgré eux !) lui révèlent :

7 Pas d'idées innées, mais les expériences, le refus de la souffrance et l'attirance par le plaisir, le bonheur recherché dans l'équilibre des relations sociales fondé en balance égale d'intérêts au nom de l'utilité, voilà en abrégé la nouveauté de cette philosophie (J. Locke, Réflexions sur lentendement humain, 1690).

8 Voire «...ce que les autres me pensent (être)». Cette dernière version est symptomatique de l'aliénation sociale que Rousseau n'arrête de dénoncer, à commencer par le Second discours, celui sur l’origine de l'inégalité parmi les hommes (1755). 
[...] Mais tout vrai que sont ces hommes, observez-les avec autant d'attention que s'ils ne l'étaient pas ; méfiez-vous d'eux comme s'ils étaient faux ; servez-vous avec eux des lumières que vous avez acquises : car quoiqu'ils soient vrais, ils voudraient souvent ne l'être pas; ils ne le sont que par force; et vous vous apercevrez bien un peu des efforts inutiles qu'ils font d'abord pour se déguiser. (JOD, VII, p. 398)

C'est encore un effet de renversement, utopique voire copernicien, que le voyageur peut observer : en vain les hommes "vrais " s'efforcent de cacher ce qui paraît malgré eux, tout naturellement. Leur langage est transparent le non-verbal et le trans-verbal surtout ; éclairé par les sages conseils de son compagnon, le narrateur n'a aucun mal à transcrire ce que, bon gré mal gré, ses interlocuteurs expriment :

[...] par ce Monde vrai, je n'entends pas des hommes qui prononcent précisément ce que je leur fais dire, leur naïveté n'est pas dans leurs mots (j’ai peut-être oublié d'en avertir) ; elle est dans la tournure de leurs discours, dans l'air qu'ils ont en parlant, dans leur ton, dans leur geste, même dans leurs regards : et c'est dans tout ce que je dis là que leurs pensées se trouvent bien nettement, bien ingénument exprimées; des paroles prononcées ne seraient pas plus claires. Tout cela forme une langue à part qu'il faut entendre, que j'entendais alors dans les autres pour la première fois de ma vie, que j'avais moi-même parlé [sic] quelquefois, sans y prendre garde, et sans avoir eu besoin de l'apprendre, parce qu'elle est naturelle et comme forcée dans toutes les âmes. Langue, qui n'admet point d'équivoque ; l'âme qui la parle ne prend jamais un mot l'un pour l'autre : et qu'on se ressouvienne que c'est d'après ce qu'on me disait dans cette langue-là, que je rapporte tous les discours que m'ont tenu [sic] les personnes avec qui j'ai eu affaire. (JOD, VIII, 400-401)

Langage des âmes, langage naturel, retour à la transparence du signe au référent : un aspect du rêve des origines semble se réaliser par lui, dans des circonstances surprenantes, car c'est à travers les vices et les travers du monde corrompu que se révèle la vision primitive, en toile de fond, ou plutôt en image à l'infra-rouge d'intentions que la convenance et l'étiquette, voiles commodes, se hâtent de dissimuler. Chose surprenante : la prétendue copie se dévoile comme original, alors que la copie impure - vision ancienne, fausse, tissée d'apparences trompeuses - ne mérite que l'oubli ou... la fuite. L'oubli pour l'ami perfide et la maîtresse infidèle qui avaient trompé le narrateur, en amenant son exil ; la fuite de chez la fiancée de Folville, prête à troquer une conquête contre l'autre.

«En faisant de l'ailleurs un nouvel ici et en affirmant l'identité du même et de l'autre ", Le Voyageur dans le Nouveau Monde allégorise " la démarche de l'anthropologue contemporain, pour qui la connaissance des autres est 
connaissance de soi, plus encore que celle du moraliste classique $»^{9}$. Le voyageur marivaudien se rend-il compte de son statut dans ses trois aspects (esthétique, ontologique et épistémologique) ? Est-il possible d'y répondre à travers ses commentaires ou ceux de son compagnon?

Tout d'abord, il faut souligner que la connaissance en question - celle des autres qui est celle de soi - ainsi que la nôtre, à propos du témoignage laissé par le philosophe qui « recueille» le manuscrit du Voyageur dans le Nouveau Monde, passe par l'écriture. Quel projet, d’après quel plan établi, réalise-t-elle?

Or, le plan, comme souvent chez Marivaux, semble une notion étrangère au procès créateur. Lorsque, au bout de six feuilles du Cabinet du philosophe $\left(\mathrm{VI}^{\mathrm{e}}-\mathrm{XI}^{\mathrm{e}}\right)$, remplies encore d'autres matières que le récit feuilleton annoncé par le titre vagabond, le lecteur pourrait s'attendre à une reprise riche en rebondissements, la narration tourne court, et cela sans façon. «Apparemment que le philosophe, à qui l'idée de ce Monde était venue, n'a pas cru qu'il était nécessaire de la pousser plus loin ; attendu sans doute que cette idée une fois donnée, tout le monde peut l'étendre, et s'en imaginer toutes les suites. Passons à autre chose. " (JOD, XI, 437). Comme si le récit devait servir au lecteur d'entraînement, tel un échafaudage qui encadre les premiers pas d'un disciple, modelés sur une démarche épistémologique stimulatrice des relations sociales renouvelées grâce à leur transparence.

Transparence unilatérale, semble-t-il, car si, de retour en France, le narrateur " entendai $[\mathrm{t}]$ alors dans les autres pour la première fois de $[\mathrm{sa}]$ vie » une langue « qui n'admet point d'équivoque " (JOD, VIII, 401), il semble avoir été mieux équipé que ses interlocuteurs pour la décoder en eux qu'ils ne le sont pour déchiffrer ses vrais motifs et intentions. Même s'il reconnaît : "j'avais moimême parlé [cette langue] quelquefois, sans y prendre garde, et sans avoir eu besoin de l'apprendre, parce qu'elle est naturelle et comme forcée dans toutes les âmes» (JOD, VIII, 401).

Mais d'abord, l'éventualité que cette langue naturelle puisse paraître extravagante et donc nécessaire à refouler, reste minimale dans le cas du voyageur lui-même : il n'a rien de blâmable à cacher, du moins le croit-il, pas de visées égoïstes non plus qui obligent à dissimuler pour paraître civil et désintéressé. Il y a pourtant des circonstances dans lesquelles il lui arrive de se servir de cette "langue des âmes " pour lui : il quitte promptement la cité où Folville entend plaire comme un petit-maître parisien modèle (il y en

9 La nouvelle proposition anthropologique de Francis Affergan, résumée par Éloïse Lièvre, se concentre sur la relation sujet observateur/sujet observé, en privilégiant l'idée de rencontre ou conjonction : É. Lièvre, "Soi-même comme un autre, un autre comme soi-même. La fiction des Lumières et anthropologie contemporaine ", dans : Les genres littéraires et l'ambition anthropologique au dix-huitième siècle : expériences et limites, sous la dir. d'A. Duquaire, N. Kremer et A. Eche, Louvain-Paris-Dudley, Éditions Peeters, 2005, p. 20. 
a imposé avec son jargon ${ }^{10}$ ) à qui la différence d'avec le chevalier-narrateur pouvait nuire (JOD, IX, 409-410), et n'arrive pas à prendre la décision devant les offres matrimoniales qui suivent l'une après l'autre, dès qu' il touche à un legs important. Pour rester avec le dernier mot du récit, « hésiter », nous partageons le suspens avec lui :

Ainsi laissez-vous séduire ; car, actuellement, je vous parle de bonne foi ; je suis parvenu à croire que vous ferez fort bien, de faire si mal. Cet homme en place est puissant, accrédité auprès des ministres ; vous jouirez de tout son crédit, j’en jouirai aussi, et il n’y a pas à hésiter... Ici finit totalement l'histoire du Monde vrai. (JOD, XI, 436-437)

Par dérision ou ironie sans doute, Marivaux - son " philosophe », s'entend se permet de terminer par un effet redondant : l'hésitation reste entière quant à l'issue du choix de la future, en contraste avec le «totalement» implacable du philosophe rédacteur de la feuille. Celui-ci pèche par une inconséquence analogue à celle affichée par ses prédécesseurs, Le Spectateur français et L'Indigent philosophe, les fictifs rédacteurs en chef des feuilles dans lesquelles Marivaux avait déjà expérimenté avec des styles, des genres et des idées ${ }^{11}$.

Quelques propos phares se trouvent juste avant l'ouverture du récit, parmi les réflexions groupées dans la sixième feuille, dédiées tantôt au style, tantôt à la critique de celui-ci. Dans les deux cas il s'agit de défendre les expressions extraordinaires ; l'essai qui traite " du style " cite deux phrases, le style de la première ayant été jugé " précieux » : "Les charmes d'une femme égarent la raison ». Et pourtant, comme le " philosophe » marivaudien tend à le prouver, ce sont les idées, d'abord présentes à l'esprit, qui se sont cherché des mots, et pas l'inverse ; une recherche dans l'expression seule, au respect de conventions langagières, aurait produit d'autres idées, trop conventionnelles ou trop guindées. Le second exemple vient d'une autorité suffisamment indiscutable pour ne pas avoir à subir le reproche de préciosité : "L'esprit est souvent la dupe du cœur ", aurait dit La Rochefoucauld. Oui, mais, dans la maxime 102 du moraliste nous lisons "L'esprit est toujours la dupe du cœur» (nous soulignons - IZ) ${ }^{12}$. Comme les considérations sur le style précèdent d’assez près le début (abrupt)

10 «À peine ai-je été arrivé que j’ai entendu parler de la petite personne que jépouse, qui est jeune, riche et maîtresse d’elle, et qui était assiégée de tous les provinciaux du pays qui se la disputaient, avec des grâces qui n’ont pas tenu contre les nôtres. On les a congédiés quand j’ai paru ; je m'y attendais : en un mot, je t'invite à ma noce pour la semaine qui vient [...]. » (JOD, VII, 399)

${ }^{11}$ Le Spectateur français (25 feuilles parues entre 1721 et 1724) et L'Indigent philosophe (7 feuilles parues en 1727) : "Chronologie », dans : JOD, p. VIII-X.

12 F. de La Rochefoucauld, Maximes et réflexions diverses [1678], éd. J. Truchet, Paris, Garnier Flammarion, 1977. 
du Voyageur dans le Nouveau Monde, il semble pertinent de les mettre en regard avec les expériences de ce dernier. Il s'agirait du pouvoir libérateur que son voyage initiatique devrait avoir pour l'esprit, le mettant à l'abri du déterminisme physico-social auquel l'ami de Madame de La Fayette croit le jugement soumis.

Cherchant à convaincre son lecteur virtuel de l'utilité de son témoignage, le voyageur dans le Monde vrai, auteur présumé de sa narration, doit dissiper la crainte qu'il diagnostique chez son lecteur : tout un dialogue fictif se noue entre eux, qui anticipe sur celui dont Diderot régale les lecteurs de Jacques le Fataliste et son Maître, et que pratiquent aussi d'autres auteurs d'Anecdotes et Divertissements qui se ressourcent à l'oralité13.

Son ami et guide le prévient, avant leur embarquement pour le voyage dans lequel ils emportent, entre autres, une Histoire du cour humain, livre fictif ou allégorique :

Il est bon d'être un peu au fait de notre monde, pour juger sainement de l'autre ; et je vous dirai même que tout homme qui nous connaît bien n'a que faire de voyager pour chercher cet autre monde dont je vous parle : il sait à n'en pouvoir douter qu'il existe ; il croit y être ; il le voit, et vous éprouverez dans les suites la vérité de ce que je vous dis là. (JOD, VII, 396)

En effet, dès le préambule le narrateur lui aussi cherche à préparer son narrataire à la surprenante analogie qu'il va constater :

De sorte qu'en vous peignant ces hommes que j'ai trouvés, je vais vous donner le portrait des hommes faux avec qui vous vivez, je vais vous lever le masque qu'ils portent. Vous savez ce qu'ils paraissent, et non pas ce qu'ils sont. Vous ne connaissez point leur âme, vous allez la voir au visage, et ce visage vaut bien la peine d'être vu; ne fût-ce que pour n'être point la dupe de celui qu'on lui substitue, et que vous prenez pour le véritable. (JOD, VI, 389-390)

L'esprit ne doit pas être la dupe des yeux, pourrait-on paraphraser La Rochefoucauld. Mais le lecteur virtuel, invité au voyage, s'ébroue à l'idée de s'exposer à un désenchantement trop brutal: " Mais que gagnerai-je à cela ? me direz-vous peut-être. En me faisant connaître les hommes, vous allez me dégoûter d'eux. Je ne me soucierai plus de leur commerce» (JOD, VII, 390).

Le voyageur-narrateur s'efforce de pénétrer les vrais motifs de la timidité de son destinataire :

13 Par exemple, A. C. comte de Caylus (1692-1765), Confidences réciproques ou Anecdotes de la société de madame la Comtesse de $B^{* * *}$, Londres 1774 ; voir B. Palus, Literatura in statu nascendi. Problemy estetyczne i genologiczne prozy literackiej Denisa Diderota, Wrocław, Oficyna Wydawnicza ATUT, 2017, p. 342. 
Je vois bien ce qui vous fait peur. Quand vous cesserez d'estimer les hommes, vous ne vous soucierez plus d'en être estimé vous-même, dites-vous, et vous vous imaginez qu'alors il n'y aura rien de si languissant que votre état, que vous périrez d'ennui et de mélancolie ; mais vous êtes dans l'erreur, croyez-m'en sur mon expérience. (JOD, VII, 390-391)

Le theatrum mundi baroque, offrant des prises de vue grotesques ou tragicomiques, dans les hantises du lecteur virtuel change en une ouverture du Jugement Dernier, lorsque les masques sur les vraies intentions, eux aussi doivent être levés; or, il n’est pas tenté de hâter cette révélation.

L'éternité des temps n'est pas toute consacrée au mensonge ; mais ne dérangeons point l'ordre des choses, n'anticipons point sur les spectacles. Si de même que nos corps sont habillés, nos âmes à présent le sont aussi à leur manière, le temps du dépouillement des âmes arrivera, comme le temps du dépouillement de nos corps arrive quand nous mourons. Mais pour aujourd'hui, je m'en tiens à ce que je vois ; gardez vos découvertes; je ne vous les envie point, et je vous crois fort à plaindre de les avoir faites. (JOD, VII, 390)

Seulement, loin de vivre un dies irae qui lui fasse éprouver une solitude absolue face à l'horreur de la corruption des hommes, le « voyageur » averti, en vrai philosophe, s'offre alors une " comédie du matin jusqu’au soir » : «[...] je ne saurais vous exprimer le repos, la liberté, l'indépendance dont je jouis. Je n'ai jamais été si content ; je ne me suis jamais diverti de si bon cœur que depuis ma découverte" (JOD, VII, 390).

Condition préalable pour apprécier cette offre ? Renoncer à l'ambition, dompter son amour-propre satisfait de l'estime dont les hommes répondent à celle dont on leur témoigne : «la flatteuse idée que vous vous faites de leur estime » une fois évanouie, l'esprit éclairé, "vos passions s'en iront, [...] vous ne le regretterez point ; [...] vous aurez le plaisir de voir clair ». Opération délicate :

Je vais instruire votre esprit sans affliger votre cœur ; je vais vous donner des lumières, et non pas des chagrins; vous allez devenir philosophe, et non pas misanthrope. Et le philosophe ne hait ni ne fuit les hommes, quoiqu'il les connaisse ; il n’a pas cette puérilité-là ; car sans compter qu'ils lui servent de spectacle, en qualité d'homme il est lui-même uni à eux par une infinité de petits liens dont il sent l'utilité et la douceur, mais qu'il tient toujours si aisés à rompre en cas de besoin, que son âme en badine, et n'en est jamais gênée [...]. (JOD, VII, 391)

Vivre au jour le jour son Jugement Dernier comme un dies gaudiae ; introduire l'eschatologie au cœur du quotidien non pour s'en dégoûter et s'en 
effrayer, mais pour dominer ses propres faiblesses à travers celles des autres. Enfin, retrouver un avant-goût du paradis perdu avec sa sérénité ignorante de l'orgueil. Et cela, grâce à la réflexion qui résulte de l'étude comparée de la relation du moi aux autres. Voilà tout un programme moral.

Le dispositif de voyage imaginaire intériorisé, utile pour une mise en scène de cette découverte - moins celle d'un Monde vrai, le monde des hommes démasqués, que celle de la juste relation à observer avec ses semblables - souligne l'identité de l'Autre à travers le Même dévoilé. Identité qui donne la mesure de la vraie révolution opérée par Marivaux, par l'intermédiaire de ses personnages, dans plusieurs romans et comédies.

L'énigme du code fourni - la lucidité s'apprend sur le tas - transpire dans le discours du narrateur, un marivaudage retourné comme un gant : au lieu de révéler malgré eux ce qu'ils veulent dissimuler, les Français croisés par le voyageur livrent tout, y compris ce qu'ils croient avoir tu, et le lecteur croule, comme le voyageur, sous la surabondance de détails qu'ils livrent, sans le voir, sur eux-mêmes. Mais, là encore, nous retrouvons ainsi l'analyse, faite d'aléas et de trottinements, que la conscience d'un Jacob ou d'une Marianne effectue en rétrospection, pour aborder leurs souvenirs enveloppant leur moi ancien.

Deux conditions de la réussite du philosophe-voyageur sont occultées, trop évidentes pour être relevées : la liberté illimitée du narrateur-voyageur et de son guide, en est la première ; le fait qu'il s'agit d'un ami à toute épreuve, digne de confiance, éclaireur, la seconde ${ }^{14}$. Sans lui, comment imaginer le succès de ce voyage paradoxal à travers un mensonge médiateur de la vérité ? Maître d'initiation providentiel ou transcendant, le nouvel ami représente le mystère et la surprise que tout départ promet : ouverture à la rencontre avec l'imprévu et l'inconnu, vraie ressource de l'âme, quelle que soit leur orthographe. Et la rareté de noms propres ajoute à l'interprétation du récit comme d'une parabole où, selon un adage vieux comme le monde, la vie est un voyage.

Des habitants du Monde vrai le narrateur-voyageur constate, en ouverture, qu'ils « ne valent pourtant pas mieux que nous [...] c'est qu'en vivant ensemble, ils se montrent toujours l'âme à découvert, au lieu que la nôtre est toujours masquée » (JOD, VI, 389). Même s'il revient vite à la distinction entre "vous »le narrataire - et « ils", « les hommes faux avec qui vous vivez », impossible de s'aveugler sur l'attitude du départ, tout d'humilité, dans cette reconnaissance, aussi humble que lucide, du sort commun de tous les hommes, faibles et pécheurs. La communauté du sort, celle du destin, permet de penser à une sorte de solidarité, même si - gagnant en lucidité - le narrateur-voyageur prétend avoir acquis le droit de jouir de sa supériorité sur les autres. Compromis avec

14 «Il n’est pas impossible que Marivaux ait songé à Fontenelle, en traçant le portrait du nouvel ami du jeune homme », font observer les éditeurs, F. Deloffre et M. Gilot (JOD, Notes Section IV, note 190, p. 619). 
l'ambition déjouée? "Le philosophe ne hait ni ne fuit les hommes » : cela suffirait-il pour un manifeste de la charité ? le narrateur marivaudien semble reculer devant ce dernier mot à lâcher, du moins de manière explicite ; mais ce qu'il propose, avec la passion d'un naturaliste converti en anthropologue, c'est l'interprétation du " ramage de l'espèce, son chant profond », une fois acquis le don de comprendre, commun aux protagonistes des romans marivaudiens dits « de maturité ", à Marianne comme à Jacob. L'objectif serait de comprendre "ce langage "naïf", cette douce et vive langue natale qui s'exprime de façon si subtile et si crue $»^{15}$, et qui procure « le plaisir de voir clair» contre le douteux plaisir d'être dupe du cynisme et de la vanité intéressés des hommes (JOD, VII, 391). Libéré d’une vie dans la méfiance, le lecteur de Marivaux se devra de s'intéresser à ses semblables, sûr de pouvoir « connaître le cœur humain dans sa vérité $»^{16}$. Effectivement, le récit-voyage n'a pas de fin, il se poursuit dans et à travers la relation proche et distante à la fois du moi à l'autre homme, liés par " utilité et douceur », sans jamais devenir l'un esclave de l'autre (JOD, VII, 391). Ne pas rejeter la chance offerte par ce périple semble un défi digne d'un homme du siècle qui se dit voué à la lumière ${ }^{17}$.

${ }_{15}$ F. Deloffre, M. Gilot, « Notice » du Cabinet du philosophe, dans : JOD, p. 333.

16 Ibid., p. 332.

17 Peut-on songer ici à un dialogue (décalé) avec les Lettres persanes? Dans la $8^{\mathrm{e}}$ feuille du Spectateur français, datée du 8 septembre 1722, Marivaux, ou plutôt son alter ego inspiré du Spectator d'Outre-Manche, fait part de ses impressions d'un début de lecture du roman, entamé le matin : il en cite le titre. Sans nier le plaisir qu'il y aurait déjà puisé et dans l'espoir d'en trouver encore, il reprend doucement son collègue pour avoir traité à la légère les affaires de la Religion idée dont il souligne la gravité par la majuscule, tout en insistant là-dessus (en italiques dans l'édition). Avec Le Voyageur dans le Nouveau Monde/Monde vrai, Marivaux voulait-il montrer comment tirer parti d'une altérité postiche et plaisante, sans blesser aucun dogme ? Voir JOD, VIII, 153-154. 
Deuxième partie

Voyageur qui se (re)met en valeur 
François Rosset

Université de Lausanne

\section{Voyageur-historien ou romancier-philosophe? Quelques leçons du voyage imaginaire}

Traveller-Historian or Novelist-Philosopher? A Few Lessons

\section{from the Imaginary Journey}

The paper proposes a reflection on the relationship between real and fictitious travellers, between authentic and imaginary journeys. The discursive articulation that makes the traveller witness a subject of speech allows us to define the conditions in which the problematic relationship between the experience of the real world and its narrative is established. It is also on this relationship that the interdependence between the narratives of real journeys and the narratives of imaginary journeys is based. The journey, as an act of narrative, can then be perceived as a figuration or metonymy of fiction itself.

Keywords: imaginary journey, truthfulness, fiction, Garnier, Casanova

Mots-clés : voyage imaginaire, véridicité, fiction, Garnier, Casanova

\section{Un philosophe parle des voyages}

Avec son petit essai didactique intitulé Des voyages (1615), Francis Bacon livre une série de conseils qui auront une riche postérité dans la succession des artes peregrinandi ultérieures. L'activité qui est ici visée, c'est le voyage apodémique ou voyage de formation, où il est exclusivement question du déplacement dans le monde réel dont il s'agit de prendre connaissance, à vrai dire moins pour accumuler des éléments de savoir à son sujet que pour parfaire la formation 
intellectuelle, philosophique et critique des jeunes gens. L'enjeu de ce voyage, c'est le voyageur, suivant le vieil adage selon lequel les voyages formeraient la jeunesse.

D’ailleurs, les conseils donnés par Bacon sont parfaitement ajustés à ce lieu commun :

Je voudrais d'abord - dit le philosophe - qu'un jeune homme ne voyageât que sous la direction d'un gouverneur ou d'un domestique sage et de bonnes mœurs, qui eût voyagé lui-même dans le pays où il se propose d'aller, qui en sût la langue et qui fût en état de lui indiquer d'avance quels sont dans ce même pays les objets qui méritent le plus de fixer l'attention d'un observateur, quelles liaisons plus ou moins étroites il doit y contracter, quels exercices, quelles sciences ou quels arts y sont portés à un certain degré de perfection; car autrement un jeune homme voyagera pour ainsi dire les yeux bandés, et, quoique hors de chez lui, il ne verra rien. ${ }^{1}$

Bacon poursuit son propos en enchaînant une longue série de conseils pratiques où l'on relève surtout l'injonction de consigner les observations dans un journal ou un compte rendu, celle de ne pas se mettre en route sans avoir préalablement acquis au moins des rudiments de la langue du pays qu'on va parcourir, celle encore de sélectionner les objets à visiter de manière à en retirer l'éventail le plus large des enseignements liés tout à la fois à la politique, à l'économie, aux arts et aux beaux-arts, à la science, à la justice, à la religion et à la morale. Il faut aussi que le jeune viator emporte avec lui des livres de géographie de même que les meilleurs cartes et relevés topographiques.

Ainsi, le présupposé qui guide le philosophe empiriste est clair : le voyage s'avère formateur quand il propose une relation immédiate à la réalité, cette immédiateté devant être garantie par la dimension personnelle de l'expérience comme par l'autorité des personnes et des ouvrages qui assurent une représentation présumée concordante de cette réalité. C'est pourquoi, sans doute, Bacon ne suggère pas de se préparer, avant de partir, en lisant les récits de voyageurs antérieurs, ni d'emporter leurs ouvrages avec soi ; car il connaît assurément cet autre adage, "À beau mentir qui vient de loin », fondé sur cette ombre suspicieuse portée depuis l'antiquité sur les voyageurs qui seraient fatalement des menteurs. On serait alors en droit de se demander comment Bacon pouvait postuler que le compte rendu produit par ces jeunes voyageurs qu'il conseille serait, lui, digne de foi, mais l'on comprend surtout pourquoi il s'abstient de donner des leçons sur ce point.

En effet, le problème posé par la fiabilité des relations de voyage impose d'abandonner cette perspective réduite sur le voyage considéré seulement comme moyen de formation du sujet, en focalisant plutôt l'attention sur la relation entre

1 F. Bacon, «Essais de morale et de politique », dans : Euvres de Bacon, éd. F. Riaux, Paris, Charpentier, 1851, t. II, p. 201. 
le sujet de la perception et les objets perçus, sur la construction complexe qui se met en œuvre lorsqu'un voyageur traduit dans le discours les observations, les sensations ainsi que les émotions vécues par lui dans sa rencontre avec des objets nouveaux, sous le régime des connaissances, des croyances, des présupposés et des dispositions affectives qui régentent nécessairement son expérience, comme des modèles de toutes sortes qui préforment son discours. Bref, ce dont il est question ici, ce n'est pas de la qualité intellectuelle et morale des voyageurs, mais de tout ce qui fait que le plus sincère et le plus honnête d'entre eux pourra toujours être suspecté de mentir parce qu'une distance plus ou moins grande se mesure inévitablement entre ce qu'il dit et ce que ses lecteurs présument ou croient savoir de la réalité décrite.

\section{Voyageurs menteurs}

Dans sa définition du vocable "Voyage », le Dictionnaire de Trévoux (édition de 1743) expose notamment la phrase suivante : "Strabon dit que tout homme qui conte ses voyages est menteur ». Allusion est faite à ce passage de la Géographie où le savant grec, quasi contemporain de Jésus-Christ, juge sévèrement les historiens qui l'ont précédé, tels Hérodote ou Ctésias, en relevant leur " extrême crédulité » et leur "grand amour du merveilleux » :

Voyant, en effet, que les auteurs qui se déclaraient mythographes connaissaient estime et succès, ils crurent pouvoir offrir eux aussi des écrits qui plairaient en exposant sous forme d'histoire ce qu' ils n'avaient jamais vu de leurs yeux ni entendu dire, du moins de la bouche de gens parlant en connaissance de cause, et en se souciant seulement d'atteindre ce qui plaît à des auditeurs et peut les émerveiller. ${ }^{2}$

D’après le géographe antique, ce sont les conditions de l'énonciation, sous la pression de récepteurs avides de merveilleux, qui dispensent pour ainsi dire le conteur de rendre fidèlement compte de ce qu'il aurait réellement vu. Dix-sept siècles plus tard, Lady Wortley Montagu constatera par elle-même la pertinence de cette observation; les réactions de certains récipiendaires de ses lettres de Turquie l'amusent assez pour qu'elle en fasse à d'autres le récit : " Elle est vraiment fâchée de ce que je ne mens pas autant que les autres voyageurs : elle s'attend apparemment à quelque relation d'anthropophages, espèce d'hommes dont la tête est au-dessous des épaules ${ }^{3}{ }^{3}$ On le voit : les mots de Jaucourt faisant observer, à l'article « Voyageur » de l'Encyclopédie, que

2 Strabon, Géographie, t. VIII, Livre 11, $6 \$ 3$, trad. F. Lasserre, Paris, Les Belles Lettres, 1975, p. 75 .

3 «Lady Montagu à Lady Mar, le 16 janvier 1717 ", dans : Lady Mary Wortley Montagu, Lettres choisies 1716-1718, trad. P. H. Anson, Paris, Payot, 2008, p. 79. 
« d'ordinaire les voyageurs usent de peu de fidélité »" s'inscrivent, sous le régime de l'euphémisme, dans une longue tradition.

Mais des contemporains du grand compilateur de l'Encyclopédie, illustres praticiens du voyage, apportent des explications très concrètes qui viennent justifier les écarts de l'énonciateur, du " conteur de voyage », en tant qu'il est exposé lui-même à des circonstances propres à conditionner, voire à biaiser sa perception, puis la relation qu'il en donne. Quand Lapérouse aborde à l'île de Pâques, il découvre une population moins misérable que ce qu'il attendait au vu des descriptions de ceux qui s'y étaient arrêtés avant lui :

[...] ce peuple m’a paru moins malheureux qu'au capitaine Cook et à M. Forster. Ceux-ci arrivèrent dans cette île après un voyage long et pénible, manquant de tout, malades du scorbut ; ils n'y trouvèrent ni eau, ni bois, ni cochons : quelques poules, des bananes et des patates sont de bien faibles ressources dans ces circonstances. Leurs relations portent l'empreinte de cette situation. La nôtre était infiniment meilleure : les équipages jouissaient de la plus parfaite santé ; nous avions pris au Chili ce qui nous était nécessaire pour plusieurs mois et nous ne désirions de ce peuple que la faculté de lui faire du bien. ${ }^{5}$

\section{Voyageur lecteur}

Épuisé ou valide, nécessiteux ou comblé, le voyageur est aussi marqué très fortement par ses lectures préalables. Lapérouse fait preuve d'une belle lucidité en révisant les jugements de ses prédécesseurs, mais ce n'est pas forcément la règle. Car comme le dit encore Jaucourt, "pour ne pas laisser le récit de leurs voyages imparfait, ils rapportent ce qu'ils ont lu dans les auteurs, parce qu'ils sont premièrement trompés, de même qu'ils trompent leurs lecteurs ensuite $»^{6}$. Le formatage du discours viatique qui s'est désormais imposé pousse les auteurs à se conformer à des modèles "parfaits». Et ces modèles sont aussi des lieux où se cristallisent les préjugés, ainsi que le fait observer Jean Potocki, en arrivant à Constantinople :

Vous serez peut-être étonnée d'apprendre que dans le grand nombre de voyageurs qui abordent en cette ville, il en soit très peu qui puissent en rapporter des idées

${ }^{4}$ Encyclopédie ou dictionnaire raisonné des sciences, des arts et des métiers, vol. XVII, 1765, http://enccre.academie-sciences.fr/encyclopedie/page/v17-p487/, consulté le 2/12/2020.

5 J.-F. de Lapérouse, Voyage autour du monde sur l'Astrolabe et La Boussole (1785-1788), éd. H. Patris, Paris, La Découverte, 2005, p. 66. Voir L. Andriès, «Lapérouse et la poétique du journal de bord ", dans : Le livre du monde et le monde des livres. Mélanges en l'honneur de François Moureau, sous la dir. de G. Ferreyrolles et L. Versini, Paris, Presses Universitaires de Paris Sorbonne, 2012, p. 535-550.

${ }^{6}$ Encyclopédie, op. cit. 
un peu exactes ; rien cependant n'est plus vrai, les plus observateurs ont épuisé leur curiosité à visiter les monuments de la Grèce, et n'envisagent les Turcs que comme les destructeurs des objets de leur culte. Ils arrivent pleins de cette idée, se logent dans le quartier des Francs, et daignent à peine traverser une fois le port pour aller voir la mosquée de Sainte-Sophie et revenir chez eux. ${ }^{7}$

Les effets de cet enfermement dans les connaissances acquises et dans les préjugés sont immédiatement perceptibles à la lecture des comptes rendus que donnent ces voyageurs bornés ; Rousseau le faisait remarquer péremptoirement dans la fameuse note $\mathrm{X}$ du second Discours :

On n'ouvre pas un livre de voyages où l'on ne trouve des descriptions de caractères et de mœurs ; mais on est tout étonné de voir que ces gens qui ont tant décrit de choses, n'ont dit que ce que chacun savait déjà, n'ont su apercevoir à l'autre bout du monde que ce qu'il n'eût tenu qu'à eux de remarquer sans sortir de leur rue, et que ces traits vrais qui distinguent les nations et qui frappent les yeux faits pour voir, ont presque toujours échappé aux leurs. ${ }^{8}$

Il ne faudrait pas seulement, dit Rousseau, apprendre à écrire une relation de voyage (et comment le faire, sinon en s'imprégnant de modèles antérieurs ?), mais il faudrait surtout savoir regarder. S'il avait écrit un traité sur l'art de bien voyager, l'auteur d'Émile aurait donné, c'est certain, tout autre chose que le chancelier Bacon.

Pourtant, ce handicap du voyageur conditionné par ses lectures préalables n'est pas toujours jugé négativement; il est même très fréquent de voir, au temps où la connaissance se construit encore majoritairement par la pratique ancestrale de la compilation, des auteurs occupés à défendre la prééminence de la lecture sur l'expérience. On peut évoquer l'ouverture de la Nouvelle relation de l'Afrique occidentale (1728) du Père Labat où est fait l'éloge de la sédentarité :

J'ai vu l'Afrique, mais je n'y ai jamais mis le pied, et j'aurais été très fâché de m’aller promener sur les côtes où je me suis trouvé, parce que j'aurais immanquablement été obligé d'aller à Maroc ou à Mequenès présenter des respects forcés à ce Prince si fameux par ses cruautés. Je ne parlerai donc de l'Afrique que sur la foi d'autrui et sur des mémoires, mais sur des mémoires de gens sages et éclairés, d’une probité reconnue, qui sont demeurés bien des années dans les pays que je vais décrire, en qualité de Commandant pour le Roy et de Directeurs généraux pour la Compagnie royale du Sénégal. ${ }^{9}$

7 J. Potocki, «Voyage en Turquie et en Égypte fait en l'année 1784 », dans : Voyages, éd. F. Rosset et D. Triaire, Paris, GF, 2015, p. 55-56.

8 J.-J. Rousseau, «Discours sur l'origine et les fondements de l'inégalité parmi les hommes », dans : Euvres complètes, t. 3, Paris, Gallimard, 1975, p. 212.

9 J.-B. Labat, Nouvelle relation de l'Afrique occidentale, Paris, G. Cavelier, 1728, p. i. 
Cette prétention d'autorité du voyageur de cabinet n'est certainement pas aussi absurde qu'elle pourrait en avoir l'air. Combien de scènes, dans les relations connues, ne nous représentent-elles pas les troubles de la perception du voyageur (le brouillard, l'inaccessibilité, la fièvre, l'erreur), les obstacles de toutes natures, les échecs dans la progression ou la connaissance? Le sujet singulier, limité dans son point de vue, exposé à toutes les illusions et à toutes les tromperies, peut-il témoigner d'autre chose que de son accidentelle et anecdotique aventure?

Mais en même temps, combien de naïveté dans la conviction que les agents du Roi seraient assurément des témoins dignes de foi ! Bougainville, en quelques phrases, met en lumière ce paradoxe qui consiste tout à la fois à décrier les descriptions des voyageurs et à se fonder sur elles pour produire de nouvelles descriptions des mêmes objets :

Je suis voyageur et marin ; c'est-à-dire, un menteur, et un imbécile aux yeux de cette classe d'écrivains paresseux et superbes qui, dans les ombres de leur cabinet, philosophent à perte de vue sur le monde et ses habitants, et soumettent impérieusement la nature à leurs imaginations. Procédé bien singulier, bien inconcevable de la part de gens qui, n'ayant rien observé par eux-mêmes, n'écrivent, ne dogmatisent que d'après des observations empruntées de ces mêmes voyageurs auxquels ils refusent la faculté de voir et de penser. ${ }^{10}$

\section{Voyageur au coin du feu}

Lapérouse, de son côté, s'insurge contre les philosophes en chambre enclins à créer et à véhiculer des mythes, comme celui du "bon sauvage", alors qu'ils ne se sont jamais frottés aux populations des lointains. Après avoir bravé ce qu'il appelle la fourberie et la cruauté des indigènes, voici ce qu'il conclut : "Les philosophes se récrieraient en vain contre ce tableau. Ils font leurs livres au coin de leur feu, et je voyage depuis trente ans : je suis témoin des injustices et de la fourberie de ces peuples qu'on nous peint si bons parce qu'ils sont très près de la nature $»^{11}$.

Oui, le contentieux est lourd entre les arpenteurs du monde occupés à sonder, mesurer, relever, cartographier et décrire les terres encore inconnues ou mal connues et les écrivains de l'ailleurs ; il est lourd surtout de préjugés et de malentendus autour de cette limite insensible, labile, poreuse, mais indéniable qui, du voyageur en action dans l'espace, distingue le voyageur occupé à relater son expérience. Il faut la lucidité d'un abbé Prévost, à la fois grand compilateur

10 L.-A. de Bougainville, Voyage autour du monde [1771], Paris, Gallimard, 1982, p. 46.

11 J.-F. de Lapérouse, Voyage autour du monde, op. cit., p. 122. On trouve une solide réflexion théorique qui permet de penser ces paradoxes dans l'ouvrage de Ch. Montalbetti, Le Voyage, le monde et la bibliothèque, Paris, PUF, 1997. 
de récits de voyages et grand romancier, pour formuler avec justesse cette situation de porte-à-faux :

Quoique les auteurs promettent avec raison, dans le Recueil de tous les Voyages connus, un système complexe d'Histoire et de Géographie moderne, ils n'ont pas fait assez remarquer que leur objet n'est pas l'Histoire des pays où les voyageurs ont pénétré, mais seulement l'Histoire de leurs voyages et de leurs observations ; de sorte que s'il en résulte effectivement de grandes lumières pour la géographie et l'histoire en général, c'est par accident, si j'ose employer ce terme, et parce que visitant divers pays, les voyageurs n'ont pu manquer de recueillir ce qui s'est attiré leur attention. La plupart s'en sont fait une étude, suivant les occasions et leur propre capacité ; mais par ces deux raisons mêmes, avec un succès fort inégal. ${ }^{12}$

\section{Casanova en romancier-philosophe}

Entre la réalité de l'expérience authentique du monde physique et cette autre réalité, discursive celle-là, qu'est la mise en texte de cette expérience, il y a une béance où la fiction trouve un de ses lieux d'incubation favoris. Parmi les innombrables exemples disponibles, il y en a un qui est particulièrement spectaculaire, quoique généralement méconnu : le roman délirant que Giacomo Casanova écrivit dans les mornes années de sa retraite au château de Dux en Bohême, dans le même temps où il finira par rédiger ce texte à la qualité référentielle établie qu'est la célèbre Histoire de ma vie. Le titre de ce roman annonce d'emblée toute la couleur : Icosaméron ou Histoire d'Édouard et d'Élisabeth qui passèrent quatre vingts un ans chez les Mégamicres habitans aborigènes du Protocosme dans l'intérieur de notre globe (1787). Dès la dédicace adressée au comte de Waldstein, le seigneur de Dux, Casanova trace tout l'enjeu intellectuel et même théorique de son ouvrage :

Personne au monde n'est en état de décider si cet ouvrage est une histoire, ou un roman, pas même celui qui l'aurait inventé, car il n'est pas impossible, qu'une plume judicieuse écrive un fait vrai dans le même temps qu'elle croit l'inventer, tout comme elle peut en écrire un faux étant persuadée de ne dire que la vérité. De cet antécédent, on peut faire une induction. On ne pourra sans preuve évidente ni nier un fait quelconque, ni y ajouter foi. L'homme qui lit doit se mettre à son aise et croire vrai tout ce qu'il trouve vraisemblable, et faux tout ce qui choque sa raison. ${ }^{13}$

12 A. Prévost d'Exiles, «Avertissement du traducteur », dans : Histoire générale des voyages, tome I, La Haye, Chez P. de Hondt, 1747, p. x.

${ }^{13}$ G. Casanova, Icosaméron, Prague, Imprimerie de l'école normale, 1787, t. I, p. ix. 
L'histoire elle-même qui est racontée dans le roman apporte une vaste illustration de cette leçon; c'est un jeu de va-et-vient entre ce qui est donné pour vrai et ce qui est avoué feint, les paramètres propres à l'un et à l'autre finissant par se brouiller et se défaire.

Édouard et Élisabeth sont deux jeunes gens, frère et sœur, qui réapparaissent en Angleterre, 81 ans après avoir disparu. Leur oncle navigateur les avait emmenés dans une traversée aventureuse ; la tempête qui survient évidemment est encore amplifiée par un tourbillon du Maelström aspirant les jeunes gens jusqu'au centre de la terre où ils découvrent un monde dans le monde, habité par la peuplade hermaphrodite au nom éloquent de Mégamicres. Les données sont réunies pour que se développe une utopie caractérisée : un espace isolé et circonscrit, une société autonome avec ses principes, ses lois et ses usages. Bientôt, les rescapés se rendent compte qu'ils n'auront pas d'autre ressource que de constituer une société parallèle à celle des Mégamicres et pour cela, il faudra briser le tabou de l'inceste pour constituer une descendance. Miracle quasi biblique de procréation : au bout des huit décennies, ce sont quatre millions de citoyennes et de citoyens qui forment la société dont Édouard est le souverain. Comme dans toute utopie, on sait que le problème n'est pas d'y accéder ; c'est d'en revenir, impératif pourtant rigoureux pour que l'histoire puisse être racontée à quelqu'un. Les deux jeunes Anglais vont donc remonter à la surface de la terre, âgés d'à peine vingt-cinq ans, tant il est mathématiquement avéré qu'au centre de la terre, le temps s'écoule bien plus lentement. Pour réapparaître parmi les humains, Édouard et Élisabeth ont emprunté des galeries qui les ont finalement fait ressortir par le lac intermittent de Zirchnitz en Carniole (auj. Le lac de Certnica en Slovénie - curiosité naturelle décrite déjà dans l'Encyclopédie). Aux notables locaux qui les ont recueillis, ils pensent ne pas devoir raconter leur « vraie " histoire, trop invraisemblable pour être crue ; ils inventent alors une histoire vraisemblable dans la mesure où elle reprend servilement le modèle de maints romans utopiques : "Je lui dis donc qu'allant aux Indes, une tempête dans la mer du Sud avait fait faire naufrage à mon vaisseau sur un banc quatre cent milles au-delà de Madagascar, et que tout l'équipage avait péri hormis moi, et ma femme $»^{14}$. À l'intention de ses interlocuteurs anglais qui écoutent le récit de ce récit, Édouard précise : "Voilà, milords, le roman que nous avons inventé, et débité en laissant tout le monde maître de ne rien croire $»^{15}$. Quant aux auditeurs de Carniole, ils se montrent satisfaits de l'explication d'Édouard, quand bien même ils ont clairement reconnu son statut : "Mon petit roman cependant ne laissait pas que d'être merveilleux, et intéressant, et le comte qui m'avait écouté me fit sagement trois ou quatre interrogations qui me

\footnotetext{
14 Ibid., t. V, p. 331.

15 Ibid., p. 334.
} 
démontrèrent que, si la politesse eût pu le lui permettre, il m’aurait fait des objections qui m’auraient démontré ses doutes $»^{16}$.

Personne n'est dupe, mais tout le monde affecte de l'être : c'est la condition pour que le pacte fictionnel puisse aboutir au récit. Et Casanova fait preuve d'une virtuosité rare dans le traitement de cette question. En témoigne ce savoureux échange qu'on trouve au début du roman, entre Édouard et deux des Anglais venus l'écouter :

M. Burghlei : Je pense que vous êtes déjà parfaitement d'accord pour ce qui regarde la composition du roman que vous allez nous réciter; mais je vous assure que j’y prêterai la même attention que je prêterais à une véritable histoire.

Édouard: Ce que je narrerai, milord, ne sera que très vrai : les trompés seront ceux qui n'y ajouteront pas foi.

M. Howard: C’est précisément la même réponse que je donne à tous ceux qui doutent des faits dont je fus le témoin dans mes longs voyages. ${ }^{17}$

Ces messieurs inventés par Casanova sont pleinement initiés aux conventions qui président à la constitution des histoires que l'on raconte. Ils confirment aussi le fait que les récits de voyage peuvent être narrés de façon parfaitement crédible par ces voyageurs en chambre que les authentiques voyageurs tiennent pour des imposteurs, alors que la question de la véridicité de la narration viatique avait été posée dès les origines de celle-ci. Le document qui décrivait, au $\mathrm{XI}^{e}$ siècle, le Royaume du prêtre Jean était un faux, ce qui ne l'a pas empêché d'inspirer de nombreuses équipées exploratoires. La réalité des voyages de Marco Polo tels que le Vénitien les a racontés est aujourd'hui sérieusement mise en doute, alors qu'on sait depuis longtemps que l'un des plus fascinants viatores du Moyen-âge, Jean de Mandeville, a écrit dans ses Itineraria bien d'autres choses que ce qu'il aurait réellement perçu. Tout cela pour une raison bien simple : le passage par l'écriture efface la différence essentielle qui distingue l'expérience authentiquement vécue d'une expérience simulée $e^{18}$.

\section{Un genre établi : le voyage imaginaire}

Ce principe était devenu tellement clair au temps de Casanova déjà que le public reconnaissait désormais l'identité d'un genre parallèle à la relation viatique : le récit de voyage imaginaire. C'est ce que documente de façon

\footnotetext{
16 Ibid., p. 335.

${ }_{17}$ Ibid., t. I, p. 117.

18 Pierre Bayard explique cela fort bien dans son essai, Comment parler des lieux où l'on n'a pas été ?, Paris, Les Éditions de Minuit, 2012.
} 
spectaculaire la collection des Voyages imaginaires, songes, visions et romans cabalistiques réunie en 36 volumes à Paris en 1787-1789 par Charles-Thomas Garnier, rédacteur chevronné, acteur infatigable de la librairie dans le dernier quart du siècle ${ }^{19}$. Pierre Versins, l'un des arpenteurs les plus avisés des mondes imaginaires, prêtait jadis à cette collection une position clé dans l'histoire de la réception de ces récits de voyages imaginaires. Il y aurait, selon lui, un avant et un après Garnier, comme si 1789 était une date qui pourrait renvoyer d'autres échos que ceux de la politique ${ }^{20}$.

Pour constituer son recueil, Garnier a collecté des romans inscrits dans une tradition vieille de deux millénaires pour les mettre en série ; il en a fait une série, comme il s'y était déjà employé en publiant avec Charles-Joseph de Mayer les quarante-et-un volumes du Cabinet des fées ou collection choisie des contes de fées et autres contes merveilleux (1785-1789), comme d'autres l'avaient fait avant lui pour donner à un public fidélisé les Amusements des Dames (1740-1741), la Bibliothèque universelle des romans (1775-1789) ou encore, dans un registre voisin, L'Histoire générale des voyages (1745-1759). Autant d'entreprises de librairie, parmi tant d'autres, conçues pour gagner de l'argent en répondant à une demande identifiée avec plus ou moins de sagacité selon les cas. Dans ce sens, ces séries peuvent être perçues comme les révélateurs des goûts du public et des modèles attendus par lui - ou en tout cas de ce que les entrepreneurs du livre se figuraient à leur sujet. Ainsi peut-on dire que publier un recueil de "Voyages imaginaires " à la veille de la Révolution, c'est confirmer qu'est désormais reconnu un genre de récit particulier, désigné par une étiquette propre et repérable sur la carte des formes littéraires convenues.

D’autres types de récits se distinguent à la même époque, du roman gothique au roman sentimental, du roman d'éducation au roman libertin. Mais s'ils se distinguent, c'est qu'on leur reconnaît des traits suffisamment... distinctifs. Comment se définissent alors les "Voyages imaginaires»? Ce n'est pas une question de chronologie, puisque la série accueille aussi bien Lucien de Samosate (II ${ }^{e}$ siècle) que des contemporains de Garnier ; ce n'est pas non plus une affaire de bassin culturel, puisque les textes réunis proviennent de France comme d'Angleterre, d'Espagne et du Portugal, d'Italie et d'Allemagne, sans parler de la Grèce de Lucien.

À l'ouverture de sa collection, dans un "Avertissement de l'éditeur », Garnier s'efforce d'apporter quelques éléments à cette définition :

L'histoire nous peint les hommes tels qu'ils ont été ou tels qu'ils sont ; les romans nous les peignent tels qu'ils devraient être : le voyageur décrit les terres qu'il

19 Il faut préciser que la série comporte en tout trente-neuf volumes, les trois derniers, consacrés à des récits de naufrages, ayant été ajoutés à l’ensemble réuni par Garnier.

20 P. Versins, Outrepart. Anthologie d'Utopies, de Voyages extraordinaires et de Science fiction, Paris, La Tête de Feuilles et Lausanne, La Proue, 1971, p. 7-9. 
a parcourues, fait le récit de ses découvertes, et raconte ce qui lui est arrivé chez les peuples jusqu'alors inconnus et dont il nous transmet les mœurs et les usages : mais le philosophe a une autre manière de voyager; sans autre guide que son imagination, il se transporte dans des mondes nouveaux, où il recueille des observations qui ne sont ni moins intéressantes, ni moins précieuses. Suivons-le dans ses courses et soyons assurés de rapporter autant de fruits de nos voyages que si nous avions fait le tour du monde. ${ }^{21}$

Les lecteurs sont donc avertis : ce ne sont pas des relations de voyageurs qui leur sont proposées, mais des élucubrations de philosophes. Ou encore, si l'on regarde le concret de la chose, ce ne sont pas des déplacements vécus et accomplis qui sont relatés avec plus ou moins de fidélité, mais des pérégrinations cérébrales de voyageurs au coin $d u f e u$.

\section{Une typologie}

Il s'avère pourtant bientôt que cette seule distinction ne suffit pas. Garnier lui-même ne tarde pas, au fil de ses interventions d'éditeur dans les volumes successifs, à préciser sa position en différenciant les composantes de son recueil. C'est ainsi qu'il établit, dans sa propre collection, des catégories plus fines, au nombre de quatre. Il y a un premier groupe de textes, rangés dans les douze premiers volumes, qui relèvent des "voyages imaginaires romanesques". Cela signifie que les éléments fictionnels avoués de ces récits obéissent à une exigence de vraisemblance; dans la plupart des cas, ce sont des voyages qui commencent dans le monde réel pour dériver à un certain point dans un espace autre, non répertorié, inventé, mais après tout possible. Ensuite viennent les histoires où "l'imagination rompt tous ses liens, et prend un libre essor ", ensemble inauguré comme il se doit par l'Histoire véritable de Lucien qui n'a justement rien de véritable, ni même de vraisemblable; suivent les voyages dans la lune et le soleil de Cyrano de Bergerac, puis les pérégrinations de Gulliver et bien d'autres de la même veine où la géographie n'a plus d'autre assise que la fantaisie et l'inventivité des auteurs ; nous sommes passés à un degré

21 Voyages imaginaires, romanesques, merveilleux, allégoriques, amusans, comiques et critiques, suivis des Songes et Visions et des Romans cabalistiques, Amsterdam, s.n., 1787-1789, t. 1, p. 1 (italiques dans la citation-FR). Précisons que la série est publiée sous l'adresse (probablement fausse) d'Amsterdam, sans nom de libraire-imprimeur, mais avec la mention «se trouve à Paris, rue Serpente». Sur Garnier et sa collection, voir notamment N. Kremer, G. Hénin, A. Teodorczyk, «Voyage au bout de l'imaginaire. Étude du discours préfaciel dans les Voyages imaginaires de Garnier (1787-1789) ", dans : Les Genres littéraires et l'ambition anthropologique au dix-huitième siècle : expériences et limites, sous la dir. d'A. Duquaire, N. Kremer et A. Eche, Louvain, Peeters, 2005, p. 135-163 et A. Beretta Anguissola, Ombres de l'Utopie. Essais sur les voyages imaginaires du XVI au XVIII siècle, Paris, H. Champion, 2011. 
supérieur de fictionnalité. Changement de registre avec la troisième division de la série, consacrée aux "voyages imaginaires allégoriques». Le premier texte de cette classe est le Voyage du Prince Fan-Férédin dans la Romancie du père Bougeant, qui situe parfaitement l'ancrage de cette nouvelle catégorie où c'est la culture littéraire et rhétorique qui donne leur consistance aux lieux imaginés : Île d'Amour, Île de Coquetterie, Île de Portraiture, Île de la Félicité, etc. Enfin, Garnier réunit dans la dernière division les voyages qu'il qualifie d'" amusants, comiques et satiriques ", qui nous ramènent dans le monde réel et même dans différentes région de France, mais pour les présenter sous le jour biaisé de l'ironie.

La typologie de Garnier sert efficacement de matrice structurante pour l'ensemble du recueil et c'est déjà beaucoup, mais il faut constater aussi qu'elle n’apporte pas d'éléments suffisamment discriminatoires pour définir clairement un "voyage imaginaire » en face d'autres formes établies. Une indication est toutefois donnée, qui ne manque ni de pertinence, ni de potentialités de développement : le caractère imaginaire d'un voyage tient aux variations possibles d'un triple rapport entretenu par les textes : avec la vraisemblance, avec les modèles constitués par la tradition littéraire et rhétorique, avec le registre énonciatif adopté par le sujet narrant face au monde dans lequel il voyage.

\section{Du voyage réel au voyage imaginaire}

Sans doute, le « voyage imaginaire » devrait-il se définir d'abord par l'adjectif qui le différencie du voyage réel. C'est une évidence qui n'est toutefois qu'apparente. Car ce qui fait problème, ce n'est justement pas cela ; c'est le noyau commun, le substantif : dans les deux cas, et quelle que soit l'évidence des adjectifs, nous avons affaire à des voyages ou, plus exactement, à des récits de voyages. La relation de voyage par les savants, les militaires, les commerçants, les missionnaires ou les aventuriers a toujours accompagné le déplacement des hommes dans le monde. Elle s'est imposée comme un genre constitué au $\mathrm{XVII}^{e}$ siècle et devenu florissant dès le début du siècle suivant, comme vient le confirmer la publication de l'Histoire générale des voyages compilée par l'abbé Prévost dans les années 1745-1759, avec la formidable ambition de réunir, comme le précise le sous-titre de l'ouvrage, «toutes les relations de Voyages par Mer et par Terre, qui ont été publiées jusqu'à présent dans les différentes langues de toutes les nations connues ». C'est ainsi qu'a été fixée une structure de récit particulière avec ses lieux communs, ses séquences reconnaissables, ses scènes, ses motifs et ses personnages types.

Le voyage imaginaire, sur ce plan des modalités narratives, ce n'est pas autre chose : qu'on débarque dans des terres réelles, mais inconnues ou qu'on aborde sur l'Île des Hermaphrodites ou dans le pays de Romancie, c'est toujours 
la même démarche d'approche et d'appropriation qu'il s'agit de raconter, les mêmes instruments de description et le même régime de la comparaison qu'il faut mobiliser. C'est bien pour cela que la rencontre d'une terre imaginée se raconte le plus souvent dans le contexte d'un voyage dans le monde réel : une tempête, une attaque de pirates, un naufrage, un coup du sort quelconque détournent le voyageur de son itinéraire prévu et le voici jeté là où rien n'est imposé, où tout devient possible, où le monde n'a pas l'air de ce qu'il est ou de ce que l'on dit qu'il est. Il a seulement l'air que veut lui donner celui qui le crée à mesure que le voyageur le découvre. Et que veut-il, ce créateur? Bien sûr, il veut ce qu'il n'a pas, ce que la réalité dans laquelle il vit ne lui offre pas, ce qu'il désire, ce qui nourrit ses rêves, ce qui est ailleurs, autre, inverse ou simplement différent. Le plus souvent, ce sont des sources collectives inscrites dans des traditions mythologiques qui donnent corps à cet ailleurs et l'on voit alors surgir devant nos yeux de lecteurs, comme pour de vrai, des sylphides et des sirènes, des centaures, des dragons et des monstres de tout acabit, des hommes volants, des bêtes parlantes, des rois sans défauts, des pays sans malheur, des paradis ${ }^{22}$. Parfois, mais plus rarement, ce sont les visions, les fantasmes et l'inspiration d'un seul qui inventent de nouveaux objets en représentant l'autre monde d'une manière inédite et en enrichissant par là même le grand réservoir commun des images (c'est le cas remarquable de Mouhy, dans Lamekis, publié par Garnier aux tomes 20 et 21 de la série).

Voilà pourquoi les voyages imaginaires ne nous surprennent que rarement : ils nous conduisent dans les lieux où paraît tout ce qui nous manque, mais ce sont toujours les mêmes choses : une société sans inégalité, des lois justes et respectées, une religion sans contraintes, une langue transparente, une nature bienveillante et généreuse, la connaissance aboutie par la perfection des arts et des sciences, une sexualité heureuse, la mort apprivoisée, le temps accepté, sinon retenu. Ou alors tout le contraire, comme pour forcer le trait en faisant voir que le malheur lui aussi peut se fantasmer plus profond, plus noir, et que l'endroit riant de l'utopie n'empêche de voir que pour un temps son envers, fatalement sinistre.

\section{Voyageurs - philosophes}

Clairs ou obscurs, les voyages imaginaires ont toujours ceci qui les distingue le plus radicalement des voyages dans le monde réel : la rencontre d'un nouveau monde n'y est pas soumise aux caprices du hasard ou du destin. Ce ne sont pas

22 Pour des développements sur ce sujet, voir J.-M. Racault, Nulle part et ses environs. Voyage aux confins de l'utopie littéraire classique (1657-1802), Paris, PUPS, 2003 ainsi que F. Rosset, articles « Paradis » et "Voyage », dans : Dictionnaire critique de l'utopie au temps des Lumières, sous la dir. de B. Baczko, M. Porret et F. Rosset, Genève, Georg, 2015, p. 889-904 et 1353-1373. 
les objets perçus (des hommes avec leurs mœurs, des animaux, des végétaux, des paysages, des climats), ni les conditions de la perception qui déterminent l'expérience, mais c'est le contraire : un monde imaginaire est tout inventé par avance et raconter sa découverte revient pour le voyageur à exécuter une partition déjà écrite. L'accent n'est pas mis sur le sujet humain qui, voyageant, va d'étonnements en découvertes, d'errements en illusions, souffre, s'émeut ou s'émerveille, se transforme et se construit au contact de l'autre. Le voyageur dans les terres inventées n'est là que pour remplir une fonction dans le discours : pour prêter son identité toute fictive à un témoignage, faire le relais entre le monde inconnu et l'attente curieuse des lecteurs. Mais cette fonction est-elle bien différente de celle qu'assume le voyageur authentique occupé à raconter son périple dans le monde réel ? Du point de vue strictement discursif, la réponse est non, bien sûr. Dès lors, si l'on peut trouver pertinente la distinction opérée par Garnier entre le voyageur qui rend compte d'une expérience dans le monde réel et le philosophe qui construit des conjectures ou projette des idées, des images et des fantasmes, on doit bien constater que cette distinction n'est plus vraiment opératoire quand on compare les productions discursives de l'un (le voyageur) et de l'autre (le philosophe). Le voyageur est philosophe, soit seulement potentiellement, soit par erreur, par naïveté ou par accident, soit par calcul et par stratégie, soit encore par docilité, consciente ou non, à des modèles codifiés. Il est philosophe dès l'instant où il a endossé la posture d'un sujet de discours.

\section{Du voyage imaginaire au voyage réel}

Si l'on revient à la question du rapport entre voyage réel et voyage imaginaire, il convient de rappeler qu'au fil des siècles, l'accumulation des récits relatant des périples dans des mondes imaginaires n'a pas pu se faire sans conséquences sur la production des récits de voyages dans le monde réel. Cette propension au mensonge dont on a suspecté tout voyageur, vient pour une bonne part de l'efficacité et de l'attractivité discursive de ce modèle constitué depuis longtemps qu'est la description d'univers inventés. Comment se fait-il, en effet, que des arpenteurs de bonne foi aient pu voir et même dessiner des dragons dans les Alpes (Scheuchzer) ${ }^{23}$, des licornes à langue épineuse sur l'île de Java (Marco Polo) ou encore, au Brésil, des ours à tête d'homme qui se nourrissent de vent (André Thevet) ? C'est que leur perception et, plus encore, le discours qu'ils produisent pour en rendre compte sont inévitablement déterminés par ce qu'ils ont lu et entendu préalablement. Voyages réels et voyages imaginaires se définissent bien l'un par rapport à l'autre, autant par ce qui les distingue que

${ }^{23}$ Voir C. Reichler, La découverte des Alpes et la question du paysage, Genève, Georg, 2002, p. 81-108. 
par ce qui les réunit : l'un et l'autre, ils sont des textes, des produits de discours, des transpositions ou des projections de l'expérience humaine dans l'univers du langage. Et dans ce sens-là, ils se ressemblent absolument, partageant cet espace où le "vrai » et le "faux» s'interpénètrent par le simple fait qu'ils se disent avec les mêmes mots, la même syntaxe, les mêmes modèles de description et de narration.

Prenons l'exemple peut-être le plus connu, le plus célébré, le seul livre que Rousseau voulait bien laisser lire à Émile quand il élaborait son plan d'éducation pour cet élève imaginé : La vie et les aventures surprenantes de Robinson Crusoë. C'est ce roman qui ouvre la collection de Garnier dont il occupe les trois premiers volumes - sans parler du quatrième, consacré à la continuation de Robinson par Dorrington (Le Solitaire anglais). Le choix est significatif, mais plutôt surprenant. Car si nos souvenirs d'enfance ne retiennent habituellement de cette histoire que l'épisode de la colonisation d'une île par un individu probe et entreprenant, le retour au texte intégral que propose Garnier rappelle à tous ceux qui l'avaient oublié qu'avant et après le séjour sur cette île (qui dura « vingthuit ans, deux mois et dix-sept jours »), Robinson a voyagé sur terre et sur mer en sillonnant l'Europe, l'Afrique et l'Asie, comme un bon héros de roman d'aventures ancré dans la réalité géographique du monde, comme un prototype évident de Phileas Fogg. On est loin des lieux inconcevables de Lucien, de la lune, du soleil, de Mercure ou de Sirius d'où certains viennent et où d'autres vont, loin des pays étranges décrits par le capitaine Lemuel Gulliver, des terres australes où tout est possible sous les plumes de Veiras d'Allais, de Foigny ou de Paltock, loin de l'île Taciturne, comme de la Terre des Perroquets ou du Pays des hommes volants. Mais finalement, le résultat est le même. Garnier a beau opérer une distinction catégorielle entre les voyages vraisemblables et les voyages ouvertement fictifs, c'est toujours la même combinaison de l'ici et de l'ailleurs qui s'impose. Que l'ailleurs soit plus ou moins fantaisiste, on ne lui cherchera de sens que dans sa confrontation avec l'ici. D'où le régime de la comparaison, explicite ou non, qui détermine la lecture de tous ces récits, d'où aussi la pesanteur des commentaires que les narrateurs les plus verbeux accolent au récit des bizarres expériences, comme par acquit de conscience philosophique. D'où encore notre propre propension à nous interroger sans cesse, en lisant ce genre de récits, sur le rapport entre le réel et le fictif.

\section{Voyage et fiction}

Garnier avait eu aussi cette intuition généralisatrice ; il semblait avoir compris que le voyage imaginaire pose des questions qui débordent bien au-delà de la problématique même du voyage. C'est du moins comme cela que l'on peut comprendre sa volonté de compléter les trente volumes réunissant les quatre 
types de voyages qu'il avait définis par six autres volumes où sont rassemblés des récits de songes, de visions et de romans dits « cabalistiques». Les mondes autres ne sont pas forcément des lieux inventés par analogie aux paramètres de la géographie et le transport dans ces mondes ne doit pas nécessairement se faire par ce qu'on appelle un voyage. Ce ne sont donc plus seulement les lieux découverts qui prennent une valeur métaphorique, mais le voyage lui-même, le déplacement du monde réel vers des univers produits par l'imagination humaine et donc la distance entre ceux-ci et celui-là. On comprend mieux dès lors pourquoi, dans son avertissement, Garnier avait dédoublé sa distinction de principe entre voyageurs et philosophes en reformulant les termes de la même opposition : celle qui postule la différence entre les productions des historiens (les auteurs de voyages réels) de celles des romanciers (les auteurs de voyages imaginaires). Ainsi, de même que les voyageurs sont philosophes, les voyages imaginaires sont des romans; ce sont les romans.

\section{9}

Dans cette perspective, il peut être intéressant, pour conclure, de revenir un instant sur le moment historique de 1787-1789. Après les expéditions de Bougainville et de Cook, la quasi-totalité du monde terrestre est connue et cartographiée. Le temps est venu où la connaissance géographique n’engage plus à combler les lacunes du savoir par le travail de l'imagination. La distinction entre contrées réelles et contrées fictives est établie et documentée. En réunissant à ce moment-là des récits qui avaient été écrits alors que cette distinction n'était pas encore fixée, Garnier ne constituait pas seulement une anthologie raisonnée qui avait peut-être même des ambitions encyclopédiques. Il faisait un bilan qui nous permet de constater que le grand tournant de ces années-là ne concerne pas seulement la politique et les valeurs qui sous-tendent l'organisation des sociétés, mais aussi, plus largement, la relation que les hommes entretiennent avec le monde et les modalités qu'ils inventent pour rendre compte de cette expérience. Ainsi, ce n'est pas tellement parce qu'il s'agit de la première collection de ce type que la publication de Garnier peut être vue comme une charnière entre deux pans de l'histoire des idées, mais justement parce qu'elle coïncide chronologiquement avec d'autres bouleversements, ce qu'il ne faudrait pas voir comme un pur hasard. 
Stanisław Świtlik

Université de Varsovie / Université Catholique de Lublin Jean-Paul II

ORCID 0000-0001-7747-136X

\section{Nicolas Klimius, Pierre Wilkins et Édouard Alfrède - quelle définition du voyageur?}

\section{Nicholas Klimius, Peter Wilkins and Édouard Alfrède - a Definition of Traveller}

The existence of travellers in the 18th-century reality encourages to search the definition of their characters. Three examples of literary imaginary travels help to define the traveller who becomes an explorer, a master of a new land. The article is an attempt to show to which extend the definition of an usurper, a "providential man" and of a conqueror are relevant to the travels to the unknown lands by Nicholas Klimius, Peter Wilkins and Édouard Alfrède.

Keywords: imaginary travel, Ludvig Holberg, Robert Paltock, Giacomo Casanova Mots-clés : voyage imaginaire, Ludvig Holberg, Robert Paltock, Giacomo Casanova

Au début de la relation de son déplacement en France, dans le Voyage sentimental de Laurence Sterne, le narrateur s'adonne à l'énumération des types possibles de voyageurs :

\footnotetext{
Voyageurs oisifs,

Voyageurs curieux,

Voyageurs menteurs,

Voyageurs orgueilleux,

Voyageurs vains,

Voyageurs sombres [...],
} 
Les Voyageurs contraints, les moines,

Les Voyageurs criminels, les coupables,

Les Voyageurs innocents et infortunés,

Les simples Voyageurs;

[...] Le Voyageur sentimental [...]. ${ }^{1}$

La réflexion sur les personnes marquées par le voyage affirme leur diversité. Sur le point de devenir l'un d'eux, le narrateur sternien distingue les attitudes que les voyageurs adoptent selon les circonstances et, sans doute, selon les choix personnels. Il semble que le critère de cette catégorisation réside surtout dans la motivation de la personne. Le voyageur-narrateur se reconnait luimême en "voyageur sentimental ». Sa réflexion, comme son regard général porté sur les autres voyageurs, se refuse à scruter l'attitude et l'évolution que prend et vit le voyageur dès qu'il arrive dans un pays inconnu. Cette tentative de catégorisation et de définition du XVIII ${ }^{\mathrm{e}}$ siècle s'approche de celle des critiques de la fin du $\mathrm{XX}^{\mathrm{e}}$ qui répertorient les voyageurs des Lumières selon leur profession : marins, soldats, marchands et religieux ${ }^{2}$.

Cependant, l'examen des expériences vécues pendant le voyage mérite de l'intérêt. Notamment, la rencontre avec l'Autre - l'habitant des terres découvertes aux confins du monde connu - peut devenir une extraordinaire occasion de changer de statut ${ }^{3}$. Nous essayons ici de commenter la catégorie de "voyageur-conquérant " qui émerge de quelques fictions du XVIII siècle ${ }^{4}$. En effet, parmi les catégories formulées par Sterne en tant que voyageur sentimental, nous n'en trouvons aucune qui corresponde, même de loin, à celle que représentent les héros des voyages imaginaires ${ }^{5}$ de Ludvig

1 Le nom au singulier de «Voyageur sentimental » met en relief le caractère exceptionnel de cette catégorie. L. Sterne, "Préface : Dans la Désobligeante », dans : Le Voyage sentimental, Paris, J. F. Bastien, 1806, https://fr.wikisource.org/wiki/Voyage_sentimental/Texte_entier, consulté le 10/11/2020.

2 M.-N. Bourguet, «Voyages et voyageurs », dans : Dictionnaire européen des Lumières, sous la dir. de M. Delon, Paris, Presses Universitaires de France, 1997, p. 1092-1095.

${ }^{3}$ Ce cas de figure n'est pas non plus obligatoire et ne se réalise pas toujours.

4 Dans toutes les citations, nous avons gardé l'orthographe originale des sources consultées.

${ }^{5}$ On confond très souvent le genre de voyage imaginaire avec celui d'utopie, même si les deux possèdent en effet bien des points communs, ou, pour mieux dire, s'alimentent mutuellement, sans que leurs limites soient toujours facilement repérables. Voir J.-M. Racault, L'utopie narrative en France et en Angleterre, 1675-1761, Oxford, The Voltaire Foundation, 2010, p. 244-287. 
Holberg $(1741)^{6}$, de Robert Paltock $(1751)^{7}$ et de Giacomo Casanova (1788) . En partant de modèles historiques, nous allons observer dans ces œuvres la figure de "voyageur-conquérant», incarnée sous des formes diverses par les protagonistes des trois récits.

Dans les œuvres de fiction de l'âge classique, quand le voyageur découvre un terrain inconnu, il adopte deux postures possibles : soit il demeure un spectateur neutre, voire passif qui se contente de retenir les renseignements sur la communauté d'accueil donnés par son guide ; soit, au contraire, non seulement il devient un explorateur actif, mais aussi il s'insère efficacement dans la vie communautaire ${ }^{9}$. Cette dernière attitude présente aussi une autre variante, beaucoup plus radicale : le voyageur évolue vers le rôle de « conquérant » d'une terre et de la communauté qui l'habite. L'examen des voyages de Nicolas Klimius, Pierre Wilkins et Édouard Alfrède dans les terres bien éloignées de l'Europe,

${ }^{6}$ L. Holberg, Voyage de Nicolas Klimius dans le monde souterrain contenant une nouvelle téorie [sic] de la Terre et l'histoire d'une cinquième monarchie inconnue jusqu’à présent, trad. E. de Mauvillon, Copenhague, J. Preuss, 1741. Ludvig Holberg (1684-1754) passe pour le «Molière danois » en raison du grand nombre de pièces de théâtre écrites en langue nationale et inspirées de celles du comédien français. On cite le plus souvent Jeppe du Mont (1722) et Erasmus Montanus (1726). À part le Voyage de Nicolas Klimius, rédigé en latin, mais traduit immédiatement en d’autres langues, et un grand choix de travaux historiques, Holberg a laissé également le poème Peder Paars (1719-1720) parodiant l'Énéide, et ses Lettres autobiographiques où lécrivain raconte, entre autres, ses propres voyages à travers la France et l'Allemagne, jusqu'en Italie. Cf. A. M. le Bourg-Oulé, "Louis Holberg, dramaturge et voyageur ", Littératures, $\mathrm{n}^{\circ} 20$, 1973, p. 27-42; https://www.persee.fr/doc/litts_0563-9751_1973_num_20_2_1061, consulté le $10 / 04 / 2021$.

7 R. Paltock, Les Hommes volans, ou les aventures de Pierre Wilkins, trad. F. de Puisieux, dans : Voyages imaginaires, songes, visions, et romans cabalistiques. t. 22-23, Amsterdam, Ch. Garnier, 1788. On possède peu d'informations sur Robert Paltock (1697-1764), cet avocat cornouaillais, proche d'Elizabeth Seymour, duchesse de Northumberland (1716-1776), à qui est dédié Pierre Wilkins qui semble l'unique œuvre attribuée à Paltock. Cf. J. Grantham Turner, "Introduction », dans : R. Paltock, The Life and Adventures of Peter Wilkins, éd. Ch. Bentley, Oxford/New York, Oxford University Press, 1990, p. XXV, XXXIX.

8 G. Casanova, Icosameron ou histoire d'Édouard et d'Élisabeth qui passèrent quatre vingts [sic] un ans chez les Mégamicres habitans aborigènes du Protocosme dans l'intérieur de notre globe, Paris, Éditions d’Aujourd'hui, 1986. Giacomo Casanova (1725-1798), aventurier vénitien, connu surtout pour son Histoire de ma vie, est également l'auteur d'autres œuvres importantes en français et en italien comme, à part l'Icosameron (1788), Le Duel (1780), Histoire des troubles de la Pologne (1774) ou Histoire de ma fuite des prisons de la République de Venise qu’on appelle les Plombs (1788). Cf. J.-Ch. Igalens, Casanova : l'écrivain en ses fictions, Paris, Classiques Garnier, 2011, p. 21-67.

9 J.-M. Racault distingue ces deux types de voyageur-narrateur dans la relation avec « utopies 'positives' » et " utopies 'dysphoriques' ». Nous retenons cette distinction, sans entrer ici dans le débat sur la définition de l'utopie, problème trop complexe et toujours valable, même si le chercheur a le grand mérite de mettre beaucoup de lumière dans la compréhension de cette question. Voir J.-M. Racault, L'utopie narrative en France et en Angleterre, 1675-1761, op. cit., p. 766-771. 
permet de mettre en relief les points communs, ainsi que les nuances et les différences nettes entre les trois voyageurs devenus maîtres de l'Ailleurs.

Le modèle qui se reflète dans le destin des voyageurs qui abandonnent leurs maisons et leur patrie pour chercher le bonheur et la gloire ailleurs, est de toute évidence celui des conquistadors espagnols du XVI ${ }^{\mathrm{e}}$ siècle. La légende de Fernand Cortez et François Pizarre a exercé une influence importante sur leurs successeurs et émules. Ces deux aventuriers, de naissance plutôt peu fortunée, avaient réussi à se hisser aux dignités de gouverneur de vastes terres du Nouveau Monde : l'exemple de ces biographies a donc de quoi séduire ${ }^{10}$. Ces figures de proue de l'époque moderne rejoignent le modèle ancien de conquérant : les expéditions d'Alexandre de Macédoine alimentent de longue date les rêves de conquête des terres connues et inconnues, vouées à la domination européenne ${ }^{11}$. Le souvenir hellénistique revient à la bouche du voyageur Klimius au moment de soumettre l'espace découvert à son autorité : "A la vue de tant d'heureux succés, je me regardai comme l'Alexandre du monde souterrain, \& je me voyois en état d'operer les mêmes révolutions, que le Macédonien avoit causées sur nôtre globe $»^{12}$. L'allusion témoigne de l'actualité des modèles passés : le voyageur regarde avec un œil lucide le chemin de gloire qu'il est sur le point d'emprunter. Le voyage lui offre la chance unique de marcher dans le sillage des grands capitaines d'autrefois.

L'ascension fulgurante qui est donnée à vivre aux découvreurs des peuples et pays ignorés, ressemble à un cadeau miraculeux du Ciel, tant désiré par tous ceux qui osent tenter l'inconnu. Le sort que leur réservent les voyages brise les règles sociales traditionnelles qui les immobilisent : ils deviennent ces « élus » du destin, «ceux qui d'un état fort bas s'élèvent aux grandeurs [...] $»^{13}$. Le voyage

10 Voici quelques exemples de textes portant le vif souvenir des deux Espagnols à l'époque considérée : B. le Bovier de Fontenelle, Nouveaux dialogues des morts, Amsterdam, Antoine Schelte, 1694 ; A. de Zarata, Histoire de la découverte et de la conquête du Pérou, trad. S. D. C., Amsterdam, J. Louis de Lorme, 1700 ; J.-B. Morvan de Bellegarde, Histoire universelle des Voyages faits par mer et par terre dans l'Ancien \& dans le Nouveau Monde; pour éclaircir la Géographie ancienne \& moderne, Amsterdam, Pierre Humbery, 1708 ; E. Burke, Histoire des colonies européennes dans l'Amérique, Paris, Saint-André-des-Arcs, Nyon l'ainé, 1780 ; J. Holl, A second dialogue of the Dead: Between Ferdinand Cortez and Wilian Penn, Worcester, HIGH Street, 1798.

${ }^{11}$ Il serait certainement intéressant d'observer dans quelle mesure la figure du « voyageurconquérant » des textes analysés reflète la réalité historique, mais cette démarche nécessiterait d'autres recherches, extérieures d'une certaine manière à la construction littéraire de l'utopie ou du voyage imaginaire qui nous occupe ici. De plus, le thème de conquête des terres est déjà présent chez More, sans se référer à un événement historique précis.

12 L. Holberg, op. cit., p. 341. L'image d'Alexandre en conquérant rejoint celle du monarque, surtout dans la perspective des rois européens de l'âge classique. Voir Ch. Grell, "Alexandre le Grand au XVII siècle ", Mètis, Paris-Athènes, Éditions de l'École des hautes études en sciences sociales, Deadalus, N.S. 1, 2003 p. 297-308, https://books.openedition.org/ editionsehess/2126?lang=fr, consulté le 10/11/2020.

13 L. Holberg, op. cit., p. 359. 
leur permet de vivre des expériences qu'ils n'auraient pu connaître s'ils avaient vécu dans le respect des routines de la société européenne ${ }^{14}$. En atteignant une position privilégiée, le voyageur n'omet pas de signaler le moment de sa gloire. Revenant du choc, après un retournement incroyable des événements qui le portent sur le trône des Quamites, espèce d'hommes vivant selon les règles d'une société primitive dans le souterrain, Nicolas Klimius reconnaît lui-même sa chance : sans oublier ses débuts comme pauvre enseignant, forcé par la suite à l'errance dans le monde souterrain, il se dit «transformé d'Echapé [sic] d'un naufrage en Monarque puissant $»^{15}$.

En effet, son parcours dans le royaume de Quama est rythmé par l'acquisition des grades reflétant l'ordre qu'il gravit dans la hiérarchie. Reconnu pour son intelligence et son ingéniosité parmi les Quamites, Klimius se voit chargé du rôle de " Général d’Armée » ${ }^{16}$, et par la suite, dans un bref délai, de celui de "Général en chef de[s] Armées [de l'empereur de Quama], à qui devoient obéir, tous les Lieutenans-Généraux, Maréchaux-de-camps, Brigadiers \& Colonels $»^{17}$ dans la guerre qui opposait les Quamites aux Tamaquites. Cette ascension autorisée par les dignitaires du royaume est une forme de récompense pour ses services, mais aussi l'expression du besoin urgent d'une intervention immédiate dans les affaires courantes du pays de celui qui peut sauver la situation. La mort du monarque souterrain ébranle les Quamites qui refusent la succession des héritiers du défunt et imposent le règne de Klimius.

Fort du titre d'empereur de Quama et de chef des armées qu'il dirige, l'homme, jadis pauvre voyageur, entreprend une marche à travers des royaumes en les soumettant l'un après l'autre. Après les guerres contre les Arctons, les Kispuciens et les Alectoriens, encore en l'honneur de l'empereur Casba ${ }^{18}$, Klimius décide d'organiser des expéditions contre l'État mezendorique, contre le peuple de Canaliques ${ }^{19}$ et contre les Martiniens. Ses adversaires se soumettent sans s'opposer : le voyageur rapporte ses victoires laconiquement, sans détailler les scènes d'affrontement. L'attribution du surnom de "Grand » à Klimius traduit sa réussite. Se comparant à d'autres porteurs historiques de titres prestigieux, "[aux] Cyrus, [aux] Alexandres, [aux] Pompées »"20,

${ }_{14}$ Dans cette perspective, le voyage est extraordinaire autrement que ne le considèrent habituellement les commentateurs du genre. Il ne s'agit pas seulement d'un déplacement dépassant les limites géographiques connues, il est également question d'un dépassement des barrières sociales. Sur le terme traditionnel de voyage extraordinaire, voir G. Atkinson, The Extraordinary voyage in French literature from 1700 to 1720, Paris, Honoré Champion, 1922, p. 7-8.

15 L. Holberg, op. cit., p. 339.

16 Ibid., p. 296.

17 Ibid., p. 298.

${ }_{18}$ Ibid., p. 328.

19 Ibid., p. 344.

20 Ibid., p. 358. 
le vainqueur orgueilleux cite la litanie de ses titres : "Nicolas le Grand, Envoyé du Soleil, Empereur de Quama \& de Mézendorie, Roi de Tanaqui, d'Aléctorie, d'Arctonie de tous les Royaumes \& Etats Mézenooriques é Martiniens, GrandDuc de Kispucie, Seigneur de Martinie \& de Canalique »" . Ainsi sa présence chez les Quamites évolue-t-elle du statut de simple inventeur et guerrier vers celui de grand chef de guerre, monarque absolu et maittre de vastes terres : les succès militaires d'Alexandre le Grand sont rappelés pour mettre en relief l'immense triomphe de Klimius.

Pierre Wilkins, bien qu'étranger et roturier, se voit également mêlé aux affaires du royaume de Normnbdfgrfutt. Après de longues années de paix et de prospérité, il est donné au peuple des Glumms de souffrir une guerre civile causée par une rébellion soulevée dans la partie occidentale du pays. Persuadés par une ancienne prophétie que Wilkins peut être leur sauveur, ces « hommes volants » lui demandent de l'aide. Un peu comme Klimius, grâce à son ingéniosité, mais également - circonstance nouvelle - grâce à la sincérité de son cœur qui lui gagne des amis, le voyageur réussit à organiser l'armée du roi Georigetti de façon qu'elle soit en mesure de s'opposer aux attaques de l'usurpateur Harlokin, et à déjouer les complots visant le roi ${ }^{22}$, dont Wilkins obtient les indices de la part de ses fidèles ${ }^{23}$. Le triomphe sur Harlokin, ainsi que le retour de la prospérité que Wilkins assure persuadent des États voisins de Normnbdfgrfutt de demander la protection et l'alliance au roi Georigetti ${ }^{24}$ : non seulement son royaume sort d'un état de crise, mais il s'agrandit et étend sa domination, sans que le sang soit versé. Les exploits de Wilkins qui suivent n'ont rien des guerres ouvertes entreprises par Klimius. La prise de la mine du mont Alkoé s'effectue grâce à la rhétorique du voyageur : la promesse de liberté parle plus aux soldats que la fidélité à leur ancien maître ${ }^{25}$. Le royaume de Narbone revient également sous le pouvoir de Georigetti par l'intervention de Wilkins : en arrivant dans la capitale de cet État, il cause la mort de celui qui menaçait le royaume ${ }^{26}$. Le résultat est immédiat : la fille du roi Oniweske peut sans encombre épouser Georigetti, ce qui revient à unir d'un commun accord les deux couronnes. Les activités de Wilkins visent la progression et l'extension du pouvoir de son souverain, le roi Georigetti, sans qu'il ait besoin d'employer des moyens cruels contre l'ensemble des populations.

Face à ces triomphes, le lecteur est en droit de s'interroger sur les mobiles qui poussent les héros à l'action. Les motivations qui les entraînent dans des exploits guerriers ne sont, le plus souvent, pas avouées par les voyageurs : le lecteur ne

${ }^{21}$ Ibid., p. 358, l'italique dans le texte.

22 R. Paltock, op. cit., v. II, p. 43-52.

${ }_{23}$ Ibid., p. 22-24.

${ }_{24}$ Ibid., p. 75.

25 Ibid., p. 137.

${ }_{26}$ Ibid., p. 179. 
peut que les déceler par l'examen minutieux du contexte de leurs aventures. Si la genèse de leur carrière militaire découle souvent de l'appel à l'aide de la part des communautés déchirées par des désordres intérieurs, l'évolution de la situation permet d'observer chez les récents triomphateurs, rongés souvent par de bas sentiments, l'attention portée sur leur propre cause. Le talent et l'ingéniosité de Klimius qui impressionnent certainement les Quamites, décident de son sort. L'empereur Casba sollicite son aide pour protéger le pays contre les voisins exigeant un tribut ${ }^{27}$. Ainsi le voyageur se laisse-t-il entraîner dans les conflits intérieurs des peuples voisins, mais il n'omet pas d'en tirer son profit. En prétextant le soin des intérêts de son maître, anobli par ses victoires, le voyageur médite la poursuite de l'entreprise militaire. " Après [...], je me mis à inventer de nouveaux moyens pour élever l'Empire Quamitique à un degré de puissance qui le rendît redoutable à toutes les nations $[\ldots] »^{28}$. La défense de l'État évolue directement, en peu de lignes, en une expédition armée contre des peuples encore insoumis. La position de Klimius devenant plus forte, au fil de sa narration, le voyageur révèle ses motivations profondes à son lecteur ${ }^{29}$ :

[...] les Pilotes [des nations subjuguées] me mirent au fait de l'Etat, de la nature des mers, \& de la situation des Terres dont elles étoient environnées. Je compris par leurs discours qu'en huit jours d'une heureuse navigation, on pouvoit aborder aux rivages de l'Empire Mezendorique, d'où par la route que j'avois faite autrefois \& qui ètoit connuë, on pouvoit passer en Martinie. [...] Ce Pays étoit le principal but de mon entreprise, ses richesses, ses forces, l'adresse, l'habileté de ses Habitants dans la navigation, où ils excelloient, $\&$ dont ils pouvoient donner des leçons utiles à un Homme qui entreprenoit de si grandes choses, tout cela, dis-je, étoit un puissant motif pour m'éxciter à soumettre cette nation à mon obeïssance ; mais ce qui m’y portait le plus, c'étoit le désir de vanger mes vieilles injures. ${ }^{30}$

Les grands exploits cachent ainsi des motivations égoïstes ${ }^{31}$. En projetant la défaite de ses persécuteurs d'antan, Klimius dévoile son cœur et, abordant à la Martinie, il dit : «Jamais aspect ne me fut plus agréable que celui de ce Païs-la, \& lorsque je pensois que j'y avois été forçat, \& que j'y revenois Empereur, $\&$ vainqueur de plusieurs nations, je ne pouvois contenir ma joye $»^{32}$.

27 L. Holberg, op. cit., p. 296.

${ }_{28}$ Ibid., p. 339-340.

${ }_{29}$ Comme dans bien des voyages imaginaires, l'histoire du voyage de Klimius se veut d'abord transcrite par le voyageur lui-même sous forme manuscrite et publiée finalement par son ami ; ibid., p. 388.

30 Ibid., p. 341-342.

31 Il faut ici souligner que le texte se veut une relation sincère de Klimius à son ami sur son voyage dans l'intérieur de la Terre ; ibid., p. 379.

32 Ibid., p. 351. 
Le début de la carrière de Wilkins parmi les Glumms, des quasi-hommes, résulte également d'une sollicitation d'aide. L'ancien oracle promet aux Glumms la venue d'un sauveur aux temps de crise. Les premiers exploits du voyageur dans leur monde accomplissent la prophétie ${ }^{33}$; les Glumms sont persuadés de n'attendre que Wilkins et lui demandent son secours. Illustre déjà en arrivant à la cour de Georigetti, le voyageur se voit quasiment obligé d'accomplir le rôle que lui impose le destin. «Très-admirable Pierre [s'adresse à lui le monarque lors de leur premier entretien] vous êtes le Glumm sur qui nous comptons aujourd'hui, pour accomplir une ancienne prédiction [...] $»^{34}$. Même si Wilkins accepte la mission proposée de « détruire l'usurpateur " ${ }^{35}$, il projette aussi d'éclairer le peuple des Glumms, ce qui entre également dans le cadre de la prophétie, sans que les habitants du souterrain s'en rendent compte. La réalisation de la demande est donc doublée d'une tâche civilisationnelle qui inspire le voyageur. Une autre prophétie engage le voyageur à assujettir un autre pays, celui de Narbone : identifié comme le "messager d'en haut " au service de Georigetti ${ }^{36}$, Wilkins arrive chez le roi Oniweske pour lui demander la main de Stygée, sa fille, pour le roi des Glumms. En sujet zélé de son monarque, Wilkins semble étendre l'influence politique de Georigetti, en se servant des moyens les moins violents possibles pour ne pas compromettre les acquis de la civilisation dont il se fait le champion.

Le succès du voyageur auprès des peuples imaginaires vient de leur état de civilisation. Coupés d'autres communautés, ou limitant leurs relations avec elles, ils semblent vivre dans l'état de la nature, lequel, du point de vue d'un Européen, signifie un retard de développement dans la pratique « des sciences et des arts ». À l'arrivée au pays des Quamites, Klimius constate :

En un mot ils étoient.

Tels qu'on nous dit que furent autre fois

Les premiers Citoyens du monde,

Dans une ignorance profonde;

Sans mours, sans art, sans Culture, sans loix. ${ }^{37}$

Même s'il apprécie les bons côtés de leur état, son jugement est sans appel : " [ils] étoient ensevelis dans d'épaisses ténèbres ${ }^{38}$. Les connaissances, les plus rudimentaires mêmes, maîtrisées par un Européen ordinaire, suffisent à dominer ces ignorants. L'arrivée du voyageur parmi des peuples moins

\footnotetext{
${ }^{33}$ R. Paltock, op. cit., v. I, p. 384-385.

${ }^{34}$ Ibid., v. II, p. 8.

35 Ibid., v. I, p. 379.

36 Ibid., v. II, p. 175-176.

37 L. Holberg, op. cit., p. 287, l'italique dans le texte.

${ }^{38}$ Ibid., p. 288.
} 
civilisés que les nations européennes se révèle une occasion pour profiter de sa supériorité. La soif du pouvoir qu'il éprouve témoigne de sa corruption morale. Klimius ne pense point à secourir les peuples primitifs avec ses connaissances, mais à tirer parti de leur infériorité.

Si le voyageur de Holberg s'avère être avide de privilèges et de puissance au point qu'il n'hésite pas à accaparer la couronne de l'empereur Casba, son attitude n'est pas partagée par d'autres visiteurs des terres inconnues ; d'ailleurs, il semble assez solitaire dans ce penchant au vice. Au sommet de ses triomphes politiques, Wilkins se voit proposer presque la même offre que celle connue par Klimius : la couronne des trois royaumes lui est promise par le roi Georigetti ${ }^{39}$. La différence entre les deux voyageurs se fait la plus nette en ce moment : Wilkins refuse la proposition royale car il ne considère l'ensemble de ses victoires que comme " un devoir " qu'il devait accomplir envers son monarque. Le voyageur couvert de gloire militaire et politique ne définit que modestement ses propres désirs : « [...] mon ambition se borne à faire du bien tant que je vivrai, \& à élever mes enfans dans les mêmes principes ${ }^{40}$. À en croire Wilkins, il n'aurait pas abusé de sa position : malgré son statut de favori royal, il se limite à perfectionner la civilisation des trois royaumes dont l'union est scellée par ses soins ${ }^{41}$. La supériorité de l'Européen le place au-dessus des Glumms et lui garantit le rôle de leur sauveur et protecteur, ce dont il refuse d'abuser, et en quoi il s'oppose à Klimius. Le voyageur s'avère être, en accord avec ses propres convictions, un homme honnête et vertueux, content d'être bienfaiteur d'autrui ${ }^{42}$.

L'histoire d'Édouard Alfrède dans le pays des Mégamicres est semblable à celle de Wilkins; cependant, le jugement sur le comportement du voyageur anglais diffère. Arrivé par pur hasard au centre de la Terre, Édouard parvient peu à peu à se faire reconnaître par la communauté des petits êtres colorés

${ }^{39}$ Wilkins s’adresse au roi : « [...] si j’avois quelque grâce à lui demander, cétoit de vouloir bien, lui ou ses enfans, prendre soin de ma famille, quand je ne serois plus. [Le monarque répond au voyageur] [...], pour ce qui me regarde, je puis bien vous le promettre; mais je ne sais pas ce qui arrivera après moi ; car je ne me marierai jamais ; non jamais : la perte de Yaccombourse [sa première épouse] m’a dégoûté des femmes ; \& à moins que les états ne jettent ses yeux sur vous pour me succéder, ce à quoi je consentirai volontiers, il y a toute apparence que le royaume sera déchiré en pièces par les divers compétiteurs qui voudront s’en emparer [...]. D’ailleurs, qui peut mieux conserver l'état dans sa splendeur, que celui qui l'a amené au point de perfection ou il est maintenant ?», R. Paltock, op. cit., v. II, p. 185-186.

40 Ibid., v. II, p. 186.

${ }^{41}$ Ibid., p. 190, 205.

42 Le rôle de civilisateur des Glumms est mis en doute par le voyageur lui-même, quelque temps avant son départ de leur pays, mais il s'agit d'une réflexion élargie sur les avantages et les faiblesses de « la police des mœurs » prônée par certains philosophes. L'interrogation sur létat de la nature en conflit avec la civilisation, à la fois progressiste et rétrograde, y est mise à jour pour refléter des ambiguïtés des Lumières. Voir J.-M. Racault, op. cit., p. 280-287. 
et hermaphrodites comme leur allié et ami. Menant un combat feutré contre l'idolâtrie pratiquée par les Mégamicres, en quoi il imite Wilkins, il réussit à gagner la confiance des « indigènes » et à devenir prince de quelques terres du monde intérieur. Par rapport aux autres voyageurs, il se révèle également inventeur et promoteur des arts inconnus parmi les peuples ignorants : une nouvelle écriture unicolore, la production de papier et la mise en place d'imprimeries, la découverte de la poudre le font considérer comme un homme extraordinaire. Par ses activités tendant à implanter les acquis civilisationnels de l'Europe dans le souterrain, Édouard se place dans le sillage d'autres voyageurs "prométhéens ». De plus, ses descendants se multiplient avec une vitesse improbable au point de devenir un peuple puissant et concurrent pour les autochtones. Le nombre des membres de la famille justifie, consolide et garantit davantage la position d'Édouard, déjà bien importante chez les Mégamicres. Ainsi, sans prendre le titre de monarque, l'Anglais devient-il de fait le maître incontestable de cet espace inconnu ${ }^{43}$.

Peut-être la plus grande différence entre lui et les deux autres voyageurs commentés consiste-t-elle dans son rapport au pouvoir sur le pays découvert. S'il ne suit pas l'exemple de Klimius et ne se fait pas proclamer empereur, ou chef suprême des Mégamicres, au moyen d'un coup d'État, il ne renonce pas non plus, contrairement à Wilkins, à ses privilèges. Voyageur devenu un prince puissant du souterrain, Édouard préfère exercer une influence discrète sur les grands, y compris sur les rois. Son pouvoir est bien réel, même s'il reste dissimulé.

Après ce long commentaire sur la vie des trois héros, on peut se demande s'il serait possible de trouver une catégorie de voyageur qui traduise le rôle de dominant que chacun de ces voyageurs exerce dans les contrées inconnues, indépendamment de ses choix individuels. Le narrateur sternien mentionnait " des voyageurs menteurs, orgueilleux et vains ", des termes qui font peut-être penser à l'exercice du pouvoir, mais ces qualifications ne saisissent pas le point commun des trois voyageurs. Certainement, ces catégories interrogent l'attitude des visiteurs dans les mondes souterrains, mais elles ne cernent pas la fonction qu'ils réussissent à remplir chez les autochtones. La difficulté vient du fait que l’influence que Klimius, Wilkins et Édouard possèdent dans l'Ailleurs, échappe à un jugement unique et simple. Malgré l'équivoque des stratégies employées par les trois voyageurs et hommes politiques à la fois, leurs séjours dans les souterrains constituent un tournant sans retour pour les autochtones, ce qui justifie un essai de recherche d'une "étiquette» adéquate.

La formule de "voyageur conquérant " semble s'imposer, ne serait-ce que par l'allusion aux modèles des conquistadores espagnols ${ }^{44}$. Pourtant, ce terme

43 G. Casanova, op. cit., t. III, p. 235.

44 Le terme espagnol même entre dans l'usage en français, mais seulement à partir des années 1840 , toujours en relation directe avec les découvertes des pays de l'Amérique du Sud 
même expose des traits qui ne conviennent que difficilement aux voyageurs commentés. Si le « conquérant » figure dans le Dictionnaire de l'Académie depuis la première édition, il s'agit seulement du nom dont la définition insiste sur l'aspect militaire : "Qui a subjugué beaucoup de pays par les armes. Alexandre estoit un grand Conquerant ${ }^{45}$. Fontenelle met le terme dans la bouche de César discutant avec Brutus ${ }^{46}$. L'abbé Prévost consacre une " Histoire » au Guillaume qui porte ce titre ${ }^{47}$, ce Normand devenu roi d'Angleterre, le jésuite Margat de Tilly en fait de même pour Tamerlan ${ }^{48}$. Aussi bien Klimius que Wilkins ou Édouard ont dans leurs parcours des épisodes marqués par une activité belliqueuse : le premier comme empereur des Quamites, fait envahir les pays voisins par ses troupes ${ }^{49}$, le deuxième écrase la révolte d'Harlokin ${ }^{50}$, et le troisième enfin mène une guerre sans merci contre une république du souterrain ${ }^{51}$. Pourtant, ces événements n'ont l'importance cruciale qui détermine le destin du voyageur parmi les autochtones que dans le cas de Klimius.

La réussite des voyageurs découle surtout de leur intelligence qui se laisse deviner dans leurs entreprises. Or, la valorisation des compétences intellectuelles $\mathrm{du}$ " conquérant» ne se laisse voir que sous la plume de Montesquieu, quand celui-ci commente les ruses et les stratégies secrètes employées par les hommes politiques afin de soumettre les peuples ennemis ${ }^{52}$. Déjà, dans le français moderne, le verbe " conquérir » reflète un sens plus large, au-delà de l'aura militaire : "s'assurer la possession de quelque chose, étendre son emprise

par les sujets de l'Espagne. Voir «Conquisador », dans : Trésor de la langue française, Centre National de Ressources Textuelles et Lexicales, https://www.cnrtl.fr/definition/conquistador, consulte le 10/11/2020.

45 «Conquérant », dans : Dictionnaire de l'Académie française, 1694, https://portail.atilf.fr/ cgi-bin/dicollook.pl?strippedhw=conquerant, consulté le 11/11/2020 ; l'italique dans le texte.

${ }^{46}$ Les deux Romains discutent de la valeur des conquêtes, en opposant les grands triomphes de César dans la Gaule aux attaques d' "un Conquérant \& un Voleur de grand chemin ». B. le Bovier Fontenelle, Dialogues des morts d'un tour nouveau, pour l'instruction des vivants sur plusieurs matières importantes, La Haye, T. Johnson, 1709, p. 238.

47 «Ainsi dans l'espace d'environ quatre mois Guillaume eut la satisfaction de se voir aussi respecté des Anglais, que si le ciel l'eût appellé par sa naissance à les gouverner ; il quitta le nom de Guillame le bâtard, qu'il n’avoit pas fait difficulté de se donner lui-même jusqu'alors, pour prendre celui de Guillaume le Conquérant, qu'il voulut porter jusques dans les actes publics ", A. F. Prévost, Histoire de Guillaume le Conquérant, duc de Normandie et roi d'Angleterre, t. I, Paris, Prault, 1742, p. 300.

48 J.-B. Margat de Tilly, Histoire de Tamerlan, empereur des mogols et conquérant de l'Asie, Paris, Hippolyte-Louis Guérin, 1739.

49 L. Holberg, op. cit., p. 341-356.

50 R. Paltock, op. cit., t. II, p. 58-66.

${ }^{51}$ G. Casanova, op. cit., t. V, p. 138-225.

52 Ch.-L. de Secondat de Montesquieu, De l'esprit des lois, ch. IV « Quelques avantages du peuple conquis ", dans Euvres de Monsieur de Montesquieu, Londres, Nourse, 1772, p.172-173. 
sur quelque chose $»^{53}$, «s[e] rendre maître [de quelque chose] $», ~ «[\mathrm{~m}]$ aîtriser, dominer quelque chose $\aleph^{54}$. Faute de mieux, pour établir un terme unique classifiant Klimius, Wilkins et Édouard, il nous semble nécessaire de retenir la catégorie de « conquérant $»^{55}$.

Pourtant, il vaut la peine de revenir aux nuances qui distinguent les trois voyageurs. Ces considérations permettent d'établir des sous-catégories qui reflètent les facettes, parfois contradictoires, de la catégorie de "voyageur conquérant", ce qui fait observer également les tensions internes qui la travaillent.

L'expérience de Klimius montre comment il prend la place du chef suprême dans le monde souterrain. Le voyageur danois est nommé empereur par la volonté des généraux, non vraiment contre son gré, mais certainement contre la loi de succession privilégiant les héritiers légitimes ${ }^{56}$. Ces circonstances décrites par lui-même le font considérer en tant qu'usurpateur. L'accusation est forte, mais elle répond à la définition d'" usurpation » et à celle d'usurpateur. L'Encyclopédie précise : "Quiconque entre dans l'exercice de quelque partie du pouvoir d'une société par d'autres voies que celles que les lois prescrivent, ne peut prétendre d'être obéi, quoique la forme du gouvernement soit conservée, parce qu'il n'a pas été désigné à jouir du pouvoir par les lois $»^{57}$. Sans qu'il soit vraiment un "sujet rebelle ", Klimius « s'érige en souverain » et usurpe « des droits de souveraineté ${ }^{58}$. Le Trésor de la langue française définit l'usurpateur comme une "Personne qui, par ruse ou par violence, s'empare d'un bien, d'un pouvoir, d'une dignité, d'un titre ne lui appartenant pas ou auquel il ne peut prétendre $»^{59}$. Le terme d'« usurpateur», profondément négatif dans ses acceptions ancienne et contemporaine, désigne en fait un voleur de privilège, et

53 «Conquérir », dans : Trésor de la langue française, op. cit., https://www.cnrtl.fr/definition/ conqu\%C3\%A9rir, consulté le 11/02/2021.

54 "Conquérir ", dans : Larousse, https://www.larousse.fr/dictionnaires/francais/ conqu\%c3\%a9rir/18318, consulté le 11/02/2021.

55 Il faut noter que la langue française connaît également le substantif « conquéreur » qui s'opposerait au «conquérant » selon les linguistes du $\mathrm{XX}^{\mathrm{e}}$ siècle : " mot repris pour éviter les connotations que comporte le mot normal conquérant triomphant ou prétentieux". Le terme littéraire et vieux de "conquéreur» date du XIII siècle et s'approche par sa forme du " conqueror » anglais. Voir " Conquérir ", dans : Trésor de la langue française, op. cit.

56 L. Holberg, op. cit., p. 337-339.

57 L. de Jaucourt, "Usurpation ", dans : Encyclopédie, ou Dictionnaire raisonné des sciences, des arts et des métiers, sous la dir. de D. Diderot, J. le Rond D’Alembert, 1751-1765, https://fr.wikisource.org/wiki/L\%E2\%80\%99Encyclop\%C3\%A9die/1re_\%C3\%A9dition/ USURPATION, consulté le 10/11/2020.

58 A.-G. Boucher d'Argis, « Usurpateur », dans : Encyclopédie..., op. cit., https://fr.wikisource. org/wiki/L\%E2\%80\%99Encyclop\%C3\%A9die/1re_\%C3\%A9dition/USURPATEUR, consulté le $10 / 11 / 2020$.

59 «Usurpateur», dans : Trésor de la langue française, op. cit., https://www.cnrtl.fr/definition/ usurpateur, consulté le 11/02/2021. 
celui d'usurpation une violence apportée aux lois établies ${ }^{60}$. De plus, l'illégitimité du pouvoir de Klimius est paradoxalement mise en relief par la révolte de ses sujets contre son autorité, événement qui l'oblige à fuir ${ }^{61}$. Le voyageur danois semble incarner la réalisation du modèle de "voyageur conquérant " sous la forme oppressive d'" usurpation».

En revanche, cette facette négative de "voyageur conquérant» ne concerne pas Wilkins et Édouard. Il est difficile de les accuser d'usurpation. Aucun d'eux ne voit éclater de révolte. Wilkins et Édouard Alfrède quittent en effet les terres où ils exercent une forme de pouvoir ${ }^{62}$, mais dans leur cas, il faudrait plutôt parler de la suspension de leur autorité sur les peuples souterrains, sans nier leur influence durable sur eux. Les réformes, les modernisations qu'ils ont effectuées au sein de leurs communautés d'accueil sont durables, l'éloignement des auteurs des changements n'annule donc guère leur autorité : une fois revenus, Wilkins et Édouard jouiraient, semble-t-il, des honneurs qui leur avaient appartenu avant le départ. Leur domination semble établie sans contestation, et vénérée même d'une certaine manière par les autochtones ${ }^{63}$.

Une autre sous-catégorie de "conquérant » est suggérée par le parcours de Pierre Wilkins. Celui-ci souligne plusieurs fois lors de son périple le rôle de la "Providence » qui se manifeste dans sa vie. Le voyageur interprète comme un "coup de providence ${ }^{64}$ la rencontre d'un bateau qui le sauve avec ses compagnons de l'errance maritime. Une autre fois, sans savoir où il va, et hésitant à opérer un choix, Wilkins se remet « entre les bras de la providence ${ }^{65}$.

${ }^{60}$ Dans l'Essai sur les mœurs de Voltaire, le terme revient à propos des personnages injustes et manipulateurs. Voir Voltaire, «Essai sur les mœurs et l'esprit des nations, et sur les principaux faits de l'histoire, depuis Charlemagne jusqu'à Louis XIII », t. II, dans : Collection complette [sic] des cuvres de $M^{r}$ de Voltaire, t. IX, Genève, [s.n.], 1769.

${ }^{61}$ Le voyageur, devenu l'empereur de Quama, commente avec une certaine amertume sa vie : il se voit entraîné dans le destin funeste de bien des monarques : « [...] après mêtre vû dans un dègré de prospérité \& de puissance au-delà presque de ce que le cœur humain peut désirer, il marriva ce qui arrive à ceux qui d’un état fort bas sélèvent aux grandeurs : car oubliant mon prémier sort, je me laissai aller à l'orgueil, \& au-lieu de prendre les intérêts, les airs \& les manières du Peuple, je deviens un cruel persécuteur de tous les ordres de l'Etat [...] »; L. Holberg, op. cit., p. 359.

${ }^{62}$ Le départ du voyageur est un élément obligatoire des voyages imaginaires, ainsi que des utopies littéraires; voir J.-M. Racault, Nulle part et ses environs: Voyage aux confins de l'utopie littéraire (1657-1802), Paris, Presses de l’Université de Paris-Sorbonne, 2003, p. 363-364.

${ }_{63}$ On pourrait se poser des questions sur l'avenir des Mégamicres qu'Édouard quitte inopinément. Après son départ, ses descendants prennent le relais de leur géniteur en cultivant ses préceptes envers les Mégamicres. Le voyageur lui-même doute être cordialement reçu par eux en cas de son retour possible, mais ceci ne conteste nullement l'influence qu'il a exercée sur les autochtones du souterrain. G. Casanova, op. cit., t. V, p. 11.

${ }_{64}$ R. Paltock, op. cit., v. I, p. 39.

65 Ibid., v. I, p. 90. 
Persuadé que toute chose se règle selon la bonté d'une force suprême ${ }^{66}$, le voyageur se décrit comme un " choisi par la providence " devant le roi Georigetti auquel il apporte la promesse d'un mariage politiquement bien avantageux ${ }^{67}$. Le voyageur serait donc un bienfaiteur de la communauté, un homme qui secourt la communauté en crise dans une épreuve cruciale, en exécutant les décisions de Dieu, un « homme providentiel $»^{68}$. Le modèle de Wilkins se révèle donc un modèle de " conquérant " nettement plus positif et surtout plus facilement accepté par les autochtones : les Glumms ne sont que satisfaits de la rencontre avec le voyageur.

Si l'« usurpateur» illustré par Klimius s'oppose à l'« homme providentiel » représenté par Wilkins, l'un étant focalisé sur la corruption de la nature humaine, l'autre se définissant à travers un providentialisme bon marché, il est possible de repérer encore un autre épithète qui pourrait s'appliquer au type de "voyageur conquérant». En retenant seulement l'importance des changements que les voyageurs opèrent au sein des communautés rencontrées, en mettant entre parenthèses les dérives de leur attitude et l'interprétation religieuse, nous nous approchons du terme de "grand homme", apparaissant sous les plumes des philosophes et encyclopédistes. Nous retrouvons sa définition chez le chevalier de Jaucourt :

On définit un héros, un homme ferme contre les difficultés, intrépide dans le péril, \& très-vaillant dans les combats; qualités qui tiennent plus du tempérament, \& d'une certaine confirmation des organes, que de la noblesse de l'ame. Le grand homme est bien autre chose ; il joint aux talens \& au génie la plûpart des vertus morales ; il n’a dans sa conduite que de beaux $\&$ de nobles motifs ; il n'écoute que le bien public, la gloire de son prince, la prospérité de l'état, $\&$ le bonheur des peuples ${ }^{69}$.

${ }^{66}$ Si Wilkins se dit chrétien, il n’entre pas dans le détail des questions religieuses. Ses réflexions sur la société des Glumms dans son évolution le ramènent à affirmer la bonté de Dieu qui organise tout en vue du Bien. Réfléchissant à l'état des autochtones avant son arrivée, le voyageur s'interroge : «[..] privés [sic] de toutes commodités des arts, ce peuple si nombreux n'a-t-il pas toujours bien vécu sous la protection de la providence? »; et, après l'examen des biens qu'il leur a apportés, il conclut : « [...] dans les endroits où on ne peut avoir guère de commodités, la providence restreint les desirs, de sorte qu’on est content de ce que l'on a ; \& lorsque les besoins sont apparens, nous voyons, par l'exemple de ce peuple, combien la providence a soin d'y suppléer [...] ». Ibid., v. II, p. 202-203.

67 Ibid., p. 181.

68 A. Gérard, "Le grand homme et la conception de l'histoire au XIX siècle », Romantisme, 1998, n 100, p. 31-48. L’adjectif serait formé à l'instar de celui de "providential ", attesté en anglais depuis la moitié du XVII ${ }^{e}$ siècle, ce qui justifie son emploi par rapport à Wilkins qui est précisément d’origine anglaise. Voir « Providentiel », dans : Trésor de la langue française, op.cit., https://www.cnrtl.fr/definition/providentiel consulté le 11/02/2021.

${ }^{69}$ L. de Jaucourt, « Héros », dans : Encyclopédie..., op. cit., https://fr.wikisource.org/wiki/L\%E 2\%80\%99Encyclop\%C3\%A9die/1re_\%C3\%A9dition/H\%C3\%89ROS, consulté le 11/11/2020. 
Les traits du "grand homme » accentuent la prospérité qui découle de ses activités au sein de la communauté. S’il est peu aisé de considérer Klimius dans cette perspective à cause de son règne despotique et contesté par ses sujets, il est plus pertinent d'adapter cette notion à Wilkins et Édouard : ces deux derniers contribuent au bien-être des sociétés inférieures par rapport aux Européens. En essayant de nuancer ce jugement, nous pouvons constater que la différence entre Wilkins et Édouard consiste en leur attitude envers les habitants des souterrains. Édouard, agissant en vue du bien des Mégamicres, n'oublie pas ses propres affaires, en quoi il adapte quelque peu le modèle de Klimius, mais s'efforce d'occulter son pouvoir. En revanche, Wilkins opère en faveur des Glumms, renonçant à son propre intérêt, en quoi il s'approche peut-être le plus de l'idéal du grand homme.

Les exemples de Klimius, Wilkins et Édouard servent d'argument pour justifier l'essai de formulation d'une catégorie à ajouter aux catalogues de types de voyageurs qui s'élaborent depuis le XVIII siècle. Ainsi la liste donnée par le voyageur sentimental de Sterne se trouve-t-elle élargie par cette nouvelle catégorie qui permet de considérer les expériences vécues par les découvreurs de mondes inconnus. Les commentaires sur le rôle joué par les trois protagonistes dans les contrées qu'ils visitent aboutissent à la formulation de la figure de "voyageur conquérant ", entendue comme celle de quelqu'un qui fait la " conquête » des sociétés rencontrées par les moyens militaires ou par la force de son intelligence. Si cette catégorie reflète la position du voyageur devenu maître des communautés d'accueil, il est nécessaire de distinguer dans son cadre trois sous-catégories, allant de la plus oppressive envers les autochtones à la plus généreuse : celle de "voyageur-usurpateur ", celle de "voyageurgrand homme » et celle de "voyageur-homme providentiel ». La perspective diachronique des trois types expose le basculement du modèle le plus despotique vers celui de l'« homme providentiel » pour aboutir à un modèle plus équilibré entre les deux : la conquête du monde souterrain par Édouard ressemble en grande partie à celle de Wilkins, ce "grand homme " "providentiel ", mais l'attitude pragmatique et intéressée d'Édouard rapproche ce dernier du despotisme de Klimius. Dans les trois sous-catégories, on retient l'influence que les voyageurs exercent sur les communautés, ce qui fait d'eux des "conquérants " des esprits aussi bien que des corps, mais chacune des formules souligne une nuance significative du modèle particulier. 
Linda Gil

$I R C L$, Université Paul-Valéry Montpellier 3

\section{Cunégonde, l'autre candide? Figure d'une voyageuse compulsive dans le récit voltairien, entre domination et émancipation ${ }^{1}$}

\section{Cunégonde, Another Candide ? A Figure of a Compulsive Traveller in the Voltairean Narrative, Between Domination and Emancipation}

Reduced to an intermittent and caricaturized figure of a sexual object, Cunégonde is, at a closer reading, a strong character, sensitive and intelligent. Her forced trip is a discovery of female condition through the world, a real experience which forces the heroine to reconsider her destiny. Her philosophical learning is coherent and much quicker than this of the male hero. Pragmatism, sensibility and lucidity are the values we need to reconsider in this feminist reading of Candide. What questions does its trajectory pose in terms of education, gender relations, alterity, construction, violence, domination and women's emancipation?

Keywords: woman, heroine, travel, violence, learning, philosophy

Mots-clés : femme, héroïne, voyage, violence, apprentissage, philosophie

Dans les Lettres persanes, les femmes restent au sérail pendant que les hommes parcourent l'Europe en quête de nouvelles connaissances et du plaisir de voyager, devenu une pratique culturelle. L'originalité des contes voltairiens consiste à jeter les femmes sur la route, au gré d'aléas politiques ou sociaux qui leur échappent. Olivier Ferret rappelle à juste titre que, dans ces contes, «toutes sortes d'“aventures" attendent les femmes dès lors qu'elles entreprennent de - ou

1 Je souhaite ici remercier chaleureusement les deux éditrices de ce volume pour leurs relectures attentives et leurs suggestions éclairées. 
sont contraintes à - voyager, sur terre comme sur mer $»^{2}$. Au gré du voyage, elles tentent de reconquérir leur liberté, de reprendre la main sur leur destin tandis que pour ce faire il ne reste à Roxane que la voie du suicide. Surtout, c'est à une expérience sensible et intellectuelle que le personnage de Cunégonde est exposé. Le voyage permet une mise en perspective de la souffrance, par deux moyens. La répétition des malheurs, en premier lieu, suscite de la part de la victime une réflexion sur son destin. La rencontre avec les souffrances des autres, en second lieu, vient contribuer à décentrer la réflexion sur soi et sur la condition humaine, et plus particulièrement féminine.

La chose semblait pourtant entendue : l'héroïne du plus célèbre des contes philosophiques voltairiens serait un personnage peu signifiant, dénué de caractère, une caricature ${ }^{3}$. Dans le parcours de Candide, Cunégonde semble n'être que l'objet de son désir, évanoui aussitôt que son amant la retrouve au terme d'une quête effrénée. L'intense focalisation à l'œuvre dans le récit, qui fait de Cunégonde l'objet d'une poursuite, génère le plus souvent une lecture subjective et paradoxale de ce personnage. Sexualisée dès sa première description, elle semble en effet réduite à un corps, désiré, fantasmé, agressé, brutalisé et finalement rejeté. "Âgée de dix-sept ans, [...] haute en couleur, fraîche, grasse, appétissante ${ }^{4}$, au début du conte, elle achève sa trajectoire en femme marquée, laide et grincheuse, précocement vieillie.

Le rythme du récit, la succession des apparitions et disparitions de la jeune femme, l'intensité de ses malheurs ont favorisé sa réduction à une figure. Pourtant, il faut relire Candide, encore : Cunégonde est bien plus prompte que le héros masculin à accepter de regarder la réalité et à diagnostiquer l'inanité des préceptes de Pangloss. Sa sagacité et sa lucidité sont remarquables, elle qui dès le premier récit qu'elle fait de l'attaque du château par les Bulgares - a perdu toutes ses illusions sur « le meilleur des mondes». Quelle est la valeur de ce

2 O. Ferret, «Les “destinées féminines" dans Zadig, Candide et L’ingénu », dans : Voltaire et ses contes, sous la dir. de F. Lotterie, Paris, Hermann, 2019, p. 76.

3 P. Fauchery, par exemple, note que Voltaire « travaille sur son personnage comme une marionnette " : La Destinée féminine dans le roman européen du dix-huitième siècle, 1713-1807. Essai de gynécomythie romanesque, Paris, A. Colin, 1972, p. 766. On peut également citer ce commentaire de J.-P. Bigel, dans un volume destiné aux étudiants des classes préparatoires, réunissant une série détudes et intitulé Analyses et réflexions sur "Candide ", de Voltaire, Paris, Ellipses, 1995, p. 65-66 : "Mlle Cunégonde, âgée de dix-sept ans, est, elle, très mignonne, et Voltaire par son portrait suggère une sensualité à fleur de peau. Pourtant, elle est assez insignifiante. Voltaire ne nous dit rien de son esprit, parce qu'il n'y a rien à en dire ». Plus récemment, Marc Hersant parle à son sujet d’apparition fantomatique, "promenée comme une poupée vide d'horreur en horreur et de catastrophe en dérision » : "Voltaire, Dictionnaire philosophique. Étude littéraire d'“Abraham" ", L'information littéraire, no 4 (6), 2008/4, p. 11-21.

${ }_{4}$ Nous donnons la référence au texte de Candide dans l'édition des Romans et contes de Voltaire, éd. Fr. Deloffre et J. van den Heuvel, Paris, Gallimard, 1979, ici p. 146. Pour la suite, nous donnons le numéro de la page entre parenthèses dans le corps de l'article. 
protagoniste dans l'économie romanesque ? Que représente le voyage dans cet apprentissage $\mathrm{du}$ " monde comme il va » ? Quelles questions sa trajectoire poset-elle en termes d'éducation, de rapports de genre, de violences, de domination et d'émancipation des femmes?

\section{Une figure problématique}

Le personnage a peu intéressé la critique, si ce n'est, le plus souvent, pour identifier des modèles biographiques. ${ }^{5}$. Plusieurs commentateurs, se croyant autorisés par la prétendue misogynie du texte - si ce n'est de Voltaire n'hésitent pas à se payer de remarques que l'on pourrait, à tout le moins, qualifier de sexistes. En 2006, Frédéric Deloffre, étudiant la Genèse de Candide, énonce cette sentence : "Quant à l'héroïne, peu semblable à celles des romans hellénistiques ou classiques, elle est incapable de préserver sa vertu, supposé qu'elle cherche à le faire. Le viol n'est pour elle que le premier pas vers l'état de fille entretenue $»^{6}$. Dix ans plus tard, les choses ont peu évolué. Jean Goldzink, dans son édition critique de Candide, annote la première occurrence du prénom de l'héroïne par cette remarque ironique : "Une princesse du même nom fut canonisée en 1012 : l'épreuve du feu avait prouvé sa chasteté ! La seconde Cunégonde sera un peu moins chaste $»^{7}$.

Qui est Cunégonde? C'est le troisième membre de la famille dans l'ordre d'apparition au générique. Le récit voltairien adopte un modèle archaïque dans lequel les filiations sont genrées : Cunégonde est la fille de la baronne, tandis que son frère est présenté comme « le fils du baron» (p. 146). Elles sont aussi thématisées par le biais d'une grille traditionnelle qui fonde la division sexuelle des tâches dans toute famille aristocratique : les femmes (la mère et la fille) sont présentées comme des corps, elles sont sexualisées. La mère est obèse, tandis que la fille, quoique désirable, présente déjà des dispositions à l'embonpoint. La respectabilité de la mère est adossée à son corps, la "considération » (p. 146) dont elle bénéficie est à la mesure de sa disproportion physique. Côté mâles, la filiation repose sur le mérite, sur les valeurs nobiliaires, puisque «le fils du baron paraissait en tout digne de son père ( (p. 146), lequel, comme l'incipit l'a suggéré, a construit son image sur les signes extérieurs de richesse attendus de la noblesse : gros château, grosse épouse, grosse meute de chiens et nombreuse domesticité, toujours prête à se faire courtisane, sans oublier

5 Voir Fr. Deloffre, Genèse de Candide : étude de la création des personnages et de lélaboration du roman, SVEC, $\mathrm{n}^{\circ}$ 6, Oxford, University of Oxford, 2006. Dans le chapitre intitulé "Cunégonde ", consacré à l'étude du modèle Bentinck, le chercheur dresse un bilan des recherches de ses prédécesseurs, p. 249-258.

${ }^{6}$ Ibid, p. 254

7 J. Goldzink, Candide, Paris, GF Flammarion, 2007, p. 38, note 4. 
l'officier ecclésiastique de service. Ce baron colère (Thunder signifie « tonnerre " en allemand $)^{8}$, boursouflé d'orgueil et adulé par des courtisans hypocrites aux ordres pour chanter ses louanges, règne donc sur cette baronnie patriarcale où les femmes sont réduites à de la chair, au sens littéral du terme. De la masse graisseuse de la baronne à la chair disponible à l'envi de Pâquette, en passant par la carnation appétissante de la jeune baronne, les corps féminins sont présentés par le biais d'un regard ironique, qui les assigne vigoureusement à leur condition de consommable et de périssable.

Mais très vite, Voltaire inverse les codes en faisant de la jeune fille un être agissant, pensant, sentant, désirant, aimant. Candide est aussi un récit d'apprentissage au féminin, l'histoire d'une ingénue philosophe brutalement déniaisée. Élevée dans un cocon familial mais exposée au regard des hommes, elle est initiée au plaisir par le spectacle des amours ancillaires de son professeur particulier, désigné à ce moment précis du récit par son titre scientifique de « docteur Pangloss » (p. 146). À partir de cet épisode, Cunégonde devient un personnage, un actant : elle fait usage de sa raison, démêlant « les effets et les causes » (p. 147). L'expérience à laquelle elle a assisté engendre un désir de connaissance : c'est elle qui entreprend une quête amoureuse, aiguillonnée par ces observations. Éveillée à la sexualité par ce biais, elle associe la science du philosophe avec ses propres émois, suscités par son condisciple et cousin, le jeune Candide (celui-ci est le fils illégitime de sa tante, rappelons-le). L'objet de son désir se fixe donc sur le jeune garçon qui, lui, n’a pas encore été initié à la conscience de son désir. À partir de ce moment, elle se conçoit en « raison suffisante » (p. 146) dans une relation égalitaire et partagée, où chacun est l'objet du désir de l'autre. L'action a lieu en deux temps. La rencontre amoureuse est d'abord racontée du point de vue de la jeune fille, désormais maîtresse du jeu : elle est le sujet grammatical qui enclenche chacune des étapes, Candide agissant en répondant. Les propositions sont juxtaposées, sans coordination, marquant le jeu de miroir, l'action mimétique. Ensuite, les réactions des deux amants sont coordonnées, et les verbes d'action sont alors conjugués au pluriel jusqu’à l'intervention violente des parents, toujours genrée, puisque le baron se charge de châtier Candide, tandis que la baronne gifle sa fille à peine revenue de son évanouissement. Certains commentateurs n'hésitent pas à signaler la culpabilité de Cunégonde, "responsable de sa première faute " ${ }^{9}$, complétant ainsi l'une des pistes de lecture qui ferait de l'espace originel du château un jardin édénique et les héros, des avatars du couple formé par Adam et Ève.

Ce premier épisode de violence familiale ouvre une série d'agressions physiques, sexuelles et morales toutes plus cruelles : suivront le viol, les coups

\footnotetext{
8 Sur l'étymologie de ce nom, voir Fr. Deloffre, op. cit., p. 223.

9 Propos courant dans les éditions scolaires, comme sous la plume de $\mathrm{Ph}$. Messière : Voltaire, Candide, Paris, Bordas, 1990, p. 15.
} 
de couteau dans le ventre, le meurtre de ses parents, l'enlèvement, la captivité, l'esclavage, renouvelés en autant d'épisodes multipliés en Bulgarie, au Portugal, en Argentine puis en Turquie. De quel modèle, de quelle source cette figure martyre, voyageuse victime de la cruauté et de la rapacité des hommes, tire-telle son origine? Plusieurs personnages légendaires ou historiques, allemands ou polonais, portent le nom de Cunégonde. Comme le rappelle Fr. Deloffre ${ }^{10}$, après $\mathrm{R}$. Pomeau ${ }^{11}$, trois Cunégonde ont pu inspirer Voltaire pour le choix du prénom de son héroïne. Deux d'entre elles sont des personnages historiques de la période médiévale. La plus ancienne, Cunégonde de Luxembourg, est née à Wettenberg, dans la Hesse. Épouse de l'empereur Henri II, elle partage avec lui le pouvoir en tant que duchesse de Bavière, reine de Germanie et co-impératrice du SaintEmpire, ce qui est remarquable et que soulignent les chroniques de l'époque ${ }^{12}$. Une légende tardive, sans doute inspirée par les problèmes de stérilité du couple, en a fait une figure de la chasteté : elle n’aurait jamais consommé son mariage et se serait soumise avec succès au jugement de Dieu consistant à marcher les pieds nus sur douze socs de charrue chauffés à blanc, pour se laver de soupçons d'infidélité ${ }^{13}$.

Une autre Kunegunda devint elle aussi une figure incarnant la chasteté en Pologne, sous le nom de Sainte Kinga. Née en Hongrie en 1234, fille du roi Béla IV de Hongrie et de Marie Lascaris, elle fut mariée contre son gré à Boleslas V, futur roi de Pologne. Désireuse de se consacrer à Dieu dans le célibat, elle refusa de consommer son mariage, ce que son époux approuva ${ }^{14}$.

Il existe en Pologne une autre princesse Kunegunda, héroïne d'une légende des Sudètes qui aurait vécu dans le château de Chojnik, une forteresse bien réelle construite au XIV ${ }^{e}$ siècle. Après la mort de son père, elle régna à son tour sur le château, amatrice de chasse au cerf et de promenades à cheval. Comme son homonyme de Cracovie, Kunegunda ne souhaitait pas se marier. Afin de se débarrasser de ses nombreux prétendants, elle leur imposait une épreuve très dangereuse. De nombreux chevaliers y laissèrent leur vie jusqu'à ce que l'un d'eux, après avoir réussi le parcours, rejette l'amour de la princesse ${ }^{15}$.

10 Fr. Deloffre, op. cit., p. 249.

11 Candide, éd. R. Pomeau, dans : Euvres Complètes de Voltaire (désormais OCV), t. 48, Oxford, Voltaire Foundation, 1980, p. 119, note 6.

12 Voltaire, Annales de l'Empire, éd. G. Laudin et al., dans : OCV, t. 44A, 2019, $\$ 1003$, « Henri II » et Essai sur les moeurs, éd. Henri Duranton, OCV, t. 23, 2010, Chap. XLV, p. 111-112.

13 Sur Cunégonde de Luxembourg, voir J. Vannerus, «La première dynastie luxembourgeoise [Ā propos de l'étude de Heinz Renxi, Das erste Luxemburger Grafenhaus (963-1136)], Revue belge de philologie et d'histoire, t. 25, fasc. 3-4, 1946, p. 801-858.

${ }_{14}$ Voir Zofia Budkowa, „Kunegunda”, Polski Słownik Biograficzny, t. 16, Wrocław Zakład Narodowy im. Ossolińskich - Wydawnictwo Polskiej Akademii Nauk, 1971, p. 186-189.

${ }_{15}$ Voir M. Chorowska, T. Dudziak, K. Jaworski, A. Kwaśniewski, Zamki i dwory obronne w Sudetach, t. 2, Wrocław, Księstwo Jaworskie, 2009. 
D’autres Cunégonde réelles, contemporaines de Voltaire, ont encore pu inspirer l'écrivain, comme cette Cunégonde de Saxe, princesse de Pologne, de Lituanie et de Saxe, née en 1740 à Varsovie, contemporaine de l'auteur. Quinzième et dernière fille d'Auguste III roi de Pologne et de Marie-Josèphe d'Autriche, elle reçut une excellente éducation : Cunégonde étudia le latin, le français, l'anglais, la philosophie, la géographie, la religion, le dessin, la musique et la danse. Membre d'une famille régnante, elle fut destinée à un mariage princier afin de consolider les relations politiques de la Maison de Wettin, qui cherchait notamment à accroître son influence dans le Cercle du Bas-Rhin-Westphalie ${ }^{16}$. On relève encore l'existence de la princesse Kunegunda Czacka, fille de Barbara Urszula Sanguszko et de Paweł Karol SanguszkoKowelski, qui épousa Franciszek Czacki, grand gardien de la Couronne ${ }^{17}$.

Outre le prénom, aux sonorités certes burlesques, Voltaire a-t-il emprunté certains traits à l'une ou à l'autre de ces figures pour élaborer son personnage? Plusieurs thématiques communes croisent ces figures féminines historiques ou légendaires : la haute naissance et le prestige familial, le passage du château au couvent, le lien entre chasteté et suspicion d'infidélité ou de sexualité transgressive, la thématique du célibat, du mariage et de l'émancipation. L'origine même du prénom mérite qu'on y revienne : Cunégonde est en effet formé de deux substantifs germaniques : kuni, qui signifie "clan, famille" et gund, qui désigne la "guerre », mais signifie littéralement « de race guerrière » ou " qui combat pour sa race $»^{18}$. Que faut-il en retenir ? le personnage de Voltaire est une femme combattive, capable de résilience, pour emprunter un concept moderne. Victime de multiples violences, de dominations masculines, elle est consciente de ses droits et se bat pour préserver sa liberté et surtout son intégrité morale. Vertueuse, elle construit son identité dans l'adversité à partir d'un épisode original et traumatisant : la guerre qui a dévasté son château natal et exterminé sa famille. Guerre et famille ont bien partie liée, même si, sur un plan phonétique, Voltaire a pu être séduit par les sonorités à connotation sexuelle du prénom, ainsi que par sa charge parodique et son potentiel caricatural ${ }^{19}$. Bien

${ }^{16}$ Voir L. Berkvens, «La nouvelle coutume de Thorn : absolutisme éclairé et codification sous le régime de la princesse Marie-Cunégonde de Saxe (1776-1784) », Revue du Nord, t. 80, $\mathrm{n}^{\circ} 324$, janvier-mars 1998, p. 188-190.

17 Voir les lettres adressées par Bernardin de Saint-Pierre à Pierre Michel Hennin, datées du 8 et du 20 août 1764, Electronic Enlightenment Scholarly Edition of Correspondence, éd. R. McNamee et al., University of Oxford, 2018, nº BSP 0020 et 0022.

18 Voir L. Grimblot, Vocabulaire synthétique de la langue française, Paris, Librairie Larousse, 1902, p. 263.

19 On pourrait aussi souligner la proximité phonétique avec le nom d'une amie de jeunesse de Voltaire, la comtesse de Rupelmonde, qui l'accompagna dans son voyage en Hollande et à Bruxelles en 1722. Il lui dédia plusieurs poèmes, dont la très subversive Épitre à Uranie, également intitulée le Pour et le Contre. 
sûr, on ne doit pas non plus écarter totalement les figures des amies de Voltaire qui ont pu constituer des sources d'inspiration, comme le suggère la célèbre thèse de la «genèse » de Candide, à rechercher du côté de sa relation avec Mme de Bentinck, ou encore l'hypothèse du modèle qu'aurait pu représenter Amélie de Prusse $^{20}$.

\section{Les voyages de Cunégonde}

Les adresses des personnages, nous rappelle Didier Blonde, font plus sûrement sens que leur description physique ${ }^{21}$. L'origine de Cunégonde, le terreau sur lequel Voltaire a placé son personnage avant d'en faire une voyageuse, sont significatifs. Cet ancrage dans le château fictif de Thunder-ten-Tronckh peut sembler anodin et relever de l'esthétique du conte. On peut aussi lui trouver des ressemblances avec des châteaux réels que Voltaire a pu fréquenter, comme celui de Bückeburg, en Basse-Saxe, où l'écrivain séjourna à plusieurs reprises dans les années 1740. Mais l'épisode de destruction du château familial, qui fera l'objet de trois récits (celui de Pangloss au chapitre IV, celui de Cunégonde au chapitre VIII et celui de son frère au chapitre XV) mérite qu'on y revienne. Si cette fiction est ancrée en Westphalie, ce n'est pas seulement parce que Voltaire cherche à se venger de l'épisode prussien. L'histoire allemande est marquée par la violence des guerres de conquêtes. Voltaire fait entrer l'histoire dans le conte philosophique. Plusieurs époques se superposent ainsi dans le conte. La Guerre de Sept Ans est la plus récente : elle constitue l'actualité, fruit d'une histoire politique tourmentée, qui nous ramène au motif du château de Thunder-tenTronckh, détruit par les Abares ${ }^{22}$.

Cet ancrage géographique mi-réel, mi-fictionnel nous invite à revenir sur l'histoire de la Westphalie. C'est surtout à partir de l'entrée en scène de Charlemagne que le motif du château devient central : lorsqu'en 772 , celui qui n'est encore que le roi des Francs engage une longue guerre contre le duché de Saxe, il ouvre une période de trente-deux ans de violences barbares. La conquête de la Saxe s'articule en effet autour de la prise et de la reprise, jusqu'à sa destruction, d'un château, celui d'Eresburg, situé près de Paderborn.

${ }^{20}$ J. Hellegouarc'h, «Une clé de Candide, Cunégonde de Prusse », dans : Voltaire en Europe : hommage à Christiane Mervaud, sous la dir. de M. Delon et C. Seth, Oxford, Oxford Voltaire Foundation, 2000, p. 151-157.

21 D. Blonde, Carnet d'adresses de quelques personnages fictifs de la littérature, Paris, L'Arbalète/Gallimard, 2020. Patrick Modiano insiste lui aussi, dans son dernier roman, Encre sympathique (Paris, Gallimard, 2019), sur l'idée qu'il est essentiel, pour le romancier comme pour le lecteur, de connaître le lieu de naissance des personnages.

22 Voir à ce sujet J. van den Heuvel, Voltaire dans ses contes, Paris, Armand Colin, 1967, p. 244. 
La forteresse était destinée à protéger le lieu de culte des Saxons, l'Irminsul, l'Arbre Monde, pilier de la cosmogonie germanique ${ }^{23}$. Cette série de succès et de revers s'acheva par la victoire totale des Carolingiens et l'élimination de la résistance des Saxons en 804. Leur conversion forcée au catholicisme, sous peine de mort, s'accompagna de la destruction de leur principal lieu de culte les Saxons étaient jusqu'alors païens - et de leur déportation massive dans l'Empire carolingien. Au cours de cette guerre de conquête religieuse, d'une grande violence, Charlemagne s'est acquis une réputation sanguinaire, jusqu'à être surnommé Charles le Boucher par les Saxons ${ }^{24}$. Dans Candide, l'histoire primitive de la Westphalie, de son occupation par les Saxons, la Westphalie convoitée ensuite par les Francs, prise et reprise, fait l'objet d'un traitement romanesque, constituant l'un des épisodes de violence originelle qui jette Cunégonde sur la route et fait d'elle une voyageuse. La guerre semble opérer de façon mécanique, puisqu'à la destruction du château de Thunder-tenTronckh, situé en terre abare, par les soldats bulgares, répond celle du château d'un baron bulgare voisin par les soldats Abares, réciprocité dans la barbarie dont se félicite l'absurde Pangloss. Les enjeux de la guerre ne sont pas explicités dans le conte voltairien, seule est donnée à lire la violence de l'agression vécue et racontée, intériorisée de façon traumatique par Cunégonde.

Que représente alors le voyage dans cet apprentissage du « monde comme il va " ? Dès l'incipit, Cunégonde est caractérisée par sa curiosité : sortant de l'espace confiné du château, elle cherche à élargir son horizon, à découvrir son environnement, «se promenant auprès du château, dans le petit bois qu'on appelait parc» (p. 146) ${ }^{25}$. Cette curiosité initiale est-elle cause de l'enchaînement de ses malheurs? L'histoire de Cunégonde est-elle une variation sur la figure de Pandore ? Subissant avec les membres de sa famille l'agression des soldats, victime capturée telle une prise de guerre par le capitaine bulgare, elle est conduite en captivité, comme elle le raconte au chapitre VIII : « [II] m’emmena prisonnière de guerre dans son quartier » (p. 161), sans qu'aucune indication

${ }^{23}$ Voir le récit ironique qu'en donne Voltaire dans les Annales de l'Empire : « Il [Charlemagne] va attaquer les Saxons, et trouve à leur tête un homme digne de le combattre : cétait Vitikind, le plus grand défenseur de la liberté germanique après Hermann que nous nommons Arminius. Le roi de France l'attaque dans le pays qu'on nomme aujourd'hui le comté de la Lippe. Ces peuples étaient très-mal armés ; car dans les Capitulaires de Charlemagne on voit une défense rigoureuse de vendre des cuirasses et des casques aux Saxons. Les armes et la discipline des Francs devaient donc être victorieuses d'un courage féroce. Charles taille l'armée de Vitikind en pièces, il prend la capitale nommée Erresbourgh. Cette capitale était un assemblage de cabanes entourées d'un fossé. On égorgea les habitants ; mais comme on força le peu qui restait à recevoir le baptême, ce fut un grand gain pour ce malheureux pays de sauvages, à ce que les prêtres de ce temps ont assuré », éd. cit., $\$ 772$.

${ }_{24}$ Voir D. Hägermann, Karl der Große, Herrscher des Abendlandes, München, Rowohlt Taschenbuch Verla, 2003.

25 Les italiques sont de l'auteur. 
géographique ne vienne préciser sa destination. Son périple se poursuit lorsqu'elle est « vendue à un Juif nommé don Issacar, qui trafiquait en Hollande et en Portugal » (p. 161), lequel, explique-t-elle, « pour m'apprivoiser, me mena dans cette maison de campagne que vous voyez » (p. 161), avant d'être repérée lors d'une messe par le Grand Inquisiteur, qui la fit conduire à son palais, avant de l'inviter à assister à un auto-da-fé organisé à Lisbonne. Peut-on encore parler de « voyage»?

Après le double meurtre de ses geôliers par Candide, c'est la fuite en Espagne puis au nouveau monde. À la première partie du voyage en captivité succède donc la seule séquence de voyage libre à travers les montagnes espagnoles, de Lisbonne à Cadix. Le récit en est ramassé : "Cunégonde, la vieille et lui [Candide] font trente milles d'une traite» (p. 165). Pour l'embarquement sur un navire espagnol et la traversée de l'océan Atlantique jusqu'à Buenos Aires, Cunégonde est englobée dans un récit collectif, associant les trois compagnons de voyage. Les malheurs de la jeune femme, qu'elle ne cesse de ressasser, sont alors décentrés et mis en perspective grâce à un épisode central dans l'économie du récit : le témoignage de la vieille, double grimaçant de Cunégonde ${ }^{26}$, qui raconte pendant la traversée les violences qu'elle a subies, faisant de ces souffrances une expérience partagée, commune à la condition féminine. Le personnage de Cunégonde, invitant à son tour ses compagnons à raconter leurs aventures, accède ici à une dimension métatextuelle. La portée heuristique du voyage comme expérience de l'altérité, comme source de connaissance est ici remarquable. La suite du voyage de Cunégonde confirme le statut, la condition de voyageuse captive. Le récit sera encore lapidaire : l'épisode de Buenos Aires, où Cunégonde est quasiment kidnappée par le gouverneur, est traité en une brève scène étonnante, où Candide cette fois ne cherche pas à s'interposer, tandis qu'à Venise, où il croyait pouvoir la retrouver, il faut se rendre à l'évidence : "Cunégonde n'est point ici, dit Cacambo, elle est à Constantinople» (p. 161). C'est encore le valet péruvien qui annonce l'ultime péripétie de la trajectoire de Cunégonde, au chapitre XXVI : "Mon cher maître, répondit Cacambo, Cunégonde lave les écuelles sur le bord de la Propontide, chez un prince qui a très peu d'écuelles; elle est esclave dans la maison d'un ancien souverain nommé Ragotski, à qui le Grand Turc donne trois écus par jour dans son asile» (p. 223). À la tragédie de la captivité s'ajoute la déchéance sociale, puisque Cunégonde est devenue la domestique d'un prince détrôné, exilé et assigné à résidence.

Que retenir de ces voyages successifs ? Pour Cunégonde, ces " accidents » (p. 160), ces « épreuves » (p. 163), ce voyage forcé autour du monde lui font découvrir l'altérité, qui passe d'abord par la découverte de l'ailleurs : «J'avais cru jusque-là qu'il n'y avait rien sur la terre de si beau que le château de Thunder-tenTronckh ; j'ai été détrompée » (p. 162), reconnaît-elle en évoquant les splendeurs

${ }^{26}$ Voir O. Ferret, op. cit., p. 77. 
du Portugal, entre campagne et canaux, luxe, calme et volupté. Le déclassement de Cunégonde est salutaire et suggère la dimension idéologique du récit. Le voyage engage aussi une altérité qui, dans Candide, remet en question la culture nobiliaire et ses prétentions. Pierre Cambou suggère une comparaison avec un personnage de conte de fées, avec là encore une nuance sexiste : "Cunégonde devient une érotique Cucendron qui traîne par le monde ${ }^{27}$. Objet de désir sexuel, Cunégonde l'est certainement, mais l'usage de l'adjectif « érotique » laisse rêveur. Plus généralement, le voyage expose les personnages féminins. Certes, Cunégonde, comme Astarté ou mademoiselle de Saint-Yves, est relativement passive, objet de visées effrénées de la part d'hommes qui tentent de s'approprier son corps et qui parviennent à la réduire en esclavage. Cunégonde prend surtout conscience de la réalité du monde, bien loin des leçons de philosophie aberrantes de maître Pangloss, dont elle aussi a été l'élève. Dès le chapitre VIII, elle en fait le constat : "Pangloss m'a donc bien cruellement trompée quand il me disait que tout va le mieux du monde » (p. 163). L'usage de la première personne est remarquable. Il singularise l'expérience du protagoniste, détachée de celle de son condisciple. Comme pour le jeune Candide, la réalité brutale la contraint à se défaire de la vision idéaliste des choses que lui a enseignée le philosophe. Mais pour le jeune garçon, cet apprentissage est bien plus laborieux et il faut finalement trente chapitres au héros de cette fiction pour que ses yeux se dessillent et qu'il rejette finalement les préceptes lénifiants de son professeur ${ }^{28}$. Les malheurs des autres, enfin, permettent à Cunégonde de mettre à distance ses propres malheurs. Le spectacle des souffrances de Candide, les retrouvailles, les récits de ses compagnons sont autant de mises à distance de l'expérience vécue, portées par une orchestration stratégique des voix narratives ${ }^{29}$ et des points de vue.

\section{Paroles et regards : entre domination et émancipation}

Les rares éléments du récit qui composent le portrait de Cunégonde sont relativement convenus et souscrivent aux codes du roman chevaleresque : c'est avant tout le corps de la baronnette qui est décrit : outre sa carnation, évoquée en incipit, sa stature, sa silhouette, ses tenues et ses bijoux font l'objet d'indications sommaires mais récurrentes. Lorsque Candide la retrouve dans les environs de Lisbonne, elle apparaît aux yeux du héros " d'une taille majestueuse, brillante de pierreries et couverte d'un voile» (p. 159-160). Voltaire

27 P. Cambou, Le traitement voltairien du conte, Paris, Honoré Champion, 2000, p. 313.

${ }_{28}$ Le disciple de Pangloss passe de l'adhésion au doute puis à l’objection, à la dénégation, à la remise en question pure et simple de ses préceptes. Ses premiers doutes sont formulés au chapitre 13, puis au chapitre 17 et c'est au chapitre 19, face à l'esclave mutilé, qu'il se démarque nettement de cette philosophie absurde.

${ }_{29}$ Voir O. Ferret, op. cit., p. 79. 
use et abuse de la formule « la belle Cunégonde », désignation figée à force d'être convenue. Alors que l'écrivain fait de ce personnage l'incarnation, de pair avec la vieille, de la cause des femmes, alors que l'un des enjeux du récit est justement de dénoncer les violences faites aux femmes, elle ne laisse pas de résister à cette assignation positive, réduite le plus souvent dans la mémoire du lecteur à une image superficielle.

Mais toute l'originalité du récit voltairien tient dans la déception du lecteur, d'abord invité à adhérer à des clichés avant d'être dérouté par des rebondissements qui déjouent les conventions romanesques. Cette beauté sur laquelle s'extasient tous les admirateurs de Cunégonde au fil de ses aventures s'inverse dans le dénouement : c'est Cacambo qui annonce à Candide l'invraisemblable métamorphose de l'héroïne au moment même où la quête est sur le point d'aboutir : " [...] mais ce qui est bien plus triste, c'est qu'elle a perdu sa beauté et qu'elle est devenue horriblement laide " (p. 223). Le personnage de Candide, tout comme le lecteur, est éprouvé par cette annonce. Voltaire joue là sur les stéréotypes pour mettre à distance les valeurs de l'amour, de la fidélité et surtout de la représentation des femmes, valorisées dans la littérature comme dans la vie pour leur image, leur apparence, leur beauté. La réaction de Candide, à n'en pas douter, est porteuse d'un discours axiologique : " Ah ! belle ou laide, dit Candide, je suis honnête homme, et mon devoir est de l'aimer toujours " (p. 223). Il s'étonne surtout de la condition de Cunégonde : "Mais comment peut-elle être réduite à un état si abject » (p. 223) - redevenue esclave malgré ses efforts pour la faire racheter. La laideur de Cunégonde n'est encore à ce stade qu'une information, qu'une idée abstraite. Les réactions de Candide évoluent avec les retrouvailles, lors desquelles ses bonnes intentions se heurtent à la réalité : "Le tendre amant Candide, en voyant sa belle Cunégonde rembrunie, les yeux éraillés, la gorge sèche, les joues ridées, les bras rouges et écaillés, recula trois pas saisi d'horreur, et avança ensuite par bon procédé » (p. 228). Le contraste entre l'idéal du héros amoureux et la dégradation physique de la dame est ici marqué par l'association d'une série d'adjectifs antagonistes : au couple «tendre » et «belle » sont désormais associés les adjectifs négatifs qui détaillent ses traits et son corps : "rembrunie ", «éraillés ", "sèche ", "ridées ", " rouges et écaillés " (p. 228), confirmant la "laideur », déclinée en plusieurs termes polyptotes " laide", " enlaidie ", assortis d'adverbes ou de locutions adverbiales modalisateurs ou intensifs - " horriblement laide", "si laide ", « tous les jours plus laide ", "à la vérité bien laide » ${ }^{30}$. À la dégradation physique correspond enfin une dégradation morale : l'héroïne déchue « devint acariâtre et insupportable» (p. 230). Les clichés sur les représentations féminines parcourent donc le conte. À l'idéalisation de la jeune beauté, objet de convoitise, répond la caricature finale, qui associe laideur et méchanceté.

${ }^{30}$ Chap. XXVII et sq. 
Objet, Cunégonde l'est assurément, de convoitise, de transaction ou de dégoût. Aux différents âges de la femme correspondent différents modes de relation, déclinant toutes les variantes du désir, de la capture, de la transaction, de la tractation, de la possession. Les premiers regards portés sur Cunégonde signalent l'intensité de la fascination : elle est aux yeux du héros « la perle des filles ", "le chef d'œuvre de la nature » (p. 158). Le capitaine bulgare lui aussi la trouve " fort jolie » (p. 161), le Grand Inquisiteur " la lorgna beaucoup » (p. 162) tandis que pour le gouverneur de Buenos Aires, "Cunégonde lui parut ce qu'il avait jamais vu de plus beau » (p. 173). À la surenchère des désirs, de la fureur d'aimer - le texte précise que le gouverneur « aimait les femmes à la fureur » (p. 173), expression à lire au sens littéral du terme ${ }^{31}-$, correspond la violence de la prise de possession. Rapt, captivité, esclavage, mariage même, sans qu'à aucun moment les protagonistes ne se posent la question du consentement de la dame - avec une exception, le gouverneur de Buenos Aires qui condescend à lui accorder « un quart d'heure pour se recueillir, pour consulter la vieille et pour se déterminer » (p. 174). Cette question manquante, c'est Voltaire qui la pose, par le récit qui met en scène la plainte et l'indignation face à ce traitement. À l'opposé de ce désir de possession brutale, égocentré, le personnage de Candide incarne une posture sentimentale, héritée du modèle chevaleresque. À l'inverse, Voltaire use de l'ironie pour désigner la relation que le Grand Inquisiteur entretient avec son esclave : "Il venait jouir de ses droits, et expliquer son tendre amour» (p. 163). La courtoisie de Candide se manifeste dès l'incipit. Déclarer ses sentiments lui semble même au-dessus de ses prérogatives, lui qui « ne pr[i]t jamais la hardiesse de le lui dire» (p. 146). L'absence décuple le désir, magnifié par le souvenir et le cycle des pertes et des retrouvailles. Voltaire joue sur les codes de la romance : l'amoureux éperdu, qui " rêve d'un amour exaltant et partagé " ${ }^{32}$, écrit le nom de sa belle sur les arbres (p. 192). Chevaleresque, il s'inscrit dans les pratiques de la tradition courtoise, avec ici un décalage ironique : "Candide n'eut plus d'autre désir et d'autre objet que d'aller présenter ses moutons à Mlle Cunégonde" (p. 191). L'archaïsme même de certaines tournures évoque les marotismes des premiers contes en vers voltairiens, comme Le Rosaire ${ }^{33}$, ou même de contes plus tardifs, comme Ce qui plaît aux dames. À Paris, Candide évoque son amour idéalisé sur le registre désuet de la fin'amor, sans comprendre qu'il a affaire à un escroc de la plus basse engeance : "car figurez-vous qu'ayant été chassé du château pour l'amour d'elle ...» (p. 207) explique-t-il très naïvement à l'abbé fripon. L'ironie repose sur une série de décalages entre galanterie éthérée et crapulerie

31 Nous soulignons.

32 J. van den Heuvel, op. cit., p. 276.

${ }_{33}$ N. Cronk, "Voltaire, le Rosaire : un conte en vers inédit », dans : Le Livre du monde et le monde des livres. Mélanges en l'honneur de François Moureau, sous la dir. de G. Ferreyrolles et L. Versini, Paris, PUPS, 2012, p. 1071-1082. 
triviale. Dans ce processus, Cunégonde demeure un objet de fantasme, de rêve. Dans les intertitres, elle est réifiée, conformément aux codes du discours galant: «[...] et comment il retrouva ce qu'il aimait» (p. 159). Au dénouement, Voltaire propose une variation plaisante de l'usage de cette désignation réifiante : "Les premiers objets qui se présentèrent furent Cunégonde et la vieille, qui étendaient des serviettes sur des ficelles pour les faire sécher » (p. 228). Parodiant le style des récits de navigation, Voltaire substitue Cunégonde à la terre idéale recherchée, objet de la découverte par le voyageur. Il ne s'agit plus ici d'utopie, l'aboutissement du voyage se fait de manière déceptive, mais l'effet n'en est que plus réaliste ${ }^{34}$.

Cunégonde est tour à tour objet de désir et de dégoût : prise et abandonnée par le capitaine bulgare, qui s'est dégoûté d'elle " au bout de trois mois " (p. 161), objet de partage établi sur une « convention » (p. 162) sordide entre deux hommes, Issacar et l'Inquisiteur, amante idéalisée et éperdument aimée devenue repoussante, Cunégonde est surtout objet de transactions. Dans le conte, les femmes se négocient contre argent sonnant et trébuchant. Le motif de la rançon structure la deuxième partie de la quête, à partir de l'épisode de Buenos Aires. Grâce aux diamants et aux millions de l'Eldorado, il ne s'agit plus que d'aller " prendre » (p. 193) et " reprendre » (p. 190) Mlle Cunégonde qu'il faudra marchander si nécessaire, «si [elle] peut être mise à prix» (p. 191) : "Si le gouverneur fait quelques difficultés, donne-lui un million; s'il ne se rend pas, donne-lui-en deux » (p. 193-194). C'est parce qu'il a payé sa rançon que Candide revendique son droit à l'épouser au dénouement. Objet de galanterie, elle est aussi victime, sommée de laver des chemises ou des écuelles, constamment agressée, fragilisée. Lors des retrouvailles à Lisbonne, la belle et fière baronnette westphalienne n'est plus qu'" une femme tremblante » (p. 159), qui vit dans la peur. Le texte en prend note, mais lorsqu'il s'agit d'exprimer la souffrance de la victime, la parole est laissée au personnage. Là réside peutêtre la dimension la plus touchante de ce réquisitoire.

Comme pour Candide, le romancier emploie le procédé de récapitulation narrative, qui donne au récit sa tournure mécanique. La répétition des malheurs, leur accumulation, leur rappel par addition sont autant de motifs d'interroger l'expérience et le scandale que constituent tant «d'épouvantables calamités enchaînées les unes aux autres » (p. 223). Cunégonde fait elle-même le récit de son périple :

Agitée, éperdue, tantôt hors de moi-même, et tantôt prête de mourir de faiblesse, j'avais la tête remplie du massacre de mon père, de ma mère, de mon frère, de l'insolence de mon vilain soldat bulgare, du coup de couteau qu'il me donna, de ma servitude, de mon métier de cuisinière, de mon capitaine bulgare, de mon

\footnotetext{
${ }^{34}$ Je remercie I. Zatorska pour cette remarque.
} 
vilain don Issacar, de mon abominable inquisiteur, de la pendaison du docteur Pangloss, de ce grand miserere en faux-bourdon pendant lequel on vous fessait, et surtout du baiser que je vous avais donné derrière un paravent, le jour que je vous avais vu pour la dernière fois. (p. 163)

Il faut écouter la souffrance qui s'exprime dans ces relations des aventures viatiques de Cunégonde. À travers la fiction, se dessine une sensibilité, une attention aux réactions du corps et aux émotions. Influencé par la vogue du roman-mémoire, Voltaire donne la parole aux personnages féminins qui prennent elles-mêmes en charge le récit de leur périple. Cunégonde, comme la vieille et Pâquette forment un trio de figures de femmes voyageuses qui, chacune son tour, livrent un témoignage cru sur les réalités sociales de leur expérience, et plus encore sur l'intensité des souffrances endurées. L'accumulation des indications décrivant les sentiments de Cunégonde est rarement commentée : dans son récit, elle insiste sur la succession des réactions émotionnelles violentes et contrastées, entre révolte, indignation et abattement. Les évanouissements, les larmes, les cris s'accompagnent de séries de notations décrivant le trouble, le traumatisme :

Je fus, à la vérité, saisie d'horreur en voyant brûler [...] mais quelle fut ma surprise, mon effroi, mon trouble [...] je tombai en faiblesse. À peine reprenais-je mes sens $[\ldots]$ ce fut là le comble de l'horreur, de la consternation, de la douleur, du désespoir. [...] Cette vue redoubla tous les sentiments qui m’accablaient, qui me dévoraient... (p. 162)

[...] j’ai encore l'âme tout effarouchée de ce que j’ai vu, de ce que j’ai éprouvé. [...] j’ai été si horriblement malheureuse [...] que mon cœur est presque fermé à l'espérance. (p. 166)

Mais Cunégonde n'est pas réduite à une figure, à un objet, ni même à un corps souffrant. Réifiée par les personnages qui abusent d'elle, qui l'insultent ou l'idéalisent, c'est in fine un personnage bien vivant. Voltaire insère dans son récit des indications inattendues, qui traduisent la vitalité du protagoniste, et l'optimisme du conte. Alors même que Candide et elle viennent de passer plusieurs heures à évoquer leurs malheurs en pleurant, Cunégonde résume : « [...] j'ai goûté le plaisir inexprimable de vous revoir, de vous entendre, de vous parler » (p. 163). Mais les besoins du corps reprennent le dessus : "Vous devez avoir une faim dévorante, j'ai grand appétit ; commençons par souper» (p. 163). Confrontée au désir des hommes, elle exprime les siens sans pudeur, confessant à propos de son bourreau bulgare : " [...] et je ne nierai pas qu'il ne fût très bien fait, et qu'il n'eût la peau blanche et douce » (p. 161), aveu qu'elle adresse un peu plus tard à Candide : "Je vous dirai, avec vérité, que votre peau est encore plus blanche et d'un incarnat plus parfait que celle 
de mon capitaine des Bulgares » (p. 162). Tout cela participe de la distanciation constitutive du traitement comique de ce récit de voyage et d'aventures ${ }^{35}$. La capacité de résistance de l'héroïne est affirmée, elle se défend physiquement lors de sa première agression : " [...] je criai, je me débattis, je mordis, j'égratignai, je voulais arracher les yeux à ce grand Bulgare, ne sachant pas que tout ce qui arrivait dans le château de mon père était une chose d'usage : le brutal me donna un coup de couteau dans le flanc gauche dont je porte encore la marque » (p. 161). Dans la description des réactions du personnage, le texte voltairien ne manque pas de porter un discours sur les événements, comme cela a souvent été relevé. Voltaire dénonce donc la culture de la guerre, dans ses manifestations de violence les plus révoltantes à l'égard des civils, qui a fait du viol, notamment, une pratique banale. L'ironie grinçante du conte réside dans la prise en charge, par l'héroïne elle-même, de ce discours décalé sur les sévices dont elle a été l'objet. La puissance suggestive de son discours tient dans sa capacité à surmonter les épreuves. Ses aventures l'ont rendue plus forte moralement, comme elle l'explique à Candide : «Une personne d'honneur peut être violée une fois, mais sa vertu s'en affermit » (p. 161). S’agit-il ici de réalisme, d'idéalisation, d'héroïsation de l'expérience ? Ou bien a-t-on affaire à un discours ironique? Difficile de démêler ici les intentions d'une telle association entre traumatisme et apprentissage moral.

Quel bilan tirer de cette lecture de Candide? Plus qu'une voyageuse, Cunégonde est une figure de femme ballotée au gré des désirs et des captures. L'émotion de Candide, sensible à son sort, exprime bien la difficulté de la condition passive de la jeune femme : "Cunégonde amenée de si loin, que deviendrez-vous ?» (p. 175). La réponse de Cacambo est significative, traduisant certaines des représentations attachées à la condition de femme : «Elle deviendra ce qu'elle pourra [...] ; les femmes ne sont jamais embarrassées d'elles; Dieu y pourvoit » (p. 175). Faut-il lire ici l'expression d'une indifférence, ou bien d'un fatalisme? La réponse de Voltaire est ailleurs. Au dénouement, il propose au lecteur une figure de femme affermie par ses déboires, qui revendique ses droits : l'héroïne " fit souvenir Candide de ses promesses avec un ton si absolu que le bon Candide n'osa pas la refuser» (p. 229). Et, un peu plus loin : "Cunégonde le pressait si vivement qu'il ne pouvait s'en dédire " (p. 229). Le voyage, apprentissage de la vie et découverte de sa force intérieure, a forgé le caractère de Cunégonde, sa capacité de résistance et de résilience, la conscience de ses droits, sa détermination. Candide est autant un récit d'apprentissage au masculin qu'au féminin, quoique la critique ait rarement analysé la dimension féminine de ce schéma narratif ${ }^{36}$. L'innocence de l'héroïne

35 O. Ferret, op. cit., p. 77-78.

36 Voir par exemple les analyses de J. van den Heuvel, op. cit., p. 289 et sq. Il faut cependant 
fait d'elle une autre candide face à la violence de la société, des institutions et des hommes. Ingénue, elle acquiert une expérience à corps défendant, se construisant grâce à une résistance intérieure, tout en tentant de profiter des rares plaisirs que le hasard de ses captivités lui autorise. Son apprentissage est plus rapide que celui de Candide. Émotive et sensible, elle traverse les épreuves avec dignité. Par son intelligence, sa lucidité et sa philosophie, elle comprend rapidement l'imposture des discours optimistes de son précepteur, et incarne, plus encore que Candide, les valeurs pragmatiques dont le conte voltairien fait la promotion dans l'allégorie finale du jardin : « tombée dans la roture $»^{37}$, ayant renoncé à ses prétentions aristocratiques, Cunégonde devient « excellente pâtissière » (p. 233), contribuant ainsi à l'effort collectif pour permettre à chacun des individus de cette communauté de trouver une forme de bonheur. Dans cette fable, la morale finale est peut-être qu'il faut apprendre à vivre avec son temps et cultiver les plaisirs qui nous sont encore accessibles. C'est ce qu'apprennent à faire Cunégonde et Candide, enfin réunis comme ont pu l'être Voltaire et sa nièce Marie-Louise Denis, couple qui constitue peut-être, on ne s'en étonnera finalement pas, le modèle du couple fictionnel mis en scène dans le dénouement du conte. L'aboutissement du voyage des personnages voltairiens illustre, une fois encore, en-dehors de toute perspective genrée cette fois, la morale hédoniste du poète, énoncée à la fin du Mondain dès 1736 : «Le paradis terrestre est où je suis $»^{38}$.

mentionner la récente contribution d'O. Ferret, op. cit.

37 Lexpression est de Pierre Cambou, op. cit., p. 313.

38 Voltaire, Le Mondain, éd. H. T. Mason, dans : OCV, Writings of 1736, t. 16, 2003, p. 303. 


\section{Troisième partie}

Voyageur qui se (re)met en cause 
Odile Richard-Pauchet

Université de Limoges

ORCID 0000-0001-5373-9405

\section{Diderot promeneur solitaire à Bourbonne et à Langres (1770)}

\section{Diderot, a Lonely Walker in Bourbonne and Langres (1770)}

Diderot's Travels in Bourbonne and Langres, two small towns in his childhood's countryside in the East of France, tell us about different matters he had to deal with in the summer of 1770: marry his daughter Angelique to a gentleman from Langres, make friends again with his brother, run a love affair in Bourbonne, a famous spa town. Unfortunately, nothing happens as he has expected. Despite his efforts to write a scientific report from these two places, the encyclopedist fails to conceal his sorrow and lets his mood appear, in a near-Rousseauistic manner of writing.

Keywords: Diderot, travelogue, epistolary, encyclopedia, walk, hydrotherapy

Mots-clés : Diderot, récit de voyage, épistolaire, encyclopédie, promenade, thermalisme

Si Diderot accepte de rédiger une brève relation de son court voyage à Langres et Bourbonne (du 2 août au 26 septembre 1770), à l'intention de son ami Grimm et de sa Correspondance littéraire, il a pourtant cet été-là mille tâches à accomplir. Son temps étant terriblement compté, il est parvenu à grouper quelques affaires essentielles afin d'optimiser son séjour en terre natale. Le philosophe doit bientôt marier sa fille unique Angélique. Ayant en vue un gendre idéal issu de Langres, sa ville d'origine, dont il connait la famille de longue date, les Caroillon, il doit y rencontrer ces gens de bien et ramener à Paris son futur gendre. Il lui faut aussi se réconcilier avec son frère chanoine, afin que celui-ci bénisse cette union. 
Pour joindre l'utile à l'agréable, il rejoindra enfin aux eaux de Bourbonne deux belles amies, Mme de Maux et Mme de Prunevaux, la mère et la fille - mère sur laquelle il a des prétentions galantes.

Or ses précédents voyages à Langres (pour lors, seuls déplacements dans sa vie) se sont souvent soldés par des échecs, eu égard aux relations délicates qu'il a toujours entretenues avec son père depuis sa jeunesse et sa "fuite " définitive à Paris. En 1742 : il échoue à faire accepter à son père son mariage avec une jeune Parisienne pauvre, Anne-Toinette Champion. En 1754 : il revient pour affaires sans sa femme chargée de la petite Angélique, un an ${ }^{1}$. En 1759: il arrive trop tard pour assister à la mort de son vieux père, malade déjà depuis de nombreuses semaines ${ }^{2}$.

En 1770 : rien ne se passe, là encore, comme espéré. La réconciliation avec l'abbé Didier Diderot ne se fait pas; Mme de Maux, à Bourbonne, se laisse tenter par un jeune M. de Foissy, écuyer du duc de Chartres. La petite ville de Bourbonne est morne et funèbre : à chaque pas elle rappelle au philosophe le lieu d'où son père, venu se soigner pour la seconde fois, s'en retourna pour décéder peu de temps après. Ce voyage lui inspire donc un profond malaise, lié, à tort ou à raison, à une série de fautes, d'échecs ou de manquements. Le philosophe finira par quitter la région avec Caroillon le 24 septembre, faisant seulement halte, sur la route de Paris, et peu fier, chez son amie de toujours Sophie Volland, en villégiature dans son château d'Isle sur Marne.

On imagine aisément combien lui pèsera, de retour à Paris, d'honorer la promesse faite naguère à Grimm, de la rédaction de ce voyage. Certes, il a pris quelques notes, mais ne semble pas pressé de compléter ce double texte curieusement intitulé Voyage à Bourbonne et à Langres (et non pas l'inverse, selon la chronologie du voyage). Ce bref écrit de quelques dizaines de pages ne sera d'ailleurs pas publié. Aurait-il déplu à Grimm, à Diderot lui-même ? Celui-ci en tirera pourtant plusieurs copies (dites du Fonds Vandeul et de SaintPétersbourg). Ce texte présente donc une énigme que nous tâcherons d'élucider en nous penchant sur sa forme, celle d'un article de l'Encyclopédie, mais aussi sa teneur et sa couleur, celles d'un hommage au père et d'un autoportrait mélancolique, enfin d'un manifeste contre les récits de voyages, celui-ci s'opposant en tout point à la tradition heureuse des récits viatiques ${ }^{3}$.

1 A. M. Wilson, Diderot, sa vie et son ceuvre, trad. de l'ang. G. Chahine, A. Lorenceau et A. Villelaur, Paris, Laffont-Ramsay, 1985, p. 157, 183.

2 B. Decron, "Diderot et Langres ", dans : Les Visages de Denis Diderot, sous la dir. de J.-Y. Pouilloux et B. Decron, Paris, Paris-Langres, 1994, p. 70.

3 Voir D. Roche, Humeurs vagabondes. De la circulation des hommes et de l'utilité des voyages, Paris, Fayard, 2003, p. 150-151 ; Littérature et voyages de santé, sous la dir. de Ch. de Buzon et O. Richard-Pauchet, Paris, Classiques Garnier, 2017, et aussi « Lettres d'Italie, voyage de rêve, rêve de voyage ", sous la dir. de G. Haroche et B. Obitz-Lumbroso, Épistolaire, n 41, 2015, ainsi que nos études «Lettres d'Italie du Président de Brosses, le paradoxe d'une "esthétique 
Le philosophe n'a pas manqué, dans des œuvres antérieures, de marquer sa prévention, voire sa réprobation à l'égard des récits de voyage, textes qu'il considère comme oiseux voire mensongers au même titre, paradoxalement, que les romans, car ils produisent tous d'effroyables bâillements chez le sultan Mangogul, héros des Bijoux indiscrets (1748) : «Pourrait-on vous demander, beau conteur, quand vous espérez être de retour à Banza, si j'ai longtemps encore à dormir ? Car il est bon, l'ami, que vous sachiez qu'il n'est pas possible d'entamer en ma présence un voyage, que les bâillements ne me prennent. C'est une mauvaise habitude que j'ai contractée en lisant Tavernier et les autres. $»^{4}$

Cette parenté du récit de voyage avec l'ouvrage romanesque pris en mauvaise part, indique assez le vice qui rebute le philosophe chez les uns et les autres écrits : leur caractère futile et divertissant, séducteur et malhonnête, infidèle et anti-scientifique ${ }^{5}$. Aussi prend-il grand soin, dans l'incipit de son propre récit de voyage dans la petite ville d'eaux, de justifier d'emblée son utilité morale et médicale : "Quand on est dans un pays, encore faut-il s'instruire un peu de ce qui s'y passe ». Il y insiste un peu plus loin, s'adressant cette fois aux deux dames qu'il a rejointes : "Épargnons à mes amies le reproche déplacé d'avoir occupé tous mes moments, et préparons à quelque malheureux que ses infirmités conduiront à Bourbonne une page qui puisse lui être utile $»^{6}$. On trouve une mention identique dans une lettre adressée à Sophie Volland au cours de ce voyage $^{7}$, justifiant cette fois non seulement l'écrit mais le séjour lui-même, anticipant d'éventuels reproches pleins de jalousie. Cette revendication morale, chez l'auteur du Voyage, n'est-elle d'ailleurs pas un peu trop affichée ? « [...] tandis qu'une mère tendre s'occupait de la santé de son enfant, le Philosophe

de la familiarité" ", publiée dans ce volume (p. 13-24) et "Diderot : Voyage à Bourbonne et à Langres : une cartographie de l'âme", dans: le corps et l'esprit en voyage: le voyage thérapeutique, sous la dir. de Ch. de Buzon et O. Richard-Pauchet, Paris, Classiques Garnier, 2012, p. 183-199.

4 D. Diderot, Contes, dans : Euvres, éd. L. Versini, t. 2, Paris, Laffont, 1994, p. 158. Tavernier est bien sûr le marchand et voyageur français, auteur des Six Voyages de J.-B. Tavernier en Turquie, en Perse et aux Indes (1676, nombreuses rééditions), source essentielle des Lettres persanes de Montesquieu.

5 Voir E. Kovacs, La Critique du voyage dans la pensée de Diderot. De la fiction au discours philosophique et politique, Paris, Champion, 2015, ainsi que l'article Voyageur dû à Jaucourt : «Il y a bien peu de relations auxquelles on ne puisse appliquer ce que Strabon disait de Ménélas : je vois bien que tout homme qui décrit ses voyages est un menteur " (Encyclopédie ou dictionnaire raisonné des sciences, des arts et des métiers, vol. XVII, 1765, p. 477, http://enccre.academiesciences.fr/encyclopedie/page/v17-p487/, consulté le 12/12/2020). Voir aussi, pour la critique des romans chez Diderot, l'incipit de son Éloge de Richardson.

6 D. Diderot, Voyage à Bourbonne et à Langres et autres récits, éd. A.-M. Chouillet et O. Richard-Pauchet, Langres, Guéniot, 2013, p. 21. Désormais abrégé VBL.

7 « J'ai passé là une partie de mon temps à m'instruire; des eaux, de leur nature, de leur ancienneté, de leur effet, de la manière d'en user, des antiquités du lieu, et j’en ai fait une lettre à l'usage des malheureux que leurs infirmités pourraient y conduire » (lettre à Sophie Volland du 23 août 1770, reproduite dans $V B L$, p. 96-97). 
allait s'informant de tout ce qui pouvait mériter sa curiosité $»^{8}$ ? Elle exprime non seulement l'obsession de l'utilité scientifique devenue déformation professionnelle, mais aussi la hantise de l'ennui qui en est le corollaire, et que l'on retrouve sous une forme burlesque chez le sultan Mangogul.

Le Voyage à Bourbonne ainsi que le Voyage à Langres qui le suit, selon Anne-Marie Chouillet qui a en été la première éditrice scientifique ${ }^{9}$, seraient il est vrai destinés à alimenter la Correspondance littéraire. Mais dans leur forme, ils se rapprocheraient davantage d'un article de l'Encyclopédie, d'où leur " utilité » scientifique brandie en tête du double texte ${ }^{10}$. En effet l'écriture factuelle, paratactique des deux récits se rapproche assez, en dehors de cet incipit à la tonalité intimiste où l'auteur se met en scène auprès de ses proches, de la rédaction encyclopédique, fréquemment composée de remarques techniques juxtaposées. C'est encore plus vrai du Voyage à Langres, fortement inspiré de l'Article LANGRES - qui ne serait pourtant pas dû, selon les connaissances actuelles, à Diderot lui-même ${ }^{11}$. Le Voyage à Bourbonne ambitionne de réactualiser un savoir thermal relativement ancien ${ }^{12}$, et s'abreuve à des sources tant canoniques que récentes. Il s'inspire notamment des travaux de collaborateurs de l'Encyclopédie comme l'astronome La Condamine (17011774) ou le chimiste Gabriel Venel (1723-1775), mais aussi des rencontres médicales de Diderot lui-même, avec le docteur Roux (1726-1776), rédacteur du Journal de Médecine, ou le docteur Juvet (1714-1789), directeur de l'Hôpital royal et militaire de Bourbonne, qui avait soigné son père avant sa mort. Il cite des sommités de la médecine de son temps, tel le médecin londonien Richard Mead (1673-1754), père de l'épidémiologie. Mais il utilise aussi les toutes dernières publications du moment, comme celle de Chevalier (17301803), chirurgien sous les ordres du docteur Juvet à l'Hôpital de Bourbonne, et auteur du Mémoire et Observations sur les effets des Eaux de Bourbonne publié dans le Journal du Docteur Roux en 1770 ; ou encore celle du chimiste et

8 VBL, p. 21.

9 D. Diderot, Voyage à Bourbonne, à Langres, et autres récits, éd. A.-M. Chouillet, Paris, Klincksieck/Aux Amateurs de Livres, 1989. Ces voyages ont été publiés pour la première fois en 1831 avec des notes de Walferdin dans les Mémoires, correspondance et ouvrages inédits de Diderot, Paris, Paulin, 4 vol.

10 A.-M. Chouillet, Dictionnaire de Diderot, sous la dir. de R. Mortier et R. Trousson, entrée "Voyages à Bourbonne et à Langres", Paris, Champion, 1999, p. 531. Eszter Kovacs parle quant à elle d'une « digression philosophique, op. cit., p. 103.

11 Voir http://enccre.academie-sciences.fr/encyclopedie/article/v9-862-0/, vol. IX, 1765, p. 244-245, consulté le 12/12/2020.

12 Voir Jean le Bon, médecin du cardinal de Guise, Des Bains de Bourbonne-les-Bains, à Lyon, chez Benoist Rigaud, 1590, p. 16 ; réédité par le Dr Émile Bougard dans sa Bibliotheca borvoniensis. Essai de bibliographie et d'histoire contenant la reproduction de plaquettes rares et curieuses et le catalogue raisonné des ouvrages et mémoires relatifs à l'histoire de Bourbonne et de ses thermes, Lhuillier / Aubry, Chaumont et Paris, 1866, 728 p. 
minéralogiste Antoine-Grimoald Monnet (1734-1817) auteur d'un tout récent Traité des Eaux minérales (1768). N'oublions pas que Diderot fut lui-même traducteur du Dictionnaire de médecine de James (1743-1745, avec Eidous et Toussaint), où il a pu se familiariser avec des concepts savants comme la « panacée mercurielle $»^{13}$. Enfin, il a fréquenté au quotidien les plus grands médecins parisiens (Petit, Bordeu) ou Genevois (Tronchin), fréquentations dont ses écrits tant philosophiques que romanesques ou épistolaires portent la trace, comme le célèbre triptyque bâti autour du Rêve de d'Alembert (1769). François Pépin a montré comment, en 1770, fort de ses connaissances récentes, Diderot donne une idée assez juste de la physique, de la chimie et de l'usage médical des eaux thermales de Bourbonne. Il n'est d'ailleurs pas dupe d'une forme de charlatanerie universelle ${ }^{14}$ ainsi que de la dimension psychologique de l'efficacité du traitement ${ }^{15}$, tout en s'exprimant parfois d'une manière poétique inattendue dans un tel traité de thermalisme, comme on le verra plus bas.

La composition du bref Voyage à Bourbonne donne à la lecture une impression assez erratique, mimant davantage les pas du promeneur désœuvré que ceux du curiste consciencieux. Elle s'avère toutefois assez exhaustive dans l'exposé des données indispensables à la compréhension du fonctionnement particulier de cette petite cité thermale très renommée dans les pays du nord, et de l'usage thérapeutique des eaux en général. Depuis le "puits qui fume sans cesse ", où l'on se fait servir à heures fixes son gobelet, jusqu'aux différents lieux de bains, en plein air ou chez soi dans des " cuves de bois ou baignoires ordinaires", le curiste amateur nous promène tout au long des sites emblématiques de la bourgade : le «bain Patrice » destiné autrefois aux personnes de qualité, et où se retrouvent aujourd'hui les paysans le samedi, alimenté directement par une source; l'hôpital lui-même où se prennent les « douges" (ou douches). Le récit énumère les innombrables affections pour lesquelles ces eaux sont indiquées, leur posologie, leur prise, en douche, en bain, en boisson, debout ou couché, la durée de la douche et la hauteur du jet, le conditionnement de l'eau à la vente en bouteilles, leur prix, etc., aucun détail pratique n'étant oublié. Sur le mode de l'énumération technique se poursuit l'inventaire des personnalités rencontrées, de quelques curiosités locales, des modestes revenus du lieu et de ses sites remarquables, inventaire mené tambour battant, et ponctué de rares moments lyriques lorsqu'il est question de s'interroger sur l'origine de ces sources chaudes, remontées des profondeurs de la Terre :

13 VBL, p. 28.

14 Voir l'anecdote du docteur Mead, après lequel un patient court d'un bout à l'autre de l'Europe, et se trouve guéri à l'issue de ce parfait voyage initiatique (VBL, p. 26-27).

15 F. Pépin, "Diderot dans l'univers des chimistes », dans : VBL, p. 217-237, ainsi que "Le Voyage à Bourbonne de Diderot, un voyage thérapeutique », dans Littérature et voyages de santé, op. cit., p. 283-295. 
Combien de vicissitudes dans l'espace immense qui s'étend au-dessus de nos têtes ? Combien d'autres dans les entrailles profondes de la terre ? Une rivière nécessaire au mouvement des moulins à sucre, à l'arrosement des terres plantées de cannes et à la subsistance des habitants, vient de disparaître à la Martinique, dans un tremblement de terre et de rendre une contrée à l'état sauvage. Les mers et la population marchent. Un jour il y aura des baleines où croissent nos moissons, des déserts où la race humaine fourmille. Les volcans semblent communiquer de l'un à l'autre pôle. Lorsque l'un mugit en Islande, un autre se tait en Sicile ou parle dans les Cordillères. ${ }^{16}$

Même ces élans poétiques sont toutefois motivés par des intuitions scientifiques puissantes, comme l'existence des couches de l'écorce terrestre et ou de la tectonique de plaques; et l'encyclopédiste semble vouloir mener de bout en bout une enquête supérieure en exigence aux traditionnels récits de voyage enjolivés, voire factices.

Dans le Voyage à Langres, une même préoccupation scientifique fait progresser le narrateur de remarque en remarque, depuis l'histoire antique et moderne de la ville, jusqu'à une description spatiale incluant les vestiges et édifices remarquables, les forces et les faiblesses économiques, enfin une forme de géographie humaine évoquant la situation éducative, politique et sanitaire de la cité. Ce panorama relativement cohérent, et moins haché que celui du Voyage à Bourbonne par des commentaires sentimentaux que l'on évoquera plus loin, recèle en contrepartie une plus grande sécheresse, faisant ainsi l'économie du récit légendaire de la ville, dont l'article LANGRES faisait le cœur de son récit. La belle histoire d'Éponine et Sabinus, devenue emblématique de l'esprit de résistance de la ville, n'est en effet évoquée qu'en passant dans les premières lignes du Voyage à Langres : "Tout le monde sait [que Langres] est située sur une haute montagne, qu'elle est très ancienne, que ce fut la patrie de Sabinus, et que César fait mention du courage ferme de ses habitants. ${ }^{17}$ Faut-il penser qu'implicitement, le narrateur condamne le récit pour son caractère romanesque et renvoie le lecteur à l'article comme à une compilation désormais connue (« Tout

${ }^{16} V B L$, p. 39. Il se peut que, pour ce passage, Diderot ait été influencé par le contenu mais aussi par le style particulièrement lyrique et grandiloquent du baron d'Holbach, qui a rédigé pour l'Encyclopédie les articles d'Histoire naturelle et de Minéralogie : Volcans et TREMblements DE TERRE.

$17 V B L$, p. 47. Julius Sabinus (mort en 78 ap. J.-C.) est un gentilhomme gallo-romain appartenant au peuple lingon installé entre Langres et Dijon. Devenu sous Vespasien « héros de la résistance » locale contre les Séquanes restés fidèles à Rome, il reste caché dix ans, selon la légende, dans une grotte abritant la source de la Marne, où vient le visiter secrètement sa femme Éponine. Ils seront tous deux suppliciés par l’empereur ( $c f$. article LANGREs, Encyclopédie, op. cit. ; et Éponine et Sabinus, sous la dir. de D. Guéniot, Musée d'art et d'histoire de Langres, Langres, Guéniot, 2011). 
le monde sait ») ? En effet, entre une évocation assez circonstanciée de la Langres ancienne et ses vestiges, et celle de la Langres moderne et ses " gens de lettres célèbres » (dont Diderot lui-même est absent ${ }^{18}$ !), l'article insérait cette anecdote dont la réalité reste sujette à caution : « Julius ${ }^{19}$ Sabinus, si connu par sa révolte contre Vespasien, \& plus encore par la beauté, le courage, la tendresse, la fidélité \& l'amour conjugal de sa femme Epponina, était natif de Langres [...] $»^{20}$.

D’autres mentions non moins acides, dans le Voyage à Langres, critiquent les habitants de la ville eux-mêmes pour leur inculture et leur manque de considération envers leur propre histoire, ce qui dénote là encore, chez Diderot, une attitude de savant intransigeant :

Si les officiers municipaux [n'avaient pas été des imbéciles, et qu'ils ${ }^{21}$ ] eussent rassemblé à l'hôtel de ville les statues, les bustes, les médailles, les bas-reliefs, les inscriptions qu'on a trouvés en différents temps, ils formeraient une galerie très précieuse. / Les particuliers se sont emparés de ces antiquités, et il n'en reste pas une seule dans la ville. ${ }^{22}$

Les habitants de Langres ont de l'esprit, de l'éducation, de la gaieté, de la vivacité et le parler traînant. / Ils ont des livres, ils lisent et ne produisent rien. ${ }^{23}$

Ces commentaires forment une critique sans appel de la médiocrité langroise, mais manifestent aussi un certain complexe de supériorité du rédacteur du Voyage, homme de lettres se félicitant d'être devenu Parisien. Quant au rédacteur de l'article encyclopédique, il a été montré qu'il utilisait peu les ressources locales, réfutées pour leur insuffisance ${ }^{24}$. Si l'on considère que Diderot

18 «Langres moderne a produit plusieurs gens de lettres célèbres, \& tous heureusement ne sont pas morts ; mais je n'en nommerai qu'un seul du siècle passé, M. Barbier d'Aucourt, parce que c'est un des meilleurs sujets que l'Académie française ait jamais eu. » (article LANGREs, op. cit.).

19 Selon Robert Bedon, "Sabinus se nommait lui aussi Iulius, et prétendait que ce nom venait du fait que sa bisaïeule aurait eu des bontés pour César : Tacite, Histoires, IV, 55, 3-5 ", voir R. Bedon, «Diderot et l'article "Langres" de l'Encyclopédie ", Diderot et l'Antiquité classique, sous la dir. d'A. Lehmann, Paris, Classiques Garnier, 2018, p. 19-46.

20 Article Langres, op. cit.

${ }_{21}$ Ce passage a été barré dans la copie de Leningrad et ne figure pas dans les autres versions.

22 VBL, p. 47. Voir ce commentaire d'une moindre sévérité, dans l'article LANGRES : « Mais comme le sort de la plupart de ces morceaux antiques est d'être enlevés de leur pays natal, s'il est permis de se servir de ce terme, pour aller grossir le recueil qu'en font les curieux étrangers, les magistrats de la ville de Langres se sont depuis longtemps précautionnés contre ces pertes [...]». Ibid.

${ }^{23} V B L$, p. 51.

${ }^{24}$ Voir par exemple ce commentaire, dans l'article LANGres : « Gruter, Reynesius, le P. Vignier jésuite, \& Gautherot dans son histoire de la ville de Langres, qu'il a intitulé, l' "Anastase de Langres, tirée du tombeau de son antiquité ", ont, à la vérité, rassemblé plusieurs inscriptions de cette 
a puisé lui-même dans l'article pour nourrir son Voyage, ce que confirment un certain nombre de mentions identiques ou proches ${ }^{25}$, on est frappé par la prise de distance et la faible implication locale de Diderot pour nourrir son enquête ou pour le rafraîchissement de ses informations, contrairement à ce qu'il avait consenti pour la description de Bourbonne. Soit, en savant accompli, il s'est tenu aux seules sources fiables, sachant parfaitement où se documenter de retour dans son cabinet; soit Langres a paru trop familière au voyageur, ne nécessitant pas d'investigations approfondies, ou bien de moindre intérêt au renégat qu'il est resté. Surtout le Langrois, logé dans sa famille et pressé par ses affaires, n'a pas pris le temps de se replonger dans les vieilles rues familières, excepté une visite émue à la promenade de Blanchefontaine. Aussi le second Voyage ne comporte-t-il pas toute la dimension pittoresque et le dépaysement présents dans le premier. Autant Diderot à Bourbonne se montre bien un voyageur, un visiteur, un flâneur désœuvré et curieux, autant à Langres il n'est que l'enfant du pays, de retour pour ses obligations. Par ailleurs, on verra que même le bref voyage thermal n'est pas exempt de commentaires chagrins ni de mesquineries indiquant un homme mal à son aise, insatisfait, en proie à une véritable mélancolie et une authentique nostalgie.

Il faut dire que cette mélancolie sous-jacente au voyage, la crainte de son inutilité, de sa vanité ou de sa médiocrité est sans doute inhérente à la conception exigeante du déplacement géographique chez Diderot : seule prime en lui le projet d'un voyage idéalisé, toujours différé, mort-né à cause de ses attentes mêmes. Le voyage des voyages, celui en Italie, consubstantiel au Grand Tour entrepris par les hommes de qualité26, reste à l'état de rêve en tête du Salon

ville, mais ils ne les ont pas toujours lues ni rapportées avec exactitude ; \& pour Gautherot en particulier, ses recherches sont aussi mal digérées que peu judicieuses. » R. Bedon, qui a inventorié les sources de l'article LANGREs en ce qui concerne les vestiges antiques, désigne l'Histoire de l'Académie Royale des Inscriptions et Belles Lettres depuis son établissement jusqu'à maintenant, I, 1717, pour l' "Explication de quelques inscriptions singulières, trouvées à Langres pendant les deux derniers siècles »; VI, 1729, p. 670-679, pour l'histoire de Sabinus mais aussi III, 1746, p. 206-210, pour les « Conjectures sur l'usage d'un instrument antique d'airain, trouvé près de Langres ». Louvrage d'A.-A. Bruzen de La Martinière, Grand Dictionnaire Géographique et Critique, V, 1, La Haye, Amsterdam, Rotterdam, 1735, de la Bibliothèque Royale, a été aussi une source importante de l'article. R. Bedon prêche d'ailleurs pour son attribution à Diderot luimême, sans pour autant emporter l'adhésion des spécialistes.

${ }_{25}$ Par exemple, en ce qui concerne la situation géographique de la ville : Article : "Elle est située sur une haute montagne, près de la Marne, aux confins des deux Bourgognes [...]. » Voyage : "Tout le monde sait qu'elle est située sur une haute montagne, qu'elle est très ancienne $[\ldots] », V B L$, p. 47.

26 Voir J. Boutier, «Le grand tour : une pratique d'éducation des noblesses européennes (XVI ${ }^{\text {-XVIII }}$ e siècles) ", Le voyage à l'époque moderne, $\mathrm{n}^{\circ}$ 27, 2004, p. 7-21, et surtout G. Bertrand, Le Grand Tour revisité. Pour une archéologie du tourisme : le voyage des Français en Italie, milieu XVIII ${ }^{e}$ siècle-début XIXe siècle, École française de Rome, 2008. 
de 1767 (position textuelle à laquelle fera sans doute écho l'incipit du Voyage à Bourbonne dont l'auteur désigne ostensiblement l'utilité morale) :

Pour ce voyage d'Italie si souvent projeté, il ne se fera jamais. Jamais, mon ami ${ }^{27}$, nous ne nous embrasserons dans cette demeure antique, silencieuse et sacrée, où les hommes sont venus tant de fois accuser leurs erreurs ou exposer leurs besoins, sous ce Panthéon, sous ces voûtes obscures où nos âmes devaient s'ouvrir sans réserve, et verser toutes ces pensées retenues, tous ces sentiments secrets, toutes ces actions dérobées, tous ces plaisirs cachés, toutes ces peines dévorées, tous ces mystères de notre vie dont l'honnêteté scrupuleuse interdit la confidence à l'amitié même la plus intime et la moins réservée. ${ }^{28}$

Le voyage rêvé, on le voit, n'est pas seulement un voyage d'étude dont le voyageur reviendrait plus savant qu'il n'est parti, mais aussi, peu éloigné de la tradition de l'époque, une expérience de connaissance de soi via la fréquentation intime d'un alter ego, expérience réservée en principe à de beaucoup plus jeunes que ces deux quinquagénaires, quoiqu'hommes de qualité. À cette expérience sensorielle, sociale, sexuelle à laquelle renvoie classiquement le voyage, s'ajoute donc chez Diderot cette exigence d'intimité et d'épanchement qu'il a si souvent recherchée dans sa vie, et partiellement trouvée dans la correspondance avec sa maîtresse, Sophie Volland ${ }^{29}$. Au sein de leur correspondance, on trouve d'ailleurs une remarque proche de celle faite à Grimm ci-dessus, chargée de définir une relation épistolaire faite de confidences :

Comment, ai-je dit, un astronome passe trente ans de sa vie, au haut d'un observatoire, l'œil appliqué le jour et la nuit à l'extrémité d'un télescope pour déterminer le mouvement d'un astre ; et personne ne s'étudiera soi-même, n’aura le courage de nous tenir un registre exact de toutes les pensées de son esprit, de tous les mouvements de son cœur, de toutes ses peines, de tous ses plaisirs [...]. ${ }^{30}$

De ce point de vue, le nouveau voyage effectué en compagnie de Grimm en terre natale, à l'été 1770 , a dû engendrer bien des espoirs auprès du philosophe, celui-ci y trouvant enfin l'occasion de se confier tant à l'ami de toujours qu'à

27 Il s'agit de F.M. Grimm, le destinataire de la critique des Salons.

28 D. Diderot, Salon de 1767, dans : Euvres, op. cit. t. 4, 1996, p. 518.

29 Voir parmi nos propres travaux, Diderot dans les Lettres à Sophie Volland. Une Esthétique épistolaire, Paris, Champion, 2007, ainsi que « Pacte épistolaire et pacte autobiographique : deux formes de l'écriture de soi dans les Lettres à Sophie Volland et les Confessions chez Diderot et Rousseau ", dans : Rousseau et Diderot : traduire, interpréter, connaître, sous la dir. d'I. Zatorska, Varsovie, WUW, 2016, p. 279-291.

30 D. Diderot, «Lettre à Sophie Volland, 14 juillet $1762 »$, dans : Lettres à Sophie Volland 17591774, éd. O. Richard-Pauchet et M. Buffat, Paris, Non Lieu, 2010, réimpr. 2020, p. 274-275. 
sa nouvelle conquête Mme de Maux, et de retrouver un second souffle afin d'envisager la vie conjugale qui l'attend désormais, sans enfant pour combler le fossé creusé entre son épouse et lui-même ${ }^{31}$. Mais l'organisation complexe du séjour à Langres ${ }^{32}$, dont Grimm repart plus tôt que son ami (d'abord vers Bourbonne, et plus tard vers Paris), ainsi que les difficultés sentimentales rencontrées sur place rompent cette intimité. Elles brisent le vœu si cher à Diderot et qui ne sera pas exaucé, ou si peu, de se reposer au sein d'un trio d'amis intimes ${ }^{33}$, masculin et féminin (comme naguère entre Grimm et Sophie, Grimm et Mme d'Épinay, Grimm et sa sœur Denise). Seuls quelques jours passés à Bourbonne, du 10 au 13 août en compagnie de Grimm et de Mme de Maux (ainsi que de sa fille Mme de Prunevaux) donneront à cette utopie quelque réalité, de même qu'un bref moment arraché à Langres, au cours duquel le philosophe a pu se laisser aller auprès de son ami, au bord du bassin de Blanchefontaine : "C'est là, mon ami, s'il vous en souvient, que nous avons passé quelques heures, causant de vous, de moi, de ma bonne sœur, de mon bizarre frère; nous rappelant ma fille et jetant un coup d'œil vers les douces amies que nous allions chercher $»^{34}$.

C'est cet état mélancolique engendré par la frustration et le sentiment de solitude, lors du double voyage à Langres et à Bourbonne, qui entraîne une série de remarques acerbes sur l'environnement : elles ne sont pas toutes, nous semble-t-il, justifiées par l'observation scientifique. D'abord, le voyageur se sent, à Bourbonne, mal accueilli :

Bourbonne, ainsi que tous les autres lieux où se rassemblent des malades, est une demeure triste le jour par la rencontre des malades ; la nuit par leur arrivée bruyante. $^{35}$

Les médecins d'eaux sont tous charlatans, et les habitants regardent les malades, comme les Israélites regardaient la manne dans le désert. La vie et le logement

31 On trouve ces confidences dans les lettres à Grimm de septembre 1770, voir CEuvres, t. 5 : Correspondance.

32 Voir le calendrier très serré de ce voyage, sensible grâce à la correspondance et opportunément rappelé par Jean-Marie Goulemot dans l'une des rares études portant sur ce texte, "Approximations, fantasmes et compensations dans le Voyage à Bourbonne et le Voyage à Langres ", dans : Ici et Ailleurs : le XVIII siècle au présent, Mélanges Jacques Proust, sous la dir. de H. Nakagava et al., Tokyo, France-Tosho 1996, p. 67-71, ici p. 67.

33 Voir B. Melançon, Diderot épistolier, Montréal, FIDES, 1996, chap. VII : « Le tiers inclus. Triangularité de la lettre », p. 369-421.

$34 V B L$, p. 51. Lors de son voyage de 1759, Diderot avait déjà rêvassé au bord de ce bassin, aspirant à la compagnie de deux êtres chers : « Je passe dans cet endroit des heures à lire, à méditer, à contempler la nature et à rêver à mon amie. Ô qu'on serait bien trois sur ce banc de pierre! C'est le rendez-vous des amants du canton et le mien » («Lettre à Sophie Volland, 3 août 1759 », dans : Lettres à Sophie Volland..., op. cit., p. 42).

35 VBL, p. 37. 
y sont chers pour tout le monde, mais surtout pour les malades, oiseaux de passage dont il faut tirer parti. ${ }^{36}$

Cette impression négative à l'égard de l'économie de la station se fait-elle le simple écho des observations, ou des « on-dit » colportés par les belles amies du philosophe ; est-elle une réminiscence du séjour du père, mal soigné, peutêtre mal reçu compte tenu de son âge et de sa détresse ? D'autres mentions défavorables à ce lieu pourtant réputé, étant donné sa fréquentation huppée, apparaissent tout au long d'un compte rendu rigoureux en apparence :

Le séjour en est déplaisant : nulle promenade. Point de jardins publics. Point d'ombre dans la saison la plus chaude. Une atmosphère étouffante. Quand on en est sorti, il est rare qu'on y revienne. Si les habitants entendaient un peu leur intérêt, ils n'épargneraient rien pour l'embellir ; ils planteraient une promenade, ils aplaniraient les chemins aux collines ; ils en décoreraient les sommets ; ils feraient un lieu dont le charme pût attirer même dans la santé. ${ }^{37}$

Ce reproche concernant l'absence de promenade ou de lieu plaisant se retrouve aussi dans le récit du Voyage à Langres, comme si le voyageur ne savait où aller, que faire de sa personne, y compris aux abords de ce lieu frais et boisé que justement, il affectionnait dans sa jeunesse : " S'ils sablaient et fermaient l'entrée des voitures aux allées qui conduisent à l'endroit qu'ils appellent Blanchefontaine, ils auraient une des plus belles promenades qu'il y ait en aucune ville de province ${ }^{38}$. Sous le commentaire économique ou environnemental, perce l'aveu sentimental et avec lui, une subjectivité irrépressible qui va jusqu'à reprocher à de modestes bâtiments leur forme et leur architecture, selon des critères visiblement contestables :

La fontaine ou le puits qui fume sans cesse est placé dans le quartier bas. C’est un petit bâtiment étroit et carré, ouvert de deux portes opposées dont l'antérieure est placée dans l'entre-colonnement de quatre colonnes dont la façade est décorée. Ce monument n'est pas magnifique, il pouvait être mieux entendu, sans excéder la dépense. Je l'aurais voulu circulaire, avec quelques bancs de pierre au pourtour $[\ldots] .{ }^{39}$

Le reproche ici, plutôt mesquin compte tenu du standing général de Bourbonneles-Bains, station de taille relativement modeste, s'entend par comparaison avec l'autre fontaine, celle de Langres et de l'enfance du philosophe, ce lieu magique
36 Ibid., p. 36.
37 Ibid., p. 38.
38 Ibid., p. 54.
39 Ibid., p. 24. 
où le ramènent tous ses pas et où les bancs de pierre et le bassin forment un rond parfait, symbole d'une origine mythique - telle peut-être cette grotte de Sabinus sur laquelle l'auteur ne souhaite pas s'appesantir, de peur de troubler sans doute un souvenir d'enfance trop précieux ${ }^{40}$. Le voyageur de retour sur sa terre natale, au lieu d'y trouver ses repères, de se replonger avec délices dans de tendres souvenirs, semble s'y retourner au contraire comme sur un gril, un lit de douleur, à l'image de ce père abandonné, de cette mère jamais revue depuis son décès en 1748. Le long incipit mélancolique du Voyage à Bourbonne, noyé sous une apologie scientifique et morale, prend alors rétrospectivement tout son sens :

Je n'ai vu mourir ni mon père, ni ma mère. Je leur étais cher, et je ne doute point que les yeux de ma mère ne m’aient cherché à son dernier instant. Il est minuit. Je suis seul, je me rappelle ces bonnes gens, ces bons parents; et mon cœur se serre quand je pense qu'ils ont eu toutes les inquiétudes qu'ils devaient éprouver sur le sort d'un jeune homme violent et passionné, abandonné sans guide à tous les fâcheux hasards d'une capitale immense, le séjour du crime et des vices, sans avoir recueilli un instant de la douceur qu'ils auraient eue à le voir, à en entendre parler, lorsqu'il eut acquis par sa bonté naturelle et par l'usage de ses talents, la considération dont il jouit : et souhaitez après cela d'être père! J'ai fait le malheur de mon père, la douleur de ma mère, tandis qu'ils ont vécu, et $\mathrm{si}^{41}$, je suis un des enfants les mieux nés qu'on puisse se promettre. ${ }^{42}$

L'intertexte affectif qui s'entrelace au commentaire viatique éclaire alors à la fois les incertitudes, les lacunes, la composition erratique, voire une certaine mauvaise volonté à rapporter ces mémoires de voyage. L'ensemble du texte semble gouverné par une forme d'épanorthose ou de réticence. Qu'on compare les deux incipit :

Quand on est dans un pays, encore faut-il s'instruire un peu de ce qui s'y passe. Que diraient le docteur Roux et le cher baron, si des mille et une questions qu'ils ne manqueront pas de me faire, je ne pouvais répondre à une seule ? $^{43}$

Après avoir dit un mot de Bourbonne-les-Bains, vous trouveriez étrange si je gardais le silence sur Langres, le lieu de ma naissance et le séjour de mes parents..$^{44}$

${ }^{40}$ Voir notre commentaire poétique en conclusion de l'édition du texte utilisée, « Les eaux retrouvées ", $V B L$, p. 247-253.

${ }^{41} \mathrm{Si}$ : pourtant.

42 VBL, p. 22-23.

43 Ibid., p. 21.

44 Ibid., p. 47. 
Au contraire d'une longue tradition odysséenne, le voyageur ici semble se faire prier pour relater ses souvenirs, et ne les délivrer qu'au compte-goutte, cédant à une instante prière sans certitude de susciter ni l'agrément ni l'intérêt auprès de son lecteur. Cette rhétorique de la rétention porte pourtant ses fruits puisqu'elle déclenche notre curiosité et nos interrogations. Un lourd secret semble se dissimuler derrière ces observations aux apparences factuelles, ponctuées d'émotions qui ne sont que le trop-plein de l'enfance, de la jeunesse et de l'âge adulte trop longtemps contenu. C'est l'un des très rares moments de l'œuvre diderotienne, en dehors de la correspondance amoureuse, où l'écriture se fait intime et exprime un malaise existentiel lié au bilan d'une vie.

En conclusion, Diderot semble vérifier avant l'heure, dans ce double récit, la leçon essentielle tirée de ses voyages par l'ethnologue et explorateur Claude Lévi-Strauss : "On conçoit généralement les voyages comme un déplacement dans l'espace. C'est peu. Un voyage s'inscrit simultanément dans l'espace, dans le temps, et dans la hiérarchie sociale [...]. Il déplace, mais aussi il déclasse - pour le meilleur et pour le pire - et la couleur et la saveur des lieux ne peuvent être dissociées du rang toujours imprévu où il vous installe pour les goûter. ${ }^{45}$

Ce voyage dont le philosophe semblait tant attendre, en termes d'amitié, d'amour et d'affaires, n'a pas tenu ses promesses. Déclassé socialement, en effet, il l'est, lui qui s'attendait à partager - durant quelques jours et en galante compagnie - l'agrément d'une vie de curiste, et qui a découvert la cherté des prix et la médiocrité des prestations bourbonnaises. Déclassé aussi dans le sens où sa réputation ${ }^{46}$, de retour au pays langrois, ne lui a pas paru à la hauteur de ses attentes : nul n'est prophète en son pays. Déclassé physiquement, aussi, dans l'espace inhospitalier de ces contrées arides habituellement tempérées (l'été 1770 est sec et torride); et déclassé dans le temps au contact avivé de ses regrets, ceux de l'enfant prodigue impardonnable, impardonné. C'est de tous ces déclassements successifs ${ }^{47}$ que rend compte le texte erratique et lacunaire des deux Voyages, aux antipodes du voyage rêvé en Italie, dans deux petites villes de province de médiocre envergure, loin de « cette demeure antique, silencieuse et sacrée, où les hommes sont venus tant de fois accuser leurs erreurs ou exposer

45 C. Lévi-Strauss, Tristes tropiques, Paris, Plon, 1955, rééd. Pocket, 1994, p. 92-94.

46 « [...] c'est le propos bourru que me tint un provincial quelques années après la mort de mon père. Je traversais une des rues de ma ville ; il marrêta par le bras, et me dit : " Monsieur Diderot, vous êtes bon ; mais si vous croyez que vous vaudrez jamais votre père, vous vous trompez» $»(V B L$, p. 23).

47 Voir aussi, sur la notion de déplacement et de déclassement, le bel article d’Aurélia Gaillard, " "Ne pas être à sa place", "ne pas rester en place". Place et déplacement dans les six premiers livres des Confessions", dans : Les Confessions. Se dire, tout dire, sous la dir. de J. Berchtold et C. Habib, Paris, Classiques Garnier, 2015, p. 81-93. 
leurs besoins, sous ce Panthéon, sous ces voûtes obscures où nos âmes devaient s'ouvrir sans réserve. ${ }^{48}$

Riche littérairement, en revanche, il l'est, d'une mise en perspective exigeante de l'espace, d'une rigueur loin de la complaisance des récits viatiques, d'un récit parfois ingrat, mais juste, à l'image du réel ou des attentes justifiées du voyageur. Riche aussi, il l'est, d'une organisation personnelle, à bâtons rompus, proche de la forme épistolaire mais aussi de la promenade solitaire à la première personne ${ }^{49}$, ne se fiant à rien d'autre qu'à sa propre humeur. Laissant loin derrière lui tous les modèles éculés de récits, il n'hésite pas à conclure ce voyage de santé par un mot de maladie, à propos d'une épidémie de fièvre qui empoisonne régulièrement la contrée langroise, résumant son chagrin et son impuissance à maîtriser le cours de sa vie : «La dernière année de [la] violence [de cette épidémie], les hirondelles qui s'étaient montrées au commencement du printemps, s'éloignèrent et ne reparurent pas; ce qui inclinerait à penser que la contagion vient de l'air $»^{50}$.

48 Salon de 1767, incipit, op. cit.

49 Voir l'introduction par Michel Delon, de son édition des Deux amis de Bourbonne et autres contes, Paris, Gallimard, 2002 ; ainsi que la thèse de Juliette Fabre, Marcher, penser, écrire : La Promenade littéraire de La Mothe le Vayer à Rousseau, soutenue en 2019 sous la direction de Michel Delon à l'Université de Paris-Sorbonne.

$50 V B L$, p. 53. 
Alain Guyot

Université de Lorraine - E.A. 7305 «Littérature, Imaginaire, Sociétés »

ORCID 0000-0003-0249-2128

\section{Éclairer la figure du voyageur à la fin des Lumières : du Voyage à l'île de France de Bernardin de Saint-Pierre au projet de sa réédition ${ }^{1}$}

\section{Highlighting the Figure of the Traveller at the End of the Enlightenment: from the Voyage à l'île de France by Bernardin de Saint-Pierre to the Plan for its Reissue}

It is now widely known that the Voyage à l'île de France (1773) by Bernardin de Saint-Pierre is no longer seen as an engineering thesis, but not yet as a literary work, mainly because of the far too little place given to the figure of the traveller. Nonetheless, it is less known that, in a reissue project which was never completed, the author intended to give to this figure a more important place. For what reasons? In what way? This paper will attempt to answer those questions.

Keywords: Bernardin de Saint-Pierre, travel account, figure of the traveller, Indian Ocean, literarity

Mots-clés : Bernardin de Saint-Pierre, récit de voyage, figure du voyageur, océan Indien, littérarité

${ }^{1}$ Cette étude reprend, prolonge et développe quelques réflexions publiées il y a quinze ans dans un volume d'hommage ( De l'exploration du monde à la découverte de soi : le Voyage à l'île de France de Bernardin de Saint-Pierre (1773) et le projet de sa réédition (1790)» dans : Le Bonheur de la littérature : variations critiques pour Béatrice Didier, sous la dir. de Ch. Montalbetti et J. Neefs, Paris, PUF, 2005, p. 303-309). Elle bénéficie en particulier des éléments nouveaux apportés par la toute récente édition critique de louvrage procurée par A. Gigan et V. Kapor (dans : J.-H. Bernardin de Saint-Pierre, Euvres complètes - t. 2 : Voyages, Paris, Classiques Garnier, 2019), et c'est à cette édition que, sauf exception dûment signalée, on se référera désormais par la mention de la page précédée de «VIdF». 
La fin du XVIII ${ }^{\mathrm{e}}$ siècle est particulièrement intéressante pour voir émerger, dans le genre viatique, la figure du voyageur au sein même de son récit. Les études à ce propos sont trop nombreuses pour qu'on les reprenne ici en détail : contentons-nous de rappeler que, parallèlement à la vogue des récits de voyage " sérieux », rédigés par des savants et des hommes de lettres participant ou non à de grandes expéditions d'exploration et de recensement du monde de Bougainville à Volney - se développe toute une littérature viatique de moindre ambition informative, héritée des voyages " amusants " inventés par Chapelle et Bachaumont au siècle précédent. La préoccupation du relateur pour reprendre le terme remis naguère à la mode par François Moureau ${ }^{2}-$ y réside plutôt dans la restitution de ses impressions ou de ses émotions et dans le plaisir de son lecteur, enchanté par les prouesses stylistiques déployées. Comme Hermann Harder l'a clairement montré, il y aura bientôt quarante ans ${ }^{3}$, le voyage en Italie joue un rôle déterminant dans ce courant nouveau où, par la qualité de l'écriture et du rendu impressif, la personnalité du voyageur se manifeste bien davantage que dans les récits à vocation didactique, même si cette dernière n'est pas totalement exclue, des lettres amusantes du Président de Brosses au déluge émotionnel, proche du pathos, auquel Mercier-Dupaty soumet parfois son lecteur ${ }^{4}$. En cela, les Lumières finissantes contribuent à favoriser la prise en main du récit de voyage par les écrivains de profession et son entrée dans un champ dont il était jusqu'alors pratiquement exclu : la littérature ${ }^{5}$.

Quelle place la - maintenant célèbre - relation par Bernardin de Saint-Pierre du périple qu'il accomplit entre 1768 et 1770 dans l'océan Indien occupe-t-elle dans cette évolution du genre viatique ? Une place assurément complexe, d'abord par la posture énonciative de l'auteur : s'il deviendra un écrivain en même temps qu'un homme de science reconnu à partir de la publication de ses Études de la nature en 1784, suivie de celle de Paul et Virginie quatre ans plus tard, on verra que ce n'est pas en cette qualité qu'il s'embarque pour les tropiques ni même qu'il rédigera le récit de son voyage. Ensuite par l'évolution même de son projet : dans les années 1790, Saint-Pierre envisagera en effet un remaniement notable de son récit, qu'il recentre sur la figure du voyageur. C'est à l'analyse de ce positionnement complexe et de sa modification au fil du temps que l'on souhaiterait s'intéresser maintenant.

2 Voir F. Moureau, Le Théâtre des voyages, Paris, PUPS, 2005, p. 12 et 18.

3 Voir H. Harder, Le Président de Brosses et le voyage en Italie au XVIII siècle, Genève, Slatkine, 1981.

4 Voir Ch. de Brosses, Lettres familières sur l'Italie (posth. 1799) ; J.-B. Mercier Dupaty, Lettres sur l'Italie en 1785 (1788).

5 Voir R. Le Huenen, «Le récit de voyage : l’entrée en littérature ", dans : Le Récit de voyage au prisme de la littérature, Paris, PUPS, 2015, p. 91-103. 
Pour cela, il faut remettre en situation l'auteur, son périple et le récit qu’il en propose. Rappelons en premier lieu que Bernardin de Saint-Pierre, lecteur passionné des récits de voyageurs ${ }^{6}$, s'est embarqué pour la Martinique à l'âge de douze ans sur le vaisseau de son oncle, avant d'effectuer des missions plus ou moins officielles en Méditerranée et dans le nord-est de l'Europe. Ces missions, il les réalise en qualité d'officier du génie, puisque la solide formation dans le domaine des lettres et de la philosophie qu'il doit à ses maîtres jésuites s'est orientée dans un sens nettement plus scientifique et technique lorsqu'il l'a poursuivie à l'École des ponts et chaussées. Les écrits qu'il rapportera de ses déplacements en Europe sont du coup moins des "récits " que des " mémoires d'ingénieur ", leurs commentateurs s'accordent sur ce point ${ }^{7}$ : Saint-Pierre les destinait au ministère des Affaires étrangères, en vue de promouvoir sa carrière, même s'ils sont restés lettre morte ${ }^{8}$. "Par le caractère technique des informations et l'attitude spéculative du point de vue ${ }^{9}$, ils sont représentatifs d'un type d'écriture qui s'inspire des documents que rédigeaient à l'époque les ingénieurs topographes pour présenter leurs projets.

Qu'en est-il du périple dans l'océan Indien et de son récit ? Des études aussi nombreuses qu'anciennes ont raconté en détail les circonstances bien particulières de ce voyage : missionné par le baron de Breteuil, officiellement pour occuper un poste d'ingénieur à l'île de France - l'actuelle île Maurice, alors possession française -, officieusement, semble-t-il, pour "relever les murs du fort Dauphin » à Madagascar et en " civiliser la colonie $»^{10}$, SaintPierre ne parviendra jamais jusqu'à son objectif final et quittera définitivement l'expédition malgache au Port-Louis de l'île de France en août 1768. Incompatibilité de caractère avec le chef de celle-ci, le comte de Maudave ? Refus exprimé par celui qui dénoncera plus tard l'esclavage colonial de participer

${ }^{6}$ Dans une note de la $13^{\mathrm{e}}$ Étude, il fait l'éloge des « livres de voyages, parce que ce sont ceux qu['il] aime et qu['il] estime le plus de la littérature moderne » (J.-H. Bernardin de Saint-Pierre, Études de la nature, éd. C. Duflo, Saint-Étienne, PU, 2007, p. 496).

7 Voir L. Aimé-Martin, Essai sur la vie et les œuvres de Bernardin de Saint-Pierre, dans : J.-H. Bernardin de Saint-Pierre, Euvres complètes, Paris, Méquignon-Marvis, 1818, t. 1, p. 83-85; F. Maury, Étude sur la vie et les ceuvres de Bernardin de Saint-Pierre, Paris, Hachette, 1892, p. 236-237 ; L. Stecca, « Significato dei viaggi di Bernardin de Saint-Pierre : dal viaggio nel reale al viaggio nell'immaginario ", Spicilegio moderno, t. 4, Pisa, 1975, p. 65-66 ; G.-R. Thibault, "Genèse intellectuelle des récits de voyage de Bernardin de Saint-Pierre », dans : Explorations et voyages scientifiques de l'Antiquité à nos jours, sous la dir. de Ch. Demeulenaere-Douyère, Paris, CTHS, 2008, p. 359, 367 sqq ; I. Zatorska, «Introduction générale » à J.-H. Bernardin de SaintPierre, Voyages dans le nord de l'Europe, dans : CEuvres complètes - t. 2 : Voyages, op. cit., p. 58.

8 Voir L. Aimé-Martin, op. cit., p. 149-150, ainsi que les considérations de Saint-Pierre luimême à ce sujet (VIdF, p. 901-902). Voir en outre I. Zatorska, op. cit., p. 55-56.

9 G.-R. Thibault, op. cit., p. 367.

10 L. Aimé-Martin, op. cit., p. 151. Voir en outre M. Souriau, Bernardin de Saint-Pierre d’après ses manuscrits, Paris, Soc. française d'imprimerie et de librairie, 1905, p. 144 sq. ; VIdF, p. 316. 
à ce qui devait se révéler une opération de traite négrière ${ }^{11}$ ? Les biographes se perdent en conjectures à ce propos, et peu nous importe : ce qui compte, c'est que nous retrouvons notre voyageur mis à disposition du commandant militaire de l'île en qualité d'ingénieur du Roi et pour le moins désœuvré - on le charge apparemment de réparer quelques maisons ici ou là. En tout cas, il ne semble " officiellement chargé d'aucune mission à caractère scientifique $»^{12}$.

Qu'à cela ne tienne : Saint-Pierre se lance dans la confection d'un ouvrage qu'il publiera en 1773 sous le titre de Voyage à l'île de France. De quel genre de récit viatique s'agit-il ? À coup sûr, d'un livre nettement plus complexe que les mémoires d'ingénieur précédemment cités ${ }^{13}$. Beaucoup plus développé que ces derniers, c'est un ouvrage circonstancié, qui n'est pas encore celui d'un homme de lettres, mais qui n'est déjà plus seulement une publication à caractère simplement informatif, technique ou scientifique : il se situe à la frontière des genres et des époques ${ }^{14}$.

Lorsqu'il écrit le récit de son périple dans l'océan Indien, l'ambition de celui qui n'est encore qu'officier du génie reste pourtant de se faire connaître et de trouver un emploi à travers les connaissances et les idées qu'il charge son ouvrage de transmettre. Comme le constate Gabriel-Robert Thibault, Saint-Pierre, en cherchant à être " utile aux hommes » et à "rend[re] service à $[s]$ a patrie $»^{15}$, " ne se présente pas comme un simple curieux de la diversité du monde, mais comme un serviteur de l'État engagé dans les intérêts de la nation ${ }^{16}$. À ce titre, le Voyage à l'île de France doit d'abord se lire comme la chorographie d'une terre mal connue à l'époque ${ }^{17}$ et, comme tel, il se soumet

11 C’est ce que prétend le Dictionnaire de biographie française, cité - et mis en question par I. Zatorska ( Un “triangle des Mascareignes” ? Bernardin de Saint-Pierre, La MarcheCourmont et le comte de Maudave ", dans : Bernardin de Saint-Pierre et l'océan Indien, sous la dir. de J.-M. Racault, Ch. Meure et A. Gigan, Paris, Classiques Garnier, 2011, p. 69).

12 P. Rodriguez, "Contraintes et contradictions du récit de voyage : l'expérience de Bernardin de Saint-Pierre », Francofonia, n VI-11, 1986, p. 44. Voir en outre VIdF, p. 359.

13 Voir en particulier L. Stecca, op. cit., p. 70 sq.

${ }_{14}$ C’est en partie ce qui lui a valu ce jugement sans appel de F. Maury : il « s'est condamné à rester à la fois en dehors de la littérature et de la science» (op. cit., p. 256).

15 VIdF, p. 444.

16 G.-R. Thibault, op. cit., p. 360. Voir, à la fin des Études de la nature, le jugement rétrospectif que porte Saint-Pierre sur son récit viatique, dans lequel il se proposait de remédier aux maux de la colonie : « Je crus d'abord rendre un service essentiel à ma patrie » (Récapitulation, note a op. cit., p. 579).

${ }_{17}$ Comme le rappelle Saint-Pierre (VIdF, p. 536-538), peu de voyageurs sétaient intéressés avant lui à l'île de France, et la prise de possession par Dufresne d'Arsel en 1715, au nom du roi de France, du territoire nommé « T’Eylandts Mauritius » par les Hollandais et abandonné par ces derniers quelques années plus tôt, n’a pas notablement modifié la situation. La relation qui avait contribué à mieux faire connaître le milieu insulaire aux Européens est le Journal historique du voyage fait au cap de Bonne-Espérance par l'abbé de La Caille (posth. 1763) : le Voyage à l'île de France fait allusion à la carte établie à cette occasion (VIdF, p. 669). 
au modèle des récits savants utilisés pour sa confection. Le lecteur ne doit pas se laisser abuser par l'Avant-Propos de l'ouvrage, dans lequel l'auteur l'avertit que les «lettres » et les « journaux» qu'il y lira « ont été écrits à [s]es amis » et qu'il se serait contenté de les " $\mathrm{m}$ [ettre] en ordre » et de les «fai[re] imprimer, afin de leur donner une marque publique d'amitié et de reconnaissance $»^{18}$ : comme l'observe Fernand Maury, Saint-Pierre reprend ici la forme épistolaire adoptée par d'autres récits de voyage informatifs, telle la Relation d'un voyage du Levant de Tournefort ${ }^{19}$, et l'on s'aperçoit vite, dans le cas du Voyage à l'île de France, qu'il s'agit d'une simple forme postiche, destinée à habiller, de manière parfois maladroite, un inventaire systématique des objets rencontrés en cours de route, tel qu'on en trouve à l'époque dans la plupart des relations de périples en terre lointaine ${ }^{20}$. Le titre donné aux lettres concernant l'île de France proprement dite est éloquent à cet égard (lettre V : "Aspect et géographie de l'île de France "; lettre VI : " Du sol et des productions naturelles de l'île de France. Herbes et arbrisseaux », etc.). En bon ingénieur, Saint-Pierre y décrit les espèces animales ou végétales en fonction de leur agrément et surtout de leur utilité potentielle, comme moyen de subsistance ou comme remède. Il invite par exemple les administrateurs et les militaires auxquels l'ouvrage est destiné à se défier des apparences trompeuses présentées par certaines espèces : ainsi, «[1]a vieille est un poisson noirâtre assez semblable à la morue pour la forme et pour le goût ", mais il " est quelquefois empoisonné », et " [c]eux qui en mangent sont saisis de convulsions", quand leur peau ne tombe pas "par écailles $»^{21}$. Dans la perspective utilitariste qui est la sienne lorsqu'il rédige le récit de son voyage, Bernardin de Saint-Pierre cherche donc à accumuler les données pratiques au fil de son exploration de l'île, afin d'envisager non seulement les possibilités de développement de la colonie mais aussi la capacité de celle-ci à résister à un siège ${ }^{22}$. En somme, cette prise de possession encyclopédique du monde exploré,

18 Ibid., p. 25.

19 Voir F. Maury, op. cit., p. 255 ; VIdF, p. 321 sq. Saint-Pierre connaissait manifestement bien le voyage de Tournefort, comme l'attesteront plus tard les références à celui-ci dans les Études de la nature (IV et XI - op. cit., p. 108, 142, 343, 347).

20 Voir L. Aimé-Martin, op. cit., p. 170-171 ; P. Rodriguez, op. cit., p. 40 sq. ; F. Lestringant, "Bernardin de Saint-Pierre et le récit de voyage. À propos du Voyage à l'île de France ", et G. Armand, "L'ancrage indianocéanique des théories scientifiques de Bernardin de SaintPierre », dans : Bernardin de Saint-Pierre et l'océan Indien, op. cit., p. 275 et 319.

${ }^{21}$ VIdF, p. 570.

22 Voir G.-R. Thibault, op. cit., p. 371 sq.; G. Armand, op. cit., p. 321. Saint-Pierre affirme ainsi avoir effectué le tour de l'île à pied « afin de [s]e faire un système de la défense de l'île, et dans l'occasion, quelques observations d'histoire naturelle » (VIdF, p. 674). Une note de l'édition du Voyage à l'île de France procurée par R. Chaudenson (Maurice, Éd. de l'Océan Indien, 1986, p. 414) signale que Saint-Pierre a dû supprimer un certain nombre de passages qui auraient pu se révéler préjudiciables à la défense insulaire - ce qui n’a pas empêché un stratège anglais d'utiliser les renseignements consignés dans l'ouvrage pour concevoir un plan d’attaque de l'île... 
dont les éléments sont envisagés en termes d'applications pratiques, est tout à fait caractéristique des récits de voyages de découverte, à vocation bien souvent colonisatrice. S'il n'est pas exclu, le récit d'aventures y occupe somme toute une place moindre que la « somme de renseignements de tous ordres $»^{23}$, qui fait alors, pour le public lettré, l'intérêt principal de ce genre d'ouvrages.

C'est peut-être ce qui explique l'accueil bienveillant réservé à celui-ci par le public lettré de l'époque ${ }^{24}$, alors même qu'il s'agit d'un Voyage on ne peut plus atypique en ce XVIII ${ }^{\mathrm{e}}$ siècle finissant. Passons sur les incohérences et les contradictions dont le texte fourmille. Tableau d'une nature qui tour à tour désole ou dégoûte le voyageur, austère essai de systématique naturaliste de la part d'un auteur qui s'avoue d'emblée ignorant en la matière, forme bâtarde et artificielle tenant, on l'a dit, à la fois de la lettre et du journal, unité à première vue absente : autant de "défauts " peut-être liés au manque d'expérience de Saint-Pierre, qui réalise ici son coup d'essai littéraire ${ }^{25}$. Bref, le Voyage à l'île de France a de quoi déconcerter la bonne volonté du lecteur contemporain, qui ne peut toutefois s'empêcher de trouver le texte attachant, précisément peut-être en raison de son caractère inclassable.

De fait, Saint-Pierre ne se contente pas de se livrer à l'inventaire précédemment évoqué. Influencé sans doute par des disciplines comme la botanique et l'histoire naturelle, auxquelles il s'initie pendant son séjour ${ }^{26}$ et que leur triomphe transforme vite en guide de toute démarche cognitive à la fin du XVIII siècle, il se passionne vite pour la classification des espèces et propose même un "ordre conchyliologique nouveau $»^{27}$, chose étonnante pour quelqu'un qui s'excuse, dans son Avant-Propos, d'aborder des sujets « qui paraissent étrangers à [s]on état » : "J'ai écrit sur les plantes et les animaux, et je ne suis point naturaliste $»^{28}$. Mais c'est pour ajouter aussitôt : "L'histoire naturelle n'étant point renfermée dans des bibliothèques, il m’a semblé que c'était un livre où tout le monde pouvait lire. J'ai cru y voir les caractères sensibles d'une providence; et j'en ai parlé, non comme d'un système qui amuse mon esprit, mais comme d'un sentiment dont mon cœur est plein. $»^{29}$

23 La formule est de R. Chaudenson (ibid., p. 53).

24 Voir L. Aimé-Martin, op. cit., p. 171 ; F. Maury, op. cit., p. 98 ; VIdF, p. 386 sq.

25 Voir F. Maury, op. cit., p. 98.

${ }_{26}$ Voir VIdF, p. 329 sq. Dans le projet de remaniement de l'ouvrage, Saint-Pierre marque à l'intendant de l'île de France, P. Poivre, sa reconnaissance pour avoir su lui transmettre son " goût " pour ces disciplines, dans lesquelles ce dernier paraissait " av[oir] trouvé son principal bonheur» (ibid., p. 959).

27 Ibid., p. 867. Selon R. Chaudenson (op. cit., p. 381-382), L'Histoire naturelle éclaircie dans une de ses parties principales, la conchyliologie de d'Argenville (Paris, 1757) serait à l'origine de la lettre $\mathrm{X}$ du Voyage à l'île de France.

28 VIdF, p. 444.

29 Ibid. 
Par-delà la captatio benevolentiae traditionnelle, cet Avant-Propos se présente comme un programme et annonce un combat. La vieille métaphore du « livre de la nature » y est reprise pour s'opposer, presque terme à terme, à l'usage qu'en faisait Galilée un siècle et demi auparavant ${ }^{30}$. Loin de chercher à maîtriser le langage mathématique, fait de symboles géométriques, dont Galilée faisait la condition sine qua non de l'accès à la connaissance de l'univers, Saint-Pierre revendique d'emblée son statut d'" amateur ", au meilleur sens du terme, qui rejette le savoir livresque ${ }^{31}$ au profit d'un accès direct à la nature aimée et aimante par le biais de l'observation et du sentiment. Là où Galilée prétendait réserver la connaissance à une élite intellectuelle préalablement formée, SaintPierre se propose de l'offrir au commun des mortels, à partir du moment où il est pourvu de sensibilité. C'est qu'à ses yeux, il ne s'agit plus de déchiffrer les caractères mathématiques qui composent les lois rationnelles d'une nature où l'intervention divine pourrait bien se révéler superflue, mais « les caractères sensibles d'une providence " qui se dérobe à toute approche intellectuelle, sans pour autant cesser de se manifester partout à l'homme de cœur et de foi. L'opposition qui conclut le passage entre le "système qui amuse mon esprit " et le «sentiment dont mon cœur est plein » renvoie définitivement l'approche galiléo-newtonienne de la nature du côté du divertissement et de la pure spéculation intellectuelle ${ }^{32}$, et met en place une forme de connaissance qui redonne sa place entière à la sensibilité, tout en offrant un accès aux desseins de la divinité en faveur de l'homme. Cet essai de discours totalisant sur le monde trouvera toute son ampleur dans les Harmonies de la nature ${ }^{33}$.

Mais c'est peut-être plus encore au plan du sentiment de la nature qu'apparaît l'originalité du point de vue de Saint-Pierre dans le Voyage à l'île de France : l'ambivalence de son projet ne peut se comprendre que dans la perspective très rousseauiste d'une exaltation de la nature « comme lieu privilégié où se révèle, même de manière éphémère, la qualité essentielle d'une dimension spirituelle »34.

30 Voir Il Saggiatore, dans : Opere, Florence, Barbèra, 1968, t. 6, p. 232.

31 On sait qu'il n'en est rien, et il faut se garder de prendre au pied de la lettre ses déclarations en ce domaine, comme en témoignent les références dont est nourri son ouvrage (voir VIdF, p. 332 sq.). Mais cette opposition polémique entre le savoir issu des livres, des cabinets ou des laboratoires et celui qui s'acquiert au spectacle de la nature se retrouve dans la $10^{\mathrm{e}}$ Étude, où l'auteur affirme préférer, pour comprendre les couleurs, la contemplation d'un lever de soleil au trompeur prisme de Newton (Études de la nature, op. cit., p. 269).

32 Voir Ch. Chelebourg, " "Lart de rendre la nature". Métalecture de Voyage à l'île de France ", dans : Bernardin de Saint-Pierre et l'océan Indien, op. cit., p. 233 et 237-238. Saint-Pierre se livrera à une attaque en règle des méthodes et des systèmes « qui nous égarent » au début de la $11^{\mathrm{e}}$ Étude (op. cit., p. 243 sq.).

33 Voir J.-M. Racault, "La cosmologie poétique des Harmonies de la nature », Revue d'histoire littéraire de la France, $\mathrm{n}^{\circ}$ LXXXIX, 1989, p. 825-842.

34 P. Rodriguez, op. cit., p. 46. 
À la double orientation scientifique et spirituelle du projet s'en adjoint donc une troisième, d'ordre plus précisément esthétique, comme l'attestent les propos mêmes de Saint-Pierre dans la dernière lettre du Voyage:

À force de nous naturaliser avec les arts, la nature nous devient étrangère ; nous sommes même si artificiels que nous appelons les objets naturels des curiosités et que nous cherchons les preuves de la divinité dans les livres. On ne trouve dans ces livres (la révélation à part) que des réflexions vagues et des indications générales de l'ordre universel : cependant pour montrer l'intelligence d'un artiste, il ne suffit pas d'indiquer son ouvrage, il faut le décomposer. La nature offre des rapports si ingénieux, des intentions si bienveillantes, des scènes muettes si expressives et si peu aperçues, que qui pourrait en offrir un faible tableau à l'homme le plus inattentif le ferait s'écrier : il y a quelqu'un ici ! $!^{35}$

Les descriptions de nuages ou d'animaux aux couleurs chatoyantes ne relèvent plus d'une volonté d'appropriation coloniale ou scientifique : il ne s'agit plus seulement de rendre compte du caractère providentiel de la nature, mais d'exalter sa beauté et la dimension artistique de la Création. Or qui mieux que l'artiste serait à même de mener à bien cette mission ? C'est le sens de l'affirmation placée quelques années plus tard dans l'Avis précédant la première édition séparée de Paul et Virginie (1789) :

[...] Homère et Virgile [...] ont souvent mieux expliqué [la nature] par leurs sublimes allégories que la plupart des physiciens, occupés uniquement à en analyser les éléments. Ceux-ci souvent n'ont vu que la matière pour principe et pour fin de leurs travaux; et ceux-là, ramenant jusqu'aux éléments à un ordre de choses qui protège la faiblesse humaine, ont entrevu, par la force de leur génie, l'ensemble de l'univers. ${ }^{36}$

Le refus de l'exclusivisme scientifique s'associe donc à une réévaluation parallèle de la figure de l'artiste et, par ricochet, de celle du relateur en passe de devenir " écrivain de voyage ", désormais seul à pouvoir tenir un discours cohérent et global sur le monde et la nature.

Or qui dit " artiste » à la fin du xviiie siècle dit nécessairement « tempérament», "caractère " et expression d'une subjectivité dans le rendu de certaines impressions visuelles, à l'instar de ce rivage de l'île Bourbon - l'actuelle île de La Réunion - battu par les flots pendant un ouragan, qui lui apparaît " couvert d'une mousse blanche comme la neige, qui s'y entassait comme des

35 VIdF, p. 854.

36 J.-H. Bernardin de Saint-Pierre, "Avis sur cette édition » (1789), Paul et Virginie, éd. C. Duflo, dans : Euvres complètes - t. 1 : Romans et contes, op. cit., p. 177. 
ballots de coton $»^{37}$. Alors que l'on pensait avoir affaire à un récit désincarné, tout entier tourné vers la transmission d'informations objectives, on voit ponctuellement transparaître la personnalité du voyageur à travers ces notations comme à travers l'expression de son désespoir à se retrouver exilé dans une contrée où tout lui déplaît : nature hostile, quelle que soit sa puissance, éloignement de sa patrie, dont il regrette « [1]es beaux tapis de lait, de safran et de pourpre que paissent nos heureux troupeaux $»^{38}$, société violente et cruelle, en particulier à l'égard des esclaves, au sort desquels il est le premier à consacrer une sorte de reportage pris sur le vif. Toutes les occasions sont bonnes pour permettre à Saint-Pierre d'exprimer sa sensibilité.

Chorographie pré-coloniale dépourvue de commanditaire, inventaire scientifique réalisé par un non-spécialiste, discours totalisant sur la nature, à peine tenu qu'il est déjà suranné, mais qui tire de son impossibilité même toute sa puissance esthétique : telles sont quelques-unes des ambiguïtés et des nouveautés du Voyage à l'île de France, qui se caractérise aussi, on l'a vu, par une grande diversité formelle. Celle-ci serait, selon Pierre Rodriguez, la trace du conflit inhérent au récit de voyage, qui tente toujours de concilier la chronologie événementielle de la narration et l'ordre thématique de la description, pour n'aboutir en fin de compte qu'à "un amalgame hétérogène de pratiques discursives qui vont du récit littéraire le plus élaboré à l'énumération la plus sèche et même au tableau le plus froidement abstrait en passant par le dialogue et le glossaire $»^{39}$.

C'est sans aucun doute cette conscience d'une trop grande hétérogénéité formelle, jamais pleinement assumée par le relateur, qui a en partie motivé le projet de révision du Voyage à l'île de France, auquel Saint-Pierre a œuvré autour de 1790, en vue d'une nouvelle édition, dans la foulée du succès des Études de la nature et de Paul et Virginie ${ }^{40}$. Ce projet n'a jamais vu le jour, mais il a été clairement mis en lumière dans les travaux sur les manuscrits réalisés par Maurice Souriau, Robert Chaudenson, ainsi que, plus récemment, par Angélique Gigan et Vladimir Kapor, et les traces qui nous en sont restées ne laissent pas

37 VIdF, p. 724. Sur l'audace visionnaire de certaines de ces images, voir J.-C. Bonnet, "Bernardin néologue à l'épreuve de l'océan Indien ou "l'art de rendre la nature" ", dans : Bernardin de Saint-Pierre et l'océan Indien, op. cit., p. 418.

38 VIdF, p. 633.

39 P. Rodriguez, op. cit., p. 43. F. Maury nétait pas plus indulgent en son temps, qui trouvait artificiel l'ordre de composition du Voyage et n'y voyait qu'un catalogue incohérent et confus. Il attribue toutefois ce désordre au fait que Saint-Pierre prétendait déjà "à un art supérieur " et à un « secret dessein d'esquisser le tableau de la vie concrète, et comme de la création à l'Ile de France » (op. cit., p. 254-255). L'utopie du projet totalisant transparaîtrait donc également dans la forme même de louvrage.

40 Sur les motivations de ce projet, voir VIdF, p. 312-314, ainsi que les différentes ébauches de prospectus et de préambule placés en annexe (ibid., p. 883 sq.). 
de retenir l'attention de qui s'intéresse à l'évolution de la forme narrative du récit de voyage. On en voudra pour preuve quelques extraits de ces manuscrits, parmi lesquels les différentes versions du préambule qui devait ouvrir cette réédition :

[...] j'ai senti que ce qu'il y avait de personnel dans un voyageur était ce qui intéressait le plus du voyage. C'est cela qui forme l'illusion qui nous rend les choses présentes. Le lecteur est en compagnie. De là arrive que les relations de voyages sont sans contredit plus intéressantes que les descriptions géographiques du même pays. [...]

Je ne changerai donc rien à la forme de mes lettres. J'y ajouterai simplement mes aventures personnelles, mes réflexions, comme un récit ou narration qui liera davantage ces lettres les unes aux autres. Cette forme de lettre même [...] me semble de plus favorable en toute chose. Je préfère la forme la plus simple. Si j'écrivais un voyage je prendrais la forme du journal, et au lieu de rendre compte à autrui ce serait à moi-même. ${ }^{41}$

L'intérêt d'un voyage cesse quand on perd de vue le voyageur. ${ }^{42}$

Un addendum aux «Observations sur les gens de mer » du journal de la navigation vers l'île de France confirme cette hypothèse : "Je crois qu'un voyageur en se mettant comme observateur de la société avec les compagnons de son voyage, bannirait pour lui-même et pour son lecteur la monotonie d'un voyage de long cours $»^{43}$.

Joignant pour ainsi dire le geste à la parole, Saint-Pierre avait l'intention de nourrir son ouvrage révisé d'une foule de détails sur son caractère, son enfance, ses précédents voyages, ses états d'âme à l'égard de l'hypothétique expédition malgache, son débarquement à l'île de France et les raisons de celui-ci, comme sur les " occupations » qui y furent les siennes une fois installé ${ }^{44}$, alors même qu'il avait pris soin d'effacer presque tous les détails le concernant dans la première édition de l'ouvrage ${ }^{45} \ldots$ On est donc frappé du déplacement du centre d'intérêt vers l'ego vians, si l'on peut dire, déplacement

${ }^{41}$ Ibid., p. 890-891.

42 Ibid., p. 895.

43 Ibid., p. 479.

44 Voir ibid., p. 899-920 et 925-935.

45 Voir M. Souriau, op. cit., p. 152. A. Gigan et V. Kapor font toutefois remarquer que, par ses interventions répétées dans la version de 1773, le « je " narratif du Voyage à l'île de France n'hésite pas à se positionner « contre l'omniscience de type encyclopédique, en reconnaissant honnêtement les incertitudes du narrateur et, le cas échéant, son ignorance " (VIdF, p. 330). De même, lorsqu'il évoque la condition des esclaves sur l'île (ibid., p. 611 sq.), Saint-Pierre revendique son statut de témoin oculaire et fait fréquemment état des violentes émotions que lui procurent les mauvais traitements infligés aux Noirs. L'émergence du moi du voyageur se profilait donc discrètement et malgré tout dès la première version de l'ouvrage... 
explicitement motivé par un intérêt éditorial, puisque la présence du je voyageur et narrateur dans le récit est censé le rendre plus abordable et participe en fait d'un projet de séduction rhétorique somme toute assez courant dans la littérature viatique ${ }^{46}$.

Mais d'autres extraits de ce même manuscrit révisé nous montrent que ce recentrement de l'ouvrage sur la figure du voyageur dépasse largement la quête de l'intérêt du lecteur :

Avant de décrire un voyage il est à propos de faire connaître le voyageur. C'est l'historien qui fait le héros. Le monde est une montagne que chacun décrit non suivant la nature, mais suivant sa manière de voir. Les uns du fond du vallon. D'autres du sommet de la montagne, les uns au matin, les autres au soir... C'est le point où le peintre est placé et l'heure du jour qu'il choisit qui fait le paysage. ${ }^{47}$

Ce qui motive la mise en avant de la figure du voyageur, c'est donc également la revendication - très nouvelle à l'époque - d'un point de vue sur le monde et de l'expression d'une subjectivité, avec pour conséquence la possibilité offerte à l'ouvrage de se distinguer de la masse des récits de voyage "sérieux », écrits par ceux qu'il nomme, dans l'extrait à suivre, les voyageurs exacts :

Nous avons déjà plusieurs voyages autour du monde mais il est plus utile de faire le tour de soi-même, de connaître les pôles sur lesquels nous tournons, et comment avec les mêmes organes et les mêmes passions nous différons tant les uns des autres. Les voyageurs exacts nous donnent ainsi que je l'ai fait les dimensions de leur vaisseau et des gens de leur équipage. Pour moi je donnerai celles de moimême $[\ldots]$.

Ce n'est point la confession de ma vie, je n'ai pas assez de confiance aux hommes. [...] J'en dirai suffisamment pour me faire connaître tel que j’ai été et tel que je suis. Cela servira à d'autres pour être plus heureux. ${ }^{48}$

On voit que, même s'il se revendique disciple de Rousseau, Saint-Pierre n'a aucune intention autobiographique lorsqu'il entend remanier son récit - on est encore très loin des "Mémoires d'une année de ma vie ${ }^{49}$ proposés par

46 Dans la dernière lettre de son ouvrage, Saint-Pierre sétait précisément insurgé contre les descriptions offertes par certains voyageurs, " arides comme des cartes de géographie » (VIdF, p. 855). Voir à ce propos F.-D. Liechtenhan, "Le voyagiste ou peregrinationum scriptor : un homme de métier à la fin du Grand Siècle », dans : Écrire le voyage, sous la dir. de G. Tverdota, Paris, PSN, 1994, p. 143-152.

47 VIdF, p. 447.

48 Ibid., p. 892.

49 F.-R. de Chateaubriand, «Itinéraire de Paris à Jérusalem », éd. Ph. Antoine, dans : CEuvres complètes, sous la dir. de B. Didier, Paris, Champion, 2009, t. 8-10, p. 137. 
Chateaubriand dans l'Itinéraire de Paris à Jérusalem. On ne peut s'empêcher toutefois d'entrevoir ici une envie de profiter de la relation viatique pour partir à la découverte de soi-même, qui fera les beaux jours du récit de voyage romantique.

Les ultimes extraits qu'on voudrait citer ici sont encore plus troublants :

J'ai vu l'île de France les yeux tournés du côté de l'Europe, maintenant je verrai dans l'Europe l'île de France, la première du temps de mon ambition, la seconde de celui de mon repos. Cependant je tâcherai de semer à la fois ma route des fleurs de mon printemps et des fruits de mon automne. ${ }^{50}$

Les objets changent du point de vue où on les voit. Je les voyais en gravissant la montagne, aujourd'hui de la descente. Vingt ans d'intervalle ont fait de moi deux auteurs. L'un qui voyait les choses de ce monde en gravissant l'autre en descendant vers la vallée. ${ }^{51}$

Comment ne pas songer dans ce cas aux allers et retours qu'une vingtaine d'années plus tard, l'auteur de l'Itinéraire fera, au sein même de son récit, entre son voyage en Orient et le voyage en Amérique qu'il effectuait précisément au moment où Saint-Pierre rédigeait ces lignes ? Mais contrairement à René, celui-ci ne profite pas de la mise en lumière de cette distance temporelle entre son moi d'alors et son moi actuel pour éprouver l'épaisseur temporelle de celui-ci et le penser non «plus comme essence autonome, mais comme unité psychologique promise à la mort $»^{52}$ : il est encore trop tôt pour cela, et l'auteur de Paul et Virginie se contente d'une sorte de point de vue "picaresque", pourrait-on dire, sur les objets qu'il a rencontrés jadis et qu'il envisage désormais sous un autre angle. Peut-être y voyait-il le moyen de justifier la transformation de l'enfer tropical qu'il décrivait dans le récit de son voyage en ce « vert paradis des amours enfantines » qu'il a représenté quinze ans plus tard dans son roman ${ }^{53}$.

Autrement dit, si les modifications profondes envisagées pour le Voyage à l'île de France obéissent à des considérations personnelles et financières, on ne peut pas ne pas y voir non plus l'annonce discrète d'une forme de récit dont le centre d'intérêt se déplacera du réel extérieur vers le monde intérieur du voyageur. À preuve l'importance accordée, dans une perspective très moderne, à la personnalité du voyageur-narrateur, dont le point de vue devient en quelque

50 VIdF, p. 893-894.

51 Ibid., p. 892.

52 J.-C. Berchet, « De Paris à Jérusalem ou le voyage vers soi », Poétique, nº 53, 1983, p. 123 124.

${ }_{53}$ C’est ainsi que Saint-Pierre insère, à la suite des lamentations qui concluent la lettre VIII, une sorte de justification a posteriori de la tristesse qui marquait alors ces lignes (VIdF, p. 555-556). 
sorte l'aune à laquelle sera mesurée la représentation du pays étranger offerte au lecteur. Bien plus, Saint-Pierre entend faire jouer la différence de voix entre l'apprenti-auteur qu'il était dans les années 1770, pas encore débarrassé de ses oripeaux d'ingénieur, et l'institution littéraire vieillissante qu'il est en passe de devenir, afin de relativiser encore sa vision des choses : il a pour cela des termes qui, par-delà Chateaubriand, ne sont pas sans annoncer Fromentin... On est loin de la transparence de la description et du style simple et naturel exaltés par les préfaces des récits de voyage des siècles précédents ${ }^{54}$, et qui semblent encore marquer le Voyage de 1773 . Une ère nouvelle s'ouvre bien au voyageur qui, à travers la mise en avant de sa personnalité, l'opacité de son écriture et les variations de son point de vue, prétendra désormais donner à son lecteur moins une information qu'une perspective sur le monde et sur lui-même : plus rien n'interdit à l'écrivain de s'emparer du récit de voyage pour en faire un objet littéraire à part entière. 
Nicolas Brucker

Université de Lorraine

ORCID 0000-0002-1510-6161

\section{La figure kantienne du voyageur dans les Lettres westphaliennes de Charles de Villers (1797)}

\section{The Kantian Figure of the Traveller in the Westphalian Letters by Charles de Villers (1797)}

Charles de Villers, known as the French introducer of Kant's philosophy, chose in his first Kant presentation to adopt the genre of "philosophical letters". The traveller of the Westphalian Letters, published in 1797 in Berlin, is a French emigrant acquainted with German culture. His discovery of German cultural realities obeys the Kantian critical approach, especially through the abilities to feel and to know. Kant himself is presented through an allegory: intercultural transfer simplifies Kantianism for greater efficiency. Villers came to Kantianism through the detour of magnetism and homeopathy, which both proceed by desubstantializing material. Literature makes Kant travel from one country to another taking into account trade needs, even if it is not obvious at first glance. Finally cultural mediation stands as a collective work, as shown by the collaboration between Staël and Villers.

Keywords: travel, Kantianism, Villers, Staël, emigrant, cultural transfer

Mots-clés : voyage, kantisme, Villers, Staël, émigré, transfert culturel

Associer kantisme et voyage a de quoi surprendre : il n'est guère de philosophe plus sédentaire que Kant, lui qui passa toute sa vie à Königsberg. Et pourtant il est peu de penseurs qui par leur œuvre ont provoqué un tel bouleversement dans l'histoire de la pensée. Si Kant compare lui-même la philosophie transcendantale à la révolution copernicienne, c'est qu'en effet le déplacement qu'elle opère de l'objet au sujet marque un retournement complet et présente les 
problèmes classiques de la philosophie sous un angle nouveau. Le dépaysement est total: on se croit en une terre inconnue, pleine de promesses de découvertes et de nouveautés. Il faut un peu de courage pour quitter les bords rassurants des systèmes connus, et un peu de témérité pour admettre qu'ils ne sont que des illusions trompeuses. Entre l'excitation de la découverte et l'audace du départ vers l'ailleurs, la thématique du voyage est bien sous-jacente à cette philosophie.

Mais le voyage est aussi celui que font les idées pour aller d'un pays à l'autre. De l'Allemagne à la France, le kantisme (ou kantianisme) s'est fait connaître grâce à des publicistes, traducteurs et vulgarisateurs, qui ont joué le rôle de médiateurs interculturels. Charles de Villers est de ceux-là. En même temps qu'il introduisait le kantisme en France, il donnait les caractères de ce qui allait durant tout un siècle constituer les éléments d'un drame, ou d'une «passion» comme l'écrit Laurent Fedi ${ }^{1}$. Dès l'origine, Kant a trouvé sa place au cœur des conflits politiques français, et le kantisme s'est vu assigner le rôle de ligne de démarcation opposant les différents clans en présence. C'est ainsi qu'il faut expliquer la vigueur avec laquelle les savants de l'époque se déclarèrent défenseurs ou adversaires de Kant.

L'émigration révolutionnaire est un facteur essentiel de la diffusion de Kant en France, et de la place qu'il occupa dans la vie intellectuelle française. Favorisés par leur connaissance de la langue, bénéficiant d'une information à jour et d'un accès direct aux sources, les hommes de lettres émigrés prirent part à la querelle du kantisme. L'un d'eux se distingue tout particulièrement. Villers, officier d'artillerie poussé à l'émigration après la déroute de l'Armée des Princes, a reçu à Göttingen l'enseignement de Bouterwek, alors fervent disciple de Kant, et a aussitôt montré un enthousiasme pour le philosophe. Il en résulta plusieurs publications, destinées au public français, deux articles dans le Spectateur du Nord, journal de l'émigration édité à Hambourg, et un essai paru en 1801, souvent réédité et traduit dans plusieurs langues. Chronologiquement antérieure, la lettre VIII des Lettres westphaliennes ${ }^{2}$ donne une première présentation de Kant. Située au centre du recueil, elle constitue une clé de lecture de l'ensemble des lettres : elle définit en effet la figure même du voyageur et rédacteur des lettres.

Converti au kantisme comme on l'est à une religion, l'auteur des lettres montre par le regard qu'il porte sur les réalités qui l'entourent comme sur les pensées qui lui viennent qu'il s'est appliqué à lui-même la démarche critique préconisée par Kant. Ce qu'il découvre ainsi en Westphalie ne saurait se réduire à une suite de détails plus ou moins anecdotiques : ce que le récit de voyage met

1 L. Fedi, Kant, une passion française. 1795-1940, Hildesheim, Georg Olms, 2018.

2 Villers, Lettres westphaliennes, écrites par M. le comte R.M. à Mme de H. sur plusieurs sujets de philosophie, de littérature et d'histoire et contenant la description pittoresque d'une partie de la Westphalie, Berlin, Vieweg, 1797. Les références aux pages sont insérées dans le texte entre parenthèses. 
en forme, c'est la découverte essentielle, et centrale, de la méthode critique. Les Lettres westphaliennes, dont on a parfois fait un fleuron de l'esprit français, cacheraient ainsi, sous leur apparente futilité, une gravité toute philosophique.

\section{Les Lettres anglaises revisitées}

On a souvent rapproché les Lettres westphaliennes des Lettres anglaises de Voltaire ${ }^{3}$. De fait, Villers ou ses correspondants ont dès l'origine encouragé ce rapprochement. Le parallèle entre Newton et Kant est devenu un lieu commun. Villers avait-il ambitionné de tenter pour l'Allemagne ce que Voltaire avait réalisé soixante-trois ans plus tôt pour l'Angleterre ? Le choix de la forme épistolaire, la variété des sujets, la gravité de la matière traitée avec la légèreté qui sied à une correspondance familière rattachent les Lettres westphaliennes au genre des «lettres philosophiques et amusantes », notamment illustré par Muralt en 1725 et Mauvillon en $1740^{4}$, et imité par la suite par nombre d'auteurs. L'adjectif westphalien a aussi une connotation voltairienne : il évoque au public le conte philosophique Candide et le château muni d'une porte et de fenêtres d'un baron dont le nom sonne aux oreilles francophones comme un coup de tonnerre. La Westphalie semble être la version hyperbolique de l'image stéréotypée de l'Allemagne. On lit dans l'Encyclopédie, sous la plume de Jaucourt : "Le commerce de ses habitans consiste en biere \& en jambons " ${ }^{5}$. Or, on le sait, le genre des lettres philosophiques s'abreuve à la source des stéréotypes, soit pour les confirmer, soit pour les contester.

Une différence cependant, et de taille, subsiste. Le point de vue de l'étranger adopté dans les Lettres anglaises, et le réflexe qui consiste à systématiquement

3 « Bien qu'il rejetât la philosophie de Voltaire, l'intervention de Villers pouvait se faire sur le modèle des Lettres anglaises ». M. Delon, "Clivages idéologiques et antagonismes nationaux à l'époque de la Révolution et de l'Empire : le cas de Charles de Villers ", dans : Feindbild und Faszination. Vermittlerfiguren und Wahrnehmungsprozesse in den deutschfranzösischen Kulturbeziehungen (1789-1983), sous la dir. de H.-J. Lüsebrink et J. Riesz, Frankfurt a M., Diesterweg, 1984, p. 26 - «Bereits der Titel Lettres westphaliennes ist kontrafaktisch zu Candide. Die Lettres weisen auf Kant hin, so wie Voltaire in seinen Lettres anglaises auf Locke und Newton gezeigt hatte ». Th. Keller, Verkörperung des Dritten im Deutsch-Französischen Verhältnis. Die Stelle der Übertragung, Paderborn, Wilhelm Fink, 2018, p. 152. - Voir F. Schmitz, « Kommunikationsprobleme von Philosophie und Literatur im Brief: Charles de Villers' Lettres Westphaliennes (1797) in Korrespondenz mit den Lettres philosophiques (1734) Voltaires ", dans : Literatur als philosophisches Erkenntnismodell. Literarisch-philosophische Diskurse in Deutschland und Frankreich, sous la dir. de S. Hüsch et S. Singh, Tübingen, Narr, 2016, p. 42-59.

4 B. de Muralt, Lettres sur les Anglais et les Français. É. de Mauvillon, Lettres françaises et germaniques. Sur ces dernières, voir R. Krebs, «Les Lettres françaises et germaniques de Mauvillon et leur réception en Allemagne », Dix-huitième Siècle, n 14, 1982, p. 377-390.

5 «Westphalie», Encyclopédie, XVII, 1765, p. 606-607. 
rapporter à la réalité culturelle française les découvertes faites dans le pays, ne se retrouvent pas chez Villers. Son voyageur n'est tout bonnement pas un étranger. Il désigne d'ailleurs l'Allemagne comme «notre nation »: « [...] mais n'est-il pas honteux pour notre nation que tant de provinces offrent encore à l'œil des étrangers le même aspect sauvage et barbare qu'elles avoient sans doute du temps de nos ancêtres les Cattes et les Cherusques? » (p. 50) - et les tribus germaniques coalisées contre Varus comme "nos bons aïeux» (p. 244). La dame à qui il écrit est appelée, avec une pointe de dérision certes, " une vraie Germaine ": "Si vous avez le cœur teuton, madame; si vous êtes une vraie Germaine, vous viendrez à Dribourg » (p. 59). S'il n'est pas étranger, le voyageur découvre cependant une région dont il ignore tout, la Westphalie orientale, entre Paderborn et Holzminden. Mis à part la mention des « jambons », qu'il fait platement rimer avec les « habitans si bons", on ne constate pas de recours aux stéréotypes, ni de réflexe comparatif. Quand il compare, c'est d'ailleurs pour valoriser, non pour dévaluer. Le référent est majoritairement français, mais aussi, surtout quand il s'agit de poésie, latin ou italien.

La difficulté d'assigner le voyageur à une identité nationale s'explique, quand on sait qui se cache sous les initiales qui sur la page de titre désignent le rédacteur des lettres. "Monsieur le comte de R. M. » renvoie à Germain Hyacinthe de Romance de Mesmon (1745-1831), officier supérieur qui connut un parcours similaire à celui de Villers. Contraint à l'émigration après les défaites militaires de 1792, il contribua pendant quelques mois au Spectateur du Nord, avant de fonder d'éphémères journaux. Cette activité de publiciste fait suite à des travaux littéraires, antérieurs à la Révolution, travaux certes modestes, mais suffisants pour lui donner une stature d'homme de lettres. Que Villers ait choisi de placer ses Lettres sous le patronage de Romance de Mesmon n'est pas surprenant, quand on songe que c'est à lui qu'il succède au Spectateur du Nord, pour la rubrique littéraire. Baudus s'est en effet fâché avec son rédacteur, sans doute sur la question, sensible, des émoluments. Dès la fin de 1797, la place est libre : Villers est donc le remplaçant de Mesmon ; son « V. » fait suite au « R. M. » pour signer les articles littéraires.

L'émigré dont Villers projette l'image idéale, sous les initiales d'un émigré homme de lettres qu'il a effectivement connu, et peut-être admiré, au regard de son kantisme ${ }^{6}$, s'est si bien acculturé au pays d'accueil qu'il a perdu tout ou partie de ses marques culturelles, sans pour autant avoir acquis celles qui l'identifieraient aux naturels qu'il côtoie. Figure identitaire transitionnelle, il a engagé la mutation qui doit achever sa transformation. Pour l'heure, il est comme suspendu, et ne peut se réclamer positivement d'aucune appartenance nationale.

${ }^{6}$ La lettre de Mesmon à Kant, du 28 mars 1798, fait état d'une correspondance suivie entre les deux hommes. Das Bonner Kant-Korpus, AA XII, Briefwechsel 1798, p. 238. 


\section{Sentir et connaître}

Dans son Éloge de Quesnay (1775), Romance de Mesmon distinguait le citadin, préoccupé de ses seules passions et de ses seuls intérêts, et l'homme sorti des villes, livré à la nature et à lui-même. "S'il porte en lui-même l'étincelle du génie, la douce contemplation ravira son cœur, \& son esprit tourmenté par une insatiable curiosité, lui fera sans cesse éprouver le besoin de sentir $\&$ de connoître. $»^{7}$ Ces deux verbes traduisent au mieux l'activité du voyageur des Lettres westphaliennes: sentir, par le contact renouvelé avec la nature, et les réminiscences littéraires ou historiques que la vue des paysages lui fait naître ; connaître, par les travaux d'érudition, les lectures, les traductions, les réflexions enfin dont les lettres donnent un aperçu. La disponibilité à soi que permet le voyage, et plus précisément ici le séjour dans un centre thermal, porte l'auteur des lettres à deux types d'attitude : la rêverie, fruit de la promenade solitaire dans des paysages inspirants; l'enthousiasme, qui découle d'une exaltation subite et incontrôlée. De Rousseau à Lamartine, ces modalités de l'âme voyageuse ont trouvé d'innombrables illustrations dans une production littéraire, en vers ou en prose, qu'on identifie aujourd'hui à l'écriture de soi. Ces lettres prennent l'allure d'un journal, où se reflète l'état d'esprit changeant, voire instable du voyageur, dans un récit qui mêle souvenirs et réflexions aux événements ou aux descriptions restitués dans le respect de la chronologie ${ }^{8}$. Ce subjectivisme peut être affilié à la philosophie sensualiste ${ }^{9}$; il peut être aussi vu, dans une perspective kantienne cette fois, comme un recentrage du sujet sur lui-même, sur ses représentations et sur la manière de les produire en soi. Les Lettres livrent, dans l'instantané d'une chronique intime, une phénoménalité de la conscience en voyage. Mais elles illustrent aussi le pouvoir transformateur du voyage sur le sujet, où la découverte de l'autre n'est que le moyen ou même parfois le prétexte d'une (re)découverte de soi. De la réalité décrite, on revient au terme d'un mouvement elliptique au moi regardant. Le récit de voyage rend compte de cette transformation du regard posé sur les choses du monde, incitant le lecteur à vivre, par imitation, une semblable conversion. Pour le voyageur, le chemin du retour, de Dribourg à Berlin, ne saurait refermer la parenthèse : une modification s'est produite, qui trouve une équivalence, du côté du lecteur français, dans le chemin qu'il est censé faire, de Paris vers le cœur de l'Allemagne.

Si le voyage apporte de la connaissance, c'est de manière indirecte, par le filtre de la raison qui, selon Romance de Mesmon, doit distinguer dans la coutume ce qui relève du local et ce qui relève de l'universel.

7 G. H. de Romance de Mesmon, Éloge de François Quesnay, Paris, Didot, 1775, p. 9.

${ }^{8}$ La seule lettre datée est la première, datée de Dribourg, le 5 juillet 1796.

9 C'est l'interprétation de M. Orcel à propos de Senancour : il parle d'un «subjectivisme sensualiste ou matérialiste ». "Rêveries d’un corps dans les Alpes », Poßsie, n 11, 2006/2, p. 122. 
Les voyages en multipliant sous mes yeux les modèles des mœurs, des usages, des opinions de toutes les nations, mettent en garde contre les préventions locales; je m'accoutume à laisser l'exemple souvent trompeur pour ne me décider que sur la règle abstraite de la raison, qui est la connaissance claire et distincte des vrais intérêts de l'humanité. ${ }^{10}$

Ce texte, paru en 1797 dans le Spectateur du Nord, s'inspire de la II ${ }^{\mathrm{ème}}$ partie du Discours de la méthode de Descartes, où il est fait référence aux premiers voyages de l'auteur en Hollande, Danemark et Allemagne en 1618-1619. Après Montaigne, Descartes tire de cette expérience une double leçon : primo, les différences dans les usages et les opinions, constatées dans les peuples du monde, ne permettent de disqualifier ni les uns ni les autres ; secundo, le cas particulier, local et concret, persuade mieux qu'aucune vérité générale et abstraite. Il conclut de là qu'il n'y a rien à attendre d'un savoir tiré de l'expérience, et qu'on ne peut rien apprendre de certain par les voyages. Mesmon suit le même raisonnement, mais, contrairement à Descartes, il accorde aux récits de voyage une valeur heuristique : le spectacle de la multiplicité des exemples conduit l'esprit à rechercher l'universalité. L'expérience n'est pas à proscrire ; elle est une étape sur le chemin de la vérité, laquelle ne peut s'acquérir que par l'application des règles de la raison.

Cette position est aussi celle du voyageur des Lettres westphaliennes : les particularités constatées n'éveillent en lui nul étonnement excessif ; elles sont décrites comme des faits, n'ayant qu'une valeur locale, dont on ne peut rien conclure de général. Leur prestige est volontairement limité. Par ailleurs, la pluralité des opinions s'illustre dans les débats portant sur l'étymologie du nom d'une idole celte, le lieu exact de la bataille d'Hermann, les propriétés des eaux de Dribourg. Sur chacun de ces débats, le rédacteur, prenant soin d'exposer les différentes thèses, analyse, compare, critique, et selon les voies rationnelles conclut à la meilleure solution. Les règles de la raison sont scrupuleusement suivies. La philosophie, affirme-t-il dans la lettre IV, n'a jamais rien produit que « de louable et de bon » (p. 42).

\section{Kant « pour les nuls»}

Le voyage culturel n'est possible qu'au gré d'une opération de transfert. Le lecteur des Lettres ne peut directement s'identifier au voyageur ; il doit construire cette identification. Il est aidé en cela par un ensemble de dispositifs médiatiques. Les références qui jalonnent les Lettres, familières à un public français, sont

10 Romance de Mesmon, «Fragment d'un manuscrit sur la sensibilité », Spectateur du Nord, août 1797, p. 212. 
autant de balises aisément repérables. La notion de "transfert culturel », définie comme " mise en relation de deux systèmes autonomes et asymétriques $»^{11}$ s'avère d'une grande utilité pour comprendre que la réception ne se fait qu'au prix d'une sélection dans les idées ou les textes de la culture exportatrice. De la philosophie kantienne, un lecteur français de 1797 ne peut percevoir qu'une petite part, celle qui se trouve compatible avec son horizon culturel, celle qu'il peut admettre et assimiler.

Pour signifier au public l'originalité de la démarche critique kantienne, Villers a recours à une allégorie. Platon a représenté une caverne, Villers figure une muraille.

Une muraille énorme, inébranlable, aussi ancienne que le monde, qui durera autant que lui, est élevée des mains de la nature entre nos foibles regards et la contrée des causes premières. On a fait dans tous les temps de vains efforts pour l'abattre; elle est fondée sur le roc. Derrière elle reposent les fameuses questions de l'origine des choses, du premier moteur, de la substance et de l'essence, de l'immatérialité et de l'immortalité de nos ames, de la liberté de l'homme, de la prescience divine, et tant d'autres. - Ne pouvant parvenir à nous faire voir réellement au de-là, on a voulu nous faire croire que nous y voyions, et il s'est trouvé dans tous les temps de brillans imposteurs qui ont couvert la grande muraille de perspectives, de vues artistement coloriées ; si bien, que l'œil surpris ne voyoit plus de muraille, et se perdoit avec plaisir dans ces lointains magiques. Point de philosophes qui n'ayent voulu à leur tour devenir peintres en perspective : armés de palettes et de pinceaux, ils se disputoient tous un coin de la grande muraille, où ils pussent barbouiller à leur aise, avec autant d'ardeur qu'on se disputoit une place au salon du Louvre [...]. (p. 143-144)

Sur le mur infranchissable qui sépare les hommes des énigmes de la métaphysique, se sont peintes au fil des siècles les rêveries des hommes. À travers l'énumération des thèses philosophiques, Villers suggère cependant l'idée d'un progrès continu de l'esprit humain : des fables des premiers temps, où figure en bonne place la religion de Moïse, à Platon et Aristote, puis aux philosophes modernes, l'humanité avance pas à pas vers la vérité. Descartes, Malebranche, Locke firent d'importantes découvertes; ils mirent à jour l'existence de la muraille. À ce titre ils illustrent la philosophie pré-critique. Mais il fallut attendre Kant, pour que l'imposture métaphysique fût enfin dénoncée.

Enfin Kant est venu ; assis près de là sur un rocher, il nous montre du doigt cette barrière insurmontable qui nous cache les causes et les premiers ressorts

11 M. Espagne, Les transferts culturels franco-allemands, Paris, Presses Universitaires de France, 1999, p. 286. 
de l'univers. Sentinelle vigilante, Kant semble placé là pour écarter à l'avenir tout imposteur qui voudroit encore venir fasciner les yeux. (p. 149)

L'image est originale certes ; pourtant elle est suggérée par Kant. Dans les Prolégomènes à toute métaphysique future (1783), celui-ci définit le périmètre du connaissable ${ }^{12}$. Il apporte cependant une précision dont Villers ne tient pas compte. Il distingue les limites (Grenzen) et les bornes (Schranken), et emploie le mot espace (Raum) pour désigner le savoir supposé mais invérifiable, ce qui est au-delà du périmètre du connaissable, mais qui pour autant n'est pas impensable. La raison, précise Kant, est bornée (eingeschränkt) aux phénomènes. Le Kant villersien pointe du doigt la borne de la connaissance, il n'envisage pas la limite de l'esprit humain. Car Villers s'attache à montrer que les idées métaphysiques, telles que l'existence de Dieu ou l'immortalité de l'âme, sortent de la sphère du connaissable; il ne montre pas que ces mêmes idées, sur la base des postulats de la raison pratique, sont l'objet d'une croyance rationnelle. C'est le reproche que Schelling lui fera en 1802, après la parution de la Philosophie de Kant : il ignorerait la négativité du criticisme kantien, et emploierait tous ses efforts à faire le procès des philosophes français du XVIII ${ }^{e}$ siècle. De fait, il faut convenir que son «Enfin Kant est venu » déclare moins la radicale nouveauté du criticisme kantien, que l'opprobre jeté sur l'échec des doctrines qui l'ont précédé. Sa cible reste prioritairement le sensualisme, dont le chef de file est Condillac, et qu'il présente comme une version aggravée du lockisme. Il en fait la cause de la décadence des mœurs, du goût et de la pensée en France ; c'est aussi à lui qu'on doit l'abus de la liberté individuelle et publique, d'où résultent les horreurs de la Révolution française. Pierre Daled, qui a soigneusement étudié l'émergence du mot sensualisme, en attribue la paternité à Villers et en situe la naissance dans l'opposition au matérialisme français ${ }^{13}$. Entre tenants du cartésianisme, monarchistes et contre-révolutionnaires d'un côté, et tenants du sensualisme, idéologues opposants décidés à Bonaparte de l'autre, Villers va rapidement se trouver doublement isolé. Sa marge de manœuvre s'en trouvera d'autant plus réduite. En cette extrême fin du XVIII ${ }^{e}$ siècle, la fortune de Kant en France est, pour un temps du moins, compromise du fait d'un jeu politique défavorable.

La métaphore de la muraille permet de tracer une histoire de la philosophie, de Platon à Kant, selon une conception historiciste caractéristique des Lumières. De Gérando adoptera la même démarche dans son Histoire comparée des systèmes de philosophie, parue en 1804. De façon concentrée, en quelques pages

12 Kant, textes choisis et présentés par M. Fossel et F. Lamouche, Paris, Points, 2010, p. 75-80. Kant, Prolegomena zu einer jeden künftigen Metaphysik, " Der transzendentalen Hauptfrage Dritter Teil: Wie ist Metaphysik überhaupt möglich? », \$57.

13 P. F. Daled, Le matérialisme occulté et la genèse du "sensualisme ». Écrire l'histoire de la philosophie en France, Paris, Vrin, 2005, p. 63-67. 
seulement, Villers peint les errements, voire les mensonges de la philosophie. C'est autant une histoire qu'un procès. Kant vient dévoiler la supercherie, il met fin aux prestiges de l'imagination, et nous fait voir la vérité nue. Ce faisant, Villers acclimate, par le didactisme de l'image, le philosophe teuton, habitant des confins de la Prusse et de la Russie, au paysage culturel européen. La même démarche s'applique à la littérature. Hermann n'a pas eu comme Énée son Virgile pour gagner l'immortalité ; mais Klopstock est venu, pour réparer cette injustice. La fontaine du Bullerborn n'a pas eu comme Blanduse son Horace; mais le rédacteur s'essaie par ses propres vers à remédier à cette carence. En rapprochant les réalités historiques ou littéraires du Nord et du Midi, en montrant que les unes ne valent pas moins que les autres, Villers dessine une vision plus complète de la civilisation européenne, incluant les cultures nordiques. Kant, placé tout au bout de la chaîne, après les philosophes de la Grèce, de France et d'Angleterre, apparaît comme un aboutissement et un dénouement.

L'approximation de l'allégorie de la muraille ne fait pas de doute. Tout effort d'explication du kantisme se heurte à ce type d'écueil. Schelling reprochera de même à Villers l'usage indu qu'il fait de la métaphore de la camera obscura pour expliquer l'esthétique transcendantale ${ }^{14}$, exemple repris par Gérando dans son Histoire comparée $e^{15}$. Mais Kant n'avait-il pas ouvert la voie, quand il recourait à l'image du bateau qui descend le fleuve, pour critiquer le principe de causalité (Critique de la raison pure, Analytique transcendantale) ? Villers, en répliquant à Schelling, justifie la nécessité d'un tel artifice pédagogique : "Es wird sich unmöglich ein Deutscher dem französischen Publicum unmittelbar verständlich machen $»^{16}$. L'adverbe unmittelbar suggère qu'il faut des médiations, fatalement insuffisantes, mais néanmoins nécessaires. Le voyage est une de ces médiations, utile autant qu'efficace.

\section{Du magnétisme au kantisme}

La figure kantienne du voyageur est aussi celle de la pensée dans son progrès, par essence indéfini. La philosophie kantienne a elle-même mis du temps pour

14 Schelling, « Notice sur les tentatives de Monsieur Villers pour introduire la philosophie kantienne en France », trad. P. Cerutti, $\$ 42$, Revue germanique internationale [En ligne], 18 | 2013, http://journals.openedition.org/rgi/1447, consulté le 2/11/2020. - Villers, Philosophie de Kant, Metz, Collignon, 1801, p. 116-118.

15 J.-M. de Gérando, Histoire comparée des systèmes de philosophie, relativement aux principes des connaissances humaines, Paris, Henrichs, an XII-1804, t. III, p. 540.

16 «Il n'est pas possible qu'un Allemand puisse se faire directement comprendre du public français ». Briefe an Ch. de Villers. Auswahl aus dem handschriftlichen Nachlasse des Ch. de Villers, éd. M. Isler, Hamburg, $1879 ; 2^{\mathrm{e}}$ éd. 1883, Villers an Schelling, 3. Januar 1803, p. 245. 
trouver sa place dans le paysage intellectuel allemand; les débats techniques que l'esthétique transcendantale a d'emblée suscités ont tendu à confiner le kantisme à un cercle d'initiés. Son effet sur les arts, la littérature ou la politique, s'ils se font attendre, finissent par se manifester. Les Rückenfiguren de Caspar David Friedrich sont une transposition à l'esthétique picturale de la doctrine kantienne de la subjectivité ${ }^{17}$. Cette forme particulière de repoussoir est l'équivalent en peinture de l'énonciation personnelle en littérature : le primat du sujet est ainsi affirmé.

La migration de Villers vers Kant se dessine avant même son initiation au criticisme. Adepte du magnétisme animal, Villers appartient à la catégorie des «psycho-fluidistes $»^{18}$. Il interprète le fluide mesmérien non comme une réalité physique, mais comme un phénomène qu'il inscrit dans l'ordre moral. Le Magnétiseur amoureux (1787) rend compte, dans la forme d'un roman, de la puissance de l'ascendant exercé par une volonté sur une autre. Ce qu'on appelle l'amour est la traduction de cet ascendant. Cette tendance à réorienter la recherche d'une causalité physique dans une direction phénoménale coïncide avec la désubstantialisation kantienne des idées métaphysiques. On peut ainsi dire qu'avant de lire Kant, Villers avait déjà adopté la démarche critique. Son intérêt pour l'homéopathie relève de cette même tendance. La correspondance qu'il entretient avec Hahnemann d'une part, avec Brandis d'autre part indique clairement, sur la question de la médecine, qu'il a compris qu'il ne faut pas chercher la guérison dans la cause du mal, mais tirer des symptômes le traitement à appliquer. La technique de réduction de la matière par dilutions successives jusqu'à l'infinitésimal part aussi d'un postulat kantien. Elle vise en effet à rétablir les conditions de possibilité de l'action de la nature, non à se substituer à elle ${ }^{19}$.

Contestataire des systèmes de pensée dominants, Villers reste pendant quelques années sans pouvoir se référer à un quelconque corps de doctrine. «Nous sommes des gens qui avons jeté bas notre vieille maison et qui n'avons encore rien rebâti : en attendant on vit mal à l'aise $»^{20}$, écrit-il pour signifier cette transition. Kant était attendu. Il vint comme s'il avait déjà été là. On ne peut autrement expliquer l'enthousiasme avec lequel Villers reçut l'enseignement

17 C. D. Friedrich, Der Wanderer über dem Nebelmeer, 1818 (Hamburger Kunsthalle).

18 B. Méheust, "Sous le magnétisme des romanciers, le magnétisme "réel” ", Traces du mesmérisme dans la littérature européenne du XIX siècle. Einflüsse des Mesmerismus auf die europäische Literatur des 19. Jahrhunderts, sous la dir. de E. Leonardy, M.-F. Renard, C. Drösch, S. Vanasten, Bruxelles, Publications des Facultés universitaires Saint-Louis, 2001, p. 37.

19 Voir N. Brucker, "Vis naturae medicatrix. Villers et Hahnemann », dans : Un homme, deux cultures. Charles de Villers entre France et Allemagne, sous la dir. de N. Brucker et F. Meier, Paris, Classiques Garnier, 2019, p. 163-178.

20 Cité dans : L'Érotique comparée de Charles de Villers, éd. E. Eggli, Paris, Gamber, 1927, p. 43 . 
de Bouterwek qui à Göttingen en 1796 l'initia à la philosophie transcendantale ${ }^{21}$, mais aussi la rapidité avec laquelle il sut s'approprier cette doctrine, de façon assez complète, quoi qu'en ait dit Schelling, et l'ardeur avec laquelle il se fit le zélateur de Kant tant en France qu'en Allemagne.

Côté français, on ignore à peu près tout du criticisme kantien. Le Magasin encyclopédique est le premier journal à avoir rendu compte de cette philosophie, par des fragments traduits, des analyses, des comptes rendus. Il publie la première notice étendue consacrée à Kant. Elle est signée A. Keil, et porte principalement sur le Projet de paix perpétuelle ${ }^{22}$. Quand Villers publie les Lettres westphaliennes, c'est donc un nom à peu près inconnu des Français qu'il dévoile alors. Encore faut-il remarquer que l'ouvrage, faute de diffusion, resta complètement ignoré du public francophone ${ }^{23}$. Il fallut attendre la notice biographique sur Kant, parue l'année suivante dans le Spectateur du Nord ${ }^{24}$, et surtout une présentation de la Critique de la raison pure, en avril 1799, pour que la France apprenne le nom de Kant. Cette dernière notice connut une audience significative : imprimée à Brunswick sous forme de brochure, elle fut largement diffusée. Mme de Staël en eut un exemplaire, et l'on sait que cette lecture ne compta pas pour rien dans son intérêt pour Kant. Avec l'essai imprimé par Collignon à Metz en 1801, sobrement intitulé Philosophie de Kant, ou Principes fondamentaux de la philosophie transcendentale [sic], Villers compléta sa présentation du kantisme.

On a parfois dit que Villers ne connaissait pas vraiment Kant au moment des Lettres westphaliennes. Nous croyons le contraire. L'enseignement de Bouterwek avait porté ses fruits. Il était déjà en 1797 un disciple distingué du maître et tout à fait capable d'exposer l'essentiel du système. Le genre des lettres philosophiques n'autorise pas d'entrer dans les arcanes de la pensée critique. Aussi se contentet-il d'une allégorie qui situe Kant dans la lignée des systèmes empiristes ou idéalistes. Cependant en d'autres endroits, il donne une illustration par l'exemple de ce qu'est le criticisme kantien. Toute la lettre VI vise à détruire l'illusion de la certitude du savoir médical ; elle tend à montrer que la rationalité n’y est qu'apparente, et que le pouvoir du médecin repose sur la croyance du patient. Le dialogue que le rédacteur, qui est aussi curiste, a avec le docteur Brandis lui

${ }^{21}$ Voir le portrait que V. Cousin trace de Bouterwek, qu'il a rencontré en 1817 lors de son séjour à Göttingen. Fragments et Souvenirs, $3^{e}$ éd., Paris, Didier, 1857, p. 111-113.

22 J. Ferrari, "L'œuvre de Kant en France dans les dernières années du XVIII siècle ", Les Études philosophiques, nº 4, octobre-décembre 1981, p. 405-406.

23 "Ces pièces ont été peu connues en France ", écrit Villers en parlant des Lettres westphaliennes et des notices parues dans le Spectateur du Nord. Philosophie de Kant, p. LX. Louvrage est aujourd'hui d'une grande rareté : on n'en connait pas d'exemplaire dans les fonds publics français; une dizaine d'exemplaires se trouve en Allemagne.

24 "Notice littéraire sur Mr. Kant », Spectateur du Nord, 1798, p. 335-367 ; reprise dans F. de Neufchâteau, Le Conservateur, Paris, Crapelet, 1799, II, p. 29-57. 
ôte tout espoir et toute consolation. Alors qu'il s'est ouvert à son ami des maux qu'il endure, attendant de sa part un possible remède, il reçoit cette réponse :

Est-ce une ordonnance qu'il vous faut ? Si vous le désirez, je vais vous en donner une dans le style le plus éloquent de la faculté. Dispensez-m’en, répliqué-je, s'il est possible. Et bien, ajoute-t-il, du même ton, puisque c'est de la raison que vous voulez, et non pas de la médecine, ne faites rien, ménagez-vous, prenez quelques verres d'eau fraîche, et surtout de la patience. (p. 83)

La réponse de Brandis est sans ambiguïté : médecine et raison ne riment pas ensemble. L'art médical est d'abord une rhétorique, puisqu'il s'agit avant tout de provoquer l'adhésion du patient. Il consiste à produire de l'illusion. La sincérité du médecin ne va pas jusqu'à mettre en doute les vertus thérapeutiques des eaux de Dribourg. Aussi les "verres d'eau fraîche " qu'il prescrit sont-ils inoffensifs : l'on n'a jamais tué personne avec une telle ordonnance. Quant à la "patience ", c'est une manière d'indiquer l'œuvre de la nature, dont la force doit peu à peu rétablir l'équilibre momentanément rompu dans l'organisme. Délimiter les champs respectifs de la connaissance et de la croyance relève d'une démarche authentiquement critique. La désinvolture du ton de cette lettre a pu tromper les lecteurs : la méthode est parfaitement maîtrisée ; elle donne l'exemple concret de l'attitude philosophique kantienne appliquée aux situations ordinaires de la vie.

\section{Faire voyager Kant}

«Un bon livre a plus de peine à passer le Rhin qu'une armée autrichienne " $^{25}$, écrit Villers dans la Philosophie de Kant. C'est la leçon qu'il a tirée de sa collaboration avec plusieurs libraires et directeurs de journaux. Amable de Baudus, qui dans ses lettres à Villers, rend régulièrement compte de la façon dont ses articles sont reçus des lecteurs de son journal, cite un extrait d'une lettre que Charles Pougens lui a adressée et où il est question de Kant. Le savant, qui est aussi imprimeur-libraire et traducteur, donc sensible à la question de la rentabilité, s'exclame, désabusé : " mais hélas ! il ne faut à nos lecteurs que des romans, des voyages et des pamphlets $»^{26}$. Les "voyages » font partie de la bibliothèque d'un homme de goût. Pougens a lui-même traduit le Voyage à la Nouvelle Galles du Sud de John White, et le Voyage philosophique et pittoresque sur les rives du Rhin de Georg Forster. Baudus, qui a recruté Villers

25 Villers, Philosophie de Kant, op. cit., p. 203.

26 "Lettre de Baudus à Villers, 13 septembre 1799 », dans : Correspondance. 1797-1815. La médiation faite ouvre, éd. M. Bernard et N. Brucker, Paris, Honoré Champion, 2020, p. 94. 
pour le ton léger et railleur des Lettres westphaliennes, découvre avec dépit un autre visage de l'écrivain. Retombant dans les habituels stéréotypes, il met en opposition Kant, philosophe réputé obscur, reflet de la pesanteur allemande, et les Lettres westphaliennes, incarnation de l'esprit français, vif et léger ${ }^{27}$. C'est aussi le point de vue de La Maisonfort, qui finance le Spectateur du Nord : « Si vous m'en croyez, Monsieur, vous vous attacherez à la poésie légère, pour laquelle je sais que l'auteur des Lettres westphaliennes est fait ", confie-t-il à Villers en $1798^{28}$. À quelques années de là, Mme de Staël raisonnera de la même manière ${ }^{29}$. Ces correspondants découvrent que chez Villers ces deux tendances cohabitent. Il en est ainsi du voyageur des Lettres, qui apparaît tantôt comme un rêveur inspiré, au lyrisme anacréontique, tantôt comme un intarissable raisonneur, au ton apodictique, ne cessant d'affirmer et de démontrer.

Avec un point de vue plus explicitement mercantile que Baudus, le libraire messin Collignon cherchera lui aussi à détourner Villers de ses travaux kantiens : Kant ne se vend pas, lui assure-t-il ; maintenant que la Révolution est passée, les Français veulent rire et non pas philosopher. «Kant, pour cette fois, cède le pas à Momus ${ }^{30}$, écrit-il à son ami. Cet antagonisme entre production savante et littérature de divertissement, Villers l'a si bien intériorisé qu'il a réglé son activité d'écrivain autour de ces deux pôles : parallèlement à ses travaux d'érudition - Kant, Luther, l'étude comparée des littératures, l'histoire des universités allemandes, etc. - il doit livrer à ses collaborateurs des comptes rendus, des traductions, des adaptations. Les "voyages" l'occupent particulièrement. Il donne à Baudus des comptes rendus, parus dans le Spectateur du Nord, des Voyages de Mungo-Park (1797) et du Voyage de La Pérouse (1797). Il travaille pour Collignon à une Relation abrégée du voyage de La Pérouse, qui paraît en un volume en 1799 sous la fausse adresse de Leipzig, tout en étant imprimée à Metz. Le libraire évoque d'autres projets de contrefaçon ou de traduction, qui n'aboutiront pas.

Avec les Lettres westphaliennes, Villers a fait voyager Kant. Il a traité un sujet grave dans une forme légère, et jeté le public français sur des routes jamais frayées auparavant. S'il n'a pas renouvelé la tentative, il ne s'en est pourtant pas repenti. En 1808 parut une «nouvelle édition» des Lettres, non plus à Berlin, mais à Brunswick. Le libraire Friedrich Vieweg a dans l'intervalle déménagé son entreprise afin de se rapprocher de sa famille (il a épousé en 1795 la fille

27 Voir notamment : «Lettre de Baudus à Villers, 21 novembre 1799 », dans : Correspondance. 1797-1815, op. cit., p. 101.

28 Cité dans : Érotique comparée, op. cit., p. 41.

29 «Lettre de Staël à Villers, 3 juin 1803 », dans : Madame de Staël - Charles de Villers Benjamin Constant. Correspondance, éd. K. Kloocke, Frankfurt a. M., Peter Lang, 1993, p. 51. Staël dit avoir reçu les Lettres westphaliennes dans une lettre à Villers du 20 juillet 1803. Ibid., p. 59.

30 «Lettre de Collignon à Villers, 18 mars 1801 », dans : Correspondance. 1797-1815, op. cit., p. 234. 
de Joachim Heinrich Campe). En fait de réédition, il s'agit d'un rhabillage de l'édition de 1797 sous une page de titre différente, pratique commerciale fréquente à l'époque. Les nombreuses corrections pratiquées par Villers sur son exemplaire personnel ${ }^{31}$, et destinées à cette réédition, n’auront servi à rien. La nouvelle parution conserve toutes les fautes d'impression de la première. Vieweg cherche à profiter de la mise en place du nouveau royaume de Westphalie, confié à Jérôme Bonaparte, et de l'installation à Cassel, où se tient la cour, d'une importante colonie française. C'est, pense-t-il, un public de choix pour ces Lettres, qui invitent à la découverte d'une région de ce royaume sous obédience française.

L'autre élément qui prouve que Villers n'a pas renié ses Lettres, c'est l'hommage qu'il en fait à Mme de Staël en juillet 1803. À la fin de 1802, celle-ci avait fait envoyer à Villers, par le libraire Cotta de Tübingen, son roman Delphine. L'envoi de Villers serait donc une politesse d'auteur. Sa correspondante lui répond de Coppet pour l'en remercier, et dit avoir lu ces Lettres " avec beaucoup d'intérêt "; si certaines lettres lui ont paru " extrêmement spirituelles ", d'autres méritent d'être discutées ${ }^{32}$. On peut imaginer que ces discussions auront eu lieu à l'automne suivant, durant le séjour que Staël fit à Metz. L'envoi à Staël de l'ouvrage de Villers éclaire l'énigme de l'identité de la destinataire fictive des Lettres : le « H. » doit se lire « Holstein ». C’est le second nom de l'époux de la fille de Necker, Staël-Holstein, descendant d'une famille noble germanobalte. La citation déjà produite - « [...] si vous êtes une vraie Germaine » - doit se comprendre au sens propre, si l'on se souvient que l'un des prénoms de Staël est précisément Germaine. Une dernière preuve confirme cette " clé » : dans une lettre, Villers avoue ne pouvoir se résoudre à appeler sa correspondante par son nom propre : "vous que je ne puis nommer ni du nom de votre père, ni de celui de votre époux, dont j'ignore le nom personnel, et que je me plais à individualiser par celui de Théano $»^{33}$.

Les Lettres westphaliennes simulent, de façon fictive, et sur un mode presque fantasmé, l'échange entre les deux écrivains. Anticipant de cinq ans sur la correspondance réelle, Villers avait ainsi dès 1797 imaginé le dialogue entre l'émigré et l'exilée ${ }^{34}$ (qui ne l'est pas encore à cette date). Il initie Mme de Staël à l’Allemagne avant même qu'elle ait eu le projet des études qui

31 Exemplaire conservé à la Staats- und universitätsbibliothek Carl von Ossietzky, Hamburg, sous la réf. 137336446.

32 «Lettre de Staël à Villers, 20 juillet 1803 », dans : Madame de Staël - Charles de Villers Benjamin Constant. Correspondance, op. cit., p. 59.

33 "Lettre de Villers à Staël, 4 mai 1803 ", dans : Madame de Staël - Charles de Villers Benjamin Constant. Correspondance, op. cit., p. 49.

${ }_{34}$ Voir M.-C. Hoock-Demarle, «Conversations entre émigré et exilée. L'Allemagne au cœur de la correspondance entre Charles de Villers et Germaine de Staël », dans : Un homme, deux cultures, op. cit., p. 43-56. 
la porteront à s'intéresser à ce pays. A-t-elle compris en recevant l'ouvrage quel rôle essentiel elle occupait dans le dispositif de médiation interculturelle mis en place par Villers? C'est très probable. Quelques années plus tard elle fit paraître De l'Allemagne : l'édition allemande de 1814 est précédée d'une préface de Villers. Les places sont alors inversées : désormais c'est la femme qui instruit, et l'homme qui lit. Dans son «Introduction ", il fait part de ses impressions : à l'admiration se mêlent cependant quelques critiques. "On peut être ou n'être pas complètement de son avis dans quelques détails, dans l'exposé de quelques opinions abstraites [...] ${ }^{35}$, écrit-il. Ces " opinions abstraites » renvoient à la doctrine de Kant telle que Staël l'a présentée au début de la III partie $^{36}$. Force est de reconnaître qu'elle y traite davantage de la morale et du beau que de la théorie de la connaissance. " Il faut une philosophie de croyance, d'enthousiasme ; une philosophie qui confirme par la raison ce que le sentiment nous révèle ${ }^{37}$, écrit-elle au moment de conclure sa présentation. Bien étrange conclusion! Le sentiment et l'enthousiasme ne sont pas les termes qui viennent spontanément à l'esprit pour qualifier la philosophie de $\mathrm{Kant}^{38}$. Sans entrer dans le débat de savoir si « Madame H. » a bien reçu les leçons kantiennes de R. M., ou de quelque autre de ses correspondants, il importe de souligner premièrement la continuité de cet échange, d'abord fictif, puis réel, entre deux des principaux intermédiaires culturels entre l'Allemagne et la France, et deuxièmement la place centrale qu'y occupe Kant. Mme de Staël à son tour a fait voyager Kant, sans doute plus loin que Villers. Son nom, sa notoriété, le prestige dont elle est entourée ont précipité la diffusion du kantisme, même s'il est décrit dans des termes qui, pour un lecteur moderne, le rendent méconnaissable.

\section{Conclusion}

La figure transcendantale du voyageur permet de renouveler le genre des lettres philosophiques : rompant avec le trop systématique schéma comparatif, Villers entend modifier le rapport à l'objet. L'intérêt se déplace insensiblement des réalités découvertes au témoin et conteur. Le point de vue de ce dernier se peint en même temps que les réalités décrites, rendant le tableau plus intéressant car plus contrasté. L'anecdote tient peu de place : on s'élève vite à des considérations générales : le voyage est une ascension. Villers teste là ses talents de médiateur

${ }^{35}$ Villers, « Introduction », dans : G. de Staël, De l'Allemagne, Leipzig, Brockhaus, 1814, I, p. LXIV.

${ }^{36}$ G. de Staël, De l’Allemagne, op. cit., IV, p. 59-84.

37 Ibid., p. 80.

${ }^{38}$ L. Fedi montre que Staël interprète le transcendantal kantien par le prisme du sentiment et de l'enthousiasme, deux notions quelle trouve notamment chez Rousseau, mais aussi Ballanche et Jacobi. Kant, une passion française, op. cit., p. 45-58. 
interculturel : quel plus grand défi que de faire comprendre Kant à des Français qui n'en ont jamais entendu parler? L'allégorie parle à l'imagination; comme le voyage, elle dépayse le lecteur, lui rendant accessibles des contrées qui sans cet artifice resteraient ignorées de lui. Il ne lui faut qu'un peu de cette souplesse ou de cette élasticité nécessaires à la découverte ${ }^{39}$. Mais en voyageant, Kant a changé d'apparence : il porte désormais les caractères du regard qu'a posé sur lui le voyageur. Ce Kant rhabillé selon les choix littéraires du vulgarisateur et les attentes du public, est bien éloigné du Kant en soi, par définition introuvable. Il reflète les conflits internes qui sourdement travaillent la société française ${ }^{40}$, mais dessine aussi les potentialités insoupçonnées d'une philosophie qui n'a pas fini de changer le monde.

39 Villers oppose la pétrification à la souplesse et à l'élasticité : "Introduction ", dans : De l'Allemagne, op. cit, I, p. LXII ; Érotique comparée, op. cit., p. 172.

40 « [Les Français] n'ont trouvé [en Kant] qu'une image d'eux-mêmes, une projection de leurs préoccupations hexagonales ». L. Fedi, op. cit., p. 7. 
Quatrième partie

Voyageur, artiste créatif ou récréatif? 
Katalin Bartha-Kovács

Université de Szeged

ORCID 0000-0002-4852-2006

\section{Les russeries d'un peintre-voyageur au XVIII siècle : Le Prince vu par les critiques d'art de son temps ${ }^{1}$}

\section{The Russeries of an $18^{\text {th }}$-Century Painter-Traveller: the Art of Le Prince in the Critical Writings of his Time}

Abstract: The aim of this paper is to examine some works of Jean-Baptiste Le Prince representing everyday life, and called russeries, through the Salon critics written primarily by Diderot. Adopting an aesthetic perspective, it aims to unveil the reasons for Diderot's reserve towards the painter's compositions, which can be traced, for the most part, to the discrepancy between the exotic subject matter and the idyllic manner of its representation according to the conventions of Rococo aesthetics.

Keywords: russerie, exoticism, Diderot, Le Prince, Boucher, Watteau

Mots-clés : russerie, exotisme, Diderot, Le Prince, Boucher, Watteau

Réticent à l'égard des voyages mais aussi des voyageurs², Diderot a tout de même été impressionné par les tableaux d'un jeune peintre de son époque, JeanBaptiste Le Prince (1734-1781). Après son retour de Russie, cet artiste a exposé

1 Le présent texte s'inscrit dans le projet scientifique du ministère hongrois de l'Innovation et de la Technologie (NKFIH, projet $\left.n^{\circ} 134719\right)$ intitulé « Communication esthétique en Europe (1700-1900)».

2 Sur la méfiance de Diderot envers les voyages et les voyageurs, voir E. Kovács, La Critique du voyage dans la pensée de Diderot. De la fiction au discours philosophique et politique, Paris, Honoré Champion, 2015. 
ses premières œuvres au Salon de 1765. Bien que dans ses comptes rendus de ce Salon, Diderot réserve en général un accueil mitigé aux tableaux de Le Prince, c'est en ces termes enthousiastes qu'il achève la présentation du morceau de réception, Le Baptême russe du peintre :

Du reste, cette composition est soutenue ; toutes les figures en sont intéressantes ; la couleur même en est vigoureuse. Je vous jure que l'artiste a fait celui-là dans un intervalle de bonne santé, et que si j'étais jeune, libre, et qu'on me proposât cet honnête Russe pour beau-père, et pour femme cette jeune fille qui tient si modestement un cierge à côté de lui, avec un peu d'aisance, tout autant qu'il en faudrait pour que ma petite Russe pût, quand il lui plairait, dormir la grasse matinée, moi lui faire compagnie sur le même oreiller, et élever sans peine les petits bambins que ces vénérables papas viendraient anabaptiser chez moi tous les neuf à dix mois, ma foi, je serais tenté d'aller voir quel temps il fait dans ce pays-là. ${ }^{3}$

Ces quelques lignes sont révélatrices à plusieurs égards : à travers la figure de l'ironie - qui consiste ici dans le décalage entre le sujet religieux de la toile et sa manière de présentation par le critique -, elles illustrent une des stratégies discursives privilégiées par Diderot qui s'introduit, métaphoriquement, dans la composition et se mêle aux personnages représentés ${ }^{4}$. Si c'est dans le cas des paysages de Joseph Vernet ou des peintures de ruines d'Hubert Robert que le critique d'art recourt le plus souvent à cette technique de présentation, celle-ci s'avère également efficace lors des commentaires des œuvres de Le Prince appartenant aux russeries. Ce peintre a notamment lancé, dans la seconde moitié du XVIII ${ }^{e}$ siècle, la mode des tableaux représentant des scènes russes.

L'objectif de cet article n'est pas de reconstituer la carrière artistique de Le Prince, ni d'offrir une analyse iconographique de ses tableaux, mais plutôt d'examiner quelques œuvres du peintre exposées aux Salons à travers les commentaires écrits par Diderot et d'autres critiques de son temps. Sur la base de ces textes, nous tâcherons de saisir les caractéristiques du " discours de russeries » qui se déploie à partir des écrits inspirés par les toiles de l'artiste. En quoi consiste la spécificité de ce discours? Quels sont les éléments que soulignent les commentaires portant sur les œuvres du peintre? Les compositions de Le Prince qu'ils décrivent peuvent-elles être considérées comme des documents iconographiques illustrant les coutumes observées en

3 D. Diderot, Salon de 1765, éd. E. M. Bukdahl et A. Lorenceau, Paris, Hermann, 1984, p. 238.

4 Parfois même, il leur adresse la parole. Voir entre autres son commentaire dans le Salon de 1761 à propos de la Magdelaine dans le désert de Carle Vanloo ou, dans le Salon de 1765, celui de la Jeune Fille qui pleure son oiseau mort de Jean-Baptiste Greuze. 
Russie ? Témoignent-elles en quelque sorte de l'expérience vécue par ce peintrevoyageur ayant réellement séjourné en Russie ou en offrent-elles une image modifiée, et devrait-on les considérer alors comme des pastorales conçues dans le style rococo, à la manière de François Boucher qui était le maître de Le Prince ${ }^{5}$ ?

De fait, les russeries du peintre participent d'une tendance plus générale, à savoir de l'engouement pour l'exotisme oriental au XVIII ${ }^{\mathrm{e}}$ siècle en France. À la différence de la mode de la chinoiserie et de la turquerie, il s'agit d'un phénomène plus tardif qui se manifeste dans le seul domaine artistique et est lié au nom d'un seul peintre, Jean-Baptiste Le Prince. Cet artiste tient une place particulière parmi les peintres-voyageurs dans la seconde moitié du XVIII ${ }^{e}$ siècle : bien qu'à cette période, plusieurs artistes français se soient rendus en Russie (dont les sculpteurs Étienne-Maurice Falconet et son élève Marie-Anne Collot $^{6}$ ), il est le seul à avoir entrepris le voyage autrement que sur invitation, et le seul à avoir osé s'éloigner de la cour russe fortement francisée. Lors de son séjour en Russie, entre 1758 et 1763, il a parcouru le vaste territoire de l'empire et visité les régions jusque-là inexplorées par les artistes (telles la Finlande ou la Livonie). De ces voyages, il résulta un immense fonds de dessins, inspiré par les paysages, les personnages et les coutumes russes, dans lequel l'artiste pouvait puiser les sujets de ses peintures et gravures après son retour en France.

Ses russeries apparaissent au moment où s'élève, au début des années 1760, le débat au sujet de la civilisation de l'empire de Russie, dans lequel s'engageaient les philosophes des Lumières et dans le détail duquel nous ne souhaitons pas entrer ici ${ }^{7}$. Notre but n'est pas alors de chercher de messages cachés ou d'idéologies sous-jacentes dans les tableaux ou les textes critiques qui en rendent compte, mais de dévoiler les raisons des incongruités que les auteurs de ces

${ }^{5}$ Selon David Vinson, le récit de voyage se présente comme « le témoignage personnel d'une expérience vécue », démarche empirique derrière laquelle « se profile l'esprit du temps et une vision ethnocentrique du monde ». Voir D. Vinson, "L'Orient rêvé et l'Orient réel au XIX siècle. L'univers perse et ottoman à travers les récits de voyageurs français ", Revue d'histoire littéraire de la France, 2004/1, vol. 104, p. 71-91. Voir aussi G. Szász, «Instrument du voyage ou source? ", dans : Aux tournants de l'histoire, sous la dir. de K. Bene et F. Dávid, Pécs, Éditions Codex, 2018, p. 25-43.

6 C’est en 1766 que Falconet, appelé à Saint-Pétersbourg par l’impératrice Catherine II afin d'exécuter la statue équestre de Pierre le Grand - immortalisée par le poème narratif d'Alexandre Pouchkine (Le Cavalier de bronze, 1833) -, quitte Paris en compagnie de sa jeune disciple MarieAnne Collot. Au XVIII ${ }^{e}$ siècle, il existe une importante colonie lorraine à Saint-Pétersbourg dont faisaient partie Collot et Le Prince. Voir M.-L. Pierre-Dulau, "Trois artistes lorrains à Saint-Pétersbourg au XVIII ${ }^{e}$ siècle ", dans : L'Influence française en Russie au XVIII ${ }^{e}$ siècle, sous la dir. de J.-P. Poussou, A. Mézin et Y. Perret-Gentil, Paris, Institut détudes slaves - Presses de l'Université Paris-Sorbonne, 2004, p. 131-157.

7 Voir à ce sujet P. Stein, «Le Prince, Diderot et le débat sur la Russie au temps des Lumières », Revue de l’Art, nº 112, 1996/2, p. 16-27. 
écrits remarquent dans les œuvres du peintre. Ils désapprouvent notamment que l'image de la Russie offerte par les tableaux de Le Prince soit idyllique, une sorte de Russie " à la française » car représentée à travers le prisme de l'esthétique rococo.

\section{L'exotisme des russeries de Le Prince}

Le terme russerie, créé a posteriori, se rapporte aux œuvres de Le Prince et désigne une forme artistique qui s'inscrit dans le cadre de la vogue de l'exotisme. Il s'agit d'un phénomène éphémère, lié à certains types de sujets propres aux genres picturaux considérés comme mineurs, tels que la scène de genre ou le paysage ${ }^{8}$. C'est grâce à la présence de motifs singuliers (les vêtements russes, la balalaïka, etc.) qu'une peinture de genre peut s'identifier en tant que russerie. De fait, l'univers des œuvres de Le Prince rangées aux russeries s'est nourri de ses souvenirs de voyages qu'il avait enregistrés dans des carnets de croquis sous forme de dessins.

Les compositions réalisées sur la base de ces dessins et présentées aux Salons ont séduit le public contemporain. Ils s'imposaient à l'imagination des spectateurs qui appréciaient leur aspect pittoresque, comme en témoigne la citation suivante, tirée de la brochure publiée à l'occasion du Salon de 1765 par le critique d'art d'origine lyonnaise Mathon de La Cour : "Le public a vu avec empressement un grand nombre de tableaux de M. Le Prince, jeune artiste arrivé depuis peu de Russie. Indépendamment du mérite pittoresque de ces différents morceaux, les mœurs étrangères qu'ils nous peignent, sont très propres à piquer la curiosité $»^{9}$. L’adjectif " pittoresque ", utilisé ici dans un sens mélioratif, est essentiel si l'on veut saisir la spécificité des œuvres de Le Prince et comprendre leur réception par le public de son temps. Il n'est pas sans intérêt d'évoquer à ce propos la définition de l'exotisme du Vocabulaire d'esthétique d'Étienne Souriau qui considère l'évasion et le pittoresque comme les deux composantes indispensables de ce phénomène ${ }^{10}$. Quant au qualificatif " pittoresque ", il marque aussi le voyage de Le Prince en Russie qui n'était guère

8 La hiérarchie des genres picturaux - qui tient la peinture d'histoire (aux sujets mythologiques, religieux et historiques) pour le seul genre noble et range tous les autres types de sujets aux genres mineurs - est encore en vigueur au XVIII ${ }^{e}$ siècle.

9 Ch.-J. Mathon de La Cour, Lettres à Monsieur ${ }^{* *}$ sur les peintures, les sculptures et les gravures exposées au Sallon du Louvre en 1765, s.l.n.d., p. 65.

10 Larticle distingue deux variantes de l'exotisme dont la première, fantaisiste, se détache de la vérité historique, alors que le second type met l'accent sur l'authenticité et la valeur documentaire. Voir A. Souriau et G. Prudhommeau, «Exotisme», dans : É. Souriau, Vocabulaire d'esthétique, sous la dir. de A. Souriau, Paris, Quadrige / PUF, 2004 [1990], p. 707. 
exempt de péripéties extraordinaires ${ }^{11}$. Même si nous ne visons pas à présenter ici la carrière artistique de Le Prince, avant d'analyser les écrits des salonniers qui traitent de ses œuvres, nous trouvons utile de rappeler brièvement les étapes majeures du parcours du peintre ${ }^{12}$.

Originaire de Metz, fils d'un maître sculpteur-doreur, Jean-Baptiste Le Prince entre vers l'âge de dix-sept ans à l'atelier de François Boucher. C'est pour fuir un mariage malheureux (conclu avec une femme bien plus âgée que lui) qu'il entreprend le voyage en Russie où il se rend par la Hollande. À Saint-Pétersbourg, c'est grâce à l'ambassadeur de France, le marquis de L'Hôpital qu'il obtient des commandes, entre autres pour la décoration du Palais d'Hiver de l'impératrice Élisabeth. À son retour en France, il se présente à l'Académie royale de Peinture et de Sculpture, devient agréé en 1764 et est reçu académicien en 1765 avec son morceau de réception, Le Baptême russe, déjà mentionné. Entre 1764 et 1768, il exécute la plupart des illustrations pour le Voyage en Sibérie de l'abbé Jean Chappe d'Auteroche, astronome ayant fait en 1761-1762 un voyage scientifique en Russie afin d'observer à Tobolsk le passage de Vénus devant le soleil ${ }^{13}$. Le Prince lance en France la mode des russeries qui se manifeste dans plusieurs domaines artistiques (il exécute des peintures, des estampes, des cartons de tapisserie), et ses représentations de vêtements populaires russes seront reprises dans des recueils de gravures ou figurent en tant qu'éléments décoratifs sur les objets d'art. Mais cette mode artistique disparaît avec la perte d'intérêt des Français à l'égard de la Russie, qui n'est plus considérée comme un pays exotique vers la fin du XVIII ${ }^{e}$ siècle $^{14}$. Dans ses œuvres plus tardives, le peintre délaisse progressivement les russeries, pour se tourner vers les scènes de genre galantes.

Cependant, à en croire Mathon de La Cour, au moment de leur apparition au Salon de 1765, les tableaux de Le Prince étaient susceptibles de " piquer la curiosité " du public indépendamment de leur aspect pittoresque, parce qu'ils représentaient des mœurs et coutumes étrangères. Les spectateurs contemporains appréciaient avant tout la nouveauté et l'étrangeté des sujets

11 Un épisode pittoresque du périple de l'artiste mérite attention : lorsque le navire sur lequel voyageait Le Prince a été attaqué par des corsaires, le peintre pouvait se libérer en leur jouant du violon. Voir M.-L. Pierre-Dulau, op. cit., p. 133.

12 Voir L. Réau, "L'exotisme russe dans l'œuvre de Jean Baptiste Leprince », Gazette des Beaux-Arts, 1921, p. 147-165.

13 Louvrage de Chappe d'Auteroche, fortement critique à l'égard de la Russie, a provoqué la colère de Catherine II. Voir l'édition critique de Voyage en Sibérie de l'abbé Chappe en deux volumes par M. Mervaud (Oxford, Voltaire Foundation, 2004), qui contient une monographie sur Le Prince et les autres dessinateurs de l'ouvrage de Chappe, écrite par Madeleine Pinault Sørensen.

14 Voir L. Chambon, "La russerie dans la construction d'un exotisme européen », dans : Encyclopédie pour une histoire nouvelle de l'Europe [en ligne], 2016, https://ehne.fr/node/1209, mis en ligne le 09/02/2018, consulté le 07/10/2020. 
de Le Prince. Le critique d'art anonyme des Mémoires secrets attribue en 1767, lui aussi, l'intérêt suscité par les compositions de Le Prince au "mérite du costume » et aux mœurs « étrangères et nouvelles » pour le public français ${ }^{15}$. Il déplore cependant l'invraisemblance des œuvres de l'artiste : "Point de coloris, une confusion d'objets, des Russes à qui le peintre veut donner l'esprit et la galanterie des bergers de Boucher. $»^{16}$

Un tel jugement diffère foncièrement du commentaire neutre et purement descriptif de Mathon de La Cour portant sur l'ensemble des œuvres exposées par le jeune artiste au Salon de 1765. Le critique d'art lyonnais est attentif surtout à la représentation des usages, coutumes et objets étrangers ${ }^{17}$, sans pour autant vouloir juger de la qualité artistique des toiles. En revanche, dans leurs comptes rendus, l'auteur anonyme des Mémoires secrets ou encore Diderot apprécient bien moins les éléments pittoresques des œuvres de Le Prince. Par la suite, ce sont en premier lieu les Salons de Diderot que nous interrogeons, pour essayer de comprendre les causes de ses réserves envers les russeries de l'artiste. Ce faisant, nous nous concentrons sur la seule perspective esthétique et faisons abstraction des arguments politico-civilisationnels qui sous-tendent ses jugements.

\section{Invraisemblances : les russeries vues au prisme de la critique d'art de Diderot}

Si l'exotisme russe mis en scène par Le Prince a été perçu comme intéressant car piquant et neuf - aux yeux de la majorité des spectateurs du Salon de 1765, Diderot est loin de partager entièrement cet enthousiasme général. Ses commentaires montrent sa distance à l'égard des pastorales russes du peintre qu'il trouve quelque peu naïves et édulcorées. Puisque lors de ses jugements de la représentation des scènes russes, c'est le critère politique qui l'emporte à ses yeux, il fait peu de cas d'une autre possibilité d'interprétation, allégorique, mais probablement plus proche des intentions du peintre ${ }^{18}$.

15 [Auteur anonyme], Salon de 1767, dans : Les Salons des Mémoires secrets 1767-1787, éd. B. Fort, Paris, ENSB-A, 1999, p. 42.

16 Ibid.

${ }_{17} C f$. ses observations concernant le berceau russe, " une espèce de hamac qu'on suspend au bout d'un bâton élastique » et que les mères peuvent emporter, la balalaïka (orthographiée balalaye), " une sorte de guitare longue, qui n'a que deux cordes ", ou le baptême russe " qui se fait par immersion, suivant l'usage russe ». Ch.-J. Mathon de La Cour, op. cit., p. 66-67.

18 Cette interprétation considère les compositions de Le Prince, surtout celles qui mettent en scène le motif du berceau russe, comme des allégories de la fécondité, tant de la nature que de l'homme. L'enjeu pour Diderot dans ses commentaires sur les tableaux du peintre était une question politique d'actualité : la modernisation de la Russie. Voir P. Stein, op. cit. 
Il est surprenant de voir que dans ses comptes rendus, le critique d'art fait peu d'allusions au voyage en Russie de Le Prince. Un exemple flagrant en est pourtant l'allusion discrète qui se trouve dans son Salon de 1767 où Diderot se réfère en ces termes au témoignage du peintre : «L'artiste dit qu'il y a en Russie des hordes de prétendus sorciers qui vivent, comme ailleurs, de la crédulité des simples. Ils errent et prédisent ${ }^{19}$. " Mais, puisque l'allusion s'arrête là, le lecteur reste sur sa faim concernant les éventuels détails de l'évocation du voyage de Le Prince et sa rencontre avec ces "sorciers». Le compte rendu se poursuit par la description du tableau et une anecdote, l'" aventure domestique " de la mère de Diderot qui, dans sa jeunesse, aurait dû rencontrer elle aussi une diseuse de bonne aventure.

Cependant, dans la plupart des cas, le critique d'art s'en tient à la description des tableaux et au jugement de leurs qualités esthétiques, sans évoquer le séjour russe de l'artiste qui les a inspirés : tout se passe comme si cet aspect était indifférent à ses yeux. Même dans le cas du commentaire du tableau intitulé Manière de voyager en hiver, le lecteur a beau s'attendre à une allusion aux circonstances du voyage hivernal en Russie : Diderot ne fait que décrire la toile, " en allant de la droite à la gauche $",{ }^{20}$ sans dire un mot de ce que le sujet relève probablement d'une expérience réelle, vécue par Le Prince. Parmi les tableaux de l'artiste exposés au Salon de 1765, c'est seulement Le Baptême russe qui lui donne envie non seulement d'entrer dans la composition, mais aussi de suivre les traces du peintre-voyageur pour visiter, en imagination, la Russie ${ }^{21}$.

Comme le remarque Stéphane Lojkine, la peinture de Le Prince est en effet peu ethnographique, et les commentaires de Diderot dans ses Salons ne font que souligner l'ambiguité qui caractérise l'œuvre du peintre ${ }^{22}$. À cet égard, le vocabulaire utilisé par le critique d'art dans ses comptes rendus de 1765 est révélateur. Jugeant de l'ensemble des compositions exposées cette année par l'artiste, Diderot affirme que "quelques-unes " parviennent à "arrêter un homme du goût » et qu'« en général », le peintre " possède la base de l'art »il dessine bien et sa touche est spirituelle -, mais sa couleur est faible et l'effet d'ensemble est peu vigoureux ${ }^{23}$. Il ne cesse de comparer les tableaux de Le Prince à ceux de Vernet - rapprochement suggéré par Chardin, qui était à cette époque-là tapissier du Salon, à savoir responsable pour l'accrochage des

19 Il s'agit du commentaire de La Bonne Aventure de Le Prince. Cf. D. Diderot, Salons III. Ruines et paysages. Salons de 1767, éd. E. M. Bukdahl, M. Delon, A. Lorenceau, Paris, Hermann, 1995, p. 304.

20 D. Diderot, Salon de 1765, op. cit., p. 229.

${ }^{21}$ C'est entre 1773 et 1774 qu'a eu lieu le voyage en Russie de Diderot qui a causé au philosophe une vive déception. Voir E. Kovács, op. cit., p. 151-194.

22 S. Lojkine, «La Russie de Le Prince vue par Diderot », Slavica Occitania, n 19, 2004, p. 13-38.

23 D. Diderot, Salon de 1765, op. cit., p. 222. 
tableaux -, mais cette comparaison est toujours défavorable au jeune peintre. Concernant les éléments pittoresques, Diderot regrette que le peintre s'asservisse trop « scrupuleusement au costume et aux mœurs » étrangers ${ }^{24}$. Il n'approuve pas l'usage de tels éléments et condamne surtout le pittoresque des vêtements des personnages. Dès le début de ses commentaires consacrés au peintre, il déclare que, faute de connaissance du «local » et des «mœurs » du pays, il ne juge pas des russeries qu'il appelle, non sans nuance péjorative, des « imitations russes $»^{25}$. Il se laisse pourtant charmer par la Pastorale russe qui "va droit à l'âme " et à propos duquel il formule son credo artistique : "La peinture est l'art d'aller à l'âme par l'entremise des yeux ; si l'effet s'arrête aux yeux, le peintre n'a fait que la moindre partie du chemin ${ }^{26}$. » (ill. 1).

Le critère majeur susceptible de rendre intéressant un tableau aux yeux de Diderot ne consiste ni dans la présence des éléments exotiques et pittoresques, ni dans la représentation de manières et coutumes étrangères ${ }^{27}$, mais dans la capacité de l'œuvre de toucher le spectateur. Bien que le critique d'art tienne le Berceau pour les enfants pour l'une des meilleures compositions du peintre, le fait qu'il répète l'adverbe "singulièrement » est un procédé textuel marquant sa distance et étant source d'ironie. Diderot désapprouve notamment que le paysan sur l'image soit trop "grossier » et " pauvrement vêtu » en comparaison à la vieille censée être sa femme ${ }^{28}$ (ill. 2).

Parmi les tableaux de Le Prince exposés au Salon de 1765, le critique est le plus touché par Le Baptême russe. Dans son commentaire abondant en termes élogieux, il ne mentionne pourtant qu'incidemment le geste du premier prêtre de la toile qui « embrasse le nouveau-né par-dessous les bras et le plonge par les pieds dans la cuve», geste qui renvoie, par métonymie, à l'exotisme de toute

${ }^{24}$ Ibid., p. 224.

25 Ibid., p. 223.

26 D. Diderot, Salon de 1765, op. cit., p. 226. L'idée que Diderot développe à propos de la même toile - à savoir que le bon tableau est celui « avec lequel on raisonne ainsi, qui vous met en scène » - fait allusion à celle de Roger de Piles, théoricien de l'art du XVII siècle, qui parle de l'« effet d'appel » de la peinture. Comparant l'effet du tableau à celui d'un coup de foudre, il prétend que la toile doit appeler elle-même son spectateur d'une manière si forte qu'il soit impossible de lui résister. R. de Piles, Cours de peinture par principes, Paris, Gallimard, 1989 [1708], p. 8.

${ }^{27} C f$. sa remarque à propos de la Manière de voyager en hiver du peintre : " Tout ce qu'on apprend là, c'est la manière dont les voitures sont construites en Russie. » D. Diderot, Salon de 1765, op. cit., p. 229.

${ }^{28} C f$. sa description d'un "vieux paysan en chemise » dont il trouve les jambes " singulièrement vêtues » et les pieds " singulièrement chaussés ». Diderot, Salon de 1765, op. cit., p. 232 et 233 . L'ironie se manifeste aussi par l'usage du terme « amphibologie» dans le commentaire : «Ou je me trompe fort, ou il y a quelque amphibologie dans cette composition. Serait-ce qu'en Russie les femmes sont bien et les maris mal ? »Ibid., p. 233. 


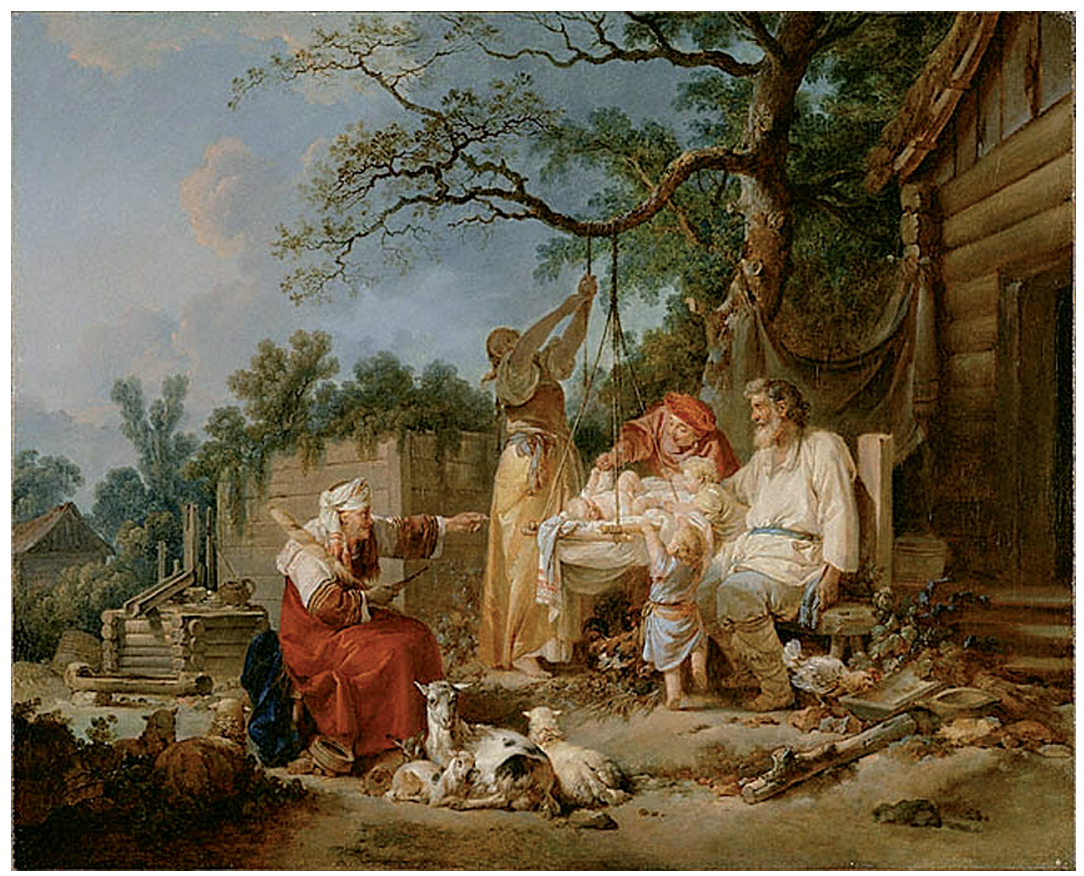

Illustration 1 : J.-B. Le Prince, Le Berceau russe

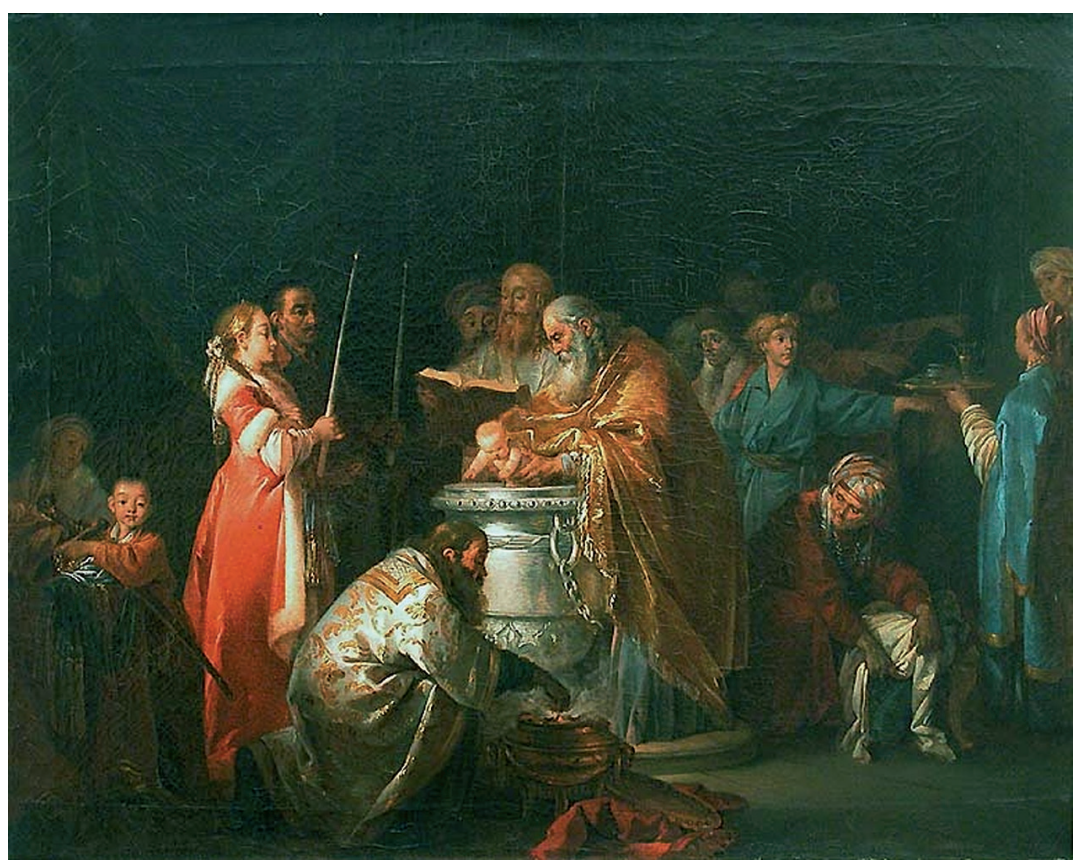

Illustration 2 : J.-B. Le Prince, Le Baptême russe 
la cérémonie du baptême ${ }^{29}$. Feignant d'avoir assisté à la cérémonie représentée, il adopte le ton de badinage lors de la présentation du morceau de réception de l'artiste, sans souffler un mot sur les éléments pittoresques de la scène. Ce ton décalé, peu propre en effet à la présentation de «la plus auguste cérémonie du christianisme $»^{30}$, marque l'ensemble du commentaire. Comme en témoigne son entrée fictive dans la scène, le tableau plaît au critique, et il ne déplore que le coloris «cuivreux et rougeâtre » de la toile ${ }^{31}$.

Même si l'enthousiasme de Diderot s'affaiblit, en 1767, pour les scènes de genre de Le Prince, la stratégie narrative d'entrer dans l'espace pictural et d'y inviter aussi le lecteur - marque bien des commentaires qu'il consacre en 1767 aux tableaux du peintre. C'est à l'aide de cette technique qu'il présente plusieurs compositions de l'artiste dont les cartons décoratifs destinés à être tissés à la Manufacture de Beauvais. Devant La Bonne aventure - qui reprend un motif iconographique mis en vogue par le Caravage - faisant partie de cette série de cartons, Diderot est visiblement gêné par l'invraisemblance de la scène ${ }^{32}$ (ill. 3). Il condamne surtout les vêtements des personnages ; l'élégance de la diseuse de bonne aventure lui semble incongrue. Elle l'est, sans doute, du point de vue de Diderot qui tient, dans ses réflexions artistiques, au principe de vérité. Mais elle l'est probablement moins si l'on tient compte de la fonction essentiellement décorative de la tapisserie qui doit obéir à des critères diamétralement opposés à ceux qui sont prônés par Diderot. Au lieu de décrire la composition, le critique préfère y insérer une anecdote, tout comme il introduit un conte dans le commentaire du tableau suivant, Le Berceau ou le réveil des petits enfants ${ }^{33}$. Certes, le refus de Diderot de parler de la plupart des «tableaux russes » du peintre et de passer à d'autres sujets dans le Salon de 1767 est une critique indirecte à laquelle il recourt bien souvent en présentant les œuvres de Le Prince.

Parfois, pourtant, son mépris transparaît on ne peut plus nettement dans son commentaire. C'est au sujet d'une scène galante que le critique exprime

${ }^{29}$ Ibid., p. 236.

${ }^{30}$ Ibid., p. 237. Élise Pavy-Guilbert attire l'attention sur la dissonance qui marque l'alliance incongrue du registre de la sensualité et de la religion. Voir É. Pavy-Guilbert, L'Image et la Langue. Diderot à l’épreuve du langage dans les Salons, Paris, Classiques Garnier, 2014, p. 128.

31 D. Diderot, Salon de 1765, op. cit., p. 238.

32 Ce tableau est une étude préparatoire à l'un des cartons : il montre la scène principale d'une tapisserie (dont un exemplaire se trouve au musée Jacquemart-André à Paris). À part La Bonne aventure, deux autres compositions exposées par Le Prince au Salon de 1767 faisaient partie de cette série (de six pièces) intitulée Jeux russiens.

33 C'est en ces termes qu'il introduit la rupture narrative dans son commentaire, s'adressant à son interlocuteur Friedrich Melchior Grimm et, en l'occurrence, aussi au lecteur : « Je m'ennuie de faire et vous apparemment de lire des descriptions de tableaux. Par pitié pour vous et pour moi, écoutez un conte. » D. Diderot, Salons de 1767, op. cit., p. 307. 


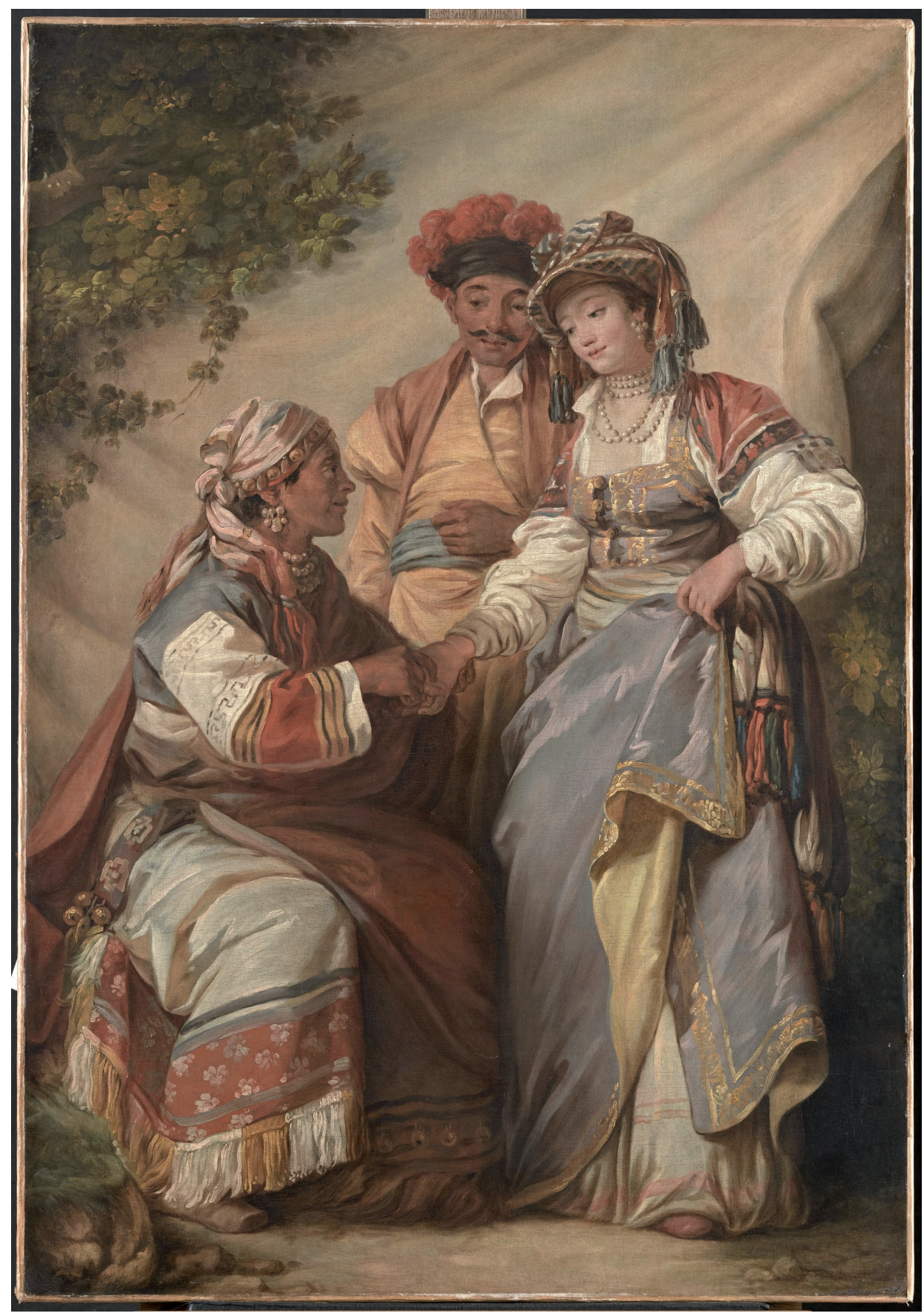

Illustration 3 : J.-B. Le Prince, La Diseuse de bonne aventure 
sans ambages son opinion sur les "petites compositions » du peintre montrant une action équivoque : ces types de tableaux ne sont, pour Diderot, " que de riches écrans, de précieux éventails $»^{34}$. Ces métaphores dévalorisantes sont une allusion évidente au style galant et décoratif de Boucher et, en général, à celui de la peinture rococo. Dans la même veine, Diderot blâme le pendant de ce tableau qu'il trouve également superficiel, impression que la richesse des vêtements ne peut guère contrebalancer, voire, elle ne fait qu'agacer le critique : "Si un Tartare, un Cosaque, un Russe voyait cela, il dirait à l'artiste, tu as pillé toutes nos garde-robes, mais tu n'as pas connu une de nos passions. $»^{35}$ Indigné à la vue de ce " pillage ", qui conduit à la fausseté de la représentation, Diderot fustige le peintre et lui reproche, entre autres, l'absence des passions. De fait, l'expression bien lisible des passions, allant de pair avec la clarté de la composition caractérisent la peinture d'histoire : ce sont donc les critères de la " grande " peinture que Diderot revendique pour les russeries de Le Prince, qui relèvent pourtant d'un genre mineur.

Son jugement à propos de l'ensemble des productions exposées par le peintre en 1767 est expéditif : " De tout ce qui précède, que s'ensuit-il ? que le principal mérite de Le Prince est de bien habiller. ${ }^{36}$ Diderot ne cesse de répéter que tout l'art du peintre s'épuise à savoir bien habiller ses personnages : "Si cet artiste n'eût pas pris ses sujets dans des mœurs et des coutumes dont la manière de se vêtir, les habillements ont une noblesse que les nôtres n'ont pas et sont aussi pittoresques que les nôtres sont gothiques et plats, son mérite s'évanouirait. ${ }^{37}$ Il laisse entendre par là que le seul attrait des russeries de Le Prince consiste dans les accessoires exotiques suggérant un parfum d'étrangeté, mais que sans ces détails, tout le charme pittoresque de ses œuvres éclaterait comme une bulle de savon. Par ailleurs, l'auteur anonyme des Salons des Mémoires secrets exprime une semblable opinion à l'égard des tableaux de Le Prince destinés à la manufacture de Beauvais : "faits uniquement pour amuser les yeux dans les appartements ", ces types d'ouvrages demandent « de la clarté et des richesses de détail $\aleph^{38}$. Tout en admettant la fonction ornementale des tapisseries, ce critique dénonce l'ensemble du projet décoratif de l'artiste. L'analogie entre son

${ }^{34}$ Ibid., p. 313. Il s'agit du tableau intitulé Une fille charge une vieille de remettre une lettre. À ce jugement sommaire fait écho celui du Salon de 1771, portant sur Plusieurs femmes au bain de Le Prince : «Éventail, joli, précieux éventail de figure et de ton de couleur. » D. Diderot, Salons IV. Héros et martyrs. Salons de 1769, 1771, 1775, 1781, éd. E. M. Bukdahl, M. Delon, D. Kahn, A. Lorenceau, Paris, Hermann, 1995, p. 173.

35 D. Diderot, Salon de 1767, op. cit., p. 313. Le tableau en question est intitulé Un jeune homme récompense le zèle d'une vieille.

${ }^{36}$ Ibid., p. 319. Il s'agit du commentaire à propos du Portrait d'une fille qui vient de recevoir une lettre et un bouquet de Le Prince.

${ }^{37}$ Ibid., p. 320.

38 [Auteur anonyme], Salon de 1767, op. cit., p. 142. 
reproche et celui de Diderot est plus que frappante. À part la faiblesse du coloris et l'absence de cohérence de la composition, les deux critiques tiennent pour défaut principal du peintre la tentative de celui-ci de concilier l'exotisme de ses sujets russes et leur manière d'exécution dans le style décoratif du rococo.

Effectivement, la plupart des réprimandes que Diderot fait à Le Prince pourraient être adressées à la peinture rococo en général, plus particulièrement à Boucher. Bien que, dans ses commentaires sur Le Prince, Diderot ne mentionne pas le nom de Boucher, celui-ci est implicitement présent dans sa critique contre l'auteur des russeries. Par la suite, nous nous proposons de rechercher les raisons de la gêne du critique face aux russeries du peintre, susceptibles d'éclairer aussi celles de son silence sur le rôle du voyage dans l'acte de la création de l'artiste. Il nous semble qu'il s'agit là essentiellement d'une question de goût, et que par son refus de l'art de Le Prince, Diderot ne fait qu'insister sur son attachement au canon classique du bon goût, sans tenir compte de la possibilité d'un autre idéal, d'une autre esthétique qui se manifeste dans l'œuvre du peintre.

\section{Filiations : Watteau, Boucher, Le Prince}

La "grande peinture » suppose un « grand goût» qui se situe aux antipodes du " petit goût » des peintres rococo. C'est au nom de la "grande peinture " vigoureuse et ayant un contenu moral que Diderot s'élève contre le style décoratif, incarné surtout par l'art de Boucher. Lorsqu'il rejette le "petit goût » qui est, pour lui, synonyme du mauvais goût, l'argument moral - à savoir la «corruption du goût » qu'il attribue à la peinture de Boucher - sous-tend son raisonnement esthétique ${ }^{39}$. Même si le critique récuse l'art du maître de Le Prince, il est question pour lui non pas de la mise en cause du savoir-faire du peintre - il reconnaît que les toiles de Boucher, parfaites du point de vue de l'exécution, attirent l'œil du spectateur -, mais bien d'un enjeu esthétique ${ }^{40}$. Si la plupart des éléments de la réprobation de Diderot envers l'art de Boucher (l'invraisemblance, la fausseté de la couleur, la platitude des figures qui sont "sans relief », etc.) se retrouvent également dans ses commentaires des russeries de Le Prince, le critique décèle chez ce dernier, à part ces défauts, maintes autres défaillances au niveau de la maîtrise technique.

Lors de la lecture des comptes rendus de Diderot consacrés à Le Prince, nous avons été frappée par un phénomène discret mais tout de même flagrant : la présence dans ces écrits de certains clichés qui marquaient aussi, quelques

39 « La dégradation du goût, de la couleur, de la composition, des caractères, de l'expression, du dessin a suivi pas à pas la dépravation des mœurs. » D. Diderot, Salon de 1765, op. cit., p. 54.

40 C. Duflo, "Le système du dégoût. Diderot critique de Boucher », Recherches sur Diderot et sur l'Encyclopédie, n² 29, 2000, p. 85-101. 
décennies auparavant, le discours sur Watteau, même s'il s'agit dans ce cas-là d'un genre différent : des biographies d'artistes. Certes, la filiation que nous suggérons entre le maître des fêtes galantes et l'inventeur des russeries peut s'expliquer par le fait que Le Prince était l'élève de François Boucher qui, lui, en tant qu'artiste débutant, a gravé la plupart des œuvres de Watteau pour le Recueil Jullienne ${ }^{41}$. C'est en copiant les dessins de Watteau que le jeune Boucher avait perfectionné sa technique et qu'il avait acquis, à part la maîtrise de la gravure, la manière d'exécution décorative et élégante qui a marqué plus tard ses pastorales ${ }^{42}$. Nous viserons à relever, dans la dernière partie de l'article, les points les plus évidents de cette filiation et à montrer que cet héritage rococo de Le Prince explique la réticence de Diderot à l'égard des russeries du peintre.

Toutefois, lors de la recherche de filiations, on peut remonter encore plus loin, jusqu'à la peinture nordique du XVII ${ }^{\mathrm{e}}$ siècle. L'influence nordique s'exprime entre autres dans la méthode de travail déjà évoquée de Le Prince : les carnets de croquis qu'il avait ramenés de Russie servaient de répertoire pour ses futures toiles. La conséquence inévitable de cette pratique est la ressemblance de ses personnages, ce qui n'a pas échappé à l'attention de Diderot ${ }^{43}$. Il s'agit là en effet d'une pratique répandue parmi les peintres du Nord, et qui a marqué aussi la manière de travailler de Watteau. À en croire le comte de Caylus, ce peintre avait l'habitude de dessiner ses études de figures « dans un livre relié », dont il choisissait les personnages pour ses tableaux. Caylus condamne pourtant cette "façon de composer » à laquelle il attribue la cause de l'« uniformité qu'on peut reprocher aux tableaux de Watteau $»^{44}$ (ill. 4).

Parmi les artistes flamands du XVII ${ }^{e}$ siècle, c'est le nom de David Teniers le Jeune que Diderot cite le plus souvent relativement à Le Prince mais aussi à Watteau. Le critique n'apprécie guère Le Cabak ou espèce de guinguette des environs de Moscou de Le Prince exposé au Salon de 1769. Dans son commentaire, il énumère les défauts de cette russerie et se réfère à Teniers : «Beaucoup de mouvements, beaucoup d'objets, beaucoup de scènes diverses, une multitude infinie de figures; mais tout est croqué, nulle image, le plus grand

${ }^{41}$ Le négociant et collectionneur Jean de Jullienne était ami de Watteau : après la disparition du peintre en 1721, il a décidé de faire graver les œuvres de l'artiste. Lors de cette entreprise, il a fait appel à des graveurs, dont le jeune Boucher.

42 Sur le rôle de Watteau dans la formation de Boucher, voir F. Joulie, « De la fête galante à la pastorale : Antoine Watteau maître de François Boucher », dans : Watteau au confluent des arts (CD-ROM), sous la dir. de C. Barbafieri et C. Rauseo, Valenciennes, PUV, 2009, p. 151-169.

${ }^{43} C f$. sa critique d'Un médecin de Le Prince : «Figures ressemblantes : même visage à des hommes, à des femmes, à des enfants, à la maîtresse, à la servante ; mêmes traits, même yeux. » D. Diderot, Salon de 1771, dans : Salons IV, op. cit., p. 171.

44 A.-C.-Ph. Caylus (comte de), La vie d'Antoine Watteau (1748), dans : Vies anciennes de Watteau, éd. Pierre Rosenberg, Paris, Hermann, 1984, p. 78-79. 


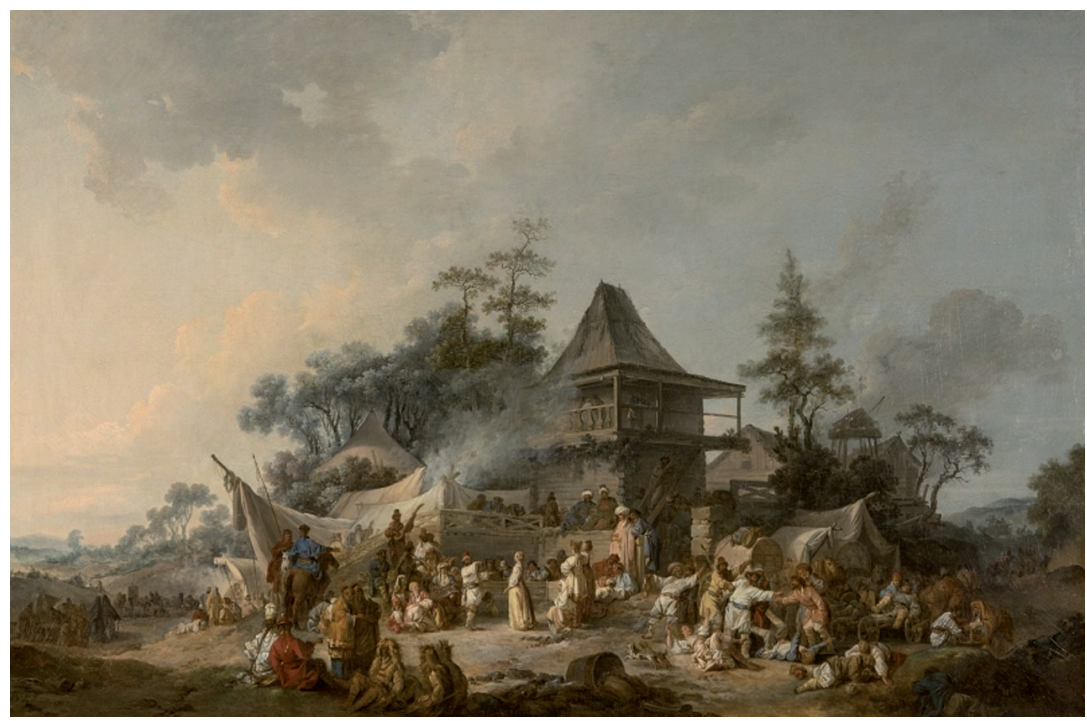

Illustration 4 : J.-B. Le Prince, Le Cabak

et le plus bel hymne qu'on pût chanter à l'honneur de Teniers. ${ }^{45}$ Sa réprimande porte sur l'aspect confus de la composition, la juxtaposition des scènes et des personnages, ainsi que l'exécution négligée, l'absence de fini ${ }^{46}$. Bien que, dans son jugement sommaire, Diderot ne s'attarde ni sur les personnages, ni sur aucun détail du tableau, nous trouvons important d'y faire allusion. Sur l'image, autour du bâtiment central (le « cabak »), on repère un grand nombre de figures (probablement des voyageurs) qui sont habillées de manières différentes, selon les coutumes régionales. Ces personnages répartis en groupes - dont la réunion semble fortuite et pittoresque - sont reliés par une ligne ondulante, celle de l'arabesque, qui marque bien des compositions décoratives conçues dans le style rococo, l'exemple le plus connu en étant sans doute Le Pèlerinage à l'île de Cythère de Watteau. Malgré la présence du joueur de balalaïka (personnage typique des œuvres de Le Prince) et les vêtements des figures, Le Cabak ne donne guère l'impression d'être la représentation authentique d'une scène russe quelconque. Si dans son commentaire, Diderot se réfère à Teniers, ce nom sert

45 D. Diderot, Salon de 1769, dans : Salons IV, op. cit., p. 71. Exposé au Salon de 1769, Le Cabak, disparu pour un certain temps, a été retrouvé et acheté en 1981 par le Nationalmuseum de Stockholm. Pour l'analyse du tableau, voir P. Grate, "Le Cabak" de Jean-Baptiste Le Prince ", Revue de l'Art, 1986, n 72, p. 19-23. Pontus Grate suggère que l'idée du couple dansant en plein air dans Le Cabak a été probablement inspirée par le Bal champêtre de Watteau.

${ }^{46}$ Le Prince n'a pas achevé ce tableau qui aurait dû être exposé originairement en 1767, c'est la raison pour laquelle il a été présenté au Salon suivant, celui de 1769. 
pour lui de prototype du peintre flamand dont les " petits sujets " rustiques, relevés par une exécution supérieure, sont à l'encontre du caractère artificiel des œuvres des peintres rococo ${ }^{47}$.

En 1767, dans son compte rendu du tableau On ne saurait penser à tout de Le Prince, le critique déplore l'absence de "magie » de la composition. Il évoque dans une phrase elliptique le nom du peintre de genre flamand : "Ôtez à Teniere son faire, et qu'est-ce que Tenieres $($ sic $) !{ }^{48}$ Comme il le précise dans la suite de la citation, le principal mérite de Teniers consiste dans la " magie des couleurs ", qualité sans laquelle les sujets vulgaires de cet artiste ne seraient guère remarqués par les connaisseurs. La formule portant sur Teniers revient sous la plume de Diderot dans son ouvrage théorique, les Essais sur la peinture, mais cette fois-ci en rapport avec Watteau : "Ôtez à Watteau ses sites, sa couleur, la grâce de ses figures, celle de ses vêtements, ne voyez que la scène, et jugez. ${ }^{49}$ La référence au maître des fêtes galantes suit directement l'évocation des "petits usages des peuples civilisés ", dont la représentation devient, selon le critique, ennuyeuse dans les arts. Diderot conseille au lecteur d'ôter aux tableaux du peintre tout ce qui constitue leur grâce, pour en juger ensuite. Si l'on ne regarde que les scènes des fêtes galantes, elles sont loin des exigences que Diderot formule envers les arts d'imitation dont il réclame « quelque chose de sauvage, de brut, de frappant et d'énorme ${ }^{50}$. De fait, il n'y a nulle histoire à raconter dans les œuvres de Watteau où le contenu narratif devient fragmenté car l'histoire la storia exigée par les théoriciens italiens de la Renaissance - s'éparpille en épisodes ${ }^{51}$. La construction par épisodes indépendants, qui n'ont rien à voir avec la scène principale, caractérise aussi de nombreuses scènes de genre de Le Prince dans lesquelles Diderot ne cesse de déplorer l'absence d'une liaison claire entre les éléments et celle d'unité d'action ${ }^{52}$.

De fait, dans le cas des cartons de tapisserie de Le Prince, la fragmentation de la narration s'explique par la «stratégie disjonctive» de l'arabesque ${ }^{53}$. Cette forme artistique, qui respecte la logique de la peinture décorative, permet

${ }^{47} C f$. sa remarque dans les Pensées détachées sur la peinture : «[...] j’aime mieux la rusticité que la mignardise, et je donnerai dix Watteau pour un Teniers ». D. Diderot, Pensées détachées sur la peinture, dans : Salons IV, op. cit., p. 381.

48 D. Diderot, Salon de 1767, op. cit., p. 304.

49 D. Diderot, Essais sur la peinture. Salons de 1759, 1761, 1763, éd. G. May et J. Chouillet, Paris, Hermann, 1984, p. 56.

${ }^{5}$ Ibid.

${ }_{51} C f$. Caylus qui écrit à ce propos : « [...] ses compositions n’ont aucun objet. Elles n'expriment le concours d'aucune passion et sont, par conséquent, dépourvues d'une des plus piquantes parties de la peinture, je veux dire l'action. » Caylus, op. cit., p. 79.

${ }_{52} C f$. par exemple son critique à propos d'Une halte de Tartares: «Les objets n’y sont liés que pour l’œil, aucune action commune qui les enchaîne. » D. Diderot, Salon de 1765, op. cit., p. 228.

53 Voir Th. Crow, La peinture et son public à Paris au XVIII ${ }^{e}$ siècle, trad. par A. Jacquesson, Paris, Macula, 2000, p. 75. 
la juxtaposition d'éléments provenant de registres différents. Le résultat en est souvent un effet peu naturel, voire invraisemblable, qui va à l'encontre de la cohérence narrative. Un autre trait caractéristique de l'arabesque est l'absence de profondeur ou, autrement dit, la platitude, élément constant de la critique de Diderot envers les figures de Le Prince. C'est en ces termes qu'il s'en prend aux personnages de l'Autre bonne aventure: "Les figures plates ressemblent à de belles et riches images collées sur toile. ${ }^{54}$ L'adjectif " plat " dans la citation peut revêtir deux sens : d'une part, il renvoie à la technique de représentation propre à la peinture décorative qui tend à aplatir les formes. D'autre part, dans un sens figuré, ce terme peut désigner l'absence d'expression des figures et, à un niveau encore plus abstrait, l'absence d'imagination de Le Prince ${ }^{55}$. Diderot regrette que le peintre soit «sans idée, sans finesse et sans âme ", lacune qui se reconnaît dans la «négligence " et la "mollesse du pinceau » que le critique attribue à la " paresse de tête $»^{56}$.

Quelque peu curieusement, le reproche de paresse a également été adressé à Watteau, bien que dans un contexte différent. Caylus désapprouve notamment la «malpropreté de pratique » du peintre, à savoir le fait que Watteau négligeait de nettoyer ses pinceaux, ce qui a conduit à l'altération des couleurs de ses tableau $x^{57}$. La référence à la négligence et à la paresse des deux peintres serait-elle un cliché récurrent du discours sur l'art, qui se retrouve dans les biographies d'artistes aussi bien que dans la critique d'art, et ce malgré le fait que Diderot n'a probablement pas connu les Vies de Watteau ? Si cet exemple montre la pertinence des stéréotypes liés en général à la figure de l'artiste - qui nourrissent les légendes d'artistes -, certaines remarques de Diderot à l'égard de Le Prince concernent plus spécifiquement la peinture rococo. Comme nous y avons déjà fait plusieurs fois allusion, à travers la critique de Le Prince, Diderot vise implicitement l'art de Boucher et celui de Watteau, bref, les principes de composition de la peinture rococo.

Bien qu'on puisse sans doute multiplier les exemples attestant l'héritage de Watteau dans l'art de Le Prince ${ }^{58}$, il est temps d'essayer de tirer des

${ }^{54}$ D. Diderot, Salon de 1767, op. cit., p. 317. Cf. aussi la critique de Diderot concernant la monotonie des têtes dans Le Concert de Le Prince : "Pourquoi ces visages si plats, si plats, si faibles, si faibles, qu’à peine remarque-t-on du relief. » Ibid.

55 Diderot imagine par ces lignes caricaturales la méthode du peintre qui n’a aucune idée préalable quand il se met au travail : « Le Prince a son papier bleu ou sa toile devant lui, il prend son crayon ou son pinceau et il se dit: Que ferai-je ? Ma foi, je n'en sais rien... » D. Diderot, Salon de 1769, op. cit., p. 71-72.

56 D. Diderot, Salon de 1767, op. cit., p. 314.

57 Caylus, op. cit., p. 78.

58 On pourrait ajouter aux éléments évoqués la « mélancolie » attribuée à Le Prince par Diderot (elle était aussi un trait de caractère de Watteau selon ses biographes) ou encore 
conclusions au sujet des russeries du peintre et du discours critique qui en rend compte. En tout état de cause, l'art du peintre-voyageur Le Prince pose la question de savoir si la peinture décorative peut avoir ou non une dimension documentaire. La revendication de l'authenticité, de la vérité de la représentation et la peinture décorative sont-elles compatibles ? Les commentaires de Diderot que nous avons passés en revue suggèrent que la volonté de les concilier est, du moins aux yeux des critiques d'art du XVIII siècle, une tentative vouée à l'échec. Pour Diderot, aussi bien que pour le critique anonyme des Mémoires secrets, l'art du peintre se réduit à des clichés pittoresques surtout vestimentaires. Ils décèlent dans les œuvres de Le Prince un exotisme peu authentique : non pas la représentation réaliste de la Russie mais des scènes champêtres rococo au sujet russe. Le fait que l'allusion au séjour de Le Prince en Russie - voyage ayant pourtant fourni une source d'inspiration pour la plupart des tableaux du peintre - n'apparaisse qu'indirectement dans les comptes rendus atteste l'écart qui sépare l'esthétique du peintre et celle des critiques d'art de son temps.

Cependant, pour la création des russeries, le voyage de Le Prince était indispensable : sans ce voyage, il n'aurait sans doute jamais eu l'idée d'exécuter ces types de tableaux et serait probablement resté un peintre rococo dans le sillage de Boucher. Bien que ses toiles ne soient pas fidèles à la réalité vue lors de son séjour en Russie, c'est tout de même une expérience authentique qui leur a servi de base, et cela malgré le fait que leur exécution témoigne d'un travail d'imagination. Nous avons vu que les critiques d'art de son temps, avec Diderot en tête, ne faisaient aucune mention du fait que Le Prince était un peintre-voyageur, mais le considéraient dans leurs commentaires comme un peintre tout court, ayant exposé ses œuvres à des Salons successifs. Le rôle du voyage est pourtant primordial dans l'acte de création de cet artiste : loin d'être un pur prétexte, il est une base solide et en même temps nécessaire qui sous-tend sa pratique artistique. De ce point de vue, le choix des sujets de Le Prince est significatif : il a notamment mis en scène dans ses tableaux des moments observés lors de son séjour en Russie. Les scènes qu'il a représentées telle la scène de guinguette évoquée (le " cabak») ou encore celles qu'il avait puisées dans la vie des Cosaques ou des Tartares ${ }^{59}-$ se basent sur ses souvenirs réellement vus, et il en va de même pour les rites et cérémonies comme la scène de baptême. Mais de tous ces éléments, qui ne manquaient sans doute pas d'un certain exotisme aux yeux du public français de l'époque, il a su construire un univers artistique singulier et homogène.

la «touche légère » du peintre (formule qui renvoie à la légèreté du pinceau de Watteau). $C f$. D. Diderot, Salon de 1765, op. cit., p. 223 et 226.

$59 C f$. entre autres les tableaux suivants de Le Prince : Un Parti de troupes cosaques, tartares, etc. qui au retour d'un pillage rassemblent leur butin pour en faire le partage ou Une Halte de paysans en été. D. Diderot, Salon de 1765, op. cit., p. 224 et 230. 
Il n'en reste pas moins que l'intérêt de l'art de Le Prince réside également dans le fait qu'il contribue à une meilleure compréhension de l'exotisme en France dans la seconde moitié du XVIII ${ }^{e}$ siècle. Le phénomène de mode de la russerie participe en effet de la pensée critique des Lumières. Au travers de la représentation des coutumes et mœurs étrangères, les scènes de genre au sujet russe de l'artiste illustraient, pour les visiteurs du Salon, l'expérience de l'altérité. Il faut souligner que l'exotisme des russeries est moins imaginaire que celui des turqueries et des chinoiseries des artistes rococo car il s'enracine dans l'expérience vécue par le peintre-voyageur Le Prince qui, en choisissant d'aller vers le Nord, a privilégié un trajet alternatif au traditionnel voyage en Italie des artistes. Puisqu'avec ses toiles, le peintre voile la réalité russe qu'il a connue lors de son voyage, et offre une vision idéalisée de la vie des paysans russes, Le Prince n'est certainement pas un peintre-voyageur « documentariste » au sens strict du terme, mais il n'est pas non plus le créateur d'un monde purement fantaisiste, comme le suggère Diderot. Malgré leur aspect décoratif, ses œuvres ont une dimension ethnographique, même si le peintre a recomposé dans ses tableaux - à la manière des capricci, à savoir des paysages imaginaires ses souvenirs du séjour russe selon les principes de l'esthétique rococo, en mettant l'accent sur les motifs pittoresques susceptibles d'attirer le public français contemporain.

On ne peut pourtant pas écarter la question de savoir ce que, selon Diderot, le voyage en Russie aurait dû apporter à Le Prince pour que, dans ses Salons, il parle de l'artiste comme d'un peintre-voyageur. Pour le critique d'art, le bon tableau est celui qui l'invite à un voyage (imaginaire) à l'intérieur de l'espace de la toile. Si seulement peu de compositions de Le Prince remplissent ce critère, c'est probablement parce que le peintre adhère à une conception du voyage diamétralement opposée à celle de Diderot. On peut donc supposer que le critique d'art et le peintre représentent deux manières différentes de voyager : alors que Diderot privilégie le type de voyage que l'on peut appeler "interne ", au sens où il y participe - semblablement à son attitude au Salon où il s'introduit dans les scènes représentées -, pour Le Prince, il s'agit (du moins d'après les commentaires des salonniers) davantage d'un voyage " externe». Adoptant le point de vue d'un observateur détaché, le peintre recherche des motifs pittoresques et exotiques et vise à l'effet que ses toiles sont censées susciter, sans pour autant prendre part à la scène qu'il représente.

Il est dès lors peu frappant de voir le caractère ambigu de ses russeries auquel Diderot a réagi par son refus de décrire la plupart des compositions de Le Prince. Mais à la lecture de son opinion méprisante à propos d'Une halte de Tartares - lorsqu'il écrit que " cela ne signifie rien $"^{60}-$, dans la perspective des théories artistiques du XXI ${ }^{\mathrm{e}}$ siècle, la question reste ouverte : le tableau doit-il

${ }^{60} \quad$ Ibid., p. 229. 
nécessairement signifier quelque chose ? Il s'agit là d'une question bien complexe dont l'examen excèderait les cadres de cet article, et qui demanderait de préciser préalablement le sens sémantique des termes «signifier » et « signification » dans le discours sur l'art. Ne suffit-il pas que le tableau soit, comme l'écrit Eugène Delacroix dans une belle formule de son Journal, une «fête pour l'œil $»^{61}$ ?

\section{Illustrations :}

Illustration 1 : Jean-Baptiste Le Prince, Le Berceau russe, vers 1764-1765, huile sur toile, 59x74 cm, Los Angeles, The J. Paul Getty Museum (domaine public). Source : https://commons.wikimedia.org/wiki/File:LePrinceBerceauRusse. jpg

Illustration 2 : Jean-Baptiste Le Prince, Le Baptême russe, huile sur toile, $73 \times 92 \mathrm{~cm}, 1765$, Paris, Louvre (domaine public). Source : https://commons. wikimedia.org/wiki/File:Jean-Baptiste_Le_Prince_-_The_Russian_ Baptism_-_WGA12599.jpg

Illustration 3 : Jean-Baptiste Le Prince, La Diseuse de bonne aventure, huile sur toile, $134 \times 93,5 \mathrm{~cm}, 1767$, Beauvais, Musée de l'Oise (domaine public). Source : http://mudo.oise.fr/collections/details/jean-baptiste-le-prince-la-diseuse-debonne-aventure/

Illustration 4 : Jean-Baptiste Le Prince, Le Cabak, huile sur toile, $97 \times 143 \mathrm{~cm}$, 1769, Stockholm, Nationalmuseum (domaine public). Source : https:// www.europeana.eu/hu/item/2048005/Athena_Plus_ProvidedCHO_ Nationalmuseum__Sweden_23776

61 «Le premier mérite d'un tableau est d'être une fête pour l'œil. » E. Delacroix, Journal (pages choisies), éd. J. Vérain, Paris, Mille et Une Nuits, 2002, p. 84. 
Aleksandra Wojda

Sorbonne Université/CNRS

ORCID 0000-0003-1391-6256

\section{Vers une écriture de l'humeur inquiète : le Voyage musical en Allemagne et en Italie de Berlioz}

\section{Towards a Writing of Wandering Mood: On Berlioz's Voyage musical en Allemagne et en Italie}

The paper is devoted to Hector Berlioz's Voyage musical en Allemagne et en Italie (1844), which offers a particularly interesting variant of musical travel writing that emerges in nineteenth-century France. The analysis of the composer's prose questions specific aspects of Berlioz's creative imagination and literary poetics that disclose deeper anthropological and aesthetical implications. The representations of alternative, solitary paths of the wandering hero, the alternate syntactic rhythms and variable tempi of the narrative, the constant play with literary conventions appear as different articulations of new dynamics of the moving, "musical" modern identity that emerges through his writing. The palimpsest-like model of the composer's creation, as well as his transgressive, eccentric deconstruction of topical representations of the visited countries, converge with these aspects of Berlioz's poetics that seem to be constantly fostered by the dialectic tension between creative energy of the ever moving self and the necessarily well-delineated dimension of the work of art.

Keywords: musical travel, literature - music, Romanticism, Berlioz, musicliterature studies

Mots-clés : voyage musical, littérature - musique, romantisme, Berlioz, études musico-littéraires 
La réflexion sur le voyage constitue aujourd'hui un domaine particulièrement fréquenté de la recherche en sciences humaines. Si l'actualité de ce thème et l'intérêt pour la question du déplacement qui y est lié ne font pas de doute, ils sont assurément à mettre en relation avec la transformation profonde de notre rapport à l'espace. Le mouvement étant une composante fondamentale de la modernité " liquide " théorisée par Zygmunt Bauman, il paraît naturel que le voyage soit propre à définir l'expérience de la contemporanéité.

Mais sans doute la liquidation contemporaine du voyage, si l'on peut s'exprimer ainsi, est-elle aussi un aboutissement autant qu'un état et que le signe d'une dynamique particulière. À cet égard, quelques évidences sont à rappeler. Qui dit mouvement dit déplacement de frontières, même si celles-ci sont invisibles et intériorisées. Sitôt le mot prononcé, s'invitent avec lui les cloisonnements génériques, institutionnels et disciplinaires. De quoi comprendre pourquoi les études dédiées au récit de voyage accueillent aujourd'hui historiens, littéraires, historiens de l'art ${ }^{2}$, logiquement concernés par la question puisque depuis l'aurore des temps modernes, le voyage s'est avéré capital pour toute formation artistique. Dans ce paysage très riche, pourtant, le voyage musical est longtemps resté une expérience de deuxième ordre. La figure du musicien itinérant a beau être enracinée dans l'imaginaire culturel européen ${ }^{3}$, il a fallu attendre la carrière littéraire et culturelle du génie musical romantique et la diversité de ses figures enchanteresses - compositeur, chanteuse, virtuose ${ }^{4}$-, pour qu'un tel voyage obtienne ses lettres de noblesse.

Il s'ensuit que l'exploration de ce lien entre voyage et art musical s'intensifie au crépuscule des Lumières et avec l'essor de l'esthétique romantique, tant dans l'art musical proprement dit que dans les représentations textuelles, picturales et culturelles dont il est l'objet. Le cycle Winterreise (1827) de Schubert, les Années de pèlerinage de Liszt, Harold en Italie (1834) de Berlioz sont autant de monuments aux titres transparents qui témoignent d'un intérêt inédit des compositeurs européens de l'époque pour le voyage, réel ou imaginaire ; une passion que nombre d'autres exemples - étudiés par Corinne Schneider dans sa synthèse très récente - pourraient venir attester ${ }^{5}$.

1 Cf. Z. Bauman, La vie liquide, trad. C. Rosson, Rodez, le Rouergue - Chambon, 2006, ainsi que M. Augé, Pour une anthropologie de la mobilité, Paris, Payot \& Rivages, 2009.

$2 C f$. entre autres R. le Huenen, Le récit de voyage au prisme de la littérature, Paris, PUPS, 2015 ; "Voyage et individuation ", Source(s) : cahiers de léquipe de recherche Arts, civilisation et histoire de l'Europe, sous la dir. de D. Coulon, nº 6, 2015 ; Le Grand Tour et l'Académie de France à Rome, XVII $-X I X^{e}$ siècles, sous la dir. d'É. Beck-Saiello, J.-N. Beck, Paris, Hermann, 2018.

3 Cf. L. Charles-Dominique, Les "bandes" de violons en Europe : cinq siècles de transferts culturels. Des anciens ménétriers aux Tsiganes d'Europe centrale, Turnhout, Brepols Publishers, 2018.

${ }^{4}$ L'œuvre d'E.T.A. Hoffmann en est l'une des sources les plus influentes dans l'Europe du $\mathrm{XIX}^{\mathrm{e}}$ siècle.

5 Voir C. Schneider, La musique des voyages, Paris, Fayard/Mirare, 2019. 
Or, cet intérêt est lié à un changement radical du statut de la musique dans la hiérarchie des arts de l'époque. Parent pauvre de la création artistique pendant les siècles où régnait en maître l'esthétique mimétique, elle se retrouve au sommet à partir du moment où l'exploration des passions humaines (anticipatrice de la psychologie moderne) devient un mot-clef ouvrant sur un espace ressenti comme insondable. Elle se charge alors de fonctions épistémologiques et anthropologiques qui participent de la construction du sujet moderne émergent ${ }^{6}$, et cette construction est, de fait, celle d'un territoire.

Vue sous cet angle, l'étude du voyage musical prend une dimension particulière. À tout le moins, elle s'avère riche de promesses pour saisir l'une des problématiques posées par le voyage en général au travers de la figure du voyageur que cette période a exhaussée. C'est ce que j'essaierai de montrer ici, en m'appuyant sur l'écriture littéraire du voyage telle que la propose un compositeur-voyageur majeur du siècle. Représentant iconique du romantisme français, Hector Berlioz est aussi un écrivain ${ }^{7}$ et par la réflexivité qu'ils impliquent, ses Voyages constituent des mines pour le sujet qui nous occupe. Quelles sont les spécificités de l'écriture du voyage quand un musicien s'y engouffre ? En quoi cette écriture contribue-t-elle à l'élaboration d'une anthropologie? Qu'en résulte-t-il pour notre appréhension des liens entre sujet, voyage et musique? Telles sont les questions que les Voyages de Berlioz nous invitent à poser.

\section{Écritures du mouvement : écritures du « je »}

Commençons par l'évidence. Parmi les compositeurs français de sa génération, Berlioz est l'un de ceux qui ont le plus voyagé ${ }^{8}$ et, surtout, celui qui a fait de cette expérience une composante inséparable de son imaginaire et de son écriture. Dans ses Mémoires, il rappelle l'éveil précoce de sa « passion pour les voyages et les aventures »: l'imaginaire du futur compositeur se nourrit, dès son enfance, des «mappemondes " qu'il trouve dans la bibliothèque de son père, mais

${ }^{6}$ C'est ce que laisse entrevoir Joseph-Marc Bailbé, soulignant la centralité du sujet - « artiste à la recherche de lui-même » dans l'œuvre de Berlioz. J.-M. Bailbé, «L'Époque de Berlioz : un moment du Romantisme », Revue d'Histoire littéraire de la France, nº 3, 2004, p. 516.

7 Comme le rappellent J.-M. Fauquet, C. Massip et C. Reynaud, «Préface », dans : Berlioz, textes et contextes, sous la dir. de J.-M. Fauquet, C. Massip et C. Reynaud, Paris, Société française de musicologie, 2011, p. 9-10) ; voir aussi B. Didier, Berlioz et la création littéraire, dans : Berlioz, textes et contextes, op. cit., p. 51-57.

8 Cf. C. Schneider, op. cit., p. 41-42, 110, passim. Énumérons, dans l'ordre chronologique : un voyage en Italie (1831-1832), puis en Allemagne (1842-1843), suivi d'un autre qui lui fait traverser, en 1845, l'Europe centrale; deux voyages en Russie; enfin, dans les années 1850 et 1860, plusieurs tournées en Angleterre et, de nouveau, en Allemagne, ainsi que de nombreux séjours à Baden-Baden. 
aussi de "l'avide lecture » de ce que celle-ci contient « de voyages anciens et modernes ${ }^{9}$. C'est dire qu'indépendamment de cet « effet de spontanéité » dont son écriture foisonne souvent quand il s'agit de relater une expérience vécue, ses récits de voyage sont ceux d'un lecteur qui dispose d'une connaissance solide du genre. C'est sur cette connaissance-là que le vécu pourra se greffer ; c'est à travers les schémas qu'elle lui fournit qu'elle trouvera à se figurer - en les confirmant, en les déplaçant ou en les retournant -, d'abord avec la publication, en 1844, du Voyage en Allemagne et en Italie, puis avec celle des Mémoires.

Aux déplacements réels de l'homme à partir des années 1830 se surimpose ainsi une image préformée du voyageur qu'on pourra qualifier, eu égard à la formation reçue dans la bibliothèque universelle à la mappemonde, de centripète autant que de rotative. Les formes littéraires, auxquelles l'expérience itinérante donne lieu, sont aussi variées que les routes prises, puisqu'elles vont des articles de presse aux Mémoires publiés - selon le souhait de l'auteur - à titre posthume, en passant par un Voyage musical en Allemagne et en Italie qui sera ici au centre de notre attention ${ }^{10}$. Par-delà la diversité des catégories génériques convoquées, ce sont, cependant, les liens entre les divers écrits issus de ses voyages qui attirent l'attention - et étonnent par leur complexité ${ }^{11}$. Début d'une circulation virevoltante autour d'un axe, aussi dynamique que droite dans ses principes. Un mouvement créateur s'affirme ici, qui n'est pas sans rappeler celui des auto-emprunts que Berlioz pratique à large échelle dans son œuvre musicale, en faisant un véritable palimpseste. Le Voyage de 1844 forme un tissu textuel cousu de nombreux articles que Berlioz avait publiés dans la presse au cours de son séjour italien. De même, ses Mémoires reconfigurent ses nombreux articles de presse aussi bien que son livre de 1844, qui deviennent par là-même des «sources autobiographiques". Reproduisant le geste de Chateaubriand, Berlioz fait de ces Mémoires plus qu'un document de son siècle. Il y donne un statut particulier à ses récits de voyage, intégrés désormais dans une écriture autobiographique toujours en devenir où l'on voit un sujet lyrique de plus en plus solide réassembler les morceaux d'un moi que le siècle pourrait potentiellement émietter.

Ce qui ne serait rien si la lecture du Voyage musical en Allemagne et en Italie de 1844 ne laissait observer une autre tendance encore, spécifique de tels penchants autocréateurs : celle d'une phénoménologie de la réflexion subversive,

9 Mémoires d'Hector Berlioz de 1803 à 1865 et ses voyages en Italie, en Allemagne, en Russie et en Angleterre écrits par lui-même, texte établi, présenté et annoté par P. Bloom, Paris, J. Vrin, 2019, chap. II, p. 133.

10 Nous nous référerons à son édition originale : H. Berlioz, Voyage musical en Allemagne et en Italie, Paris, Jules Labitte, 1844, 2 vol.

11 Voir l'Introduction et les annotations de Peter Bloom à l'édition critique récente des Mémoires d'Hector Berlioz..., op. cit., passim, ainsi que H. Berlioz, La Critique Musicale, éd. R. Cohen et Y. Gérard, Paris, Buchet/Chastel. Pierre Zech Éditeur, 1996, vol. I : 1823-1834. 
aux deux sens du mot réflexion. Le narrateur, en accentuant l'écart entre ses premières expériences de voyage, essaye aussi d'explorer les diverses facettes d'un je-personnage dont le statut de sujet, et de héros à bien des égards, se bâtit au gré de cette traversée identitaire. Il y a là quelque chose d'un parcours initiatique où le moi joue le rôle et de l'initié et de l'initiateur et qui subvertit la représentation normative et académique de l'initiation. Le Berlioz des années 1830 - tel qu'il se construit à travers ses écrits de la période, repris et remaniés par le narrateurBerlioz en 1843/1844 - apparaît comme jeune lauréat du Prix de Rome. Mais cette récompense censée devenir un tremplin pour sa carrière et lui permettre d'acquérir une place digne de son talent au Parnasse de la musique française, lui impose nombre de compromis qui pourraient désagréger l'identité même qu'elle semble reconnaître. Conséquence : le sujet ne peut pas la recevoir sans mettre en cause la figure, pour part fabriquée par d'autres, qui la reçoit - la sienne même. Ainsi le personnage du récit accepte-t-il fort mal ces compromis. Et certes, sa position de provincial de la Côte-Saint-André à qui l'on n'a jamais appris à jouer du piano n'est pas des plus confortables pour contester le scénario qu'on lui propose. C'est néanmoins grâce à cette situation socialement instable que le récit du voyage en Italie devient plus personnel : rétrospectif par définition, il témoigne d'une gestation, et focalise l'attention sur l'émergence de l'écriture d'un « je » à la fois voyageur, musicien et créateur de lui-même.

On peut dès lors suivre le mouvement... à l'envers. Le voyage en Allemagne, dont la description publiée dans le premier volume du Voyage musical prend la forme d'un récit épistolaire, apparaît logiquement plus conforme au projet identitaire du Berlioz des années 1840 - mais il n'en est pas moins dans la continuité du geste inaugural de dissociation envers le milieu - autrement dit d'ingratitude créatrice. Compositeur majeur de la " nouvelle école " et critique reconnu, il se rend avant tout en Allemagne pour s'affirmer sur la scène internationale en faisant exécuter ses œuvres dans un pays qu'il considère comme nouveau centre musical de l'Europe, car il est la patrie des maîtres de la musique instrumentale moderne qu'il vénère : Gluck, Weber et Beethoven. Ici, le rapport entre le voyageur et l'espace qu'il traverse est plus harmonieux, alimenté par une complicité longtemps rêvée entre le créateur et sa "patrie spirituelle». Mais c'est aussi une façon symbolique de continuer à subvertir les codes de reconnaissance. Si, comme l'avait déjà suggéré AlfredAuguste Cuvillier-Fleury, " au lieu de nous donner une quatre-vingt-dixième édition de quelque voyage descriptif, $\mathrm{M}$. Berlioz ne décrit, en Italie, que luimême $»^{12}$, c'est que ce "lui-même " choisit délibérément de mettre à mal la notion du "même » comme telle, en se représentant à la fois dans ce qu'il a de fixe, d'atemporel, d'égal à soi, et dans ses métamorphoses ou son historicité.

12 A.-A. Cuvillier-Fleury, " Hector Berlioz, Voyage musical en Allemagne et en Italie: compte-rendu ", Journal des Débats, le 23/03/1845, p. 2-3. 
L'énergie de l'écriture présente dès les premiers extraits parus dans la presse, rédigés le plus souvent sous la pression du temps et des circonstances, sera rétroactivement subsumée en un autoportrait qui tentera de saisir une identité dynamique, dès l'origine et jusqu'à son terme vivante et (é)mouvante.

\section{Lieux en déplacement}

On imagine bien que ce type d'identité ne se forge pas sans tensions. Il suffit de citer ici la première description de la villa Médicis, siège de l'Académie de France à Rome, proposée par Berlioz dans le cinquième chapitre de son Voyage musical, pour saisir le conflit paradoxal, à la fois contraignant et fructueux, entre la personnalité du créateur qui émerge de cette écriture et l'expérience du lieu dans lequel il vient s'installer en tant que lauréat du Prix de Rome dans le domaine de composition musicale ${ }^{13}$ :

[...] le palais s'ouvre sur de beaux jardins, dessinés dans le goût de Lenôtre, comme doivent l'être les jardins de toute honnête Académie. Un bois de lauriers et de chênes verts, élevé sur une terrasse, en fait partie, borné d'un côté par les remparts de Rome et de l'autre par le couvent des Ursulines-Françaises, attenant aux terrains de la villa Medici. En face on aperçoit, au milieu des champs incultes de la villa Borghèse, la triste et désolée maison de campagne qu'habita Raphaël ; et, comme pour assombrir encore ce mélancolique tableau, une ceinture de pinsparasols en tout temps couverte d'une noire armée de corbeaux, l'encadre à l'horizon. ${ }^{14}$

Bois «borné " par des remparts et des murs, "ceinture " de pins-parasols qui « encadre " l'horizon : l'intentionnalité de l'auteur de cette description ne fait pas de doute. Le narrateur fait avant tout remarquer à son lecteur un ensemble d'infrasignes, aussi subtils qu'omniprésents, qui renvoient à une situation d'enfermement. Les adjectifs qui émaillent cette description ne font que renforcer le sentiment de désolation qui s'en dégage (" inculte», " triste », « désolé(e) », " mélancolique » et « noir »). Quelques précisions sur le quotidien de la villa Médicis complètent la lecture topographique déceptive : les chambres des pensionnaires sont " petites, incommodes, et surtout excessivement mal meublées »; la bibliothèque s'avère «totalement dépourvue

13 Voir C. Reynaud, "Voyages musicaux dans le cadre du Grand Prix de Rome de composition musicale (1803-1850)», dans : Voyages d'artistes et artistes voyageurs. $130^{e}$ congrès national des sociétés historiques et scientifiques, sous la dir. de J.-R. Gaborit, Paris, Éditions du Comité des travaux historiques et scientifiques, 2008, p. 143-148.

14 H. Berlioz, Voyage musical..., op. cit., vol. II, p. 56-57. Toutes les citations suivantes viennent de cette édition à laquelle nous renvoyons désormais en utilisant le sigle VM. 
d'ouvrages nouveaux » (VM II/58); le fameux Café Greco situé à proximité apparaît enfin comme " la plus détestable taverne qu'on puisse trouver, sale, obscure et humide » (VM II/64). Nous voilà dans un espace de privation au sens le plus radical du terme : car le sentiment d'enfermement relève non seulement d'une organisation de l'espace physique, mais aussi d'un manque des ressources propices à l'évasion que la vie sociale ou la lecture pourraient offrir. Les expériences musicales vécues dans la «Ville éternelle» ne changent pas la donne. La musique entendue dans la chapelle Sixtine est exécutée par un petit chœur incapable de créer autour de lui un espace sonore; l'image du petit orgue à roulettes caché derrière un pilastre devient une synecdoque aussi triste que grotesque du statut de l'art musical dans la capitale italienne tel que Berlioz le perçoit. Et quitter Rome ne donne pas plus d'air. Le nouvel opéra shakespearien de Bellini entendu à Florence, I Montecchi ed i Capuletti [sic], ne contient " point de Shakespeare, rien » (VM II/92); la représentation de la Vestale de Pacini finit par pousser l'auditeur-Berlioz à quitter le théâtre avec une citation d'Hamlet sur les lèvres : «Ceci est de l'absinthe ! » (VM II/93).

On n'évacue pas mieux les stéréotypes culturels (tout en les confirmant par ailleurs), surtout quand on prend la parole après des siècles d'exclamations exaltées sur une ville qui fait office de centre d'une civilisation et de destination consacrée de pèlerinages et de Grands Tours. Fondée sur ces schémas, la rhétorique du discours académique adressé aux lauréats du Prix de Rome ( Allons, jeune homme, macte animo... vous allez faire un beau voyage... la terre classique des beaux-arts... [...] un ciel inspirateur... [...] Vous êtes en beau chemin "; VM II/34) se voit balayée par un récit que l'on pourrait plus facilement rapprocher de l'imaginaire mélancolique du centre déplacé, problématique et fuyant dans la célèbre formule "Rome n'est plus dans Rome ${{ }^{15}}^{15}$ si seulement l'auteur du Voyage musical prêtait un peu plus d'attention à ce noble objet. Mais trop désinvolte et provocateur, en apparence, pour s'en occuper, Berlioz est surtout porté par un autre défi : faire entendre le « je » d'un musicien vivant opposant à l'immensité d'un héritage artistique consacré son droit personnel à se frayer son chemin en toute indépendance. Il s'agit, en d'autres termes, de n'obéir qu'à une instance fonctionnant comme un absolu : son imaginaire - singulier et unique - de l'artiste compositeur.

À cet égard, Berlioz tranche d'emblée. Le paradis des peintres, des architectes et des sculpteurs n'a rien à offrir au compositeur contemporain ; car " [a]u milieu de tous les autres arts, pleins de vie [...], éblouissants de l'éclat du génie ", la musique se voit - selon lui - « réduite au rôle d'une esclave dégradée [...] chantant d'une voix usée de stupides poèmes » (VM II/153-154). La "patrie des Pergolèse, des Piccinni » vantée par les académiciens appartient au passé ;

${ }_{15}$ Cf. Ch. Imbert, Rome n'est plus dans Rome. Formule magique pour un centre perdu, Paris, Classiques Garnier, 2011. 
pour entendre un art musical réellement novateur, c'est-à-dire une musique instrumentale digne de ce nom, il faut traverser le Rhin (VM II/5). La louange de Berlin contenue dans le premier volume du Voyage musical constitue un miroir inversé de cette topique de "l'Italie artiste " : loin de cette "Juliette au cercueil étendue " (VM II/136), la musique « est dans l'air, on la respire, elle vous pénètre »; " grande et fière toujours, et forte et agile », elle est "prête à reprendre son vol vers le ciel » (VM I/191).

Quelques années après la parution de l'élogieuse Vie de Rossini de Stendhal (1824), qui chantait la louange de l'Italie à travers son représentant musical le plus célèbre dont les opéras venaient de conquérir le public parisien ${ }^{16}$, plus d'un topos est ici mis à mal. L'énergie sensorielle doublée d'un érotisme vital, portée selon le grand enthousiaste du bel canto - par les voix italiennes nourries des paysages ensoleillés du Sud, se voit réduite à un effet superficiel n'apportant, en guise de plaisir sensoriel, qu'un chatouillement épidermique (VM II/208). À cet effleurement des sens, Berlioz oppose l'énergie plus charnelle et spirituelle que véhicule l'art de Beethoven et de Weber. C'est lui qui déborde de l'enthousiasme et du dévouement illimité pour la musique décrits dans le premier volume de son Voyage; c'est lui qui transpire la passion qui anime les compositeurs, mais aussi les chanteurs et les instrumentistes allemands (VM I/119). L'opposition entre l'enthousiasme vital du Sud et la mélancolie passive du Nord, héritée de l'imaginaire du siècle précédent, est renversée. Plus encore, les composantes de cette opposition sont redéfinies. La dialectique des deux volumes du Voyage renoue avec celle qu'avait instaurée Germaine de Staël au début du siècle ; mais en proposant un éloge du " volet musical » qui était quasiment absent du De l'Allemagne ${ }^{17}$, elle rompt avec le projet de l'auteur de Corinne qui tendait à ériger l'Italie en figure de synthèse heureuse des imaginaires du Nord et du Sud, ou qui associait à la culture allemande un certain manque d'énergie vitale, revers d'une profondeur appréciée ${ }^{18}$.

Alors, certes, parmi les compositeurs de son temps, Berlioz n'est pas le premier à mettre en cause la suprématie de l'art musical italien. Un Auguste Blondeau, par exemple, prix de Rome 1808, anticipait ses jugements dans son Voyage d'un musicien en Italie. "Grand dépréciateur de la musique italienne ${ }^{19}$, il s'inscrivait déjà dans un mouvement visant à définir les traits particuliers

16 Voir É. Bordas, « Bel ou mal canto ? Le chant romantique selon Berlioz », Romantisme, $\mathrm{n}^{\circ} 103,1999$, p. $57-58$.

17 Cf. S. Balayé, Les Carnets de voyage de Madame de Staël. Contribution à la genèse de ses œuvres, Genève, Librairie Droz, 1971, p. 41, note 63.

${ }_{18} \mathrm{Cf}$. A. Wojda, "Espaces vibratoires, explorations de l'intime : l'anthropologie musicale du paysage dans les romans de Germaine de Staël », Littératures, n 82 : le Paysage musical : littérature et musique dans la première moitié du XIXe siècle, 2021, à paraître.

19 J.-M. Fauquet, "Préface ", dans : A.-L. Blondeau, Voyage d’un musicien en Italie (18091812), Paris, Éditions Mardaga, 1995, p. 15. 
d'une « école française » capable d'opposer à sa cousine latine son goût du livret bien conçu et son imaginaire dramaturgique ${ }^{20}$. Mais si Blondeau pointait les failles de la culture italienne de son temps, avec son idolâtrie du beau chant, son approche "désinvolte " des livrets et son ignorance des acquis de la musique instrumentale moderne ${ }^{21}$, l'écriture du voyage qu'il proposait était encore fondée sur une anthropologie classique. Sans cacher ses déceptions, le compositeur... composait. Il restait soucieux d'une objectivité mesurée de son jugement ; il approchait les failles de la culture du pays qu'il visitait avec un mélange d'humour et de curiosité ethnographique pour se tourner raisonnablement vers les charmes que le patrimoine artistique italien était en mesure d'offrir - quitte à laisser de côté ses préoccupations strictement musicales. C'est dire que pour l'auteur du Voyage d'un musicien en Italie, il était naturel et légitime que le cadre extérieur objectif - institutionnel, social, culturel - impose ses lois à l'individu ; celui-ci s'y pliait spontanément, essayant d'y trouver son compte sans mettre en cause les scénarios qui lui étaient prescrits.

Avec Berlioz, ces rapports entre le sujet et le monde extérieur volent en éclats. Chez lui, le sujet ne cède à rien : l'anthropologie de son voyage, de son écriture, de son existence même est essentiellement créatrice. Le réel est là pour nourrir des scénarios qu'il cherche lui-même à inventer en même temps qu'ils déploient leur propre potentiel, pour alimenter des dramaturgies imaginaires alternatives que l'auteur signe de son nom de sujet en devenir, d'identité grosse de tous ses possibles. L'écriture ne peut pas ne pas en être touchée.

La logique d'un tel renversement régit donc la composition de nombreux extraits du voyage en Italie de Berlioz. Ce voyage n'est pas celui " d'un musicien »; partie intégrante de l'identité qu'il contribue à construire, il se désigne comme «musical». Qu'il s'agisse de la description de la villa Médicis, d'une représentation d'opéra ou d'une musique religieuse entendue à Saint-Pierre de Rome, on y retrouve à chaque fois un même schéma transgressif. L'horizon d'attente du lecteur-modèle, convoqué par la référence à une tradition culturelle consacrée, se voit dépassé, voire anéanti face à l'expérience concrète, charnelle et affirmée d'un « je » fortement individué qui oppose aux représentations reçues l'énergie de son récit, séduisante par son rythme, entraînante par la force de son imaginaire, et conquérante par ses désirs. Le résultat de cette expérimentation est radical. Se mettant en mouvement, le sujet entraîne derrière lui l'espace même, redéfini comme relationnel. Le sens de la lecture oblige : le lecteur n'a qu'à le suivre.

${ }^{20}$ Ibid., p. 11. Voir aussi G. Loisel, La Musique au défi du drame. Berlioz et Shakespeare, Paris, Classiques Garnier, 2016.

${ }^{21}$ Cf. A.-L. Blondeau, op. cit., p. 51-54. 


\section{Le « je » comme lieu (é)mouvant d'une écriture inquiète}

On ne rêve pas par hasard d'une carrière de marin. Pas plus qu'on ne commence à voyager dans une bibliothèque qu'une mappemonde fait tourner ${ }^{22}$. Les espaces qui attirent Berlioz ont en commun d'être vastes. Leurs contours semblent émerger de ce nouveau centre mouvant, le « je »-créateur, qui en définit le statut, les caractéristiques et les fonctions. Il ne les découvre pas de l'extérieur, ne les contemple pas. Il les crée à son contact ${ }^{23}$, dans un choc " électrique ", pour utiliser la métaphore qui lui est chère ; il en dispose comme le compositeur (érigé en maître de son orchestre dans le Traité d'instrumentation), crée à travers sa partition un nouvel espace musical en appréhendant le son dans sa globalité : définissant l'emplacement des instruments et explorant les effets acoustiques que cette disposition peut faire émerger, en fonction de chaque salle concrète où l'œuvre doit surgir. Le confessionnal de la basilique Saint-Pierre devient désormais un lieu de lecture : Berlioz y introduit le Corsaire du scandaleux Byron, pour en faire l'espace d'une confession implosive. Semblablement, les paysages des alentours de Nice deviennent un lieu de création musicale : le musicien abandonne le salon et le piano pour s'y immerger dans un espace ouvert potentiellement illimité qu'il sillonne son album à la main.

En tout cela, une même logique : celle de la co-immixtion de tous les éléments constitutifs d'une expérience. Le rapport sujet-objet est remplacé par la découverte d'un milieu global dont le sujet participe, qui fait de lui comme de sa musique ou de son écriture, sans jeu de mot, un medium ${ }^{24}$. Il s'ensuit un certain nombre de conséquences. Le voyage d'un sujet disposant de telles prérogatives s'accompagne notamment de déplacements irréductibles à ceux qu'un voyageur classique peut observer en traversant un espace considéré comme fixe, défini et indépendant de celui qui le perçoit.

Ainsi, et d'abord, le personnage-Berlioz voyage seul. Plus encore : son récit fait entendre à maintes reprises que sa trajectoire diffère de celle de ses prédécesseurs, de ses camarades, de tout ce qui est attendu. Tous les lauréats du Prix de Rome se rendent à la villa Médicis en traversant ensemble les Alpes. Lui part plus tard et choisit la voie maritime. Il se rend à Marseille. Un « calme plat » arrête son bateau pour trois jours près de Nice. Puis, il manque de perdre la vie dans une tempête dont la description ferait penser au célèbre poème éponyme de Byron, si la veine héroïcomique ne finissait pas par prendre le pas sur les élans pathétiques ${ }^{25}$. Autant d'éléments pour comprendre que le chemin pris autant

22 Mémoires d'Hector Berlioz..., op. cit., p. 133.

${ }_{23}$ Cf. D. Catteau, Hector Berlioz ou la philosophie artiste, Paris, Publicook, 2001, p. 203.

24 Dans cette même logique, René Maubon souligne : "On pourrait presque dire que le personnage principal d'Harold [en Italie] n'est pas Harold mais le paysage ». R. Maubon, Hector Berlioz ou la passion de la musique, Paris, Les Éditions de Paris, 2003, p. 66.

25 Cf. B. Didier, op. cit., p. 57. 
que le récit qui le double sont tout sauf battus : au contraire, l'imprévu rattrape le sujet en permanence et mine les cadres sécurisants que l'Académie, mais aussi tout legs culturel, pourraient lui assurer. Le contexte social environnant ne fait qu'alimenter une telle démarche excentrique : parmi ses compagnons de voyage, on trouve quelques matelots italiens et des patriotes rejoignant le soulèvement de Toscane... Nous l'avons compris : ce qui intéresse ce voyageur, ce sont les trames secondaires, les parcours qui se creusent en marge de l'Histoire représentée et de son récit héroïque, fût-il celui du grand Lord ironiste dont l'ombre plane sur son voyage musical. L'obstination avec laquelle il fuit ainsi le centre du monde, figuré par l'image de la Rome somnolente, va jusqu'à perturber toute la composition du voyage : le « je » ne finit par arriver à Rome qu'au début du chapitre V (VM II/59), pour la fuir aussitôt et n'y revenir qu'au chapitre VII (VM II/85) situé au milieu de son récit. La capitale des arts a beau figurer au centre architectural du récit-monde, le narrateur préfère errer dans les environs de Nice ou flâner dans les Abruzzes pour découvrir une Italie toute autre : libre, sauvage, imprévisible.

Et cette tendance n'est pas réductible à une extravagance de jeunesse : comme le prouve son Voyage musical en Allemagne, elle oriente durablement ses choix. Sans doute Berlioz ne jouit-il pas ici de la même liberté que pendant son séjour italien; pourtant, son goût du " hors-centre " reste un principe de sa tournée allemande. Dans la cinquième des dix lettres qui composent ce récit épistolaire - toujours au centre de son ouvrage, donc-, il signifie à son destinataire que, malgré la recommandation que celui-ci lui a faite " de ne pas [s]'arrêter dans les petites villes en parcourant l'Allemagne " parce que "les capitales seulement [lui] offriraient les moyens d'exécution nécessaires à [s]es concerts ", il restera fidèle à son tempérament : "plein du désir de connaître ce que possède d'institutions musicales votre harmonieuse patrie, je formai le projet de tout voir, de tout entendre et de réduire beaucoup mes prétentions chorales et orchestrales, afin de pouvoir aussi me faire entendre presque partout "(VM I/93-94). Même curiosité que pendant son séjour italien de découvrir le potentiel des lieux que les circuits tracés rabougrissent, quitte à affronter des situations imprévues. Les données distinctives du voyage du compositeur-chef d'orchestre de son temps sont désormais posées. Dans la Lettre adressée à Liszt, il souligne ainsi que, contrairement au virtuose, le compositeur qui dirige lui-même ses œuvres dépend entièrement des orchestres, des théâtres, des salles qu'il ne découvre que sur place... Un milieu de co-immixtion, de nouveau, qu'il s'agit simplement d'appréhender comme tel car une fois qu'on réussit à vaincre les obstacles, il en résulte des moments et des rencontres musicales inoubliables.

À moins qu'il ne s'agisse de recomposition des liens ? Cet attrait de Berlioz pour des espaces périphériques peu explorés n’est pas sans rapport, en effet nous l'avons vu - avec la reconfiguration de l'imaginaire social qui traverse ses 
écrits. L’anthropologie qui se forge à travers sa création valorise des facultés peu compatibles avec la maîtrise de soi, centrale pour la sociabilité classique ; c'est l'énergie de l'engagement individuel, c'est la force de l'intuition esthétique, c'est la fidélité aux élans passionnels qu'elle érige en qualités principales. Premier à avoir été véritablement ému par sa cantate, le concierge de l'Institut devient le premier héros de son épopée italienne (chapitre II). Le chapitre IX offre l'immortalité à la jeune Vincenza et à son amour. Quant à Crispino, le « demibandit, demi-conscrit "de Subiaco, sa sérénade - notée dans le Voyage réapparaît sous la forme de la Sérénade d'un montagnard des Abruzzes à sa maîtresse dans Harold en Italie, œuvre autrement autobiographique issue du séjour italien. Air du temps? Tendance universelle, plutôt. La démocratisation de l'imaginaire sonore ne relève pas tant, chez Berlioz, d'une passion ethnographique que d'une conviction selon laquelle l'art musical véritable ne saurait connaître de frontières. Passionnées, dévouées et capables de s'émouvoir, les âmes musicales se rencontrent dans tous milieux et sous tous les ciels, car la musique réussit à toucher chacun : "Les riches et les pauvres, le clergé et l'armée, les artistes et les amateurs, le peuple et le roi »(VM I/191-192). Le propos est bien idéaliste ; il n'en est pas moins remarquable par le pouvoir de transgresser les hiérarchies sociales qu'il attribue à l'art musical. C'est également à ce pouvoir que les « vagabondages » des musiciens - détachés de ces objets matériels qui orientent les voyages des architectes - doivent de jouir d'une liberté particulière : le rythme et le sens de leurs parcours ne dépendent que de leurs «sympathies personnelles", de leur « désir de voir » et de leur « humeur inquiète» (VM II/105).

À partir de là, nous pouvons comprendre que le Voyage musical de Berlioz fasse assister à l'expansion d'une écriture de l' "humeur inquiète». Celle-ci se construit à travers un phrasé aux rythmes oscillatoires, au prétendu hasard de phrases dont le «tempo » capricieux et les «crescendos» imposent à la narration des paliers, des chutes et des culminations vertigineuses ${ }^{26}$; elle se traduit aussi - souvent conjointement - par des mouvements changeants et imprévisibles du voyageur-vagabond qui traverse les paysages; elle résulte enfin de sa manière de convoquer telle ou telle convention littéraire pour l'abandonner aussitôt au profit d'une autre, comme s'il s'agissait de masques que le sujet se sent libre de revêtir, refusant d'être réduit à aucun de ces rôles. Son aventure sur le navire bousculé par les flots au large de Nice, que nous avons déjà évoquée, apparaît comme une métonymie dont nombre d'extraits du Voyage constituent des variantes. Que penser de cette course dans laquelle le personnage-Berlioz se lance à la fin de sa longue marche de Naples à Rome ? Précédée d'un déplacement en calèche, elle n'est pas sans lien avec le rythme

${ }^{26}$ Cf. K. Ellis, "The Criticism ", dans : The Cambridge Companion to Berlioz, sous la dir. de P. Bloom, Cambridge, Cambridge University Press, 2000, notamment p. 158. 
de cette lettre adressée à Liszt, faite essentiellement de longues digressions sterniennes qu'il assume comme telles en déclarant : "Voilà, mon cher Liszt, une bien longue digression, et j'allais oublier, en causant avec toi, de continuer le récit de mon voyage. J'y reviens "(VM I/60). Ici comme là, le narrateur essaye de suivre le mouvement, de rattraper un courant en résumant soudain son voyage dans un tempo extrêmement rapide qui fait penser à une strette : "Me voilà de nouveau sur le Rhin! - Je rencontre Guhr. - Il recommence à jurer. - Je le quitte [...] » (VM I/64). Dans la lettre à Girard, c'est encore tout un imaginaire romanesque du voyage romantique qu'il convoque - cette fois en creux, de façon à revivre les effets de rythmisation sonore que l'éloignement et l'absence même des réalités évoquées procurent :

La route de Francfort à Stuttgardt [sic] n’offre rien d'intéressant, et en la parcourant je n'ai point eu d'impressions [souligné dans le texte original - A.W.] que je puisse vous raconter : pas le moindre site romantique à décrire, pas de forêt sombre, pas de couvent, pas de chapelle isolée, point de torrents, pas de grand bruit nocturne, pas même celui des moulins à foulons de Don Quichotte; ni chasseurs, ni laitières, ni jeune fille éplorée, ni génisse égarée, ni enfant perdu, ni mère éperdue, ni pasteur, ni voleur, ni mendiant, ni brigand [...] (VM I/64).

Changement de tempo marqué par les ponctuations fortes, rebond des [i] du premier syntagme de l'énumération privative qui sont comme des cailloux lancés dans le vide, récurrences phonétiques en clôture de syntagmes qui forment des couples nostalgiques d'une rime chaque fois révoquée aussi bien que convoquée (l'« enfant perdu » et la «mère éperdue », le « pasteur» et le « voleur », le «mendiant» et le «brigand») sont autant d'inscriptions du voyage poétique de la vie dans le flux de la prose musicale qui rappelle ses emportements, élans passionnels compris.

Naturellement, il y a là du jeu. La figure du brigand est souvent un masque de Berlioz, ce personnage " véhémentement soupçonné d'avoir violé la musique " (VM I/41) ; mais s'il met ce masque, le sens de l'autodérision lui permet de ne pas s'emprisonner dans ce rôle. "Je revins donc clopin-clopant, en songeant aux charmes de la vie de brigand »(VM II/186-187), dit-il ailleurs, revenant de l'un de ses vagabondages trop éprouvants pour l'honnête-homme qu'il reste... pour la durée du paragraphe. Mais jusque dans ces retours, quelque chose est dit du mouvement foncier de la création - et de l'existence : il n'est qu'inquiétude jusqu'au moment où il se fixe pour se figurer, sans cesser de l'être tout à fait même alors, car la figure qu'il se fait, qu'il doit se faire, le défigure... jusqu'au prochain avatar qui reproduira le schéma.

Une esthétique s'impose, et elle est résolument moderne, au sens baudelairien du terme. Si débordante que soit la dynamique créatrice, Berlioz sait bien que 
le processus créatif - selon ce qu'avec son époque il s'imagine être une œuvre ne peut aboutir qu'au moment où le mouvement se cristallise dans une forme écrite. Mais cette forme n'est jamais qu'un moment, un état bancal de silhouette qui clopine, à laquelle il faudra bien que le vol du brigand redonne des ailes. Logiquement, c'est à une dialectique du mouvement et de l'arrêt que se réfère l'un des extraits les plus frappants de son Voyage musical:

\begin{abstract}
[...] prenant un fusil ou une guitare, je m’acheminais, ainsi, chassant ou chantant, insoucieux de mon gîte du soir, certain d'en trouver un, si besoin était, dans les grottes innombrables ou les madones qui bordent toutes les routes, tantôt marchant au pas de course, tantôt m’arrêtant pour examiner quelque vieux tombeau, ou, du haut d'un de ces tristes monticules dont l'aride plaine de Rome est couverte, écouter avec recueillement le grave chant des cloches de Saint-Pierre, dont la croix d'or étincelait à l'horizon ; tantôt interrompant la poursuite d'un vol de vanneaux pour écrire dans mon album une idée symphonique qui venait de poindre dans ma tête, et toujours savourant à longs traits le bonheur suprême de la vraie liberté. (VM II/130)
\end{abstract}

L’art de l'écriture de Berlioz se révèle le plus pleinement quand son mouvement « inquiet » se traduit à plusieurs niveaux du discours. C'est bien ce qui arrive dans ce passage. La représentation des déplacements du voyageur y est doublée par un rythme syntaxique marqué, rehaussé par la répétition du mot " tantôt » dont le «toujours » final est à la fois une variante sonore et un accomplissement paradoxal, qui permet de dépasser l'accidentel par le rêve d'éternité qu'il convoque. Faut-il nécessairement «immobiliser » ce réel vivant, symbolisé par la guitare, à l'aide d'un fusil, pour en faire une création durable, arrêtée par la partition ? Telle est la question qui se pose à la phénoménologie problématique du romantisme. C'est aussi cette aporie que Berlioz cherche à dépasser : car ici, fusil et guitare apparaissent moins comme antinomiques que comme les deux versants d'un mouvement libérateur qui doivent se ranimer l'un l'autre. Si la nécessité de clore le processus de création pour lui donner une forme achevée apparaît aussi inévitable que la dialectique de la vie et de la mort, l'énergie inquiète du mouvement libre est là pour vaincre la pesanteur des schémas figés par ses élans dramaturgiques et expressifs toujours imprévisibles.

Peut-on aller jusqu'à dire que cette « humeur inquiète » constitue l'une des ressources les plus profondes de l'anthropologie créatrice de Berlioz, la substance même de ses écritures - qu'elles prennent la forme d'un récit de voyage fait de mots, d'une symphonie ou d'un mélologue ? Nous savons combien ces écritures sont animées par le même élan autobiographique et autofictionnel ; nous savons aussi combien l'imaginaire de Berlioz, si attiré soit-il par l'éthos hérö̈que d'obédience beethovénienne, se rapproche de l'anti-héroïsme byronien, 
erratique et coupable ${ }^{27}$, tout en évitant de s'y identifier d'une manière trop définitive. En conclusion de son analyse de la Symphonie fantastique, Jean-Pierre Bartoli constate que la stratégie formelle de Berlioz consiste à transgresser la tâche qu'il assigne lui-même au discours musical, déjouant les attentes de l'auditeur, pour faire naître des tendances destructives et interruptives mises en œuvre une dynamique linéaire et dotée d'une puissance dramaturgique novatrice ${ }^{28}$. Suivant l'herméneutique de l'écoute romantique, "l'auditeur berliozien est ainsi invité à suivre le cheminement d'une idée musicale, métaphoriquement associée à un personnage évoluant de lieu en lieu $»^{29}$. Chez un artiste pour lequel la musique naît de la même impulsion créatrice que celle qui anime la poésie ${ }^{30}$, les représentations des vagabondages d'un voyageur portant le nom de Berlioz semblent constituer une autre cristallisation de cette quête esthétique. Une quête qui se ressource de ses propres tendances ex-centriques et disruptives - pour fuir toujours en avant.

${ }^{27}$ Cf. C. Palfy, « The Emergence of the 'Byronic hero' Archetype in the Nineteenth Century ", Indiana Theory Review, $\mathrm{n}^{\circ}$ 1-2 (32), 2016, p. 161-198.

${ }^{28}$ J.-P. Bartoli, « Forme narrative et principes du développement musical dans la Symphonie fantastique de Berlioz », Musurgia, n 1 (II), 1995, p. 45.

${ }_{29} \mathrm{Cf}$. E. Reibel, Comment la musique est devenue «romantique ». De Rousseau à Berlioz, Paris, Fayard, 2013, p. 339.

30 Cf. J.-P. Bartoli, op. cit., p. 47. 
Małgorzata Sokołowicz

Université de Varsovie

ORCID 0000-0003-0554-8852

\section{Un voyageur qui peint, un voyageur qui écrit... Le double (?) regard de Gustave Guillaumet}

\section{A Traveller Who Paints, a Traveller who Writes... The Double (?) Look of Gustave Guillaumet}

The aim of this paper is to examine the relationship between text and image in the works of Gustave Guillaumet (1840-1887), a French painter, who - after having several times visited Algeria - started to publish in Nouvelle Revue short stories inspired by his travels. After his death, they were edited conjunctly under the title Tableaux algériens (1888) and constitute, altogether with Guillaumet's paintings, an interesting example of intermediality. Following the brief presentation of the artist, three types of relationships between his texts and paintings are to be defined: equivalence, explication and correspondence. From those relationships emerges a particular type of traveller, the one who paints and writes, but who also carefully observes the world and tries to render it in his works, regardless of the medium chosen.

Keywords: Gustave Guillaumet, travel, text, image, intermediality, Algeria Mots-clés : Gustave Guillaumet, voyage, texte, image, intermédialité, Algérie

«Tout le monde sait que M. Fromentin raconte ses voyages d'une manière double, et qu'il les écrit aussi bien qu'il les peint, avec un style qui n'est pas celui d'un autre ", c'est en ces termes que Charles Baudelaire décrivait l'œuvre d'Eugène Fromentin (1820-1876), considéré souvent comme précurseur de Gustave 
Guillaumet (1840-1887)1. " [S]es œuvres écrites ou peintes sont si charmantes que s'il était permis d'abattre et de couper l'une des tiges pour donner à l'autre plus de solidité, plus de robur, il serait vraiment bien difficile de choisir ", ajoutait-il en soulignant le lien inséparable qui s'établissait entre les tableaux et les livres du peintre-voyageur². Ce lien fait penser à l'intermédialité.

Le concept d'intermédialité désigne "les relations entre divers médias (voire entre diverses pratiques artistiques associées à des médias délimités) $»^{3}$. Bien sûr, les relations entre texte et image sont plus anciennes que le terme d'intermédialitét. Le précepte horatien, Ut pictura poesis, a uni à jamais ces deux médias différents, bien qu'ayant aussi des points communs. L'union du texte et de l'image visait également à créer une œuvre plus complète et, de fait, plus universelle ${ }^{5}$.

Le concept d'intermédialité renouvelle ces liens, permet de les saisir dans leur intégralité : "L'intermédialité étudie [...] comment textes, images et discours ne sont pas seulement des ordres de langage et de symbole, mais aussi des supports, des modes de transmission, des apprentissages de codes, de leçons de choses. Ces matérialités de communication font partie du travail de signification et de référence ", écrit Éric Méchoulan ${ }^{6}$. Et Hans-Jürgen Lüsebrink et Ibrahima Diagne commentent : «L'intermédialité s'avère donc être un nouveau paradigme qui permet de comprendre les conditions matérielles et techniques de transmission et d'archivage de l'expérience. $»^{7}$

Notre but est justement de " comprendre les conditions matérielles et techniques de transmission et d'archivage de l'expérience » de voyage de Gustave

1 Ch. Baudelaire, "Salon de 1859 ", dans : Euvres complètes II : Curiosités esthétiques, Paris, Michel Lévy Frères, 1868, p. 311. Pour les relations entre l'œuvre de Fromentin et celle de Guillaumet voir, par exemple, B. Wright, "Fromentin, précurseur de Guillaumet ? ", dans : L'Algérie de Gustave Guillaumet (1840-1887), Montreuil, Éditions Gourcuff Gradenigo, 2018, p. 151-159.

2 Ch. Baudelaire, op. cit., p. 311.

3 É. Méchoulan, "Intermédialités : le temps des illusions perdues », Intermédialités/ Intermediality, $\mathrm{n}^{\circ} 1,2003$, p. 22.

${ }^{4}$ Le concept date des années 1990. Son histoire est décrite dans plusieurs travaux, par exemple J. E. Müller, «L'intermédialité, une nouvelle approche interdisciplinaire. Perspectives théoriques et pratiques à l'exemple de la vision de la télévision ", Cinémas. Revue détudes cinématographiques, nº 2-3 (10), 2000, p. 105-112, I. O. Rajewsky, «Intermediality, Intertextuality, and Remediation : A Literary Perspective on Intermediality ", Intermédialités / Intermediality, $\mathrm{n}^{\circ}$ 6, 2005, p. 43-54 ou I. Diagne, H.-J. Lüsebrink, «Introduction - Intermédialité. Approches théoriques, état de la recherche, enjeux et défis africains", dans: Cultures médiatiques et intermédialité dans les littératures sénégalaises. Enjeux culturels et écritures littéraires, de leépoque coloniale à la postmodernité, sous la dir. d'I. Diagne, H.-J. Lüsebrink, Paris, L'Harmattan, 2020, p. 11-23.

5 Pour plus de détails voir I. Diagne, H.-J. Lüsebrink, op. cit., p. 16-17.

6 É. Méchoulan, op. cit., p. 10.

7 I. Diagne, H.-J. Lüsebrink, op. cit., p. 19. 
Guillaumet. En parlant de l'orientalisme pictural, Christine Peltre déplore que les œuvres « forment un recueil d'images fortuitement rassemblées, défets d'un livre dont on aurait perdu les premiers chapitres » et qu'on oublie souvent l'expérience qui a vu naître le courant : celle du périple 8 . L'intermédialité nous aidera à relire l'œuvre picturale et littéraire de Gustave Guillaumet, d'examiner son expérience viatique et de voir quelle figure du voyageur en émerge. Nous nous concentrerons sur quelques-uns de ses tableaux inspirés de ses nombreux voyages en Algérie et sur ses récits de voyage, publiés à partir de 1879 dans la Nouvelle Revue, puis, en 1888 - conjointement - sous le titre de Tableaux algériens. Notre contribution sera divisée en quatre parties. La première présentera la figure de Gustave Guillaumet, les trois suivantes analyseront trois types de relation s'établissant entre ses tableaux et ses récits : l'équivalence, l'explication et la correspondance.

\section{Gustave Guillaumet, « le peintre des Algériens »}

«Peintre orientaliste ${ }^{9}$, Gustave Guillaumet jouissait, au XIX ${ }^{\mathrm{e}}$ siècle, d'une popularité incontestable qui s'est rapidement éteinte après sa mort précoce en 1887. Au XXI e siècle, il semble revenir peu à peu en grâce auprès du public et des chercheurs. En 2015, Marie Gautheron a soutenu sa thèse de doctorat consacrée à l'œuvre picturale de l'artiste ${ }^{10}$. En 2018, sur son initiative, le Musée des BeauxArts de La Rochelle a organisé une exposition, L’Algérie de Gustave Guillaumet, accompagnée de la publication d'un beau catalogue se composant de photos de tableaux guillaumetiens et d'articles commentant son œuvre, rédigés par d'éminents spécialistes ${ }^{11}$.

Issu d'une famille aisée, Gustave Guillaumet fut l'un des rares peintres de son époque à ne pas devoir s'inquiéter d'argent. Pourtant, les débuts de sa carrière artistique n'étaient pas évidents. À la demande de son père, il s'initiait au travail de teinturier dans la manufacture familiale. Fils obéissant, il avouait dans une lettre :

8 Ch. Peltre, Latelier du voyage. Les peintres en Orient au XIX' siècle, Paris, Gallimard, 1995, p. 22.

${ }^{9}$ Cf. F. Pouillon, "Gustave Guillaumet », dans : Dictionnaire des orientalistes de langue française, sous la dir. de F. Pouillon, Paris, Karthala, 2012, p. 496.

$10 \mathrm{M}$. Gautheron, L'invention du désert, émergence d’un paysage du début du XIX siècle au premier atelier algérien de Gustave Guillaumet (1863-1869), thèse d'Histoire de l'art, université Paris-Ouest Nanterre, sous la dir. de S. le Men, 2015.

${ }^{11}$ L'Algérie de Gustave Guillaumet..., op. cit. Il faut également mentionner l'étude d’Anna Zoppellari publiée déjà en 2014 : "The Painting and Writing of Gustave Guillaumet », dans : Moving Bodies, Displaying Nations National Cultures, Race and Gender in World Expositions Nineteenth to Twenty-first Century, sous la dir. de G. Abbattista, Trieste, EUT Edizioni Università di Trieste, 2014, p. 197-211. 
Je m’appliquais de mon mieux pour contenter mon père, mais plus celui-ci était satisfait, plus j'étais mécontent de moi-même. Les visites que je ne manquais pas de faire au Louvre le dimanche me rendait rêveur toute la semaine, et tout en combinant les mordants chimiques, tout en surveillant le bouillonnement d'un bel azur ou d'un vif écarlate, j’avais l'esprit hanté par le souvenir des tableaux que j'avais vus. ${ }^{12}$

Un jour, le jeune homme prit son courage à deux mains et annonça à son père qu'il voulait être peintre. Selon Eugène Mouton, écrivain et ami de l'artiste qui s'est chargé de la publication de Tableaux algériens et les a préfacés avec un long texte biographique, il fut secouru par Abdel de Pujol. Après avoir vu les dessins de Gustave, le grand peintre néoclassique réussit à convaincre M. Guillaumet d'accepter le choix de son fils ${ }^{13}$. Le jeune homme entra à l'École des beaux-arts en 1857. Il remporta rapidement plusieurs succès et, en 1861, concourut pour le Prix de Rome. Pourtant, bien que tous les peintres du jury aient unanimement voté pour son paysage, Guillaumet ne reçut que le second prix. Découragé, il décida de quitter l'École et de partir pour l'Italie à ses propres frais. Cependant, en janvier 1862, le mois pour lequel il projetait son voyage, il faisait un temps affreux : il neigeait et gelait. Le jeune peintre, qui ne voulait pas renoncer au départ, changea de lieu de destination : il ne partit pas en Italie, mais... en Algérie. « [C]'est ainsi, commente Mouton, par un hasard de température, [que] le jeune artiste fut porté sur cette terre où l'attendaient, pour atelier, l'immensité d'une nature vierge peuplée d'hommes primitifs, et pour maître, le soleil d'Afrique $»^{14}$.

Le voyage ne commença pas de façon favorable. En plein Sahara, Guillaumet fut atteint de fièvres paludéennes. Il passa trois mois à l'hôpital militaire de Biskra dont six semaines, pratiquement sans connaissance. À en croire Eugène Mouton, Guillaumet ne s'est jamais remis de cette maladie qui a sans doute contribué à sa mort ${ }^{15}$. Pourtant, elle n'a aucunement diminué l'amour qu'il avait pour l'Algérie. Il est revenu une dizaine de fois encore dans ce pays qui a alimenté, et même dominé, son œuvre picturale et littéraire.

12 G. Guillaumet, «Lettre à Gehuzac », citée d’après F. Mouquin, "Gustave Guillaumet (1840-1887) », dans : L’Algérie de Gustave Guillaumet..., op. cit., p. 19.

13 E. Mouton, «Gustave Guillaumet. Sa vie et ses œuvres », dans : G. Guillaumet, Tableaux algériens, Paris, Plon, 1888, p. 2.

14 Ibid., p. 3

15 Ibid. La mort suicidaire de l’artiste n’est quévoquée par Roger Benjamin, «L’oasis de Biska au temps de Gustave Guillaumet », dans : L’Algérie de Gustave Guillaumet..., op. cit., p. 12. C’est Anna Zoppellari qui en parle en détail. Selon la chercheuse, le peintre est mort à la suite du coup de revolver qu'il s'est donné après une dispute avec une jeune femme pour qui il avait abandonné sa famille. Cf. A. Zoppellari, op. cit., p. 198-199. 
Lors de ses voyages, Guillaumet prenait des notes et faisait des esquisses en même temps, les faisant coexister sur la même page de son carnet ${ }^{16}$. Juliette Adam, directrice de la Nouvelle Revue, a incité le peintre à les transformer en récits de voyage : les premiers textes ont vu le jour en 1879. Eugène Mouton raconte : "La plume, entre les mains de ce maître de la lumière, est devenu pinceau. Il a vu si vivement, il a si profondément senti, que, par une sorte de merveille, il a condensé l'effet littéraire, qui est successif, en un effet de peinture, qui est simultané. Et il a fait un tableau ${ }^{17}$. Selon Mouton, Guillaumet était, lui-même, content du résultat et insistait, sur son lit de mort, pour que ses récits fussent publiés dans un volume, ce qui sera fait en 1888. Ces écrits, très condensés, dépourvus d'artifice ou de grandiose, constituent en effet un témoignage particulier de ses voyages en Algérie, un témoignage d'autant plus précieux qu'il est « doublé » par ses œuvres picturales.

En ce qui concerne ces dernières, à en croire Eugène Mouton, Guillaumet a laissé " plus de cinq cents études peintes et quatre fois autant de dessins $»^{18}$. Le catalogue de l'exposition à La Rochelle en montre cent quarante-quatre, ce qui permet, toutefois, de se faire une idée de l'œuvre guillaumetienne et de comprendre pourquoi on l'appelait le " Millet de l'orientalisme $»^{19}$, «le peintre saharien $»^{20}$, ou même «le vrai peintre des Algériens $»^{21}$. En effet, ses tableaux reflètent la vie quotidienne des habitants de l'Algérie : les moments de travail et de repos. Pourtant, comme le remarque avec justesse François Mouquin : «sa peinture n'est pas une simple peinture de genre : c'est le portrait d'une culture, celle de l'Algérie, dont il a su merveilleusement apprivoiser la lumière [...]. Guillaumet n'a cessé de manifester une admiration profonde pour les hommes, les choses et les paysages de ce pays dont la grandeur et la simplicité lui ont fourni tous les sujets de son art ${ }^{22}$. Malika Dorbani Bouabdellah rappelle que les impressionnistes « disaient des classiques qu'ils faisaient du vrai avec du faux et d'eux-mêmes qu'ils créaient du faux avec du vrai. On trouve [...] que Gustave Guillaumet a fait du vrai avec $[\mathrm{du}]$ vrai $»^{23}$.

Pour le moment, il n'y a pas beaucoup de travaux qui examinent les relations entre les toiles algériennes et les récits de voyage de Gustave Guillaumet. Anna

${ }^{16}$ Malheureusement, aucun exemple n'existe. Sur son lit de mort, Guillaumet a demandé qu'on brûle toutes ses notes. $C f$. F. Mouquin, op. cit., p. 23.

17 E. Mouton, op. cit., p. 30.

18 Ibid., p. 24

19 Cf. F. Pouillon, " Gustave Guillaumet », op. cit., p. 497.

20 E. Mouton, op. cit., p. 23.

${ }_{21}$ Cité d’après M. Gautheron, «Guillaumet ou la poésie du réel », dans : L'Algérie de Gustave Guillaumet..., op. cit., p. 26.

22 F. Mouquin, op. cit., p. 19.

${ }_{23}$ M. Dorbani Bouabdellah, "Gustave Guillaumet, entre genre et histoire », dans : L'Algérie de Gustave Guillaumet..., op. cit., p. 69. 
Zoppellari annonce tout simplement que « [l]'orientalisme réaliste des poursuites picturales de Guillaumet trouve ses échos dans ses textes $»^{24}$. Marie Gautheron constate: "Presque tous les "tableaux" de Guillaumet renvoient implicitement à ses peintures, bien qu'aucun d'eux n'en constitue l'équivalent textuel $»^{25}$. François Pouillon arrive à la conclusion que les écrits de Guillaumet « sont des pièces éparses qui complètent plus qu'elles n'éclairent sa peinture $»^{26}$. Nous examinerons ces thèses de plus près, en nous penchant sur quelques exemples choisis.

\section{L'équivalence ou le texte qui (se) nourrit (de) l'image}

Selon Marie Gautheron, aucun tableau littéraire de Guillaumet ne constitue l'équivalent textuel de sa peinture ${ }^{27}$. Pourtant, plusieurs titres des récits guillaumetiens correspondent aux titres de ses tableau ${ }^{28}$. Tandis que " La Famine » n'a en effet presque rien à voir avec le tableau La Famine en Algérie $(1868)^{29}$, et que la «Prière du soir » se concentre autant sur les impressions auditives que visuelles et, en cela, dépasse, en quelque sorte, la toile sous le même titre ${ }^{30}$, d'autres tableaux littéraires permettent de penser à une certaine équivalence. Nous allons le démontrer, en nous servant de deux exemples bien différents : «La Rivière » et «Les chiens du douar».

Selon Irina O. Rajewsky, parmi les types de relations intermédiales se trouve la «transposition médiatique » (medial transposition) : «transformation d'un produit médiatique dans un autre médium $»^{31}$. L'ekphrasis, comprise dans

24 Anna Zoppellari, op. cit., p. 198.

25 M. Gautheron, «Les Tableaux algériens, de La Nouvelle Revue à lédition de 1888 », dans : L'Algérie de Gustave Guillaumet..., op. cit., p. 71.

26 F. Pouillon, « Textes contre images : un mélange des genres ? Gustave Guillaumet entre Fromentin et Dinet », dans : L'Algérie de Gustave Guillamet..., op. cit., p. 57. Pouillon se demande même si les Tableaux algériens méritent d'être réédités, ou s'ils peuvent l'être, vu les pages que le chercheur juge antisémites. Cf. ibid., p. 59.

${ }_{27}$ M. Gautheron, «Les Tableaux algériens... », op. cit., p. 71.

${ }_{28}$ Il s'agit notamment des récits « La Rivière », la " Prière du soir », "Les Chiens du douar », «Les labours », "La Famine » et des tableaux : Jeunes filles à la rivière (s.d.), Jeunes filles dans l'Oued de Bou Saâda (vers 1882) (ill. 1), Laveuses dans l'Oued de Bou Saâda (vers 1882), La Prière du soir (1867), La famine en Algérie (1868), Chiens arabes dévorant un cheval mort, connu aussi sous le titre Chiens du douar (exposé au Salon de 1883) ou Le labour, frontière du Maroc (Salon de 1869).

${ }^{29}$ Huile sur toile, $309 \mathrm{~cm}$ x $234 \mathrm{~cm}$, Constantine, musée public national Cirta : L'Algérie de Gustave Guillaumet..., op. cit., p. 79.

30 Salon 1863, huile sur toile, $137 \mathrm{~cm}$ x $285 \mathrm{~cm}$, Paris, musée d'Orsay, accessible sur le site du musée : https://www.musee-orsay.fr/fr/collections/catalogue-des-oeuvres/notice.html?no_ cache $=1 \&$ nnumid $=2164 \& S=1$, consulté le 8/11/2020.

31 I. O. Rajewsky, op. cit., p. 51. 
son sens le plus restreint, comme description de l'œuvre d'art, serait alors un exemple de la transposition médiatique. Pourtant, comme nous venons de le dire, Guillaumet prenait des notes et faisait des esquisses en même temps. Les dates de l'exposition de ses tableaux et celles de la première publication de ses textes dans la Nouvelle Revue montrent souvent qu'il travaillait sur ses textes et ses toiles en même temps. Il ne s'agirait pas alors de la transposition du contenu d'un médium à l'autre, mais plutôt d'une certaine transposition de l'expérience dans les deux médias à la fois.

Le premier paragraphe de "La Rivière " (publiée dans la Nouvelle Revue en octobre 1884) met en scène le voyageur. Cela n'est pas très fréquent dans l'œuvre littéraire de Guillaumet qui privilégie surtout les formes impersonnelles et où le « je » est bien rare. L'incipit du récit montre la fascination du voyageur pour le paysage algérien : "Par les sentiers d'irrigation qui séparent les jardins en fleurs, je descends de bon matin jusqu'au lit de la rivière, errant sur ses galets, escaladant les filons rocheux qui, à tout moment, détournent ou divisent le cours d'une eau peu profonde, guéable sur tout le parcours $»^{32}$. Émerge de cet extrait le plaisir d'une promenade solitaire, une gaie admiration de l'œuvre parfaite de la nature.

La description qui suit est très picturale : «Le soleil n'atteint que la cime des palmiers qui, sur les rives, déploient leurs panaches toujours verts. Dans la clarté des ombres, l'eau tranquille reflète les escarpements des berges, avec les cactus épineux et les lianes grimpantes qui foisonnent dans le roc » (p. 129). Sont-ce les berges qu'on voit sur le tableau Jeunes filles dans l'Oued de Bou Saâda (vers 1882) ${ }^{33}$ (ill. 1) ? Certes, au centre de la toile se trouvent, bien évidemment, les jeunes filles du titre qui font la lessive, mais dans le récit le voyageur ne reste pas longtemps seul : « les femmes de divers quartiers du ksar arrivent une par une, par petits groupes, et vont installer leurs lessives aux places accoutumées »:

Elles disposent sur les galets leurs nippes bariolées.

Puis, retroussées jusqu'aux hanches, elles les foulent du pied en cadence, jetant de droite et de gauche leurs jambes nues, de telle sorte qu'à première vue l'on croirait assister aux exercices d'un corps de ballet. Le rapprochement s'impose d'autant mieux à l'esprit que la nature semble avoir combiné l'effet de son paysage

32 G. Guillaumet, Tableaux algériens, op. cit., p. 129. Toutes les citations viennent de cette édition. Dorénavant, nous n'indiquerons que le numéro de la page entre parenthèses dans le corps du texte.

${ }^{33}$ Huile sur toile, $52 \mathrm{~cm}$ x $75 \mathrm{~cm}$, collection particulière : L'Algérie de Gustave Guillaumet..., op. cit., p. 224, le tableau est accessible sur le site du Ministère de la Culture française : https:// www.culture.gouv.fr/var/culture/storage/images/media/thematiques/musees/images/ expositions-in/musee-des-beaux-arts-de-la-rochelle/gustave-guillaumet-laveuses-dans-1-ouedde-bou-saada-collection-particuliere/2023528-1-fre-FR/Gustave-Guillaumet-Laveuses-dans-1Oued-de-Bou-Saada-Collection-particuliere.jpg, consulté le 27/10/2020. 


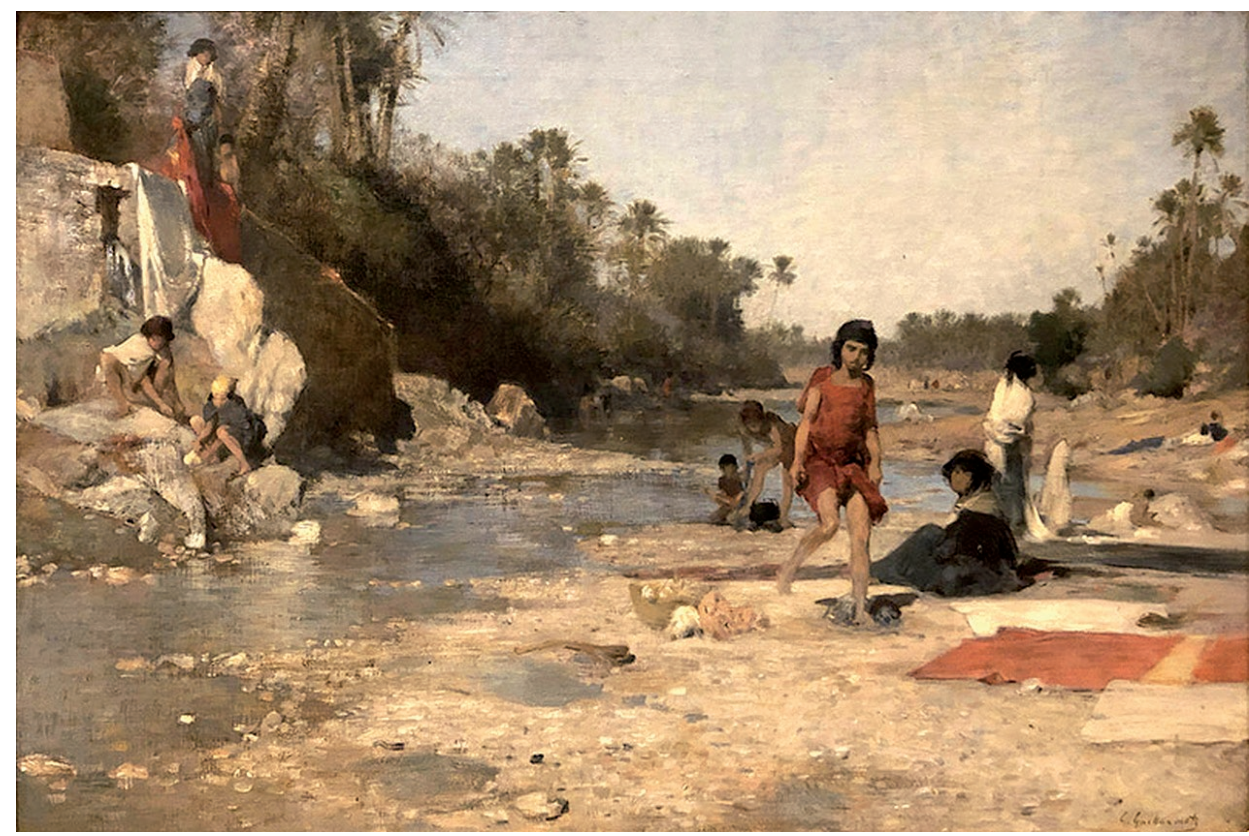

Illustration 1 : G. Guillaumet, Jeunes filles dans l'Oued de Bou Saâda

suivant les données théâtrales. Çà et là, les costumes scintillent comme sous le jet de lumières factices, dans une décoration où tout s'arrange au souhait du spectateur.

À mesure que les blanchisseuses finissent leurs savonnages, elles tordent leurs draperies mouillées, les font sécher sur le sable où se vautrent leurs enfants nus. $\mathrm{Ou}$ bien, enjambant la roche, elles courent les étaler le long des murs qui soutiennent les terres des vergers. (p. 130)

C'est la scène qu'on voit sur la toile : les jambes nues, les vêtements colorés, le mouvement - assez bien rendu - et même la lessive étalée « le long des murs qui soutiennent les terres des vergers ». Il semble que Guillaumet-voyageur ait habillement transposé ce qu'il avait vu en texte et en image qui se répondent parfaitement.

En surplus, le texte apporte un commentaire qui rend très bien l'atmosphère de la toile : "Ce papillonnement désordonné, cette variété d'actions diverses, de pantomimes bizarres, d'ajustements flottants [...], tout cela, au milieu des arbres en pleine floraison, compose un ensemble extraordinaire, harmonieux dans des notes extrêmes, qui étonne et ravit les yeux » (p. 131). Le tableau Jeunes filles dans l'Oued de Bou Saâda n'est-il pas cet « ensemble extraordinaire, harmonieux dans des notes extrêmes, qui étonne et ravit les yeux »? 
Du texte et de l'image émerge la figure de Guillaumet-voyageur qui se laisse absorber par le monde qui l'entoure. Peintre ou écrivain, il essaie de rendre le mieux possible ce qui le ravit. Si les deux médias sont différents, le contenu reste le même : la transposition médiatique est réussie. En analysant le texte et l'image ensemble, on remarque facilement quelque valeur ajoutée. L'intermédialité évoque toujours une certaine hybridité ${ }^{34}$. Le texte permet de regarder différemment la toile, l'anime, laisse deviner où se trouve le peintre. La toile est une équivalence visuelle possible du texte. Les deux permettent de reconstituer pleinement l'expérience qui se trouve à leur origine : une promenade au bord d'une rivière et la rencontre avec des laveuses.

Une tout autre expérience émerge de la relation entre le tableau Chiens arabes dévorant un cheval mort (exposé au Salon de 1883) ${ }^{35}$ (ill. 2) et le récit "Les chiens du douar» (publié dans la Nouvelle Revue en janvier 1882). Le texte est absolument impersonnel, ni « je », ni « nous », ni même " on » n'apparaissent dans ce récit partagé en deux parties visibles qui ne sont pourtant pas reflétées graphiquement. La première décrit le sort difficile du chien arabe, constamment battu par son maître et mal nourri. La seconde se concentre sur un événement qui a sans aucun doute alimenté la toile : la dépouille d'un cheval a été jetée à l'écart du douar. Guillaumet la décrit :

L'encolure aplatie semble enfoncer dans le sable. La tête osseuse ne montre plus que des naseaux flasques, une bouche entrouverte et des dents souillées d'une bave visqueuse et verdâtre. L'effort du râle final n'a pas sensiblement modifié l'expression de douceur passive qui caractérise le docile animal. [...] L’oil terne, demi-clos, s'est profondément retiré dans la cavité de l'orbite. (p. 147)

C'est le cheval du tableau (ill. 2), même si la composition de la toile dédramatise un peu la représentation. Au premier abord, le spectateur remarque un paysage désertique. Ce n'est qu'à force de regarder qu'il aperçoit toute l'horreur de la scène et du cheval qui - gardant toujours des traces de sa beauté et dignité a le ventre cruellement déchiré.

Dans la suite du récit, l'équivalence entre tableau et texte persiste :

Un chien au pelage de lion et de mine féroce s'est avancé avec hardiesse. Il flaire en tous sens le cadavre; puis, tranquillement, pose sur lui la patte en même temps que ses crocs fouillent l'endroit tendre et s'y enfoncent. Arc-bouté sur ses jarrets nerveux, les muscles du cou gonflés par l'effort, il déchire les flancs, met à vif les côtes rouges et saignantes, et tirant à même la chair crue de toute la puissance de ses mâchoires, il en arrache des lambeaux qu'il dévore gloutonnement, pendant

34 Cf. I. O. Rajewsky, op. cit., p. 44.

35 Huile sur toile, $131 \mathrm{~cm}$ x $175 \mathrm{~cm}$, Carcassonne, musée des Beaux-Arts : L'Algérie de Gustave Guillaumet..., op. cit., p. 189. 


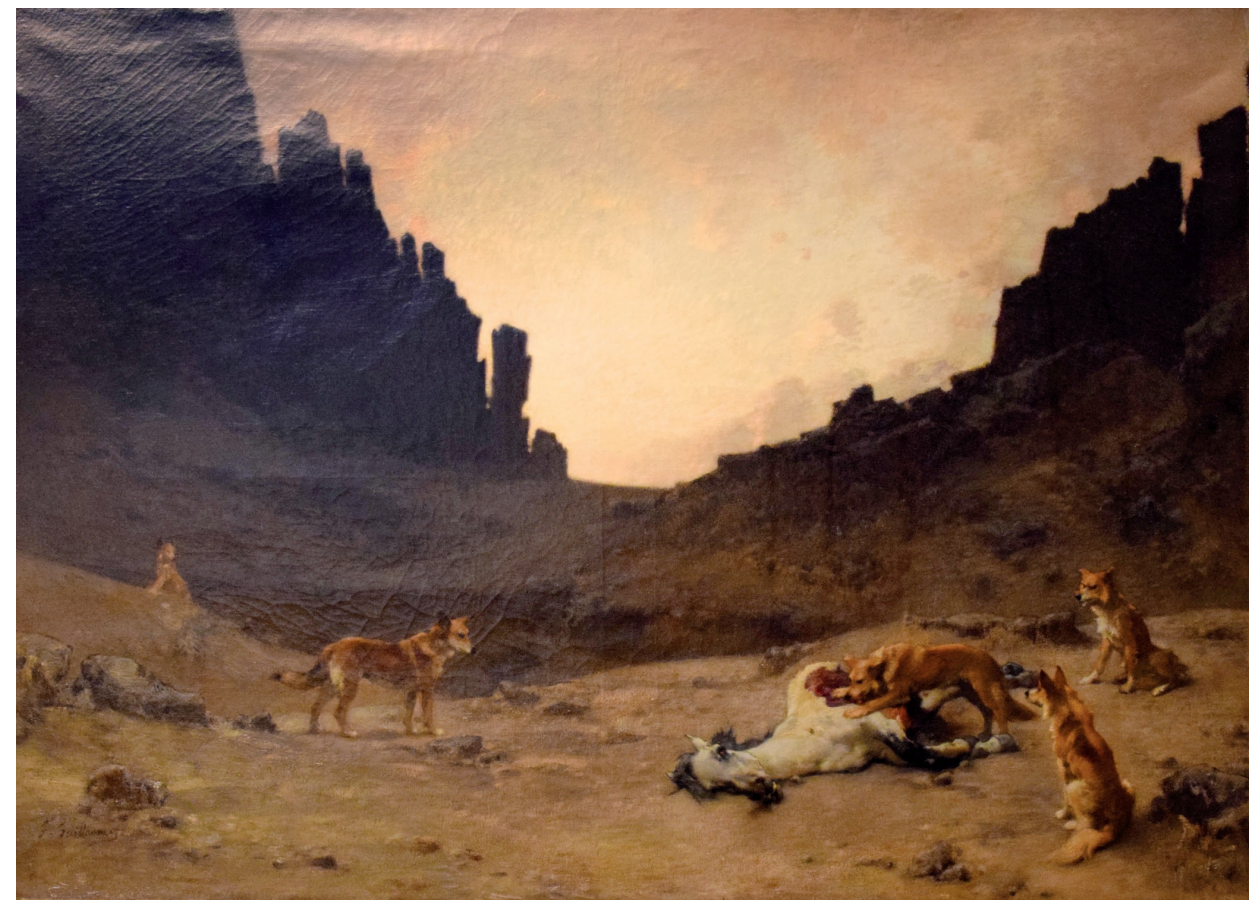

Illustration 2 : G. Guillaumet, Chiens arabes dévorant un cheval mort

que ses pareils, attendant leur tour, postés de loin en loin, l'observent avec anxiété et se lèchent le bout du museau en reniflant l'odeur de venaison. (p. 148-149)

La description commence par le mouvement, difficile à rendre sur la toile, mais ensuite la couleur du chien, sa position, la réaction de ses pareils reflètent ce qu'on voit sur l'image.

Par le brun-gris qui domine la toile, le vide du paysage et la scène cruelle (ou naturaliste ?) représentée, le tableau ressemble un peu au Sahara $(1867)^{36}$. Sur les deux toiles, Guillaumet peint le ciel d'une façon qui fait penser à cet extrait du récit : "De magiques reflets se jouent un moment [...] ; puis la nuit gagne doucement la plaine, et le silence se refait peu à peu autour des sinistres épaves » (p. 150). Ayant peur de la nuit ou des animaux nocturnes, les chiens du récit reviennent au douar. Ce silence inquiétant de la nuit qui tombe se laisse lire sur la toile. De nouveau, l'expérience se reflète parfaitement dans les deux médias : d'un tronc émergent deux branches.

${ }^{36}$ Huile sur toile, $105 \mathrm{~cm}$ x 200,5 cm, Paris, musée d’Orsay, accessible sur le site du musée : https://www.musee-orsay.fr/fr/collections/oeuvres-commentees/recherche/commentaire/ commentaire_id/le-sahara-282.html?no_cache=1, consulté le 8/11/2020. 
Il est facile de trouver chez Guillaumet d'autres exemples de cette équivalence presque parfaite entre texte et image. Pourtant, le voyageur ne se limite jamais à la description, un commentaire plus ou moins personnel suit, explique au lecteur la situation et, en même temps, fait mieux comprendre le tableau.

\section{Le texte qui explique (le contexte de) l'image}

Cela nous conduit à un autre type de relation intermédiale. Même si François Pouillon constate, comme nous venons de le dire, que les narrations « complètent plus qu'elles n'éclairent [1] a peinture [guillaumetienne] " ${ }^{37}$, à notre avis, il est possible de parler d'une certaine fonction explicative. Nous l'avons montré déjà à travers le récit "La Rivière » qui éclairait le contexte de la création des Jeunes filles dans l'Oued de Bou Saâda. C'est un autre type d'intermédialité où le contenu transposé ne doit pas être identique, mais contient un surplus permettant de lire plus facilement la réalisation du sujet dans un autre médium. Il est possible de remarquer cette relation dans plusieurs récits; nous en avons choisi deux : «Les Intérieurs » (1884) et la « Prière du soir » (1887).

Parmi les œuvres picturales de Guillaumet se trouvent beaucoup d'intérieurs : Intérieur à Bou Saâda (n.d.) ${ }^{38}$ (ill. 3), Tisseuses à Bou Saâda (1887) ${ }^{39}$, Scène de gourbi, ou Intérieur à Biskra (n.d.) ${ }^{40}$. On imagine facilement la difficulté de les peindre. Guillaumet en parle dans son récit « Les Intérieurs » où il nous laisse aussi son portrait intéressant en voyageur :

Dans les rues, quand je passe, les Arabes se demandent quel est ce « Roumi » et ce qu'il vient faire.

Me voyant tantôt à pied, tantôt à cheval, avec le commandant supérieur, ils me croient son parent ou quelque officier en tournée. [...]

Mais comme, en même temps, l'outillage du peintre m'y suit presque toujours, la profession dénonce les projets; des gens à qui je deviens tout à coup suspect s'éloignent ; j'éveille des défiances, je provoque des terreurs, qui ne font qu'augmenter lorsque je pénètre dans l'intérieur de la maison. (p. 177)

37 F. Pouillon, «Textes contre images... », op. cit., p. 57.

38 Huile sur toile, 74,7 cm x 102,7 cm, Paris, musée d'Orsay, accessible sur le site du musée : https://www.musee-orsay.fr/fr/collections/catalogue-des-oeuvres/notice. html?no_cache $=1 \&$ zoom $=1 \&$ tx_damzoom_pi $1 \% 5$ Bzoom $\% 5 \mathrm{D}=0 \&$ tx_damzoom pi $\% 5$ BxmlId $\% 5 \mathrm{D}=020586 \&$ tx_damzoom_pi1\%5Bback\%5D=\%2Ffr\%2Fcollections $\% 2 F$ catalo gue-des-oeuvres\%2Fnotice.html\%3Fno_cache\%3D1\%26nnumid\%3D020586\%26cHash\%3D7 584511ec1, consulté le 8/11/2020.

${ }^{39}$ Huile sur toile, $94,5 \mathrm{~cm}$ x $113 \mathrm{~cm}$, Paris, musée d'Orsay : L'Algérie de Gustave Guillaumet..., op. cit., p. 193.

40 Huile sur toile, $43 \mathrm{~cm} \times 33 \mathrm{~cm}$, collection particulière : ibid., p. 80 . 


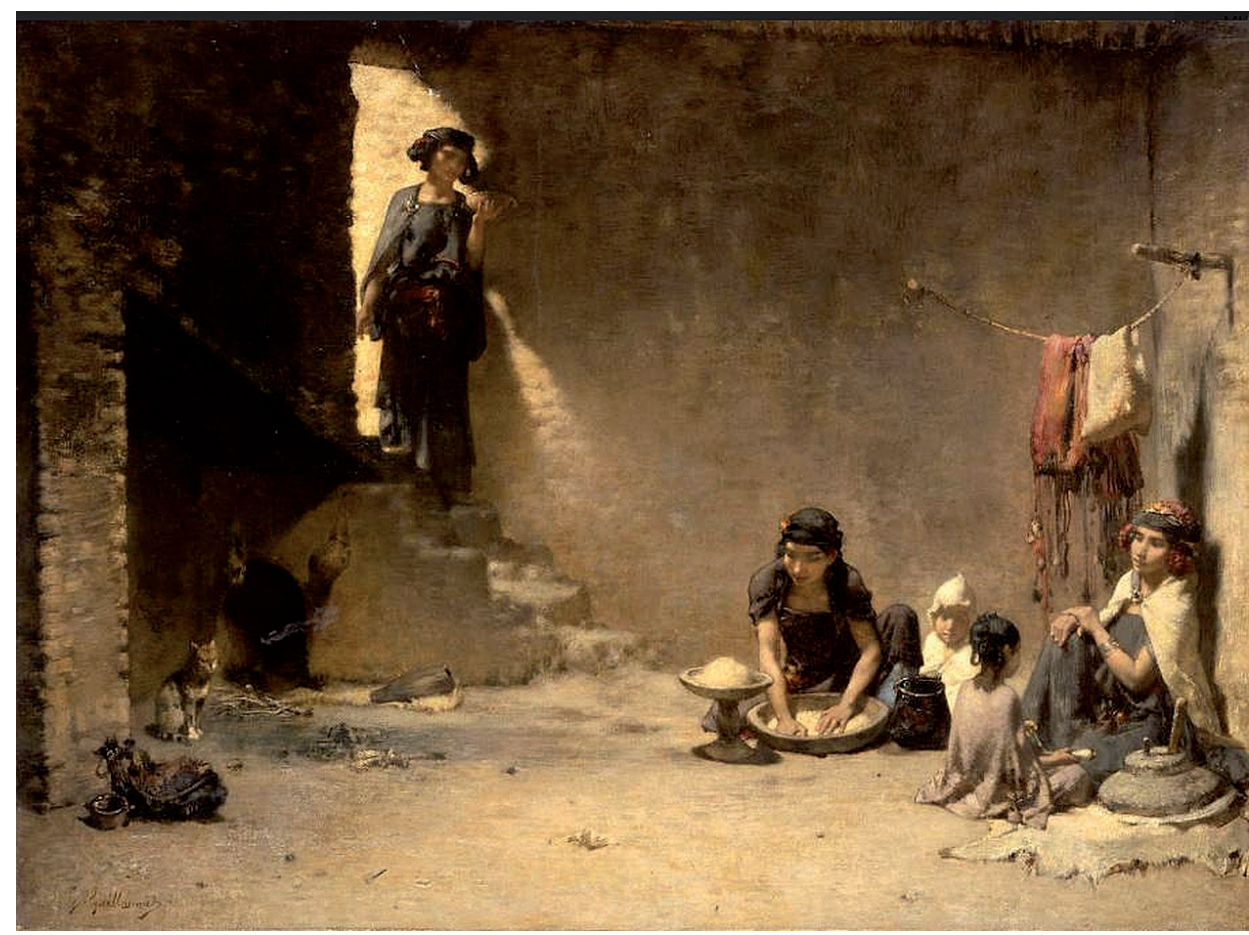

Illustration 3 : G. Guillaumet, Intérieur à Bou Saâda

L'extrait montre la réciprocité du regard, tellement rare à l'époque. Dans les récits de voyage européens, on décrivait ce qu'on voyait, de sa propre perspective. On se souciait peu du regard de l'autre : celui qui regardait restait invisible ${ }^{41}$. Et pourtant, Guillaumet montre qu'il n'était pas invisible pour les Algériens. Ils le regardaient aussi et se posaient des questions sur son identité. Au début, ils le traitaient avec méfiance, mais avec le temps cette méfiance disparaissait. Il a même pu pénétrer dans quelques demeures dont les habitants « promena[ient] sur [s]a personne des regards étonnés » (p. 180).

Guillaumet comprend le caractère exceptionnel de son expérience : «L'étonnement de ces femmes de me voir n'est pas moindre que le mien d'être au milieu d'elles, les observant du regard qu'on donne à de jolis animaux en cage, étudiant leurs allures comme si elles appartenaient en réalité à quelque race humaine distincte de la nôtre " (p. 187). Les femmes le regardent-elles de la même façon?

${ }^{41}$ Cf. M. Jeğemoğlu, Colonial Fantasies: Towards a Feminist Reading of Orientalism, Cambridge, Cambridge University Press, 1999, p. 62-63. 
Il semble qu'avec le temps ce regard change. Le voyageur et les femmes qu'il peint deviennent moins étrangers les uns pour les autres. Guillaumet raconte :

Elles se penchent jusque sur mon épaule, voulant voir si je les fais ressemblantes. Celle-ci se plaint que j’aie omis quelques-uns de ses tatouages, celle-là réclame plus de rouge sur ses pommettes. L'une, qui n'est vue que de dos, me demande pourquoi je ne montre pas sa figure ; l'autre, se reconnaissant à son costume, s'écrie : « Machimeleh!» (mauvais) parce que je me refuse à représenter tous ses bracelets sur son bras nu. (p. 188)

Une sorte de complicité s'instaure entre le peintre et ses modèles, complicité qui change aussi notre regard sur les toiles qu'il a peintes. C'est un peu l'effet des notes de Delacroix qui, en faisant ses esquisses pour les futures Femmes d'Alger dans leur appartement, a noté les prénoms de ses modèles ${ }^{42}$. Les silhouettes anonymes du tableau renvoient soudain à des scènes particulières, "sortent de l'anonymat de l'exotisme »: on s'imagine les femmes négociant avec le peintre le nombre de leurs bijoux qui seront éternisés. Le postulat de Christine Peltre se réalise : on se rappelle que derrière la peinture orientaliste se trouve un voyage et la rencontre avec l'autre et sa culture ${ }^{43}$.

Les récits de Guillaumet permettent donc de lire différemment ses toiles, montrent des histoires qui se cachent derrière leur création. L'intermédialité, écrit Jürgen E. Müller, «ne considère pas les médias comme des phénomènes isolés, mais comme des processus où il y a des interactions constantes [...] ${ }^{44}$. Ces interactions ne doivent pas forcément dire l'équivalence. Elles peuvent juste enrichir la lecture du tableau.

C'est aussi le cas du récit «Prière du soir » (1887). Le tableau sous le même titre est assez connu ${ }^{45}$ (ill. 4). Critiqué pour « les inexactitudes que l'on décèle dans le rendu des positions des orants ${ }^{46}$, il séduit par une atmosphère mystique qui gagne encore en profondeur lorsqu'on compare l'image avec le texte.

$\mathrm{La}$ «Prière du soir » littéraire est l'un des récits guillaumetiens où la figure du voyageur est bien exposée, même si le « je » du début change rapidement en " on » :

42 Citons Assia Djebar : « [...] Delacroix se force à noter sur ses croquis chaque nom et prénom de femme. Aquarelles armoriées aux noms de Bayah, Mouni et Zora ben Soltane, Zora et Kadoudja Tarboridji. Corps crayonnés sortant de l'anonymat de l'exotisme. »Cf. A. Djebar, Femmes d'Alger dans leur appartement, Paris, Albin Michel, 2002, p. 239-240.

${ }^{43}$ Cf. Ch. Peltre, op. cit., p. 22.

44 J. E. Müller, op. cit., p. 113.

45 Il a joué un rôle important dans la carrière du peintre : exposé au Salon de 1863, il est acheté par l'État dans le cadre du programme de respect de l'islam en Algérie, lancé par Napoléon III, et placé au Musée du Luxembourg : M. Gautheron, « Prière du soir dans le Sahara », dans : L'Algérie de Gustave Guillaumet..., op. cit., p. 72.

${ }_{46}$ Cf. F. Pouillon, « Gustave Guillaumet », op. cit., p. 496. 


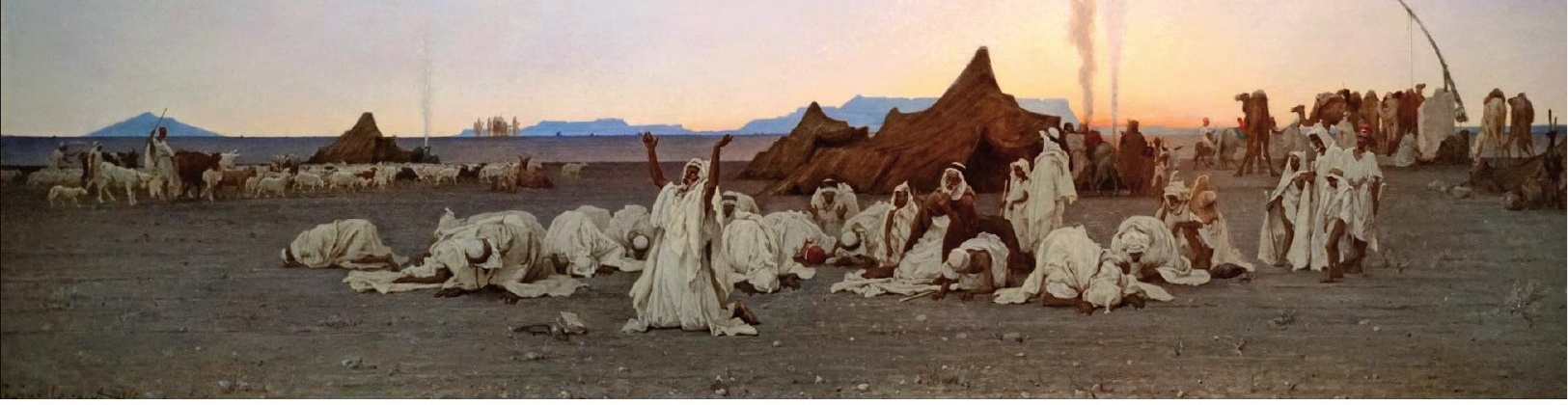

Illustration 4 : G. Guillaumet, Prière du soir dans le Sahara

Derrière moi, plusieurs monticules hérissés de rochers me cachent une à une les maisons de Bou-Saada. Je cesse bientôt de voir l'oasis, ses palmiers, ses bancs de sable. J'avance au sud, en plein cœur d'été [...].

Nos chevaux foulent avec peine un sol dur et pierreux, succession de plateaux désolés, servant de transition aux contrées mystérieuses que les indigènes désignent d'un nom qui se passe de commentaire : Pays de la soif ! [...]

Rien ne bouge en dehors de nous, rien ne rappelle la vie. [...]

Chaque jour ressemble au précédent. Point d'événement qui en marque le passage, et cependant, tant l'impression de grandeur nourrit l'âme qui la cherche, quelles journées pleines! (p. 135-137)

Le "Pays de la soif », bien connu du livre Un été dans le Sahara d'Eugène Fromentin, attire le voyageur ${ }^{47}$. L'écrivain admire ce vide du paysage qui immobilise le temps, mais dont se dégage une plénitude spirituelle. Le voyage devient une expérience mystique. La prière du soir que le voyageur observe dans un douar semble dépasser le cadre de l'islam :

${ }^{47}$ D’ailleurs Fromentin ressentait la même attirance pour le désert : « [...] ce nom bizarre et qui donne à penser, Bled-el-Ateuch, avec sa traduction : Pays de la soif. D'autres reculeraient devant la nudité d'un semblable itinéraire; je t'avoue que c'est précisément cette nudité qui mencourage. » E. Fromentin, "Un été dans le Sahara », dans : CEuvres complètes, éd. G. Sagnes, Paris, Gallimard, p. 18. 
La nuit s'approche. [...] Alors, dominant, tout bruit, une voix d'homme s'élève, vibrante [...] : «Allah ah Kbir! (Dieu est grand !) » [...]

«Dieu est grand ! Dieu est grand ! » redisent ensemble les croyants, tandis que derrière eux l'auréole du soleil disparu empourpre encore la transparence des vêtements blancs, et que, des hauteurs du zénith, le ciel laisse tomber des reflets d'azur sur tous les dos courbés vers la terre.

Quand le verset final expire sur les lèvres du prieur, les ombres de la nuit obscurcissent les visages. Alors les groupes se séparent. [...]

Dans le lointain, les horizons se couvrent de mystère. Peu à peu le ciel se constelle.

La lune s'élève avec majesté. Toute la nature semble s'associer à cette parole de l'homme :

- Dieu est grand! (p. 138-140)

Le narrateur s'efface. C'est la contemplation de Dieu qui domine le texte, d'un Dieu qui ne s'attache à aucune religion, mais au désert, cette terre nue, mais pleine de mystères.

Le récit ne raconte pas uniquement l'expérience qui a pu être à l'origine de la création de la toile. Mis ensemble avec le texte, le tableau gagne de nouvelles dimensions. On a l'impression d'entendre les paroles décrites dans le récit. La scène renvoie à une religiosité universelle. Cette interprétation n'est pourtant possible que lorsqu'on juxtapose le texte et l'image, elle résulte de l'intermédialité.

Dans les Tableaux algériens, il est alors possible de voir l'explication de quelques-unes des toiles guillaumetiennes. Les interprétations des peintures s'enrichissent et l'expérience du voyage qui les a engendrées est mise en valeur.

\section{Le texte et l'image qui se correspondent ou la sensibilité unique de l'artiste}

Alors que plusieurs tableaux littéraires de Guillaumet s'attachent plus ou moins directement à ses toiles, quelques-uns de ses récits paraissent indépendants des images au niveau de leurs titres et contenu, par exemple "Un jour de soleil ", "Le $1^{\text {er }}$ janvier », " Mars », "Le Fou ». Il nous semble pourtant qu'une certaine relation existe, même si elle est beaucoup plus complexe. Selon Eugène Mouton, le secret de la peinture guillaumetienne se trouve dans la lumière que le peintre était capable de rendre de façon parfaite. Dans son œuvre littéraire, on retrouve les mêmes " touches de lumières et de couleur ${ }^{48}$. Le texte et l'image se correspondent parce que c'est le même regard qui les fait naître, la même sensibilité qui se réalise indépendamment du choix du médium.

48 E. Mouton, op. cit., p. 33. 
C'est très visible dans le cas du premier récit publié, "Un jour de soleil » (1879). "Dans ce chapitre, raconte Mouton, l'artiste écrivain a entrepris de raconter, rayon par rayon, ombre par ombre, reflet par reflet, l'histoire lumineuse d'une journée de soleil ${ }^{49}$. En effet, "Un jour de soleil » est un hommage au soleil : «Dans les vastes plaines qui se développent entre les massifs montagneux de notre frontière marocaine, le soleil a des splendeurs sans égales. Il règne en roi superbe sur ces pays étranges où l'homme tient si peu de place. Il les égaye de ses éclats, il les couve par sa chaleur, il leur donne une éternelle sérénité » (p. 45). L'extrait fait penser au célèbre Sahara. Là aussi, le soleil « règne en roi superbe ", donne l'impression d'" une éternelle sérénité ", mais aussi montre à l'homme toute sa petitesse.

Il nous semble que Guillaumet rend la même impression deux fois : dans le texte et sur le tableau. Même si la réalisation peut paraître indépendante, en réalité, on peut y observer une certaine relation intermédiale. Elle résulte du fait même que le tableau et le récit ont le même auteur. Müller parle du dynamisme du concept d'intermédialité ${ }^{50}$. Les «médias ne peuvent plus être conçus comme des nomades isolés " ${ }^{51}$, spécialement quand leur contenu résulte d'un seul regard.

Dans « Un jour de soleil », une autre relation intermédiale s'établit encore : l'écrivain entre aussi en compétition avec le peintre. On y voit ce que Rajewsky appelle la "référence intermédiale " (intermedial reference) ${ }^{52}$, référence à un autre médium. C'est une autre ekphrasis qui se produit, celle d'un tableau qui n’a jamais été peint et qui représente un lever de soleil :

Déjà les ombres raccourcissent. Les teintes pourprées deviennent roses ; le rose se dore ; l'or pâlit ; le jour, un jour intense, éclate et se répand sur toute la plaine, qu'il inonde de ses chatoiements argentins. Chaque brin d'herbe, chaque pierre, en accroche une parcelle, allonge sur le sol sa traînée d'ombre bleuâtre, qui diminue à mesure que le soleil monte. L'astre touche au zénith, et cette lumière placide, qui partout s'est étendue, confond la terre et le ciel dans un même éblouissement. (p. 47)

Même si l'extrait n'a aucune marque grammaticale personnelle, on ressent l'admiration complète du voyageur devant ce spectacle de la nature. Il est aussi enchanté que dans "La Rivière " où, de bon matin, il admire les berges ensoleillées.

Dans le récit «Un jour de soleil », Guillaumet montre aussi que le soleil régit l'existence des Algériens. À midi, où les températures sont les plus dures

49 Ibid., p. 32.

50 J. E. Müller, op. cit., p. 107.

${ }^{51}$ Ibid., p. 105

52 I. O. Rajewsky, op. cit., p. 52. 
à supporter, la vie disparaît, rien ne bouge. Le paysage reste figé comme sur le tableau Le Sahara. La vie reprend le soir. Après le coucher de soleil, admirablement décrit, vient le moment que Guillaumet dépeint souvent sur ses toiles ${ }^{53}$ (ill. 5) : «C'est l'heure mystérieuse où les ténèbres épaississent leurs voiles, où les couleurs se mêlent, où les contours se noient, où toute chose s'assombrit, où toute voix se tait, où l'homme, à la fin du jour, laisse flotter sa pensée devant ce qui s'éteint, s'efface et s'évanouit » (p. 49). Le voyageur montre clairement sa prédilection pour certaines vues qui apparaissent aussi sur ces tableaux. Il explique sa sensibilité.

Les Tableaux algériens montrent donc la façon de regarder du peintre, laissent comprendre son choix des scènes. L'intermédialité, explique Müller, " prend en charge les processus de production du sens liés à des interactions médiatiques ${ }^{54}$. La juxtaposition des textes et images guillaumetiens laisse justement comprendre "le processus de production du sens». Certes, les correspondances entre texte et image peuvent parfois paraître floues : il n'y a pas d'équivalence ni d'explications au sens propre du terme. Le contenu présenté dans les deux médias n'est pas identique, mais il se forme de la même façon car c'est la même personne qui regarde, écrit et peint.

\section{Conclusion}

Le concept d'intermédialité est focalisé «sur les médias, leurs matérialités et leurs interrelations $»^{55}$. Ces interrelations entre peinture et écriture se trouvent au centre de l'œuvre de Gustave Guillaumet. Elles sont de natures différentes. Parfois, le contenu voyage de façon parfaite entre les deux médias. Il est difficile de dire si le récit constitue l'équivalence du tableau ou le tableau équivaut au récit. On a plutôt l'impression que l'artiste se sert des deux médias, indépendamment, pour éterniser ses expériences viatiques.

Il existe aussi, dans l'œuvre guillaumetienne, des récits et des tableaux qui portent les mêmes titres, mais qui ne forment pas une telle équivalence. Le texte ne présente pas réellement la même scène que le tableau, mais montre le contexte présumé de sa création, l'explique. La coexistence du texte et de l'image rend plus pleinement l'expérience de voyage.

Une certaine unité intermédiale se laisse percevoir même là où apparemment il n'y a pas de relation directe entre tableau et récit. Les scènes décrites et peintes ne sont pas toujours les mêmes, mais le regard de l'artiste et sa technique le sont.

${ }^{53}$ Nous pensons ici, par exemple, au Labour au coucher de soleil (Salon de 1876) (ill. 5), huile sur toile, $80 \mathrm{~cm}$ x $137 \mathrm{~cm}$, collection privée : L’Algérie de Gustave Guillaumet..., op. cit., p. 166 ou à la Plaine d'Oujda (1869), huile sur toile, $20 \mathrm{~cm}$ x $48 \mathrm{~cm}$, collection particulière : ibid., p. 186.

54 J. E. Müller, op. cit., p. 106.

55 I. Diagne, H.-J. Lüsebrink, op. cit., p. 13. 


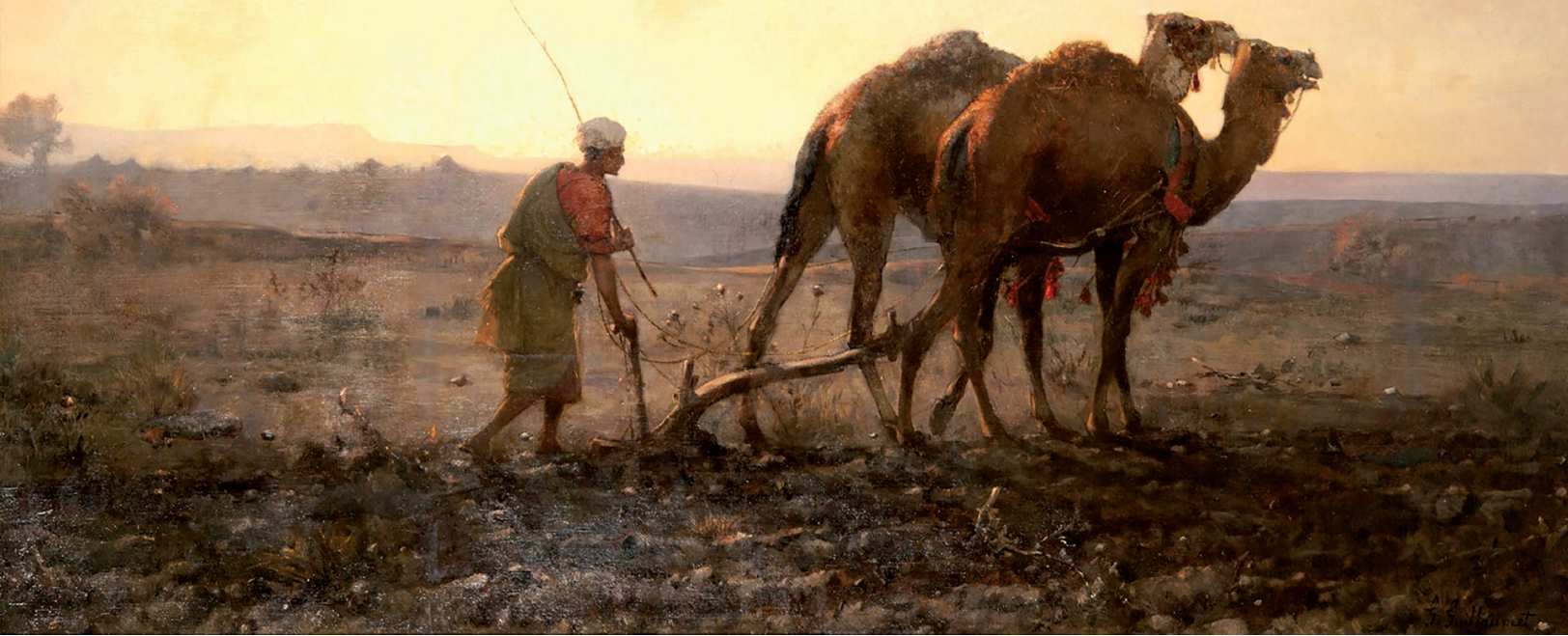

Illustration 5 : G. Guillaumet, Labour au coucher de soleil

Indépendamment du fait qu'il peigne ou qu'il écrive, Guillaumet regarde le monde de la même façon et le reflète de la même façon dans son œuvre picturale et littéraire, tenant bien évidemment compte des particularités du médium choisi. C'est le seul regard qui se trouve à l'origine de sa « double » œuvre.

Et de ces relations intermédiales complexes émerge un voyageur, un voyageur qui peint, un voyageur qui écrit. Le seul autoportrait de Guillaumet se forge à travers ses écrits de voyage. C'est en écriture qu'on découvre pleinement celui qui est en mouvement continu, qui lie un dialogue respectueux avec les Algériens, s'enthousiasme devant ce qu'il voit ou s'attriste devant les tragédies dont il devient un témoin involontaire. Dans la dynamique des relations intermédiales est inscrite l'histoire de sa découverte du monde algérien et de son amour pour l'Algérie. 


\section{Illustrations :}

Illustration 1 : Gustave Guillaumet, Jeunes filles dans l'Oued de Bou Saâda, vers 1882, huile sur toile, $52 \mathrm{~cm} \times 75 \mathrm{~cm}$, collection particulière. Source : L'Algérie de Gustave Guillaumet (1840-1887), Montreuil, Éditions Gourcuff Gradenigo, 2018, p. 224.

Illustration 2 : Gustave Guillaumet, Chiens arabes dévorant un cheval mort, exposé au Salon de 1883, huile sur toile, $131 \mathrm{~cm} \mathrm{x} 175 \mathrm{~cm}$, Carcassonne, musée des Beaux-Arts. Source : Wikimedia Commons : https://commons. wikimedia.org/wiki/File:Gustave_Guillaumet_chiens_arabes_devorant_ un_cheval_mort.jpg

Illustration 3 : Gustave Guillaumet, Intérieur à Bou Saâda (n.d.), huile sur toile, $74,7 \mathrm{~cm} \times 102,7 \mathrm{~cm}$, Paris, musée d'Orsay. Source : L’Algérie de Gustave Guillaumet (1840-1887), Montreuil, Éditions Gourcuff Gradenigo, 2018, p. 168.

Illustration 4 : Gustave Guillaumet, Prière du soir dans le Sahara, exposé au Salon de 1863, huile sur toile, $137 \mathrm{~cm} \mathrm{x} 285 \mathrm{~cm}$, Paris, musée d'Orsay. Source: Wikimedia Commons : https://commons.wikimedia.org/wiki/ File:Pri\%C3\%A8re_du_soir_dans_le_Sahara_de_G._Guillaumet_ (Mus\%C3\%A9e_d\%27Orsay,_Paris)_(48685507452).jpg

Illustration 5 : Gustave Guillaumet, Labour au coucher de soleil, exposé au Salon de 1876, huile sur toile, $80 \mathrm{~cm}$ x $137 \mathrm{~cm}$, collection privée. Source : L'Algérie de Gustave Guillaumet (1840-1887), Montreuil, Éditions Gourcuff Gradenigo, 2018, p. 166. 


\section{CONTRIBUTEURS À CE VOLUME}

Sylviane ALBERTAN-COPPOLA, professeur émérite de littérature française à l'Université de Picardie. Spécialiste du débat entre les Philosophes des Lumières et leurs adversaires (L'abbé Bergier. Des Monts-Jura à Versailles, le parcours d'un apologiste du XVIII siècle, Champion, 2010 ; Réponses chrétiennes à la critique des Lumières, coll. "Lire le dix-huitième siècle », 2013), elle est aussi l'auteur d'une étude littéraire sur Manon Lescaut (PUF, 1995) et d'une dizaine d'articles sur l'Histoire générale des voyages de l'abbé Prévost, portant notamment sur la représentation des femmes.

Katalin BARTHA-KOVÁCS, maître de conférences HDR au Département d'Études Françaises de l'Université de Szeged (Hongrie). Ses travaux portent sur les rapports de l'image et du discours, la réflexion picturale française des XVII ${ }^{\mathrm{e}}$ et XVIII siècles ainsi que sur l'animal et l'animalité. Ses principales publications sont : Figures $d u$ silence en peinture [en hongrois], 2010 ; Le singe aux XVII ${ }^{e}$ et XVIII siècles. Figure de l'art, personnage littéraire et curiosité scientifique, éd. F. Boulerie et K. Bartha-Kovács, 2019 ; Diderot et Watteau. Vers une poétique de l'image au XVIII siècle, 2019.

Nicolas BRUCKER, professeur de littérature française du XVIII siècle à l'Université de Lorraine, membre du centre de recherche Écritures (EA 3943). Il s'intéresse en particulier à l'histoire des idées, dans le champ philosophique et religieux, notamment aux Anti-Lumières (Une réception chrétienne des Lumières. Le Comte de Valmont de l'abbé Gérard, Paris, 2006) et aux phénomènes interculturels entre la France et l'Allemagne autour de 1800 (édition de la Correspondance de Charles de Villers, Paris, 2020). 
Linda GIL, agrégée de Lettres Modernes et Maître de conférences à l'Université Paul-Valéry de Montpellier 3. Spécialiste de l'histoire du livre et de l'édition au XVIII siècle, elle a consacré sa thèse à l'étude de la première édition posthume des œuvres complètes de Voltaire. Son livre, L'édition Kehl de Voltaire : une aventure éditoriale et littéraire au tournant de Lumières, est paru en 2018 aux éditions Honoré Champion. Elle travaille actuellement sur la construction du mythe de Voltaire pendant la Révolution française. Membre de la Société Voltaire et de la Société d'études voltairiennes, elle est co-directrice de la Revue Voltaire.

Alain GUYOT, professeur à l'Université de Lorraine (Nancy), s'intéresse à la poétique et à la stylistique des récits de voyage, du tournant des Lumières à la fin du romantisme. Il a consacré plusieurs ouvrages, personnels ou collectifs, et de nombreux articles à cette thématique. Il dirige avec Sarga Moussa la section "Voyages " dans l'édition des Euvres complètes de Théophile Gautier chez Champion et prépare celle de L'Espagne sous Ferdinand VII (1838) de Custine. Depuis 2020, il est rédacteur en chef adjoint de la revue Viatica.

Jean-Michel RACAULT, ancien professeur émérite de littérature française et comparée à l'université de La Réunion. Domaines de recherches : utopies de forme narrative en Europe du XVI ${ }^{e}$ au XIX ${ }^{e}$ siècle, littératures des voyages de l'âge classique aux Lumières, mythe de Robinson et insularité romanesque, histoire des littératures francophones de l'océan Indien. Il dirige l'édition en cours des Euvres Complètes de Bernardin de Saint-Pierre (Garnier). Il a publié récemment une édition critique des grands textes utopiques du XVII ${ }^{\mathrm{e}}$ siècle (Trois utopies classiques, 2020).

Odile RICHARD-PAUCHET, maître de conférences HDR à l'Université de Limoges, se consacre à l'exploration des romans épistolaires, des écrits esthétiques et des écrits intimes de la seconde moitié du XVIII siècle : correspondances de Diderot, de Rousseau, du cercle de Mme d'Épinay et d'autres écrivains. Elle contribue à la vie de la Société Diderot ainsi qu'à celle de l'AIRE (Association Interdisciplinaire de Recherche sur l'Épistolaire), et à leurs revues. Depuis 2019, elle est présidente du Prix Dix-huitième siècle décerné par la SFEDS. Inédit d'HDR : Les Écrits indiscrets. Autoreprésentation et formes de l'écriture de soi dans l'œuvre de Diderot (2017).

François ROSSET, professeur de littérature française à l'Université de Lausanne. Il a publié une trentaine de livres et plus de deux cents articles scientifiques. Ses travaux concernent principalement les variations de la fiction narrative européenne au XVIII ${ }^{e}$ siècle avec un accent particulier sur des auteurs comme Jean Potocki, Benjamin Constant, Germaine de Staël, mais également la culture 
littéraire en Suisse romande au temps des Lumières, ainsi que les rapports culturels et symboliques entre la Pologne et la France, l'imagologie littéraire, la littérature de voyage. Il a aussi donné de nombreuses contributions dans le domaine de l'édition scientifique.

Małgorzata SOKOŁOWICZ, maître de conférences HDR à l'Institut d'études romanes de l'Université de Varsovie et à l'Université de musique FrédéricChopin, membre associée du laboratoire CERCLE de l'Université de Lorraine, est l'auteure des livres La Catégorie du héros romantique dans la poésie française et polonaise au XIX ${ }^{e}$ siècle (2014), Orientalisme, colonialisme, interculturalité. L'œuvre d'Aline Réveillaud de Lens (2020) et d'une soixantaine d'articles sur les relations entre littérature et art, l'orientalisme, les relations de voyage, l'écriture (post)coloniale et les questions identitaires.

Stanisław ŚWITLIK, diplômé de la Sorbonne, assistant à l'Université catholique de Lublin Jean-Paul II, prépare à l'Université de Varsovie une thèse de doctorat portant sur les utopies littéraires des années 1780. Il s'intéresse aussi aux échanges d'idées entre les élites francophones de l'Europe du XVIII ${ }^{e}$ siècle ainsi qu'aux formes de la fiction philosophique des Lumières. Il a collaboré à la nouvelle publication de la correspondance de Mme Geoffrin et du roi StanislasAuguste Poniatowski (en cours). Il a également publié quelques articles sur les tensions qui travaillent les utopies littéraires et les voyages imaginaires aux XVII et XVIII ${ }^{e}$ siècles.

Aleksandra WOJDA, docteure en littérature comparée et en études slaves, spécialiste des relations inter-artistiques des Lumières jusqu'à la modernité dans les domaines français et centre-européen. Auteure d'une thèse consacrée à l'écriture fragmentaire de l'époque romantique, ainsi que d'une cinquantaine d'articles sur l'intermédialité littérature - musique et les paradigmes de diffusion esthétique du XVIII ${ }^{e}$ au XX $X^{e}$ siècles. Professeure agrégée de polonais, chargée de cours à Sorbonne Université, membre associée de l'UMR Eur'Orbem (CNRS/ Sorbonne Université) et du laboratoire ALITHILA (Université de Lille).

Izabella ZATORSKA, professeur à l'Université de Varsovie, dix-huitiémiste tournée vers la francophonie de l'océan Indien. Les Polonais en France 16961795. Bio-bibliographie provisoire (2000, 2010 avec M. Kamecka), Discours colonial, discours utopique. Témoignages français sur la conquête des antipodes (XVII ${ }^{e}$-XVIII ${ }^{e}$ siècles) (2004). Éditions critiques : Maximilien Wikliński Voyages/ Podróże (2008), Bernardin de Saint-Pierre, "Voyages dans le Nord de l'Europe ", OC, t. 2, Voyages, dir. J.-M. Racault et al. (2019), Chansons madécasses d'Évariste Parny (avec E. Kalinowska, M. Sokołowicz, 2021). 


\section{TABLE DES MATIÈRES}

Izabella Zatorska, Małgorzata Sokołowicz

Chroniqueur, philosophe, artiste. Figures du voyageur dans la littérature française aux XVIII $-X I X^{e}$ siècles. Introduction

\section{Première partie :}

\section{Voyageur, chroniqueur fidèle ou imposteur?}

Jean-Michel Racault

"Il n'y a point d'état plus immoral que celui de voyageur »:

autour des contributions de Diderot à l'Histoire des deux Indes . . . . . . . 12

Sylviane Albertan-Coppola

Peut-on se fier au voyageur? Réponses de l'abbé Prévost dans

les introductions de l'Histoire générale des voyages (1746-1759) . . . . . . . 27

Izabella Zatorska

Le statut esthétique, ontologique et épistémologique du narrateur dans

Le Monde vrai de Marivaux

\section{Deuxième partie :}

\section{Voyageur qui se (re)met en valeur}

François Rosset

Voyageur-historien ou romancier-philosophe? Quelques leçons

du voyage imaginaire

Stanisław Świtlik

Nicolas Klimius, Pierre Wilkins et Édouard Alfrède - quelle définition

du voyageur? .

Linda Gil

Cunégonde, l'autre candide? Figure d'une voyageuse compulsive dans

le récit voltairien, entre domination et émancipation. 


\section{Troisième partie :}

\section{Voyageur qui se (re)met en cause}

Odile Richard-Pauchet

Diderot promeneur solitaire à Bourbonne et à Langres (1770) . . . . . . . . . 101

Alain Guyot

Éclairer la figure du voyageur à la fin des Lumières: du Voyage à l'île

de France de Bernardin de Saint-Pierre au projet de sa réédition . . . . . . . 115

Nicolas Brucker

La figure kantienne du voyageur dans les Lettres westphaliennes

de Charles de Villers (1797) . . . . . . . . . . . . . . . . . . . . . 128

\section{Quatrième partie :}

Voyageur, artiste créatif ou récréatif?

Katalin Bartha-Kovács

Les russeries d'un peintre-voyageur au XVIII siècle : Le Prince vu par les critiques d'art de son temps . . . . . . . . . . . . . . . . . 145

Aleksandra Wojda

Vers une écriture de l'humeur inquiète : le Voyage musical en Allemagne et en Italie de Berlioz . . . . . . . . . . . . . . . . . . . . . . . 165

Małgorzata Sokołowicz

Un voyageur qui peint, un voyageur qui écrit... Le double (?) regard de Gustave Guillaumet

Contributeurs à ce volume 
Le présent volume se concentre sur la figure du voyageur qui émerge dans la littérature française des XVIII -XIX ${ }^{\mathrm{e}}$ siècles, dans les voyages réels et imaginaires. D'éminents spécialistes des universités du monde entier (Réunion, Montpellier, Nancy, Lausanne, Szeged...) analysent les changements apparaissant dans la façon de représenter le voyageur. Les récits de voyage se réfèrent-ils toujours aux voyages réels ? La littérature viatique parle-t-elle (uniquement) de voyages ? À quoi sert le voyage imaginaire ? Chaque époque a-t-elle son propre modèle de voyageur? Le volume apporte des réponses à toutes ces questions et à bien d'autres.

« Cet ouvrage collectif s'inscrit dans le cadre du développement des études viatiques, qui a produit un certain nombre de synthèses ces dix dernières années [...], mais il en excède aussi le périmètre, puisqu'il étend la réflexion à la figure du voyageur dans des ouvrages de fiction, montrant ainsi toute l'importance de cette figure dans l'histoire des représentations et des savoirs dans la littérature, en particulier à l'époque des Lumières. [...] Il s'agit d'un [livre] de très bonne tenue intellectuelle, composé de contributions substantielles, dont certaines issues de spécialistes reconnus internationalement dans leur domaine, mais aussi de jeunes chercheurs dont certains sont très prometteurs. Le sujet de « La figure du voyageur », aussi surprenant que cela paraisse, est relativement nouveau en tant que tel...»

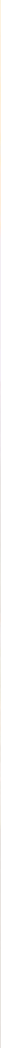

